\title{
BARRIERS TO THE ADOPTION OF \\ ENVIRONMENTALLY SUSTAINABLE DESIGN METHODS IN \\ RESIDENTIAL BUILDINGS. \\ THE ARCHITECTS' AND BUILDING OWNERS' PERSPECTIVES IN \\ FOUR NIGERIAN STATES
}

BY

TAMARAKURO TAMMY AMASUOMO

A thesis

submitted to the Victoria University of Wellington

in fulfilment of the requirements for the degree of

Doctor of Philosophy in Architecture

Victoria University of Wellington

2021 
I dedicate this thesis to my parents for always reminding me to fan the flame (2 Timothy 1:6), and to my beautiful wife Funmi and daughter Enepowei for fuelling me. 


\section{Acknowledgements}

I would like to thank my academic supervisors, Prof. Regan Potangaroa, Dr. Emina Petrovic, and most importantly, Emeritus Professor George Baird who has always gone the extra mile to ensure that in addition to my academic success, New Zealand was a home away from home.

My heartfelt gratitude goes to all the participants who willingly provided me with the data and resources that made this thesis possible.

In addition, my appreciation goes to my colleagues, church family (Arise Church), and my Nigerian brothers and sisters in Wellington, una welldone ohh!!!

My final acknowledgements go to my beloved parents Prof and Mrs. Amasuomo, my brother Dr. Ebikapade Amasuomo, the joy of my heart Enepowei Oyinoluwa Amasuomo, and my forever beautiful and understanding wife Florence Olufunmilayo Amasuomo. 
AC - Air Conditioner

ADM - African Diaspora Marketplace

AEC - Architects, Engineers, and Contractors

AEMO - Australian Energy Market Operator

AGA - American Gas Association

ANOVA - Analysis of variance

ARCON - Architects Registration Council of Nigeria

AKTESP - Agreement, Knowledge, Technology, Economic, Social, and Political

ASHRAE - American Society of Heating, Refrigerating and Air Conditioning Engineers

BCA - Building Consent Authority

BNRCC - Building Nigeria's response to climate change

BREEAM - Building Research Establishment Environmental Assessment Method

BRE - Building Research Establishment

CMIP5 - Coupled Model Intercomparison Project

COREN - Council for the Regulation of Engineering in Nigeria

ECN - Energy Commission of Nigeria

ESD - Environmentally Sustainable Design Methods

FEPA - Federal Environmental Protection Agency

HBS - Heinrich Böll Stiftung

IEQ - Indoor Environmental Quality

IIED - International Institute for Environment and Development

LASPPPA - Lagos State Physical Planning Permit Authority

LEED - Leadership in Energy and Environmental Design

MAN - Manufacturers Association of Nigeria

MBIE - New Zealand Ministry of Business, Innovation and Employment

NBC - National Building Code

NBS - National Bureau of Statistics

NCDMB - Nigerian Content Development and Monitoring Board

NESREA - National Environmental Standards and Regulations Enforcement Agency

NGN - Nigerian Naira

NIA - Nigerian Institute of Architects

NIQS - The Nigerian Institute of Quantity Surveyors

NIMET - Nigerian Meteorological Agency

NZGBC - New Zealand Green Building Council

POP - Plaster of Paris

QDA - Qualitative Data Analysis software

RCP - Representative Concentration Pathway

TRA - The theory of reasoned action

TAM - The technology acceptance model

SD - Standard Deviation

SDG - Sustainable Development Goals

SHS - Solar Home System

UN - United Nations

UNEP - United Nations Environment Programme

UNFPA - United Nations Population Fund

USAID - United States Agency for International Development

USD - United States Dollars

USGBC - United States Green Building Council

GBCA - Green Building Council of Australia 
GBCN - Green Building Council of Nigeria

GBCSA - Green Building Council of South Africa

GBRS - Green Building Rating System

GBT - Green Building Technology

GSSA - Green Star SA

VUW - Victoria University of Wellington (Te Herenga Waka), New Zealand

WBG - World Bank Group

WGBC - World Green Building Council

WMO - World Meteorological Organization 


\section{Abstract}

This thesis investigates Nigerian architects' and building owners' perceptions of Environmentally Sustainable Design Methods (ESD) to identify barriers preventing ESD adoption for providing thermal comfort and energy efficiency in Nigerian residential buildings. Most of the surveyed architects and building owners agree on the problem of thermal discomfort in Nigerian residential dwellings. However, the results show that architects and building owners opt for non-sustainable methods for addressing this problem. This study aims to understand why architects and building owners are choosing non-sustainable methods. To achieve this aim, the study investigates barriers preventing the widespread adoption of ESD in Nigeria to understand why ESD is not generally adopted as a preferred solution for addressing the problem of thermal discomfort.

The thesis reports on a three-stage evaluation of current barriers to environmentally sustainable design methods in four Nigeria states (Lagos, Abuja, Rivers, and Bayelsa) and concludes by providing basic ways through which ESD could be adopted for ensuring thermal comfort and energy efficiency. A mixed-method research approach was utilised due to its robustness in addressing the research objectives. Stage 1 involved the distribution and analysis of questionnaires from 130 architects; stage 2 undertook semi-structured interviews with 21 architects; stage 3 undertook the distribution of questionnaires to 142 building owners and a visual physical examination of their respective buildings. The results showed that the barriers preventing the adoption of ESD in Nigeria include: a lack of technological development, cost of building construction and operation, public perception, poor governance, and most importantly, a lack of knowledge on the means of adopting ESD. The results from the interview with architects on the main obstacles to ESD showed that a lack of knowledge had the highest citing of $85 \%$, poor governance a citing of $66 \%$, economic factors $57 \%$, and social factors $52 \%$, respectively. These figures were similar to the results from the building owner's survey.

Given the lack of knowledge on adopting ESD, the thesis provides an explicit but straightforward set of ESD strategies that would add to the existing body of knowledge on ESD, resolve the lack of knowledge, and make ESD easily applicable. It is recommended that the Nigerian government and related institutions set a clear strategy for educating the public on the benefits and means of adopting a pro-sustainable culture. This strategy would include highlighting the importance of environmental protection and ESD, the possible environmental and health implications of environmental degradation, and the long-term economic benefits of sustainable design. Such a strategy should include a structured system of information dissemination through formal and informal mediums such as public campaigns and social media to reach a wide-ranging audience. The research findings identify the range of possible barriers preventing the attainment of a sustainable environment in Nigeria and other countries with similar issues. They also form the basis for an action plan.

Keywords: Architects, Building owners, Environmentally Sustainable Design Methods, Housing, Thermal Comfort, Energy Efficiency 


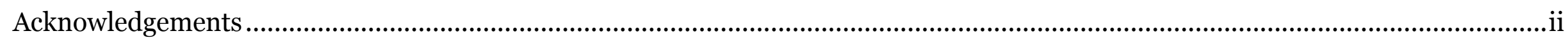

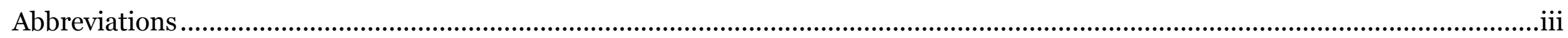

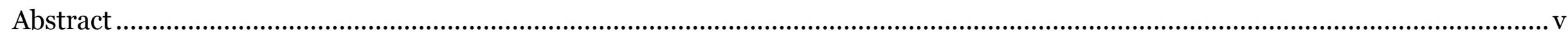

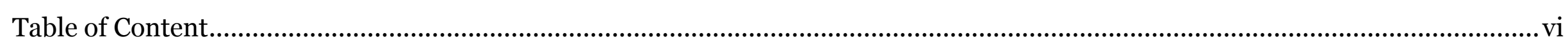

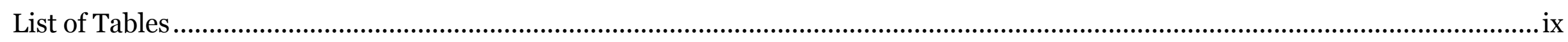

List of Figures

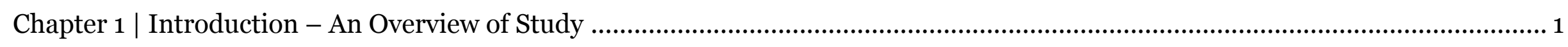

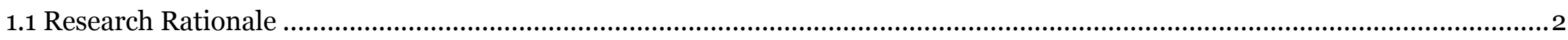

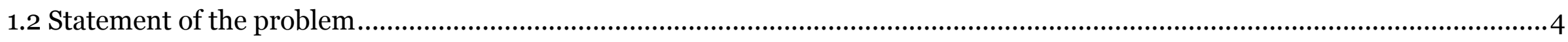

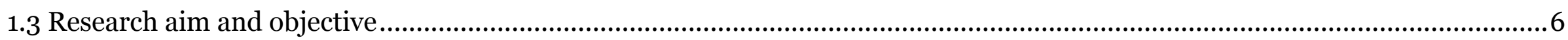

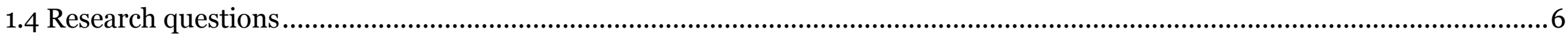

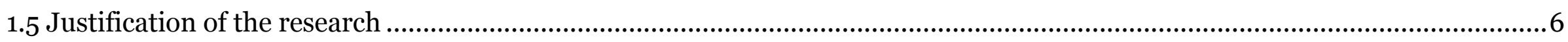

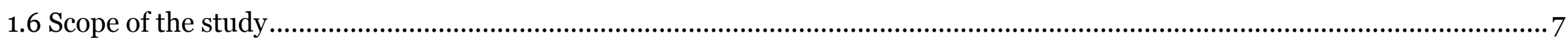

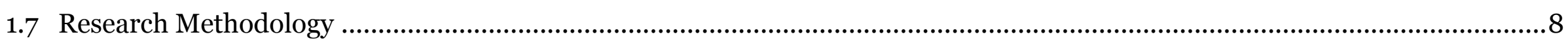

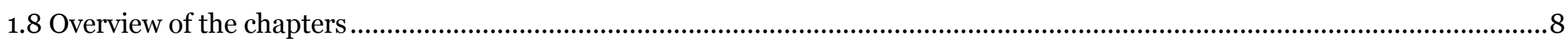

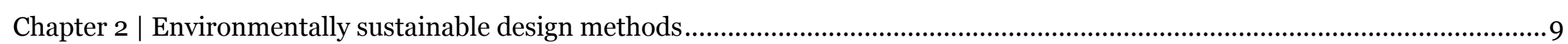

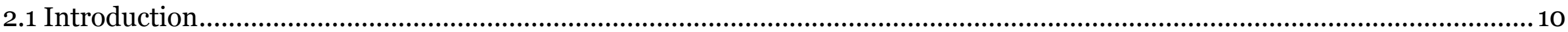

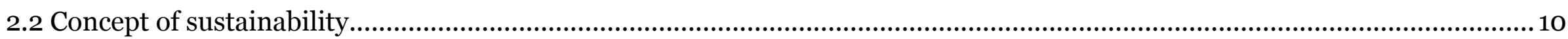

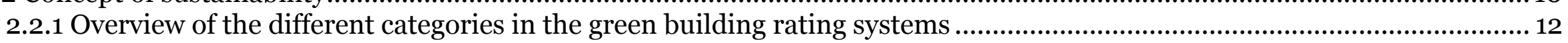

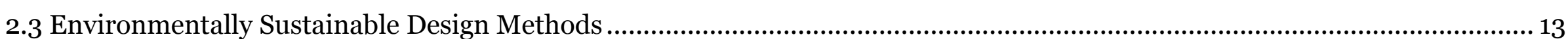

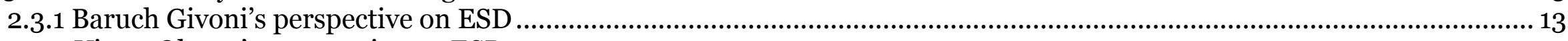

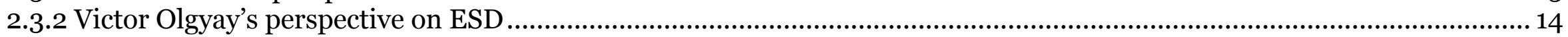

2.3.3 Carl Mahoney, Otto Konigsberger, and Martin Evans' perspective on ESD ................................................................. 14

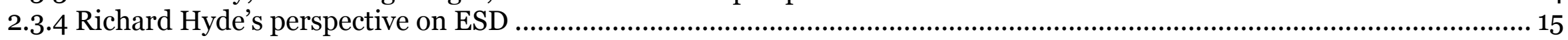

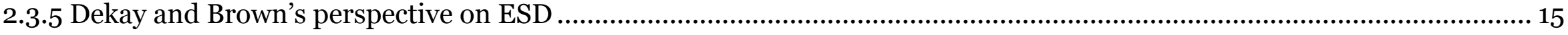

2.4 Implementation of Environmentally Sustainable Design Methods …......................................................................... 17

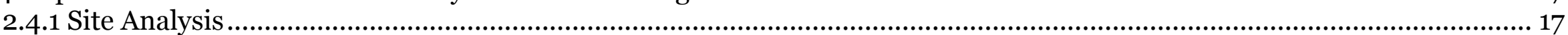

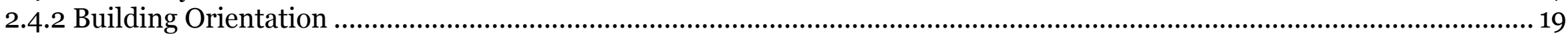

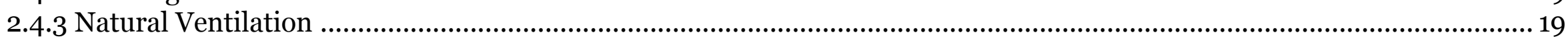

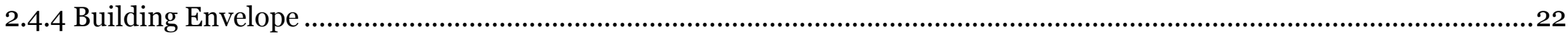

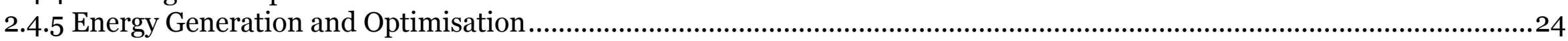

2.4.6 Summary of Environmentally Sustainable Design Methods Implementation...............................................................24

2.5 An adapted checklist for the physical survey of selected buildings in Nigeria .....................................................................25

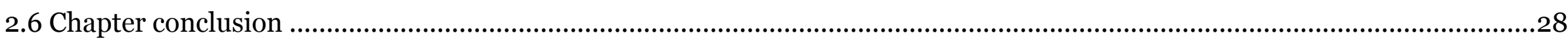

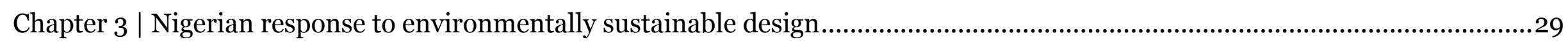

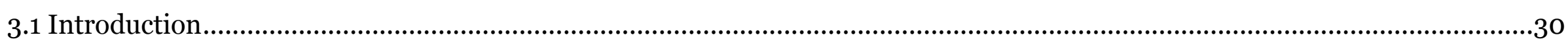

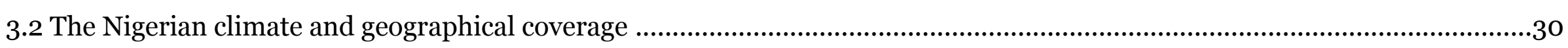

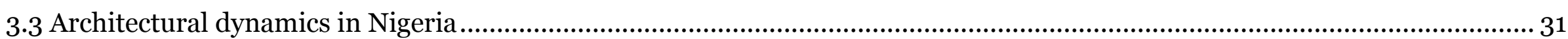

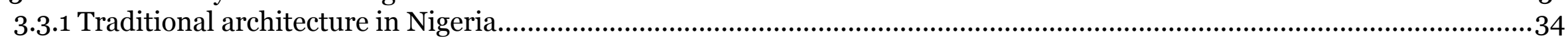

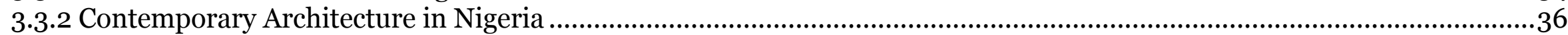

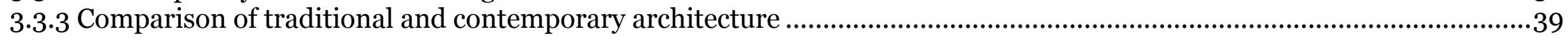

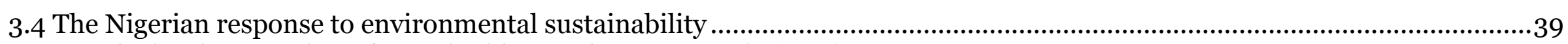

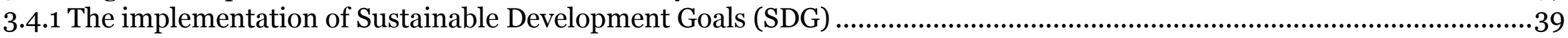

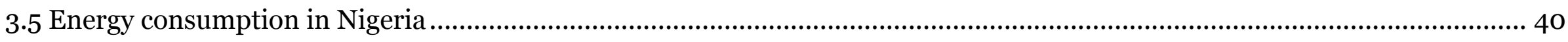

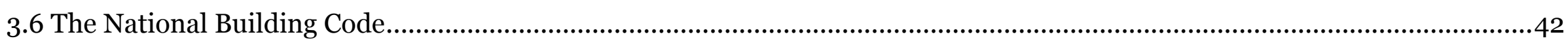

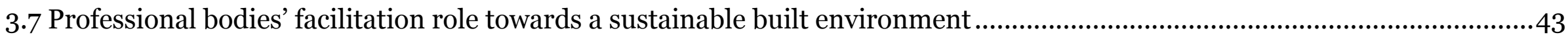

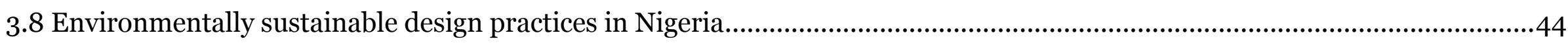

3.9 A review of the barriers to environmentally sustainable design practice ..........................................................................46

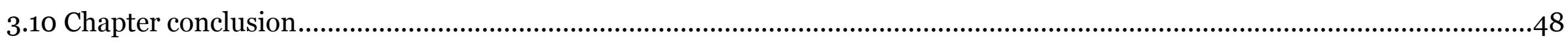

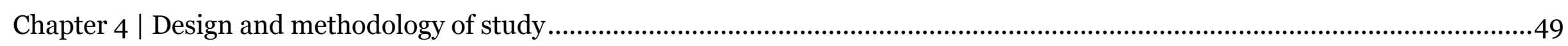

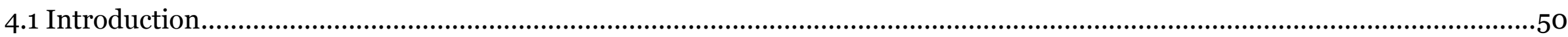

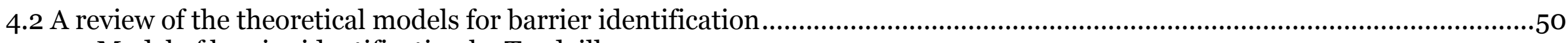

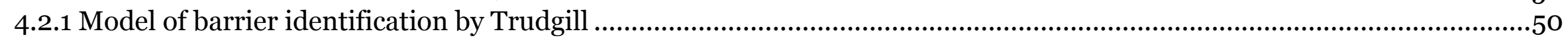


4.3 Research method.

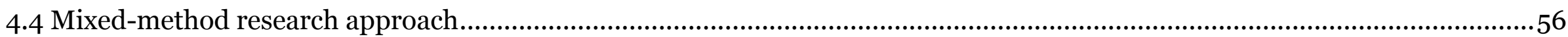

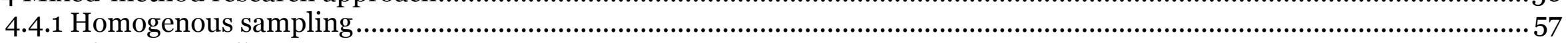

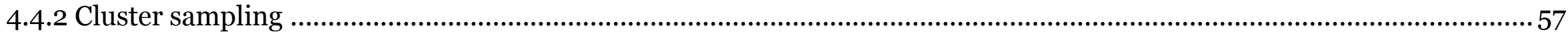

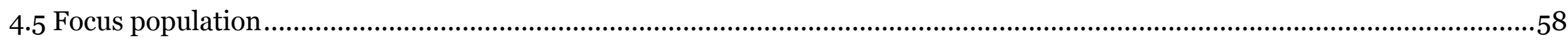

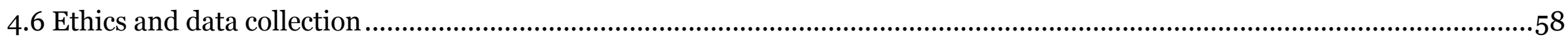

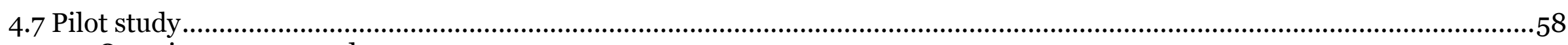

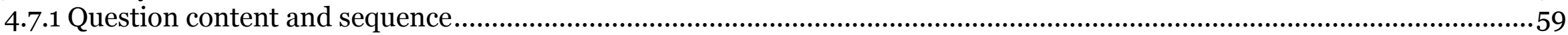

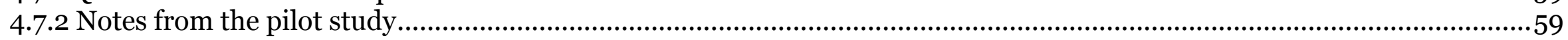

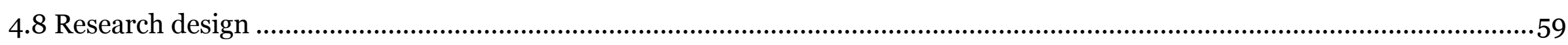

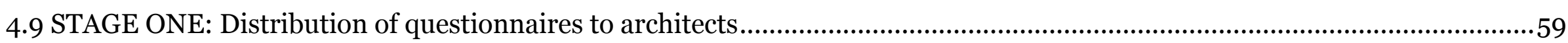

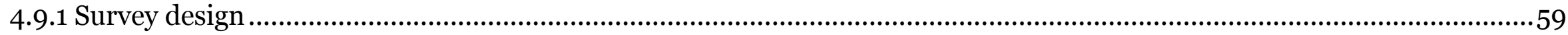

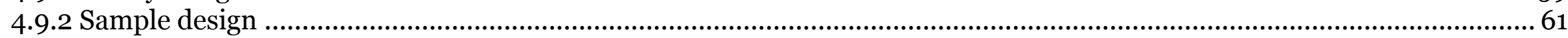

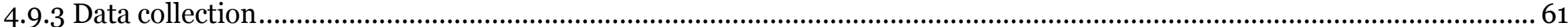

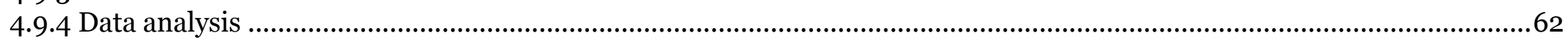

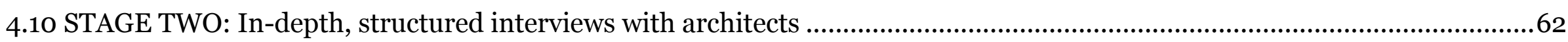

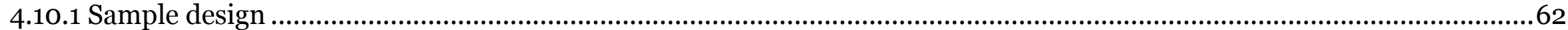

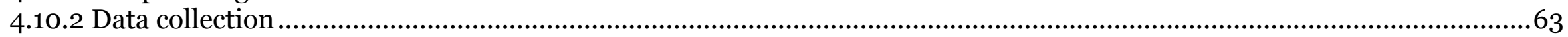

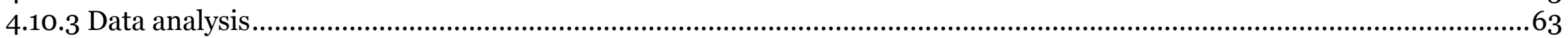

4.11 STAGE THREE: Distribution of questionnaires to building owners and a visual survey of their buildings ...........................64

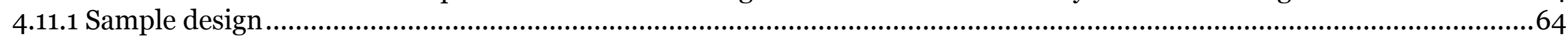

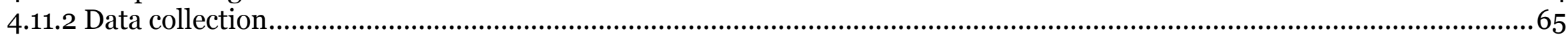

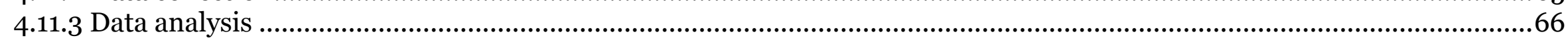

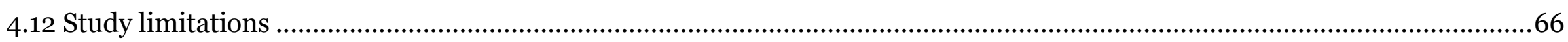

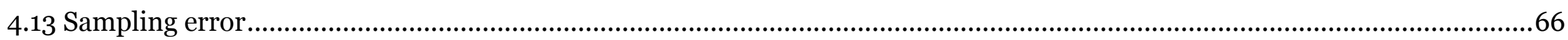

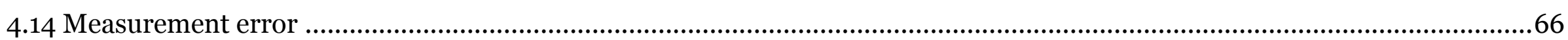

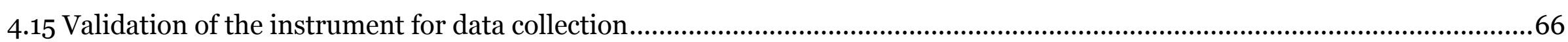

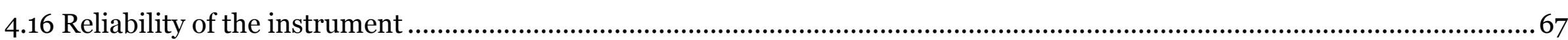

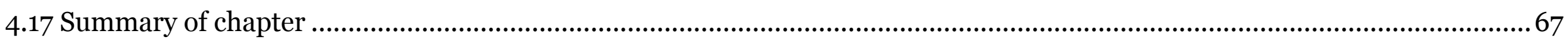

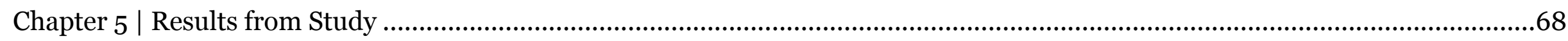

5.1 Stage One: The Architects perceived barriers preventing the adoption of Environmentally Sustainable Design......................69

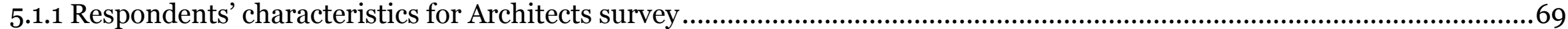

5.1.2 Do architects agree on the need for environmentally sustainable design methods in Nigeria? ............................................70

5.1.3 How knowledgeable is the Nigerian architect about environmentally sustainable design methods?.................................70

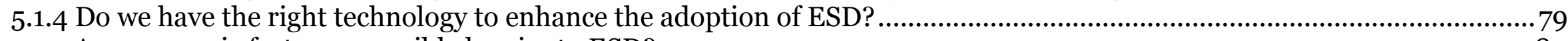

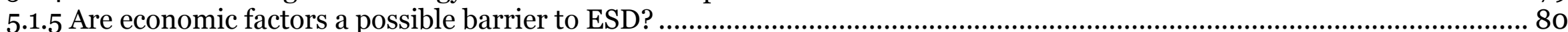

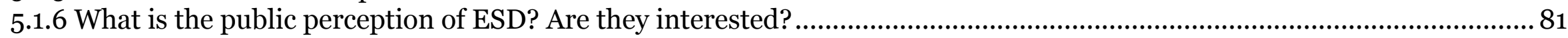

5.1.7 Are there favourable ESD policies? If no, is that a possible barrier?

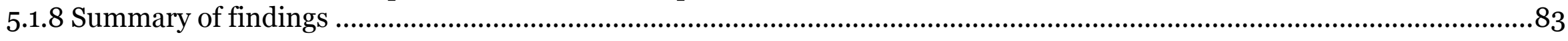

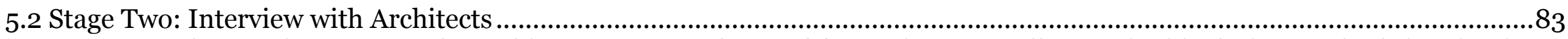

5.2.1 Research Question one: Do the architects agree on the need for environmentally sustainable design methods in Nigeria?

5.2.2 Research Question two: How knowledgeable is the Nigerian architect about ESD and what do they consider as a

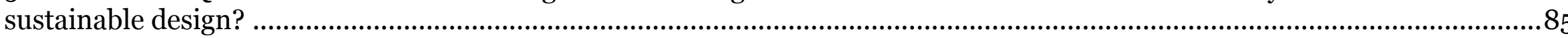
5.2.3 Do we have the right technology to enhance the adoption of ESD? If no, is that a possible barrier?....................................86

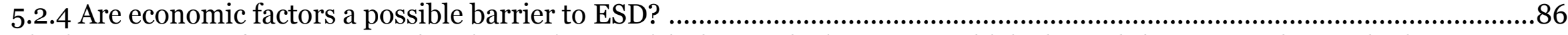

The last comment from a respondent is consistent with the results in stage 1, which showed that respondents who have specified renewable energy sources like solar panels think they are expensive. ................................................................... 87

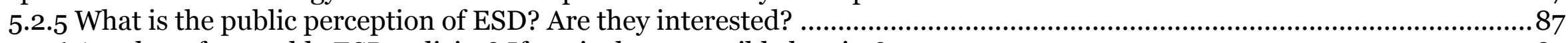
5.2.6 Are there favourable ESD policies? If no, is that a possible barrier?

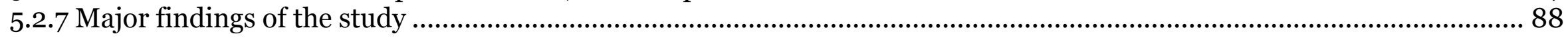

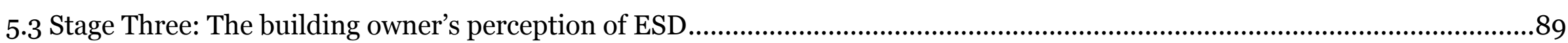

5.3.1 What the building owner considers most important during the design and construction of a building …......................... 90

5.3 .2 The building owners' level of satisfaction with the building ........................................................................................ 91

5.3.3 What is the building owner's level of ESD awareness and the public interest in ESD? .................................................92

5.3.4 During the building design consultation with your architect, did he or she inform you of any environmentally sustainable

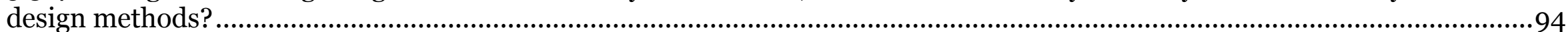

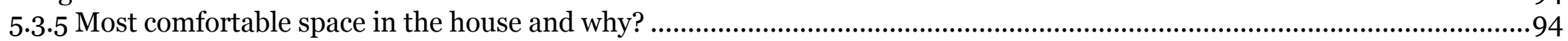

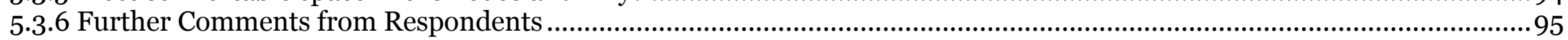

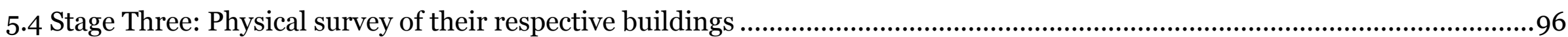

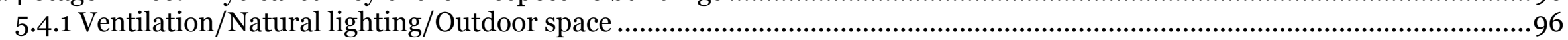

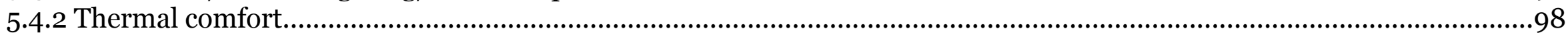

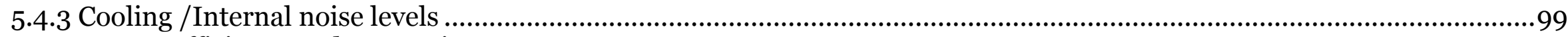

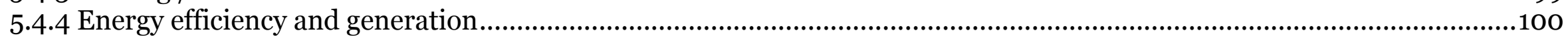

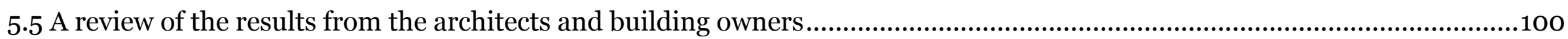

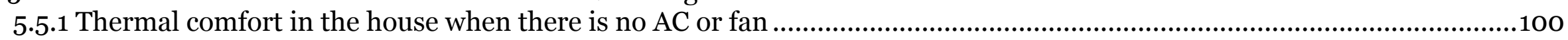

5.5.2 Limited information and promotions on sustainable architecture 


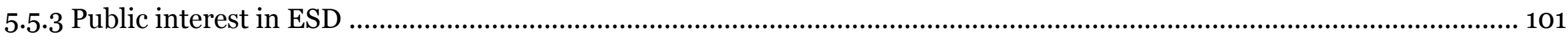

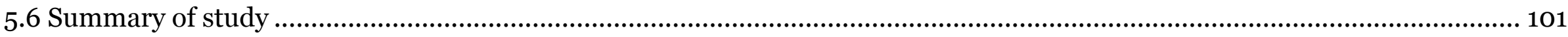

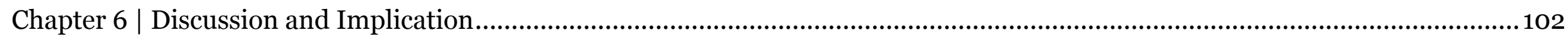

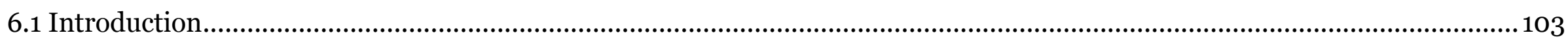

6.2 Do the architects and building owners both agree on the issue of indoor thermal discomfort? ............................................103

6.3 How knowledgeable is the Nigerian architect and building owner about ESD? .................................................................103

6.4 Do we have the right technology to enhance the adoption of ESD? If no, is that a possible barrier? ..................................... 105

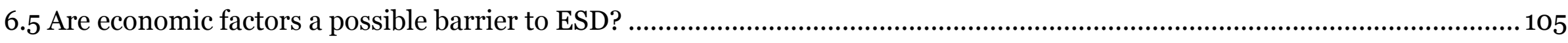

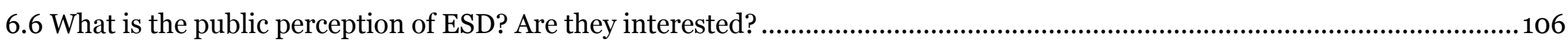

6.7 Are there favourable ESD policies? If no, is that a possible barrier? ................................................................................106

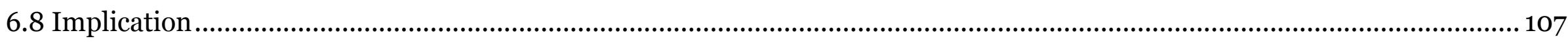

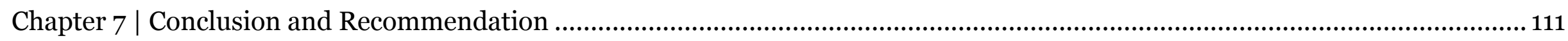

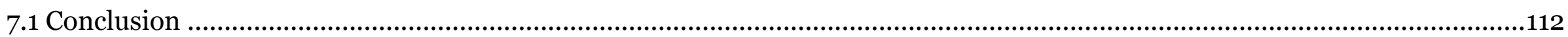

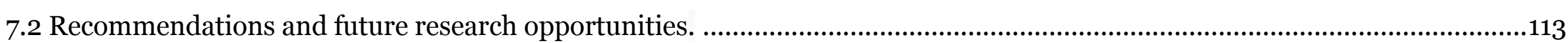

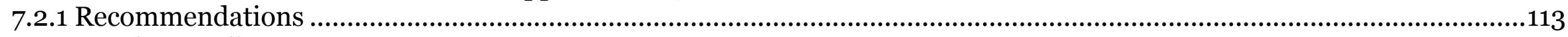

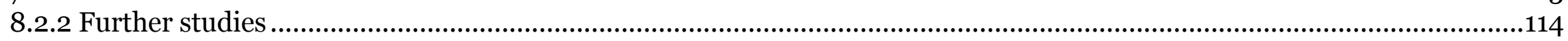

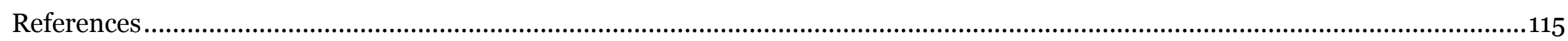

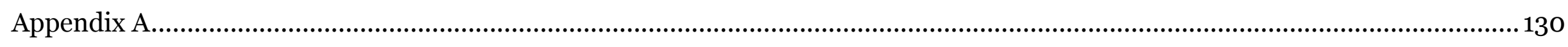

A.1 Ethics approval for stages $1 \& 2$ of study: Distribution of questionnaires and interviews with architects in Nigeria................131

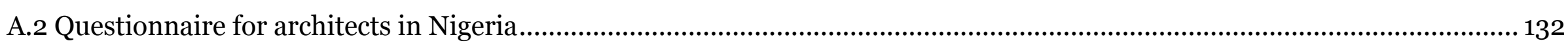

A.3 Descriptive statistics from stage 1 survey: Distribution of questionnaires to architects ..................................................... 137

A.4 Cross examination between "I frequently apply the principles of sun shading in my design" and respondents' characteristics

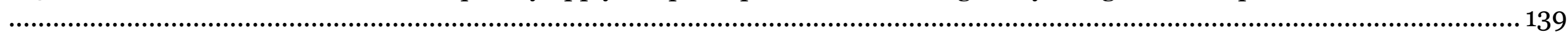

A.5 Cross examination between "Most Nigerian architects always provide cross ventilation in their designs" and respondents'

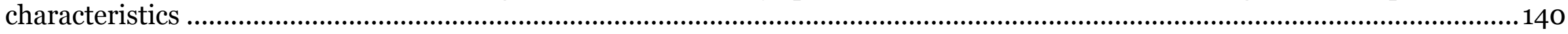

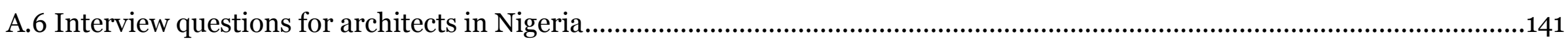

A.7 Results from the interview with architects in stage 2 of the survey ….........................................................................141

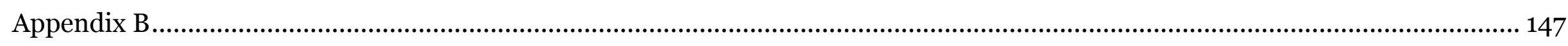

B.1 Ethics approval for Stage 3 of Study: Distribution of questionnaires to building owners and physical survey of their buildings

Q

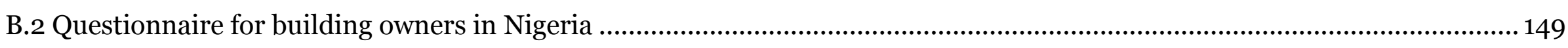

B.3 Descriptive statistics from stage 2 survey: Distribution of questionnaires to building owners ..............................................151

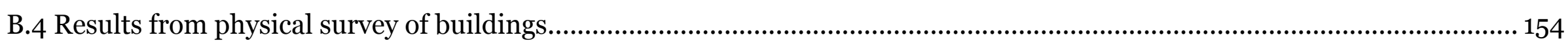

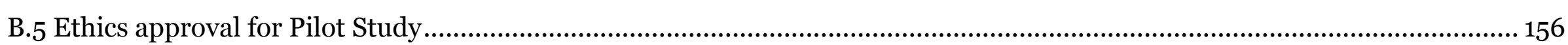


Table 1. 1: A review of existing studies on the barriers to sustainable design in Nigeria ............................................................................... Table 1. 2: Research Map

Table 2. 1: An overview of performance assessment tools (Amasuomo et al., 2017; GBCSA, 2019) …….....................................................11

Table 2. 2: Stages in climate investigations (Hyde, 2000; Lippsmeier, 1980) …................................................................................... 15

Table 2. 3: Checklist for physical survey of selected buildings. Based on: (Amasuomo et al., 2017; BRANZ, 2017; Dantata \& Alibaba, 2018;

DeKay \& Brown, 2014; GBCSA, 2019; Givoni, 1976, 1994; Hyde, 2000; Mahoney et al., 1971; Olgyay, 2015; Wu, Liu, Li, \& Hsieh, 2005 )... 26

Table 3. 1: Average climate statistics in Nigeria between 1980 - 2019 based on states/geopolitical zones....................................................... 31

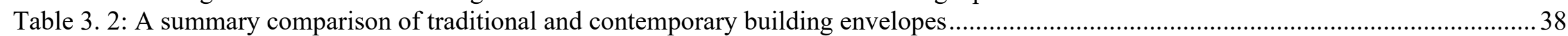

Table 3. 3: Appliance categorise and power rating (Olaniyan et al., 2018) …............................................................................................. 41

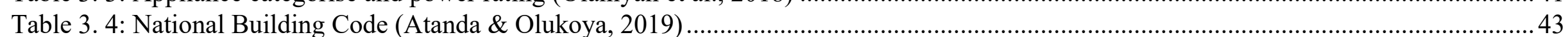

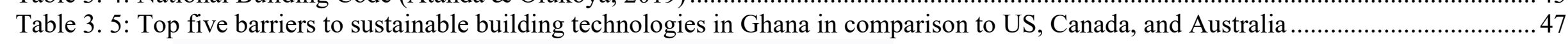

Table 3. 6: A summary of the top barriers identified in different African countries. .....................................................................................

Table 4. 1: Sample sizes needed for different population sizes and characteristics at the $95 \%$ confidence level, at three levels of precision (Dillman et al., 2009; Shari, 2011)

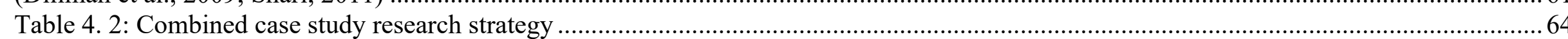

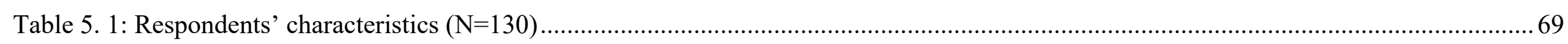

Table 5. 2: Pearson Correlation between "Nigerian architects always provide cross ventilation in their designs" and "As an architectural student,

I was always encouraged to include environmentally sustainable design methods in my studio/design courses" ................................................ 72

Table 5. 3: Pearson Correlation between "I frequently apply the principles of sun shading in my design (i.e. shared shade, shadow umbrella, overhead shades, daylight enhance shade)" and "As an architectural student, I was always encouraged to include environmentally sustainable design methods in my studio/design courses"

Table 5. 4: Pearson Correlation of the relationship between four ESD variables that relate to the provision of natural light................................... 73

Table 5. 5: Pearson Correlation of the relationship between self-reported questions and general perception ........................................................ 73

Table 5. 6: Analysis of variance between Age and "I frequently apply the principles of sun shading in my design (i.e. shared shade, shadow umbrella, overhead shades, daylight enhance shade)".....

Table 5. 7: Analysis of variance between respondents' Age and "Most Nigerian architects always provide cross ventilation in their designs"... 75

Table 5. 8: Analysis of variance between respondents' Gender and Nigerian architects always provide cross ventilation in their designs............. 76

Table 5. 9: Analysis of variance between respondents' age and "For most of my designs I specify photovoltaic systems or other renewable energy sources".

Table 5. 10: Analysis of variance between respondents' years of architectural experience and "For most of my designs I specify photovoltaic

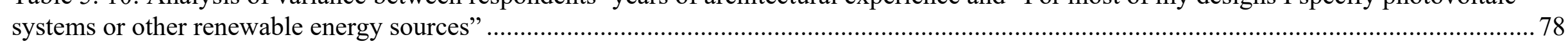
Table 5. 11: Pearson Correlation examining the relation between unsatisfactory electricity supply and the specification of renewable energy

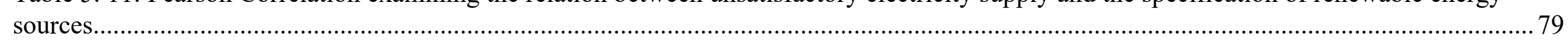

Table 5. 12: Pearson Correlation between "Buildings in Nigeria are designed with the intention that air conditioners and fans are going to be used in them" and "I design buildings with the intention of having an air-conditioner and fan" .....

Table 5. 13: Pearson Correlation between environmentally sustainable design methods and renewable energy sources like solar panels are expensive and "For most of my designs I specify Photovoltaic systems or other renewable energy sources"......................................................... 81 Table 5. 14: Pearson Correlation between the lack of interest among clients/developers and the government/private sector not providing sufficient financial incentives and rewards for saving energy or using renewable energy sources like solar panels ............................................8. 82 Table 5. 15: Pearson Correlation between "Your level of awareness on environmentally sustainable design methods (ESD)" and "ESD adoption

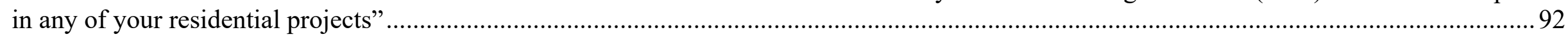
Table 5. 16: Pearson Correlation between "Your level of awareness on environmentally sustainable design methods (ESD)" and "Available information on ESD, i.e. promotion of sustainability by the government, media, professional bodies, etc." ....................................................93 Table 5. 17: Pearson Correlation between "The general public interest and enlightenment on ESD" and "Available information on ESD, i.e.

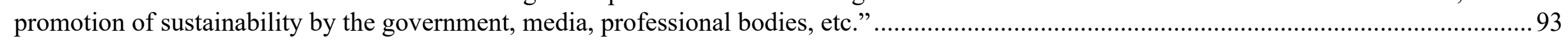
Table 5. 18: Photos from physical survey of selected buildings... 
List of Figures

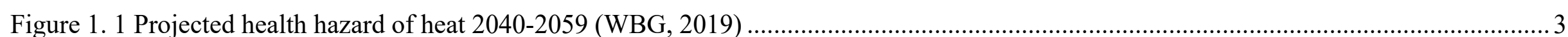

Figure 1. 2: Projected Cooling Degree Days in Nigeria (WBG, 2019) .................................................................................................. 3

Figure 1. 3: Average duration of hourly power outages per year in selected countries in Africa (Statista, 2019) .................................................... 5

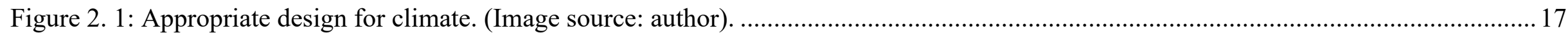

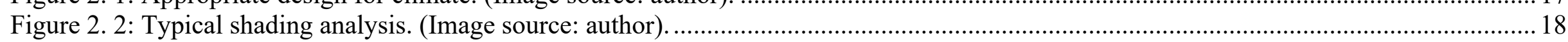

Figure 2. 3: Building orientation based on sun and wind. (Image source: Author)

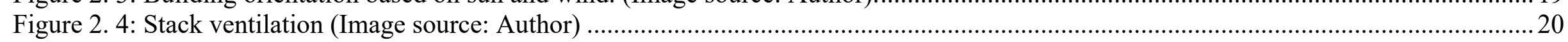

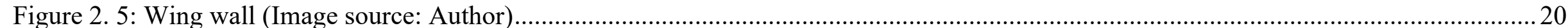

Figure 2. 6: Typical floor plans and sections for improving cross ventilation and stack ventilation. Drawn by Author and adapted from (DeKay \&

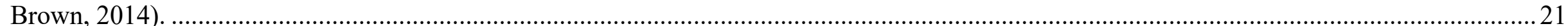

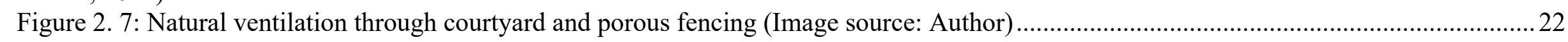

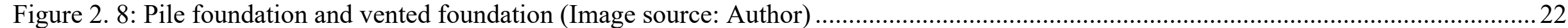

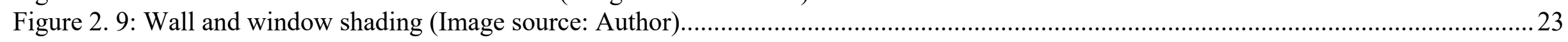

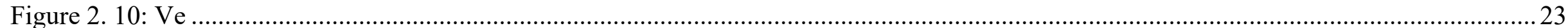

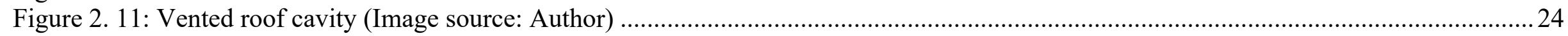

Figure 3. 1: Typical vernacular Nigerian architecture with clay and thatch roof in a compound setting (Image source: Author) ..........................32

Figure 3. 2: Typical building site and spatial composition of a Nigerian traditional compound showing air flow movement. ..............................32

Figure 3. 3: The courtyard principle (Amasuomo \& Baird, 2016b) ..................................................................................................33

Figure 3. 4: A summary of the projected cost of energy from different sources Nigeria (IIED, 2012) ........................................................ 42

Figure 3. 5: Professional bodies' responses towards ensuring a sustainable built environment (Waniko, 2014) ................................................4 44

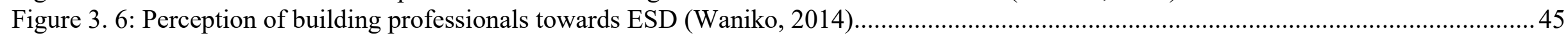

Figure 3. 7: Who is responsible for promoting ESDs in Nigeria? Adapted from (Waniko, 2014), .................................................................45

Figure 4. 1: Model on barrier identification and classification (Trudgill, 1990) ..................................................................................50

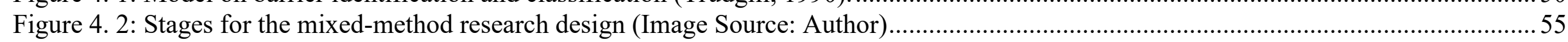

Figure 4. 3: Sequential step for developing a questionnaire. Adapted from (Norland-Tilburg, 1990; Radhakrishna, 2007), .............................60

Figure 4. 4: Map of Nigeria showing the four locations selected for the case study. Image adapted from (D-Maps, 2019) ....................................65

Figure 5. 1: Do the architects agree on the need for environmentally sustainable design methods in Nigeria? Please select the option that describes your opinion about the following statements on a scale of 1 to 6 , with 1 being strongly disagree and 6 being strongly agree............... 70 Figure 5. 2: How knowledgeable is the Nigerian architect about environmentally sustainable design methods? Please select the option that describes your opinion about the following statements on a scale of 1 to 6 , with 1 being strongly disagree and 6 being strongly agree................ 71 Figure 5. 3: Means plot of the relationship between respondents' Age and "I frequently apply the principles of sun shading in my design (i.e. shared shade, shadow umbrella, overhead shades, daylight enhance shade)".....

Figure 5. 4: Means plot of the relationship between respondents' Age and "Most Nigerian architects always provide cross ventilation in their

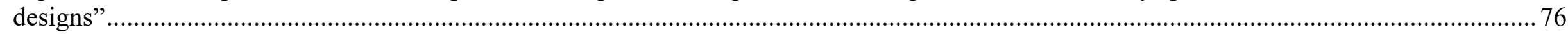
Figure 5. 5: Means plot of the relationship between respondents' gender and "Most Nigerian architects always provide cross ventilation in their

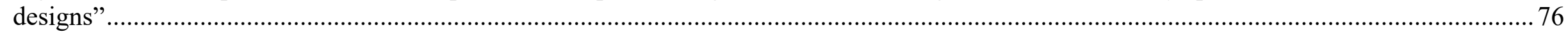
Figure 5. 6: Means plot of the relationship between respondents' age and "For most of my designs I specify photovoltaic systems or other

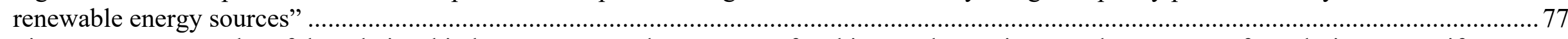
Figure 5. 7: Means plot of the relationship between respondents' years of architectural experience and "For most of my designs I specify

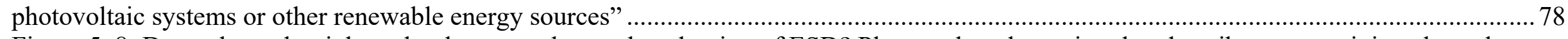
Figure 5. 8: Do we have the right technology to enhance the adoption of ESD? Please select the option that describes your opinion about the following statements on a scale of 1 to 6 , with 1 being strongly disagree and 6 being strongly agree ........................................................ 79 Figure 5. 9: Are economic factors a possible barrier to ESD? Please select the option that describes your opinion about the following statements on a scale of 1 to 6 , with 1 being strongly disagree and 6 being strongly agree ............................................................................ 80 Figure 5. 10: What is the public perception of ESD? Are they interested? Please select the option that describes your opinion about the following statements on a scale of 1 to 6 , with 1 being the lowest and 6 being the highest ..................................................................................... 81 Figure 5. 11: Are there favourable ESD policies? If no, is that a possible barrier? Please select the option that describes your opinion about the following statements on a scale of 1 to 6 , with 1 being strongly disagree and 6 being strongly agree .......................................................... 82 Figure 5. 12: What the building owner considers most important during the design and construction of a building. On a scale of 1-6, with 1 being not important and 6 being extremely important, please rate the most important factors you considered during the design and construction of your

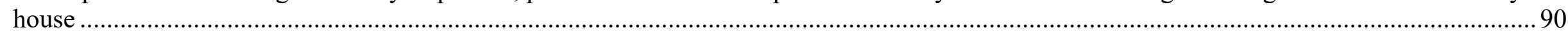
Figure 5. 13: The building owners' level of satisfaction with the building. On a scale of 1-6, with 1 being extremely dissatisfied and 6 being extremely satisfied, how satisfied or dissatisfied are you with your house in terms of the following ............................................................... 91 Figure 5. 14: What is the building owner's level of ESD awareness and the public interest in ESD? On a scale of 1-6, with 1 being extremely low extent and 6 being extremely high extent, please rate the following statements ........................................................................................92 Figure 5. 15: During the building design consultation with your architect, did he or she inform you of any environmentally sustainable design

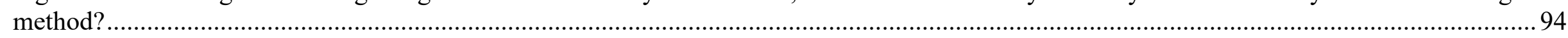

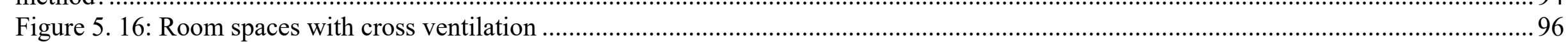

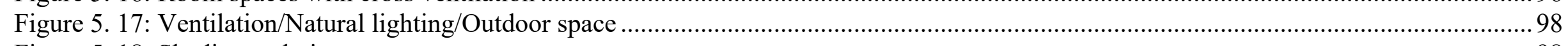

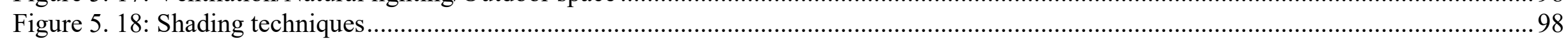

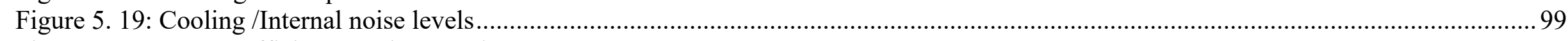

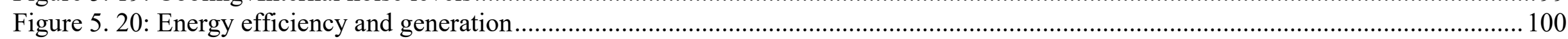

Figure 6. 1: A comparison of Trudgills' model and the Nigerian context. Adapted from (Trudgill, 1990)................................................... 108 
Chapter 1 | Introduction - An Overview of Study

Chapter 1 | Introduction - An Overview of Study 


\subsection{Research Rationale}

This study evaluates the Nigerian architects' and building owners' perception of environmentally sustainable design methods (ESD). Arguably, the architects, building owners, and other stakeholders in the building industry are responsible for designing and constructing buildings that minimise the impact on the environment whilst enhancing energy efficiency and user comfort. Despite the benefits of ESD, studies (Adaji, Watkins, \& Adler, 2017; Okafor, 2018; Oyefusi \& Adeyemo, 2019) show that only a few buildings in Nigeria ultimately adopt sustainable design features. Although the architect is not to be solely blamed for the limited adoption of ESD in the Nigerian building industry, the architect should be responsible for their design. Unlike any other profession in the building industry globally, the architect's role is considered crucial in the design and construction of the built environment due to their involvement in the building process from the conceptual to completion stages, and as such, should be accountable for minimising the energy consumption and impact on the building on the environment (Time, 2017). The initial aim of this thesis was to develop a sustainable design tool for improving thermal comfort. However, this changed after the review of existing literature suggested that sustainable design tools already existed for the Nigerian context. In response, the thesis investigates why these tools are not widely adopted and the possible barriers preventing their adoption. This investigation began as an evaluation of the architects' perception of environmentally sustainable design methods (ESD) in Nigeria but later expanded to include the building owners due to their influence in the decision-making process of a building design and construction. The investigation of the architects and building owners suggested that, in addition to other factors, a lack of knowledge was a significant contributing factor. To mitigate the possible lack of knowledge, Chapter 2 provides simple ESD strategies, thereby making their adoption easily applicable.

Adopting sustainable design methods has long-term economic benefits, improves thermal comfort, and is beneficial for the natural environment. However, studies show the Nigerian building industry opting for unsustainable design methods (Akagwu, 2017; Elum \& Momodu, 2017; Okafor, 2018). Unsustainable design and construction methods have negatively impacted the natural environment (Abisuga \& Okuntade, 2020). If this trend continues, increased temperatures, thermal discomfort and health crisis in Nigeria are predicted (Oyefusi \& Adeyemo, 2019; Ugbah, Olaniyan, Francis, \& James, 2020). Climatic projections suggest that Africa is very likely to warm more than the global temperature at an increase of approximately $1.1^{\circ} \mathrm{C}-2.5^{\circ} \mathrm{C}$, with countries like Nigeria being the most affected because of their growing populations (WMO, 2015). Statistical data from the United Nations (2015) predicts that more than half of the global population growth between now and 2050 is expected to occur in Africa. With Nigeria ranking as the most populated country in Africa, one of the fastest-growing populations in the world, and the 7 th most populated country in the world with a current population of over 180 million, it is predicted that Nigeria would be most vulnerable to the impacts of anthropogenic climate change (WMO, 2015). In recent years, extremely high temperatures and heatwaves have prevailed throughout Nigeria, with high temperatures of $43^{\circ} \mathrm{C}$ recorded in most parts of Nigeria due to the impacts of climate change and global warming (WBG, 2019; WMO, 2015). According to WBG (2019), average maximum temperatures in Nigeria have increased, with maximum temperatures ranging between $31-33^{\circ} \mathrm{C}$. The annual number of hot days has increased by 73 days and cold days decreased by 45 , with the highest rate decrease seen during the dry season (September - November). The mean annual temperature is projected to increase between $1.1^{\circ} \mathrm{C}$ and $2.5^{\circ} \mathrm{C}$ by the 2060 s and $1.4^{\circ} \mathrm{C}$ and $4.6^{\circ} \mathrm{C}$ by the 2090s. The annual number of hot days is expected to increase between $32-60 \%$ by 2079 and $37-74 \%$ by 2099. It is projected that the northern part of Nigeria will be most affected by this increase (WBG, 2019).]

Human health in Nigeria has a clear connection to climate change through both direct exposure and indirect pathways. The negative impact on health generally comes from extreme climatic conditions such as heatwaves, floods, and droughts. This gradually affects the water, food, and air quality (Elum \& Momodu, 2017). Temperature extremes in Nigeria tend to have the highest impacts on the health and wellbeing of people and infrastructures, with increased temperatures leading to disease such as meningitis (Mohammed, Iliyasu, \& Habib, 2017). In 2018, a total of 481 cases of meningitis were reported in Nigeria due to the scorching weather that allows the virus to thrive (Sun, 2018). As noted by Mohammed, Iliyasu, and Habib (2017), climate change has been suggested as a reason for the proliferation of meningitis infection in Nigeria. According to WBG (2019), the annual distribution of days with a high heat index provides a good insight into the impacts of scorching conditions. Figure 1.1 shows the projected change in the number of heat days (Tmax $>35 \mathrm{~A}^{\circ} \mathrm{C}$ ) per month by 2050 compared to a reference period (1986-2050) under all Representative Concentration Pathway (RCPs) of Coupled Model Intercomparison Project (CIMP5) ensemble modelling. RCP 8.5 indicates a high impact, and RCP 2.6 a lower impact, respectively. 
Change in Number of Heat Days in Nigeria for period: 20402059

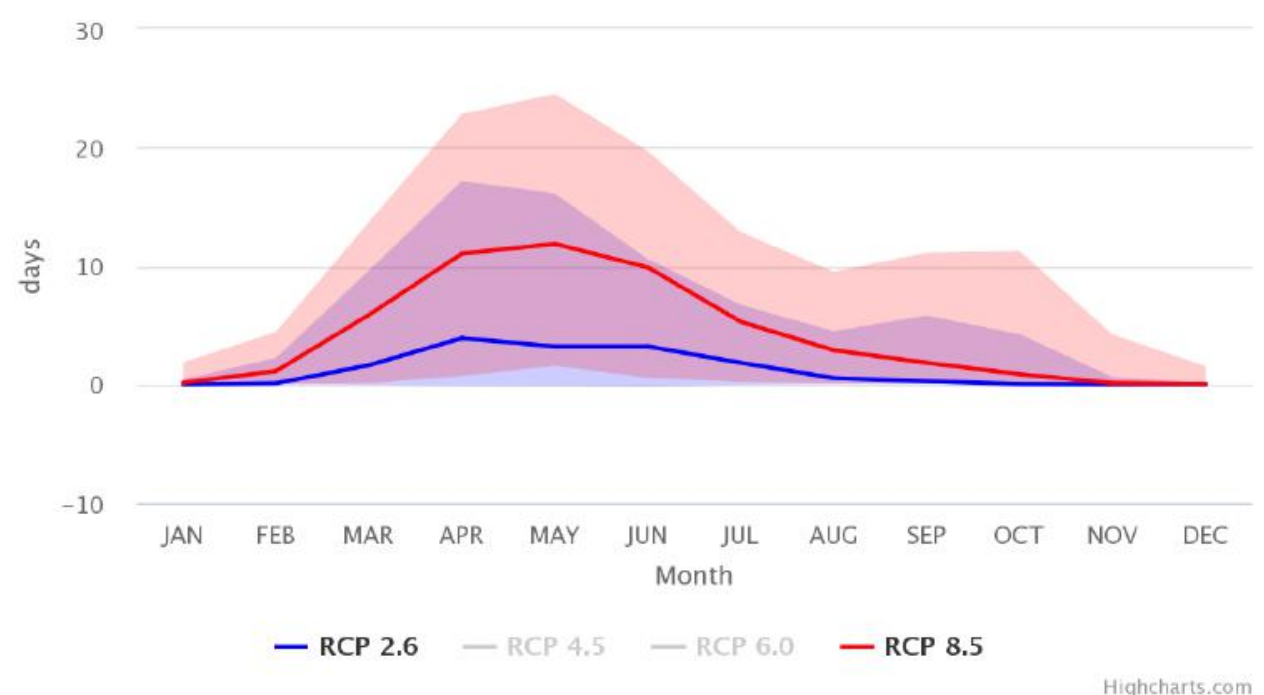

Figure 1. 1 Projected health hazard of heat 2040-2059 (WBG, 2019)

Change in Cooling Degree Days in Nigeria for period: 20402059

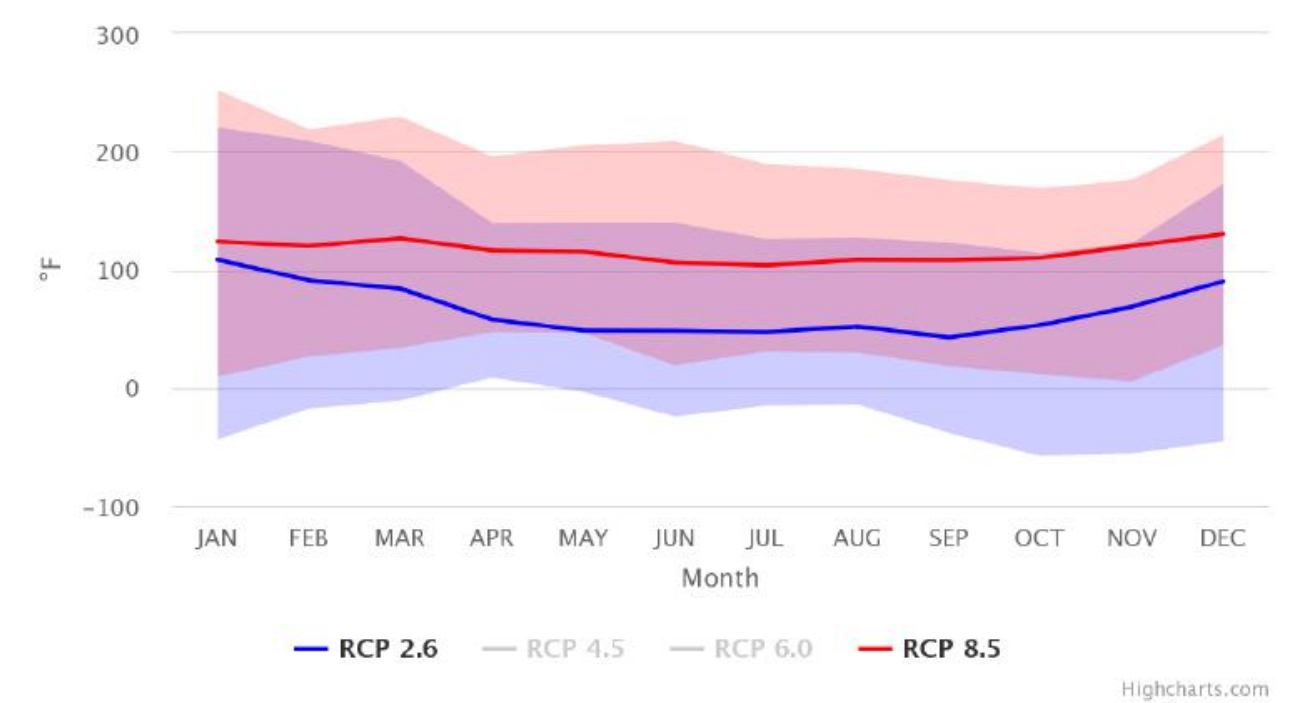

Figure 1. 2: Projected Cooling Degree Days in Nigeria (WBG, 2019)

The internal spaces of Nigerian buildings are most affected by the impacts of global warming due to an increase in temperature, humidity, and poor air circulation. Unfortunately, most of the built environment in Nigeria has not been sufficiently designed to sustainably adapt to, and mitigate, these problems. Instead, the built environment in Nigeria has adopted environmentally unsustainable measures such as an excessive reliance on auxiliary cooling devices and fuel-powered generators (Dalibi et al., 2017). Elum and Momodu (2017), anthropogenic climate change (i.e. man-made) is the primary reason the building industry accounts for over $40 \%$ of the carbon emissions in Nigeria. Under the emission scenario in Nigeria, annual temperatures are expected to rise by an average of $4.9^{\circ} \mathrm{C}$ by 2100 if sustainable actions are not promptly initiated (WHO, 2015). The relationship between the impacts of climate change and the electricity demand can be projected using a quantity called the Cooling Degree Days. This quantity accumulates temperatures above $18^{\circ} \mathrm{C}$ but not exceeding $25^{\circ} \mathrm{C}$, which is generally considered a comfortable temperature range for living conditions in Nigeria (De Rosa, Bianco, Scarpa, \& Tagliafico, 2014). Figure 1.2 provides insight into the potential period of high power demand during high indoor temperatures exceeding $25^{\circ} \mathrm{C}$ and the relative impact on emissions. Low emissions of RCP 2.6 indicate low emissions connected to lower power demand, and RCP 8.5 indicates higher emissions resulting from high power demand (WBG, 2019). The unsustainable production of energy in Nigeria is a contributor to high emissions, and with the growing demand for power as a result of the population growth, the emission rates are projected to increase if sustainable measures are not implemented (WBG, 2019). This reinforces the need for sustainable energy generation to reduce the negative impact on the environment and improve thermal comfort.

Despite rising temperatures, thermal discomfort and other manifestations of climate change and global warming, studies show that architects and building owners opt for non-sustainable methods during building design and construction (Akande, Fabiyi, \& Mark, 2015; Waniko, 2014). Some of the barriers preventing the adoption of sustainable design methods include the perception of different decision-makers, such as architects and the building owners, who influence ESD adoption in building design and construction (Dalibi et al., 2017). A lack of knowledge or interest in ESD by the architect or building owner could hinder ESD adoption due to their role in 
the design and construction of a building (Nii Addy, Adinyira, \& Koranteng, 2014). In addition to the lack of adequate knowledge, a lack of agreement on the scope of the problem and possible solutions, and the means of achieving those solutions, also acts as a barrier to ESD adoption (Dalibi et al., 2017). In a study conducted by Asekun-Olarinmoye, Bamidele, Odu, \& Ojofeitimi (2014) on 1,019 residents in Nigeria, approximately $89 \%$ of respondents acknowledged that there had been climate change in the last ten years. However, the respondents accorded this change to supernatural reasons. The respondents agreed on climate change but did not understand the scope of the problem, nor did they have the correct information to mitigate climate change. This demonstrates that, despite the agreement, other factors such as a lack of knowledge could still impede ESD adoption.

Closely related to the issue of knowledge is the lack of technology. Appropriate technology is needed to maintain and develop renewable energy systems like solar panels and wind turbines, build energy-efficient technologies like smart lighting systems and automated windows, and design responsive building envelopes for improving thermal comfort and energy efficiency (Abdul Majid \& Hussaini, 2015; Wojuola \& Alant, 2017). A study conducted by (Dalibi et al., 2017) on 480 professionals in the Nigerian building industry highlighted the lack of technological development as an impediment to ESD. Arguably, the lack of technological development in energy efficiency is closely linked to the absence of research and development on ESD and the lack of mainstream investments in renewable energy technologies. Economic factors can also affect the mainstream adoption of ESD: these include the lack of financial incentives from the government, banks and other financial institutions reluctancy to fund renewable energy, and most Nigerians favouring short-term financial gain over the long-term benefits of ESD (Abdul Majid \& Hussaini, 2015; Dalibi et al., 2017; Nii Addy et al., 2014).

Social factors have also been known to impose barriers to the adoption of ESD. As noted by Asekun-Olarinmoye et al. (2014) a third of the respondents in their study believed that climate change and global warming was an act of God to punish humans due to their sins. Similarly, for reasons of social status and acceptability, the building owner's lifestyle could pose a social barrier to ESD, specifically in Nigerian societies where social symbol and wealth is directly proportional to how big your house is or the number of air conditioners you have or how often your generator set is switched on. Some Nigerians tend to follow fads, and when compared to social status, energy efficiency may be less important to some building owners (Comaroff \& Comaroff, 1993; Forbes, 2015; Paul \& Zango Modi, 2014a). To keep up with the demands of clients and fads, most architects tend towards designing for aesthetics rather than sustainability or energy efficiency (Paul \& Zango Modi, 2014b).

Another factor that impedes the adoption of ESD is the political barrier. According to Edomah (2016), legal and regulatory barriers within the political discourse primarily relate to policy uncertainties and inconsistencies. This includes inconsistent standards and compliance requirements in the form of poor standards and codes to enhance and enforce a sustainable built environment. Too often, this includes the lack of knowledge of the government. In other cases, there is a lack of funding and financial resources from the government as incentives to building owners or for research and development (Abdul Majid \& Hussaini, 2015).

Little research has been undertaken in understanding the architects' and building owners' reason for adopting or not adopting ESD in Nigeria (Abdul Majid \& Hussaini, 2015; Dalibi et al., 2017; Wojuola \& Alant, 2017), specifically in terms of conducting a systematic and scientific review to understand the architects' and building owners' preferences and perceptions of ESD based on prevalent barriers. This study adopts the model for barrier identification to understand the barriers to ESD from the architects' and building owners' perspectives (as explained in Chapter 4). The hypothesised barriers based on the model of barrier identification include agreement, knowledge, technology, economic, social and political factors. These are discussed in a systematic and scientific method throughout the thesis. It is anticipated that the Nigerian population of over 180 million and its impact on the African continent makes the significance of this study extend beyond the borders of Nigeria.

\subsection{Statement of the problem}

Currently, the issue is twofold. The first challenge is the increasing external temperatures which, in addition to inferior building design methods, has led to indoor thermal discomfort in residential buildings. The second challenge is the increasing demand for electricity to power mechanical cooling systems. The unreliable electricity supply has led to an increasing reliance on fuel-powered generators, which is harmful to the environment.

First and foremost is the issue of inferior design methods and the resulting impacts on thermal discomfort in Nigerian residential dwellings. The level of efficiency in a residential building can be reflected through the configuration of the internal spaces to the 
climatic parameters of the immediate environment. In Nigeria, several factors determine the efficiency of the configured spaces within a residential building. These include user characteristics, building design typology, and indoor thermal environment (Adunola \& Ajibola, 2016) (see Chapters 2 for a detailed review of these factors). The indoor thermal environment is a significant factor in any building because of the interconnection between the climate, wellbeing, and human health. In Nigeria, this problem of thermal discomfort has increased due to prevalent high temperatures (WMO, 2015). This issue can either be addressed through the building design or the use of fuel-powered air-conditioners/fans, with the latter seemingly ubiquitous in Nigerian residences (Allu \& Elimisiemon, 2017).

The second problem relates to Nigeria's increasing population, which has resulted in increased demand for energy, and an electricity crisis. Inconsistent electricity supply means that fuel generators are commonly used to power air-conditioners/fans to achieve thermal comfort. The use of these generators increases greenhouse gas emissions like $\mathrm{CO}_{2}$, which are harmful to the environment and human health. Electricity from the national grid is available to only approximately 40-50\% of the Nigerian populace, and it is estimated that out of the 8,76o hours in a year (Figure 1.3), Nigeria experiences 4,600 hours of power outage (Abanihi, Ikheloa, \& Okodede, 2018; IIED, 2012; Statista, 2019).

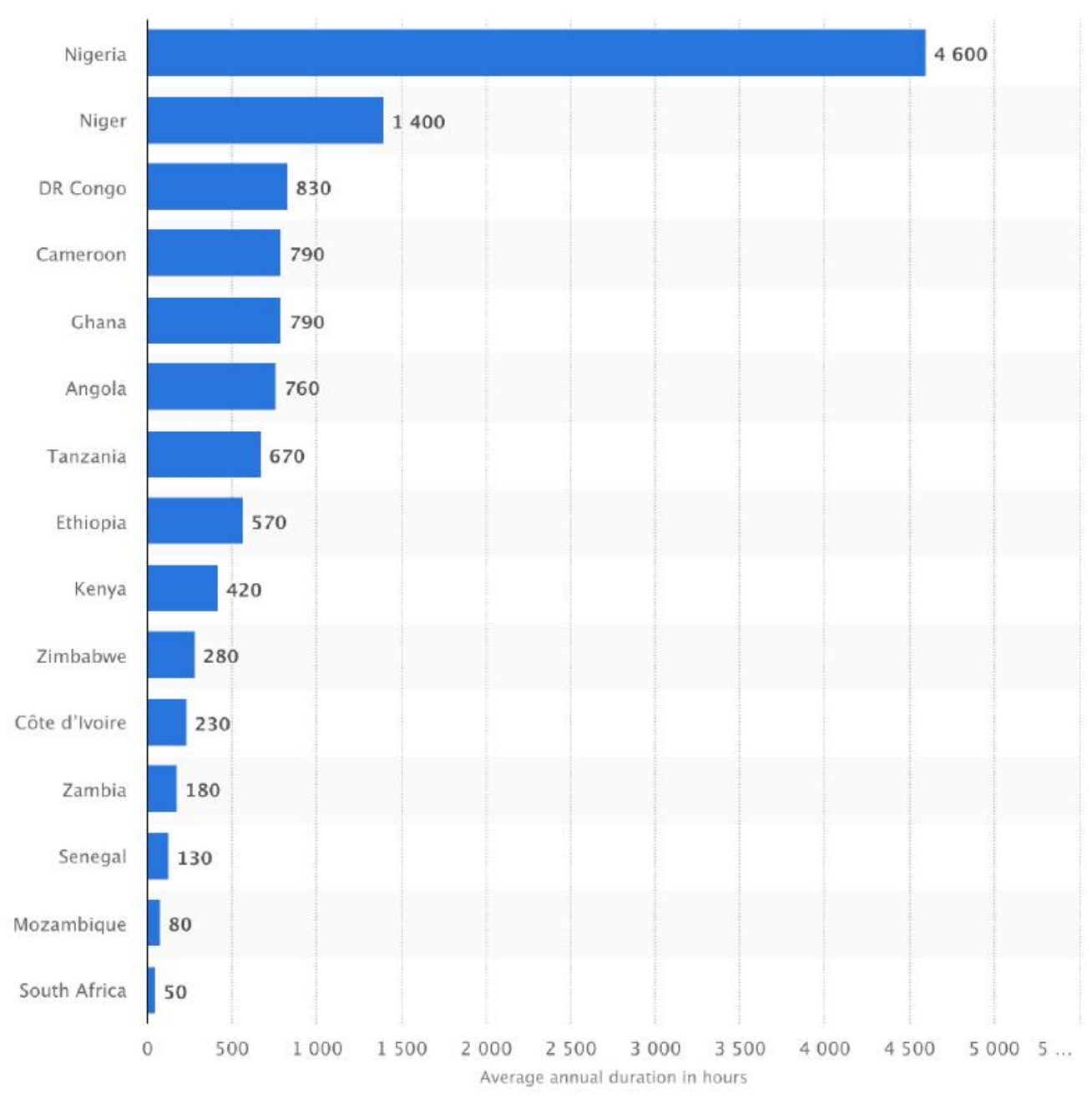

Figure 1. 3: Average duration of hourly power outages per year in selected countries in Africa (Statista, 2019)

As a result of the paucity in electricity supply from the national grid and the lack of on-site renewable energy generation, fuel-powered 'stand-by' generators have become the primary source of power in many residential buildings. The use of fuel has led to an increase in demand and cost, as well as political and economic instability in the country (Aliyu, Dada, \& Adam, 2015). Fuel-powered generators also release particulate matter (PM), which is harmful to the environment and could lead to respiratory and cardiopulmonary disease (AGA, 2017). In addition, generators affect sleep and contribute significantly to noise pollution, which reduces the quality of life for residents (Abanihi et al., 2018; Olamijulo, Ana, \& Morakinyo, 2016). A report from World Bank (2014) projects a rise in local health costs and even more significant impacts from PM in densely populated urban centres like Abuja, Lagos, and Port Harcourt. With the current trend, it is projected that the $\mathrm{CO}_{2}$ emission from buildings and the demand for electricity in Nigeria will double over the next decade (Bamisile, Dagbasi, Babatunde, \& Ayodele, 2017; UNEP, 2012).

If the trend of poor building design and increased reliance on fuel-powered generators continues, the impacts of an unsustainable built environment could extend beyond building efficiencies to include significant illnesses and loss of life (Akagwu, 2017; Omonijo, Adeofun, Oguntoke, \& Matzarakis, 2013). Existing literature (Atanda \& Olukoya, 2019; Giwa, Alabi, Yusuf, \& Olukan, 2017; Wojuola \& Alant, 2017) suggests that limited knowledge, economic, and social and political issues are barriers preventing the adoption of ESD for resolving the problem of thermal discomfort and energy generation. Considering these issues and the benefits of ESD, it is 
appropriate to investigate the barriers preventing ESD adoption as a mainstream solution in Nigeria, specifically from the architects' and building owners' perspectives, due to their roles in designing and constructing buildings. It is also appropriate to conclude the thesis by providing basic recommendations to address thermal comfort and energy generation issues.

\subsection{Research aim and objective}

The purpose of the study is to investigate the architects' and building owners' perceived barriers to the adoption of ESD in the design and construction of residential buildings in Nigeria. The study begins by identifying the possible barriers to ESD to establish an appropriate context for discussion. It specifies and exemplifies the similarities and diversities of the barriers in detail and analyses and investigates each barrier within the Nigerian context. It has the primary objective:

- What are the primary barriers preventing the mainstream adoption of ESD in Nigeria?

\subsection{Research questions}

Based on existing studies (Dalibi et al., 2017; Edomah, 2016; Trudgill, 1990; Wojuola \& Alant, 2017) on barriers preventing the adoption of ESD in Nigeria, and within the context of this study, six research questions were derived to explore the architects' and building owners' perception on the barriers preventing the adoption of ESD in Nigeria. These are:

- Do the architects and building owners both agree on the issue of indoor thermal discomfort?

- How knowledgeable is the Nigerian architect and building owner about ESD?

- Do we have the right technology to enhance the adoption of ESD? If no, is that a possible barrier?

- Are economic factors a possible barrier to ESD?

- What is the public perception of ESD? Are they interested?

- Are there favourable ESD policies? If no, is that a possible barrier?

The research scope involves a wide range of literature review regarding perceived barriers preventing the adoption of ESD in Nigeria. A quantitative and qualitative survey consisting of three stages was designed to understand these barriers within the Nigerian context better. Architects and building owners were chosen as the sole respondents for this study due to their involvement in various building project stages, from conceptualisation, design, and construction.

\subsection{Justification of the research}

Based on existing research, environmentally sustainable design methods (ESD) have been highlighted as an environmentally appropriate solution to the problem of thermal discomfort and renewable power generation (Amasuomo, Atanda, \& Baird, 2017; Edomah, 2016; Irouke \& George, 2016). However, there have been specific barriers to ESD adoption, one of which is the lack of knowledge by the architects and building owners on the means of adopting ESD for the provision of thermal comfort and renewable power generation. Existing studies have failed to concurrently investigate the architects' and building owners' perception of ESD, and if any, the barriers preventing their adoption of ESD (Table 1.1). This creates a gap in scientific knowledge within the Nigerian context. It is expected that the findings from this study will provide insights into the barriers preventing the adoption of ESD from an encompassing perspective involving the key decision-makers in building design and construction. For most medium-sized residential projects, the building owner and the architect are the key decision-makers from the conceptual stages to construction and completion. The architect makes the technical decisions with limited input from other consultants like the structural, mechanical and electrical engineers (Ayeni \& Adedeji, 2015). The majority of the responsibility is with the architect and the building owner, hence the need for this research. 
Table 1. 1: A review of existing studies on the barriers to sustainable design in Nigeria

Existing Studies

\begin{tabular}{|c|c|}
\hline (Akagwu, 2017) & $\begin{array}{l}\text { - The focus of the study was on architects only } \\
\text { - There was no theoretical model or framework adopted for the study }\end{array}$ \\
\hline (Akinola et al., 2018) & $\begin{array}{l}\text { The study was limited to architects in a single state; hence the } \\
\text { results and findings did not address any possible regional factors } \\
\text { - The findings from the study were based on the results from the } \\
\text { distributed questionnaires alone. There were no additional } \\
\text { research methods adopted to counterbalance the shortcomings of a } \\
\text { single research method }\end{array}$ \\
\hline (Allu \& Elimisiemon, 2017) & $\begin{array}{l}\text { - The study was based on literature review with no quantitative or } \\
\text { qualitative data/analysis to validate the study }\end{array}$ \\
\hline (Dalibi et al., 2017) & $\begin{array}{l}\text { - The focus of the study was on professionals within the building } \\
\text { industry with no reference to building owners who are the key } \\
\text { decision-makers. }\end{array}$ \\
\hline (Nduka \& Ogunsanmi, 2016) & $\begin{array}{l}\text { The findings from the study were based on the results from the } \\
\text { distributed questionnaires alone. There were no additional } \\
\text { research methods adopted to counterbalance the shortcomings of a } \\
\text { single research method }\end{array}$ \\
\hline (Wojuola \& Alant, 2017) & $\begin{array}{l}\text { - Although this study was based on a very comprehensive theoretical } \\
\text { model (TAM and TRA), the focus of the study was only on the } \\
\text { public perception of renewable energy. }\end{array}$ \\
\hline (Waniko, 2014) & $\begin{array}{l}\text { In this study, references were made to architects and engineers; } \\
\text { however, the primary focus was on quantity surveyors and the } \\
\text { Nigerian Institute of Quantity Surveyors. The study did not address } \\
\text { the role of the building owners who play a critical role in the } \\
\text { adoption of sustainable design. } \\
\text { - There was no theoretical model or framework adopted for the study }\end{array}$ \\
\hline
\end{tabular}

\subsection{Scope of the study}

This research focuses on residential buildings in Nigeria, considering that the household sector contributes around 70\% of the total $\mathrm{CO}_{2}$ emissions in the built environment (Ezema, Opoko, \& Oluwatayo, 2016). The scope of the study (Table 1.2) involved a nationwide electronic distribution of questionnaires to architects, whilst the physical interview with architects and the survey of building owners and their respective buildings was limited to four states in Nigeria - Lagos, Abuja, Bayelsa, and Rivers. These areas were selected for three main reasons. Firstly, Lagos state has the highest population in Nigeria and is considered its commercial hub; Abuja is the capital of Nigeria and the helm of government affairs; Bayelsa and Rivers states are the hub of the Niger Delta and the centre for crude oil exploration (BBC, 2018; Elleh, 2001; Williams, 2008). Secondly, the researcher had easy access to residential buildings in the selected states. Thirdly, due to the insecurity in Nigeria's northern and eastern states, these regions are unsafe for conducting a field study. Nigeria was chosen as the focus of this study because of its rapid population growth and high vulnerability to global warming. The study was focused on practising architects in Nigeria because they are responsible for the design and construction of buildings, while the building owners (as detailed in succeeding chapters) are the end-users of the buildings. The study is divided into the following stages:

- The distribution of questionnaires to architects to provide an overview of their perception of ESD

- Interviews with architects to better understand the architect's perception and view on the prevalent barriers to ESD.

- Distribution of questionnaires to building owners to establish their perception of ESD and reinforce the results from stages 1 and 2. Additionally, the use of a checklist to conduct a physical survey of their respective buildings.

Based on the research outcomes, the study identifies the barriers preventing the adoption of ESD in Nigeria. In addition, the study develops a research method that could be adopted in other regions of the globe to understand the architects' and building owners' perceptions regarding the appropriateness of ESD. The thesis concludes by providing practical yet straightforward ESD strategies that could add to the existing body of knowledge on ESD, thus improving its level of adoption in Nigeria. 
Table 1. 2: Research Map

\begin{tabular}{|c|c|c|}
\hline Objectives & Methods & Chapters \\
\hline $\begin{array}{r}\text { To establish the research } \\
\text { questions, aims and } \\
\text { objectives. Overall, validate } \\
\text { the importance of the } \\
\text { research }\end{array}$ & $\begin{array}{l}\text { Review of existing literature } \\
\text { on the level of ESD adoption in } \\
\text { Nigeria and any barriers } \\
\text { preventing its adoption }\end{array}$ & $\begin{array}{l}\text { Chapters } 2 \text { and 3: Systematic } \\
\text { review of the concept of ESD } \\
\text { and the Nigerian response to } \\
\text { the concept }\end{array}$ \\
\hline $\begin{array}{r}\text { Choose the most suitable } \\
\text { method for an extensive } \\
\text { investigation }\end{array}$ & $\begin{array}{l}\text { Review of the various research } \\
\text { methods and how they relate } \\
\text { to the theoretical framework } \\
\text { from chapters } 2 \text { and } 3 \text { and } \\
\text { address the research questions }\end{array}$ & $\begin{array}{l}\text { Chapter 4: A review and } \\
\text { applicability of the selected } \\
\text { mixed-method research } \\
\text { strategy (i.e. questionnaire } \\
\text { distribution, interviews, and } \\
\text { case studies) }\end{array}$ \\
\hline $\begin{array}{r}\text { Survey to investigate the } \\
\text { architects' and building } \\
\text { owners' perceptions of ESD } \\
\text { and their level of adoption }\end{array}$ & $\begin{array}{l}\text { Investigate the association } \\
\text { between the architects and } \\
\text { building owners and their } \\
\text { adoption of ESD }\end{array}$ & $\begin{array}{l}\text { Chapter 5: Report the results } \\
\text { from the questionnaires, } \\
\text { interviews, and physical survey } \\
\text { of selected buildings }\end{array}$ \\
\hline \multirow[t]{2}{*}{$\begin{array}{r}\text { Understand the architects' } \\
\text { and building owners' } \\
\text { perceptions regarding the } \\
\text { appropriateness of ESD. }\end{array}$} & $\begin{array}{l}\text { A review of the results from } \\
\text { the survey and comparison to } \\
\text { the existing literature }\end{array}$ & $\begin{array}{l}\text { Chapter 6: Discussion of the } \\
\text { results from all three stages of } \\
\text { the study }\end{array}$ \\
\hline & & $\begin{array}{l}\text { Chapters 7: Implementation of } \\
\text { ESD, conclusion, } \\
\text { recommendation and future } \\
\text { studies }\end{array}$ \\
\hline
\end{tabular}

\subsection{Research Methodology}

The research method implemented in this study is driven by a quest to understand the barriers preventing the adoption of environmentally sustainable design methods. Existing research has provided environmentally sustainable design methods suitable for the three different climates in Nigeria (equatorial in the south, tropical in the middle belt, and arid in the north) (Amasuomo et al., 2017), however, these methods are not widely adopted (Ajibola, 2001; Dalibi et al., 2017; Ogunsote, 2010). An understanding of the reason for the lack of widespread adoption provides a theoretical base for this study. This study adopts a mixed-method approach, mainly using an exploratory sequential design (i.e. quantitative followed by a qualitative phase) and concludes with a case study.

The goal of the quantitative phase was to identify the barriers to ESD and validate the appropriateness of Trudgill's (1990) structural theoretical model for barrier identification and classification for a sustainable built environment. The structural theoretical model suggests that the barriers hindering the development of a sustainable built environment could be summarised into six categories: agreement, knowledge and technology, economic, social, and political constraints, respectively. The qualitative phase was to validate and gain a deeper insight into the barriers highlighted in the quantitative phase. This entailed synthesis of the results from the quantitative phase (distribution of questionnaires to architects), qualitative phase (structured interviews with architects) and a case study involving the distribution of questionnaires to building owners in Nigeria and a physical survey of their respective buildings. A summary of the results provides insight into the barriers to ESD in Nigeria and provides a good understanding of Nigeria's current residential building morphology.

\subsection{Overview of the chapters}

This thesis is subdivided into seven chapters with appendices containing additional information. Table 1.2 provides a schematic demonstration of the thesis, highlighting the interrelationship between each chapter to provide the reader with a good understanding of the development of the thesis. 
Chapter 2 | Environmentally sustainable design methods

Chapter 2 | Environmentally sustainable design methods 


\subsection{Introduction}

This chapter provides a systematic literature review of environmentally sustainable design methods (ESD) to establish the architectural dynamics in Nigeria with regards to the adoption of ESD and evaluate the possible barriers preventing the mainstream adoption of ESD in Nigeria. It has two main objectives:

1. Provide an understanding of environmentally sustainable design methods.

2. Provide a checklist for evaluating the level of ESD adoption in selected Nigerian buildings.

\subsection{Concept of sustainability}

Sustainable solutions to existing environmental problems are becoming a global phenomenon with a wide range of interest within the built environment. Sustainability issues are constantly highlighted, debated, and explored, thus highlighting the issue globally. The World Commission on Environment and Development (WCED, 1987) defines sustainability as the development that meets the needs of the present without compromising the ability of future generations to meet their own needs. This concept adopts a rounded approach which has progressed significantly over the years into the Sustainable Development Goals (SDG) (GA \& UN, 2015). The SDG is a universal call to action to reduce poverty and hunger, promote good health and wellbeing, ensure quality education and gender equality, ensure clean water and sanitation, encourage affordable and clean energy, decent work and economic growth, improve industry, innovation, and infrastructure, reduce inequalities, promote sustainable cities and communities, responsible consumption and production, improve life below water, life on land, peace and justice, and partnerships for the goals to reduce the impact on the natural environment (UNDP, 2020). According to Marsh (2005), sustainability balances natural resources with society's social, economic, and environmental needs. These definitions cover the specific arguments of the processes and end result for people, addressing their different priorities and backgrounds, such as the varying socio-cultural, environmental, and economic angles from which they emanate (Mawhinney, 2002). Within the built environment, sustainability assessment tools have grown to become an accepted method for evaluating the social-economic and environmental parameters of a building. In light of this, the green movement has been encouraged by national governments globally and incorporated into the building codes of several countries (Zhang, Kang, \& Jin, 2018). This movement has led to the development of green building certification bodies such as the Building Research Establishment Environmental Assessment (BREEAM), Leadership in Energy and Environmental Design (LEED), the Green Building Council of South Africa, and the Green Building Council of Nigeria (Atanda \& Olukoya, 2019). The assessment tool developed by the certification bodies provides an effective framework for evaluating the performance and level of sustainable integration in the building and construction process. The Green Building Council of Nigeria (GBCN) is still on a prospective membership level of registration with the World Green Building Council (WGBC). The GBCN is yet to be registered and thus has not produced an environmental rating tool that could be used for office, retail, multi-unit residential, public and educational building projects in Nigeria (Abisuga \& Okuntade, 2020; Prucnal-Ogunsote et al., 2018; WSP, 2014). In the meantime, the GBCN is working in collaboration with The Green Building Council of South Africa (GBCSA) to manage and allow certification through its current rating. The certification issued in collaboration with the GBCSA will be called Green Star SA - Nigeria (Abisuga \& Okuntade, 2020; WSP, 2014).

In the interest of practicality, this thesis provides an overview of three assessment tools. They include The Building Research Establishment Environmental Assessment (BREEAM), Leadership in Energy and Environmental Design (LEED), because of their global recognition (Awadh, 2017), and the Green Star SA (GSSA) because of its affiliation to the Green Building Council of Nigeria (GBCN). The primary purpose of the assessment tool is to evaluate the building specification, including the design, construction and use at different stages of the building's life cycle (Zhang et al., 2018). Generally, the assessment is calculated by awarding a point or credit that is based on various categories such as building design and construction, building operations and maintenance, interior design and construction, neighbourhood development and homes, management, health and wellbeing, energy efficiency, transportation, water supply and efficiency, material selection, waste management, land use and ecology, pollution and innovation. The total number of credits awarded for each category is multiplied by an environmental weighting factor that records the category's importance. The category score is later calculated to generate an overall scale, identified as unclassified, pass, good, very good, excellent, or outstanding. A star rating from 1-5 is also provided (Amasuomo et al., 2017). Table 2.1 provides an overview of the three different rating systems, highlighting their similarities and differences. 
Chapter 2 | Environmentally sustainable design methods

Table 2. 1: An overview of performance assessment tools (Amasuomo et al., 2017; GBCSA, 2019)

\begin{tabular}{|c|c|c|c|c|c|c|c|}
\hline Categories & BREEAM & LEED & GSSA & Categories & BREEAM & LEED & GSSA \\
\hline $\begin{array}{l}\text { Sustainable site and } \\
\text { Ecology }\end{array}$ & & & & Energy & & & \\
\hline Ecological status & & & & Natural Resources & & & \\
\hline Biodiversity protection & $\sqrt{ }$ & $\sqrt{ }$ & $\sqrt{ }$ & Renewable energy strategy & $\sqrt{ }$ & $\sqrt{ }$ & $\sqrt{ }$ \\
\hline Contaminated land & $\sqrt{ }$ & $\sqrt{ }$ & $\sqrt{ }$ & Energy performance & & & \\
\hline Enhancing site ecology & $\sqrt{ }$ & $\sqrt{ }$ & $\sqrt{ }$ & HVAC & $\sqrt{ }$ & $\sqrt{ }$ & $\sqrt{ }$ \\
\hline Ecological impact & $\sqrt{ }$ & $\sqrt{ }$ & $\sqrt{ }$ & Lighting (internal) & $\sqrt{ }$ & $\sqrt{ }$ & $\sqrt{ }$ \\
\hline Construction site & & & & Lighting (external) & $\sqrt{ }$ & $\sqrt{ }$ & $\sqrt{ }$ \\
\hline Site protection & $\sqrt{ }$ & $\sqrt{ }$ & $\sqrt{ }$ & Ventilation & $\sqrt{ }$ & $\sqrt{ }$ & $\sqrt{ }$ \\
\hline Site selection & $\sqrt{ }$ & $\sqrt{ }$ & $\sqrt{ }$ & Heat transmission & $\sqrt{ }$ & $\sqrt{ }$ & $\sqrt{ }$ \\
\hline Site development & $\sqrt{ }$ & $\sqrt{ }$ & $\sqrt{ }$ & Economic Aspect & & & \\
\hline $\begin{array}{l}\text { Indoor Environment and } \\
\text { Health }\end{array}$ & & & & Operation and maintenance & $\sqrt{ }$ & $\sqrt{ }$ & $\sqrt{ }$ \\
\hline Ventilation & $\sqrt{ }$ & $\sqrt{ }$ & $\sqrt{ }$ & Pollution & & & \\
\hline $\mathrm{CO}_{2}$ monitoring & $\sqrt{ }$ & $\sqrt{ }$ & $\sqrt{ }$ & $\begin{array}{l}\text { Prevention of refrigerant } \\
\text { leakage }\end{array}$ & $\sqrt{ }$ & & $\sqrt{ }$ \\
\hline $\begin{array}{l}\text { Provision of natural } \\
\text { ventilation }\end{array}$ & $\sqrt{ }$ & $\sqrt{ }$ & $\sqrt{ }$ & NOx emission & $\sqrt{ }$ & $\sqrt{ }$ & \\
\hline Ventilation system & $\sqrt{ }$ & $\sqrt{ }$ & $\sqrt{ }$ & $\mathrm{CO}_{2}$ emission & $\sqrt{ }$ & $\sqrt{ }$ & $\sqrt{ }$ \\
\hline Fresh air supply & $\sqrt{ }$ & $\sqrt{ }$ & $\sqrt{ }$ & Night light & $\sqrt{ }$ & $\sqrt{ }$ & $\sqrt{ }$ \\
\hline Thermal comfort & $\sqrt{ }$ & $\sqrt{ }$ & $\sqrt{ }$ & & & & \\
\hline Lighting and Illumination & & & & Noise pollution & $\sqrt{ }$ & $\sqrt{ }$ & $\sqrt{ }$ \\
\hline Daylight & $\sqrt{ }$ & $\sqrt{ }$ & $\sqrt{ }$ & Watercourse pollution & $\sqrt{ }$ & $\sqrt{ }$ & $\sqrt{ }$ \\
\hline View out and glare control & $\sqrt{ }$ & $\sqrt{ }$ & & Natural disasters & $\sqrt{ }$ & $\sqrt{ }$ & $\sqrt{ }$ \\
\hline Lighting control & $\sqrt{ }$ & $\sqrt{ }$ & & Contaminant level & & & \\
\hline Illumination level & $\sqrt{ }$ & $\sqrt{ }$ & & $\begin{array}{l}\text { Volatile organic compounds } \\
\text { (VOC) }\end{array}$ & $\sqrt{ }$ & $\sqrt{ }$ & $\sqrt{ }$ \\
\hline Noise and acoustics & & & & $\begin{array}{l}\text { Microbiological contaminant } \\
\text { level }\end{array}$ & $\sqrt{ }$ & $\sqrt{ }$ & \\
\hline Noise level & $\sqrt{ }$ & $\sqrt{ }$ & $\sqrt{ }$ & Thermal comfort & $\sqrt{ }$ & $\sqrt{ }$ & $\sqrt{ }$ \\
\hline Sound insulation & $\sqrt{ }$ & $\sqrt{ }$ & $\sqrt{ }$ & $\begin{array}{l}\text { Cooling/heating and humidity } \\
\text { control }\end{array}$ & $\sqrt{ }$ & & $\sqrt{ }$ \\
\hline Innovation & & & & Proper zoned control & $\sqrt{ }$ & $\sqrt{ }$ & \\
\hline Exceptional performance & $\sqrt{ }$ & $\sqrt{ }$ & $\sqrt{ }$ & Operational & & & \\
\hline Innovation in design & $\sqrt{ }$ & $\sqrt{ }$ & $\sqrt{ }$ & Energy monitoring & $\sqrt{ }$ & & $\sqrt{ }$ \\
\hline Transport and Location & & & & Optimising energy & $\sqrt{ }$ & $\sqrt{ }$ & $\sqrt{ }$ \\
\hline Accessibility & $\sqrt{ }$ & $\sqrt{ }$ & $\sqrt{ }$ & $\mathrm{CO}_{2}$ reduction strategy & $\sqrt{ }$ & $\sqrt{ }$ & $\sqrt{ }$ \\
\hline Car park capacity & $\sqrt{ }$ & $\sqrt{ }$ & $\sqrt{ }$ & Insulant GWP & $\sqrt{ }$ & $\sqrt{ }$ & $\sqrt{ }$ \\
\hline Pedestrian access & $\sqrt{ }$ & $\sqrt{ }$ & $\sqrt{ }$ & Energy efficient strategies & $\sqrt{ }$ & $\sqrt{ }$ & $\sqrt{ }$ \\
\hline Cycling safety and facilities & $\sqrt{ }$ & $\sqrt{ }$ & $\sqrt{ }$ & & & & \\
\hline Density development & $\sqrt{ }$ & $\sqrt{ }$ & $\sqrt{ }$ & & & & \\
\hline Community connection & $\sqrt{ }$ & $\sqrt{ }$ & $\sqrt{ }$ & & & & \\
\hline
\end{tabular}


Chapter 2 | Environmentally sustainable design methods

2.2.1 Overview of the different categories in the green building rating systems

The green building assessment tools are broadly divided into the following categories (Table 2.1):

Sustainable site and ecology: This category aims to recognise activities that maintain the ecological value, minimise negative impacts on the environment, and enhance ecological service provision on site. It also encourages the reduction of site pollutants during and after construction by controlling soil erosion, waterway sedimentation, biodiversity and airborne pollutants (Awadh, 2017; GBCSA, 2019).

Energy: Due to the environmental impact of energy generation and use, this category is awarded the most significant portion of credit within the environmental indicators (Awadh, 2017; GBCSA, 2019). This indicator encourages sustainable and efficient energy design and management, renewable energy strategies, energy conservation and monitoring (BREEAM, 2019; LEED, 2019b).

Water and waste management: This category aims to reward practices that ensure efficient water consumption in and out of the building, and water treatment to mitigate the health and environmental impact of wastewater (Amasuomo et al., 2017). It also rewards operational practices that decrease the quantity of solid waste going into landfill: this waste could be from general building operations, or during construction (GBCSA, 2019).

Material: This category ensures best practice for the consumption of resources in terms of material selection. BREEAM developed a Green Guide to Specification, which contains over 1500 specifications of building materials: this database guides the decision making for materials and their environmental impacts (BREEAM, 2019). Similarly, LEED focuses on the reusability and maintenance of construction materials (LEED, 2019b).

Management: Site and construction management are also critical factors in ensuring sustainable development. This creates an opportunity to evaluate the commissioning level and offer guidance on how the building should operate efficiently. This can be visible in the BREEAM performance assessment tool under the heading management. LEED and Green Star SA also covers the management category extensively.

Indoor environment and health: The quality of the indoor environment is a fundamental aspect of the assessment tool. It encourages the delivery of healthy indoor spaces using lightning, illumination, noise, acoustics, ventilation rate, thermal comfort, quality of view, daylight and protection from hazardous substances on the health of occupants (BREEAM, 2019; GBCSA, 2019; LEED, 2019b). The category is described as health and wellbeing for BREEAM and Indoor Environmental Quality (IEQ) in LEED, and Green Star SA. LEED covers low-emitting materials, BREEAM covers Heating Ventilation and Air-Conditioning (HVAC) systems. In contrast, Green Star SA covers emissions and ventilation.

Economic aspect: The economic category covers the construction, operational, and maintenance cost of the building. The assessment tools cover this fairly (BREEAM, 2019; GBCSA, 2019; LEED, 2019b).

Pollution: The aim of this category is to encourage operational practices that minimise the release of pollutants such as refrigerant leaks, $\mathrm{NOx}$ and $\mathrm{CO}_{2}$ that would have an impact on global warming and increase "Heat island effects" (BREEAM, 2019; GBCSA, 2019; LEED, 2019b).

Innovation: This category encourages and recognises pioneering initiatives, processes, strategies, and overall exceptional performance in all sustainable aspects of building management and operations (BREEAM, 2019; GBCSA, 2019; LEED, 2019b).

Transport and location: This category aims to recognise and award building projects that enhance accessibility to the site, protect farmland and wildlife habitat and improve overall human health while encouraging physical activity (BREEAM, 2019; GBCSA, 2019; LEED, 2019b).

Social aspect: This category covers building and community-related issues such as the improvement of health, awareness, comfort, quality of life, social cohesion, equity, satisfaction, education, safety security, accessibility and participation, which are critical factors in ensuring a sustainable building (BREEAM, 2019; GBCSA, 2019; LEED, 2019b).

The BREEAM, LEED, and Green Star SA assessment tools cover various environmental issues using scientifically based sustainability metrics and indices. They evaluate water and energy use, health and wellbeing, pollution, transportation, waste and ecological 
management. The primary aim of these tools is to raise awareness amongst building owners, occupiers, and designers of the benefits of adopting environmentally sustainable methods in a cost-effective manner that reduces the negative impacts of construction and development on the environment. Given the extensiveness of these tools, the scope of this study has been limited to the primary indicators that are readily applicable to the Nigerian housing context. They include thermal comfort and energy generation due to the increasing demand for power for achieving thermal comfort in Nigeria, and the resulting impact on the environment (WBG, 2019). The following section provides a review of ESD and how it relates to the broader subject of sustainability. A combination of the review on ESD and the assessment tools above provides a good foundation for developing a checklist in the subsequent sections used for conducting the physical survey of selected buildings in Nigeria.

\subsection{Environmentally Sustainable Design Methods}

Climate change and global warming have a fundamental impact on thermal comfort through increasing temperatures and extreme climatic conditions. This impact has led to excessive reliance on fossil fuels to power auxiliary cooling systems to achieve thermal comfort in indoor spaces in Nigeria (Okafor, 2018). Existing literature recommends ESD as a preferable alternative to auxiliary cooling systems whilst reducing the cost of energy demand in the building and mitigating the building's impact on the environment. ESD are not recent but date back to the primitive ages. According to Fitch and Branch (1960), in the building of shelters, primitive dwellers were faced with one supreme and absolute limitation; the impact on the environment. They ensured that the building was in harmony with the environment, utilising building techniques and materials that the environment afforded. A review of the architectural dynamics in Nigeria shows that traditional builders constantly responded to the challenges of nature and climate and their religious and socio-cultural beliefs by ensuring that buildings were in harmony with the environment (Adebamowo, 2013). ESD methods can be defined as employing design techniques to minimise environmental degradation by utilising low-impact materials and energy sources to provide shelter and comfort (OxfordDictionary, 2017). Elleh (1997), before Western civilisation, the adoption of ESD through the utilisation of renewable sources was ubiquitous in Nigeria; however, the reverse is true for contemporary times. The emphasis in this study is on ESD methods tailored to improve indoor thermal comfort: they include passive ventilation techniques and renewable energy generation methods. The following section provides varying but similar definitions by various authors to expand on these methods.

\subsubsection{Baruch Givoni’s perspective on ESD}

Givoni (1994) refers to ESD as a climatic design approach that is divided into two broad categories: passive architectural systems and bioclimatic architecture. Within this context he presents research and applications of passive building systems and cooling strategies such as building orientation and layout, window size and shading, the application of radiative and reflective exterior colour, and landscaping. 'Passive' and 'bioclimatic architecture' are part of an environmental approach to building development, also known as ESD. According to Givoni (1994), the design and application of passive architectural systems are often confused with climate responsive architectural design, also known as bioclimatic architecture. However, some distinction exists between these concepts, and it is essential to establish the differences.

Bioclimatic architecture is a backdrop to the vernacular architectural ideologue developed across centuries by many civilisations induced by climate, socio-cultural structure, economy, materials and ancient technological availability. Architectural means of achieving this include conventional design elements such as the building layout and orientation; number, size, location, and types of aperture; envelope shading devices and the thermo-physical properties of the building materials (Givoni, 1976).

Passive architectural systems provide comfortable indoor conditions at extremely low cooling loads by utilising passive architectural means to transfer heat from the building to various natural heat sinks (Givoni, 1994). Roaf et al. (2013) efficient passive architectural systems minimise the total energy demand of dwellings by optimising the efficiency of all building components, systems, and appliances whilst reducing the ecological footprint of the building. The application of passive architectural systems usually requires specialised details in the design and construction of the various building components, including the roof component and supplementary internal structural systems, and on-site renewable energy sources (Wolfgang, 2015). Bioclimatic architecture deals exclusively with the building design and materials to achieve energy efficiency and thermal comfort, while passive architectural systems afford the same requirements through passive and active mechanical systems like photovoltaic panels etc. (BioclimaticX, 
2009; Givoni, 1994; Roaf et al., 2013). The basic concepts and techniques of passive architectural systems include, but are not limited to, the following:

- Passive solar architecture

- Active solar architecture

- Renewable energy

- Sustainable architecture

- Self-sufficient house

Comprehensive studies on the above concepts and techniques have been undertaken (Khan, 2008; Omidreza, Haw, Sopian, \& Sulaiman, 2012; Roaf et al., 2013; Schniedersa, Wolfgang, \& Ludwig, 2015; Wolfgang, 2015). Appropriate bioclimatic architecture can be considered a prerequisite for applying passive architectural systems, with the two concepts supplementing and reinforcing each other.

\subsubsection{Victor Olgyay's perspective on ESD}

Olgyay (2015), uses the term climate balanced to describe environmentally sustainable design. He defines it as a structure that, in a given environmental setting, reduces undesirable stresses, and at the same time utilises natural resources favourable to human comfort. A perfect balance is seldom achieved except in exceptional environmental circumstances; however, what is generally attainable is a house with thermal comfort, at lowered cost and energy demand, devoid of excessive mechanical cooling (Olgyay, 2015). To achieve an environmentally sustainable design, (Olgyay, 2015) provides a sequential interplay of four variables: climate, biology, technology, architecture.

Climate data or site analysis involves a survey of the climatic characteristics and constituent of the given location, such as temperature, relative humidity, radiation, and wind velocity. The climatic data, if possible, should be adapted to the living level and the resulting modified effect on the microclimate of the building.

Biological evaluation is based on the users' comfort and living conditions. Plotting a bioclimatic chart on a yearly timetable will indicate the measures required for providing thermal comfort.

Technology solutions potentially prevent the adverse impacts of ambient climatic conditions, utilising advantageous elements at the optimal time and in appropriate quantities. This involves analysing the existing building parameters to establish the site selection, building orientation, and shading calculations (using a chart of the sun's path, plus geometric calculations). It also requires the building to adapt to the favourable or unfavourable impact of the thermal environment, air movement, and indoor temperature balance.

\subsubsection{Carl Mahoney, Otto Konigsberger, and Martin Evans' perspective on ESD}

Carl Mahoney, Otto Konigsberger, and Martin Evans (1971) published Climate and House Design for the United Nations Department of Economic and Social Affairs. This publication also assumes a similar sequential process of climate, biological evaluation, and architectural techniques. Their research led to the development of the notable Mahoney Table, which provided a set of reference tables used as a guide for designing environmentally sustainable buildings. They argued that it is impractical to plan a building exclusively on cost or spatial morphology and expect a few minor additions to provide a comfortable indoor climate. Such buildings tend to rely excessively on mechanical air-conditioning systems. They proposed that the ambient climate and the natural environment are paramount and must be considered when deciding on the project's overall concept, from the layout and orientation of the building to the shape and character of structures to the enclosed spaces and spaces between buildings. 


\subsubsection{Richard Hyde's perspective on ESD}

According to Hyde (2000), bioclimatic and climate responsive design are subsets of an environmental approach to building development, also known as ESD, which examines the holistic relationship between the building, its users, and the environment. The main factors for consideration within this approach include waste reduction and recycling, benign use of energy sources, efficient use of building materials and embodied energy, minimising the building impact on human health and wellbeing, and enhancing thermal comfort. Globally, architects' and other building professionals have developed concepts to access the building's correlation with the natural environment from an 'energy use' perspective. The first of these concepts is 'embodied energy', which forms a part of a more comprehensive environmental analysis system that includes operational energy, (i.e. energy used daily to operate a building) (Hyde, 2008). Hyde (2000), provides a systematic strategy similar to that of Olgyay (2015), and Mahoney, Königsberger and Evans (1971) (Table 2.2).

Table 2. 2: Stages in climate investigations (Hyde, 2000; Lippsmeier, 1980)

\begin{tabular}{lll} 
Stage 1: & Stage 2: & Stage 3: \\
\hline $\begin{array}{l}\text { Climate analysis and data } \\
\text { collection }\end{array}$ & $\begin{array}{l}\text { Bioclimatic comparative } \\
\text { analysis } \\
\text { (i.e. bioclimatic chart) }\end{array}$ & Selection of ESD \\
\hline - Solar radiation & $\begin{array}{l}\text { Analysis of the climate } \\
\text { data in relation to the }\end{array}$ & $\begin{array}{l}\text { Cooling methods through } \\
\text { dehumidification, }\end{array}$ \\
- Sunshine & provision of thermal & ventilation, evaporation, \\
- Humidity & comfort & and mass. \\
- Rainfall & & \\
- Wind velocity and & & \\
& &
\end{tabular}

\subsubsection{Dekay and Brown's perspective on ESD}

Dekay and Brown (2014), describe ESD as an integrated design that proffers both a theoretical approach for creating a sustainable building and a practical method for the design and construction of buildings. It involves a synthesis of climate, architectural strategies, and renewable energy systems for achieving a more thermally comfortable and productive environment for building occupants. At the heart of their proposed approach is an iterative combination of synergies at every stage of a project. They developed a Design Decision Plan for Net-Zero, Peak-Zero, and Net-Positive building to assist designers to make climate-responsive decisions during the design and construction stages. This provides a method for linking design concepts, or synergies, with bundles and individual architectural strategies. The Design Decision Plan is conceptually broken down into seven questions and synergies: resources; use; neighbourhood access and site microclimate; morphology, zoning and pathways; thermal storage and envelope; apertures; systems, control and generation.

Resources point to the available resources on-site and their relationship to potential building loads. In climates with extreme conditions, they recommend trimming the building load to a minimum. In tropical climatic regions like Nigeria characterised by plentiful sunlight, solar energy can be converted to power and used to supplement cooling demands (IIED, 2012).

Use refers to the occupants' patterns and behavioural elements and their impact on building energy use. This refers to the adaptive model of thermal comfort. The philosophy behind this strategy is such that when a change stimulates thermal discomfort, building occupants adjust to re-establish thermal comfort (Hacker \& Holmes, 2007). Occupants aware and knowledgeable of this technique can take advantage of physiological traits, such as space migration, change of clothes, adapting to the thermal or lighting levels to reduce energy consumption. Essentially, through their activities, energy-conscious occupants reduce the energy requirements for cooling, ventilation, and lighting. A study by Adunola and Ajibola (2016) showed that in most instances, respondents surveyed in a case study in Nigeria adopted space migration techniques and other behavioural procedures to improve thermal comfort.

Neighbourhood access and site microclimate address outdoor spaces and the building's access to climate resources at the neighbourhood or urban scale. This includes access to sunlight, wind, and light. This allows for the prevention of the adverse impact of the ambient climatic conditions or the utilisation of the advantageous at the optimal time and in appropriate quantities. Olgyay 
Chapter 2 | Environmentally sustainable design methods

(2015) describes this strategy as a technological solution. Outdoor comfort; access to sun, wind, and light; and energy generation are the fundaments of this strategy.

Morphology, zoning, and pathways focus on the design decisions dealing with the building morphology and its internal organisation. This strategy seeks to optimise zoning and spatial interactions for energy reduction and occupants' comfort. Mahoney, Königsberger and Evans (1971), also recommend similar strategies for exterior and interior morphology. They include - optimising the building orientation to take advantage of the wind for air admittance and a buffer for solar radiation through solar shading techniques, open floor plans to enhance flexibility and air movement within the interior space, etc.

Thermal storage and envelope address the integration of thermal storage and responsive envelopes. In most parts Nigeria, thermal storage is not required due to the negligible diurnal and nocturnal ranges (Ogunsote, 2010). According to Givoni (1976), the building envelope modifies the resultant effects of temperature, rain, humidity, solar radiation, wind, etc., and the envelope's quantitative effect depends on its thermo-physical properties, thickness, and spatial composition. Essentially, the building should resist or admit conductive, convective and radiative heat transfer when required.

Apertures refer to the designing of apertures and other complex multi-use elements. Dekay and Brown (2014); Mahoney, Königsberger and Evans (1971); and Givoni (1976), provide similar recommendations for aperture sizing for enhancing air movement through the building's interior. Amongst other methods, these include stack ventilation, venting, and cross ventilation.

Systems, controls and generation is the final stage and constitutes the selection of mechanical systems, controls, and on-site energy generation systems such as wind turbines, photovoltaic panels, and other renewable energy sources. According to Givoni (1994), this stage is only required when every other bioclimatic approach has been thoroughly utilised. The primary aim of this section and its corresponding active tailored systems is to adapt the systems as precisely as necessary to the size and energy demand for cooling, ventilation, and lighting loads. At this stage, the Energy Balance Index (EBI) can be calculated based on the envisaged Energy Production Intensity (EPI) and the Energy Use Intensity (EUI).

Energy Balance Index (EBI) = Energy Production Intensity (EPI) - Energy Use Intensity (EUI)

According to Torcellini, Pless, and Deru (2006), the EUI measures the amount of energy demand in a building per unit area basis and is calculated by dividing the total building area by the annual energy demand. The EUI is weighed against the total energy generated on-site from wind turbines, photovoltaic panels or other renewable energy sources (DeKay \& Brown, 2014). In the interests of practicality and comprehensibility, this study has adopted the term ESD as it addresses the climatic parameters and building design strategies and the broader social-cultural factors that play a role in a design process. A summary of the above methods and the green building assessment tools are adapted to develop the checklist. 


\subsection{Implementation of Environmentally Sustainable Design Methods}

As shown in Figure 2.1, an appropriate design for climate reduces the need for auxiliary cooling systems like air conditioners or fans, thereby reducing the energy demand in a dwelling (Olgyay, 2015). However, in extreme climatic conditions with higher temperatures, it might be challenging to achieve adequate cooling simply through natural ventilation, so renewable energy cooling would remain essential for supplementing natural cooling techniques. This could include supplementing natural ventilation with low powered cooling systems like ceiling or table fans powered by an onsite renewable energy system like solar panels (DeKay \& Brown, 2014; Givoni, 1994). As noted earlier, the emphasis in this study is on ESD methods tailored to improve indoor thermal comfort. The following sections provide five basic requirements for achieving indoor thermal comfort.

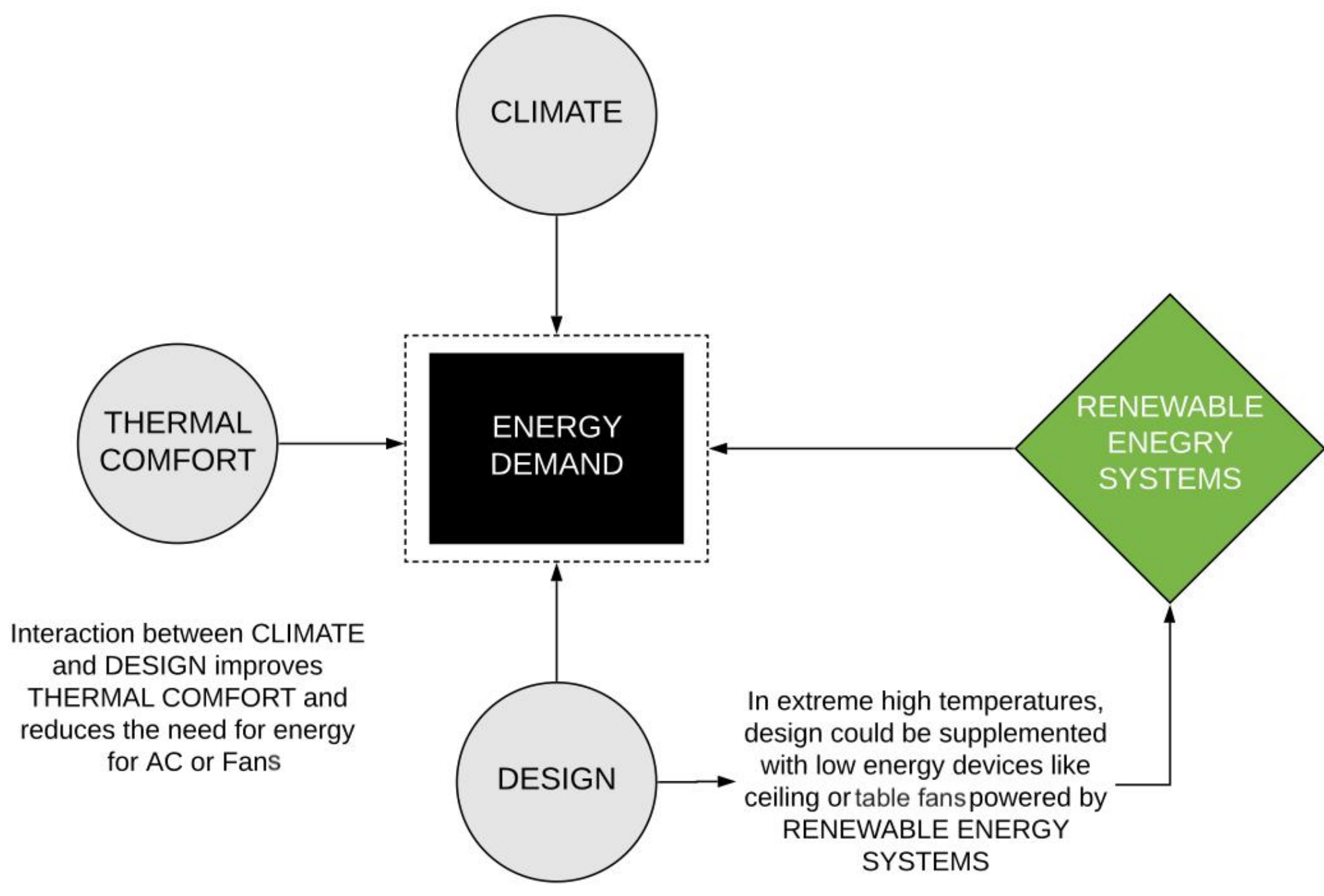

Figure 2. 1: Appropriate design for climate. (Image source: author).

\subsubsection{Site Analysis}

According to Mahoney et al. (1971) the first and fundamental step towards an environmentally friendly design for indoor comfort is data collection and analysis of the microclimatic parameters. The microclimate determines the level of energy and airflow through a building envelope and the resulting impact on the attainment of user comfort. These conditions include the ambient wind, temperature, radiation, and humidity. These conditions are generally affected by the site topography, street width and orientation, surrounding structures and setbacks, vegetative landscaping, surrounding water bodies, built form and available open spaces (Ajibola, 1997). A detailed understanding of these factors is essential for a successful site analysis. It influences the building orientation and morphology (i.e. the building form, courtyards, patio, building height and setback from boundaries, etc.). A well-oriented building with an appropriate form assists in enhancing natural light, sun protection, and natural ventilation (DeKay \& Brown, 2014). A site analysis broadly includes information about the sun path, temperature range (seasonal, diurnal, and nocturnal minimum and maximum temperature), humidity, precipitation, available local winds or air movement (Butera, Adhikari, \& Aste, 2015). It also includes the site topography, proposed building orientation for natural light and ventilation, neighbouring structures and air quality. Most importantly, the site analysis should involve the following.

Shading analysis: A shading analysis is critical specifically due to the site restrictions and compactness of houses in most urban areas (Silva, 2014). The shading analysis would help in establishing the level of daylight availability and obstruction. This enables an architect to understand how the sun would impact on a site and building throughout the year. The shading analysis involves using a solar path diagram to establish the shading related to a particular site and building throughout the year. It also enables the architect to establish the best building orientation for natural light (Butera et al., 2015). Computer-Aided Design (CAD) software such as ArchiCAD and Autodesk suites come with an in-built shading analysis feature, making it easy for the architect to plot a sun path 
diagram. A detailed shading analysis would also identify any shading from surrounding structures (Figure 2.2) that might prevent the transmission of the sun to solar panels. This is especially important in Nigeria due to the erratic electricity supply from the national grid and the need for onsite renewable energy generation (Elinwa, Ogbeba, \& Agboola, 2020). In addition, the shading analysis allows the architect to make informed decisions about the overall building orientation and the location of trees/vegetation for buffer as required (DeKay \& Brown, 2014).

Figure 2.2 provides a visual representation of the shading effects on a proposed building at 9 am and 12 pm, plotted using ArchiCAD. The proposed building has a side boundary setback of 2 metres on both sides, making a total setback of approximately 4 metres to the foundation of the neighbouring houses on each side. As shown in the figure, the proposed building receives good shading from the neighbours on the east and west axis at 9 am, creating a cooling zone in the eastern and western axis of the proposed dwelling. Additional buffers, either through strategic vegetative landscaping or other shading techniques that allow the transmission of natural light whilst preventing heat gain into the building, could be located on the northern axis of the site. At $12 \mathrm{pm}$, the shade from the neighbouring buildings is insignificant, however, the southern part of the proposed building remains shaded. Based on Figure 2.2, the southern part of the proposed building remains shaded for most of the day, creating a perfect cooling zone. Based on the shading analysis, decisions can be made on the window location and configuration, vegetative landscaping, zoning, courtyard and patio locations. For example, as shown in Figure 2.2, location 'A' would be appropriate for a courtyard and location 'B' for a patio because of the shading effect.

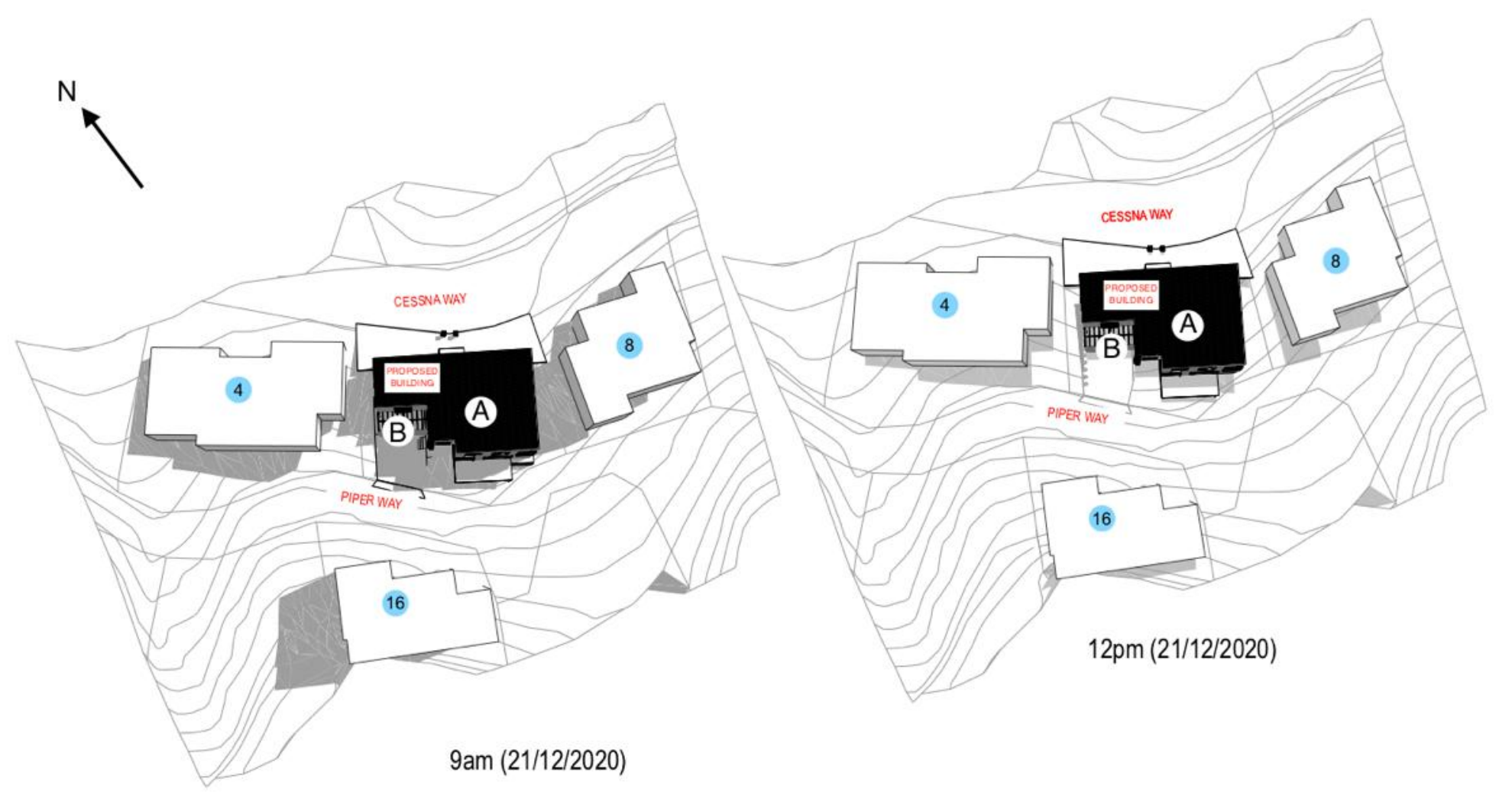

Figure 2. 2: Typical shading analysis. (Image source: author).

Wind assessment: Existing studies (Adunola, 2017; Irouke \& George, 2016; Okafor, 2018) have emphasised the need for natural ventilation for achieving thermal comfort. A detailed wind assessment is essential for adequate natural ventilation. A wind assessment involves using wind rose and wind square analysis to establish the direction and availability of local winds (Mahoney et al., 1971). The wind assessment determines the total heat gain and losses for estimating indoor thermal comfort. Data for the wind assessment could be retrieved from local airport records. However, the airport wind speeds should be adjusted for local terrain and for speeds below average (DeKay \& Brown, 2014).

Given the site restriction, compactness, and solid security fencing in some residential areas (Silva, 2014), a detailed wind analysis is crucial. It would enable the architect to establish the best location for windows and apertures for ensuring optimum natural ventilation via air movement. In addition, a good wind assessment identifies if fencing or any neighbouring buildings or structures would block transmission of local wind into the proposed building (Butera et al., 2015). In cases where fencing could obstruct wind movement into the proposed building, porous fencing (Figure 2.7) should be adopted for enhancing a good level of air circulation (Idowu, Junaid, \& Humphrey, 2018). According to Hyde (2008) a good site analysis establishes the available site resources for optimising cooling, ventilation, lighting and power needs. 


\subsubsection{Building Orientation}

Appropriate building orientation is fundamental to the success of ESD. In Nigeria, the general rule is that the longer axis of the building should be oriented on the east-west axis (Figure 2.3) to decrease exposure to the sun whilst considering the prevailing ambient wind for natural ventilation and the apertures for natural ventilation natural lighting (Akande, 2010). Poor building orientation could lead to thermally uncomfortable indoor spaces without auxiliary cooling systems (Olgyay, 2015). Vegetative landscaping such as trees could be planted on the southern axis to create some level of shading whilst allowing natural lighting into the building (Butera et al., 2015). Generally, it is recommended, where possible, to adopt courtyards with open spaces and loose floor plan layouts that create good pathways for natural light and air movement through the building interior.

According to Mahoney et al. (1971) western orientation of the largest façade needs to be avoided because solar radiation and temperatures are generally at their peak on the west-facing side. Spaces not frequently used like bathrooms and storage areas could be located on the east or west axis, providing a good buffer. Spaces that require good daylight should be located at the building façade needing less protection from the sun. Bedrooms and living areas where thermal comfort is most required should avoid a western orientation (DeKay \& Brown, 2014). Sometimes the best solar orientation might not be the preferred orientation for wind (Akande, 2010). The best location for a window for improved natural ventilation based on the wind assessment might be on the façade most exposed to sunlight. This would mean that despite the improved natural ventilation, there could be heat gain into the interior space making such space thermally uncomfortable and the natural ventilation less effective. In such instances, the best orientation for wind (i.e. natural ventilation) should be favoured (Butera et al., 2015). By using different shading techniques, windows and surfaces exposed to the sun could be protected whilst letting in the required amount of ventilation.
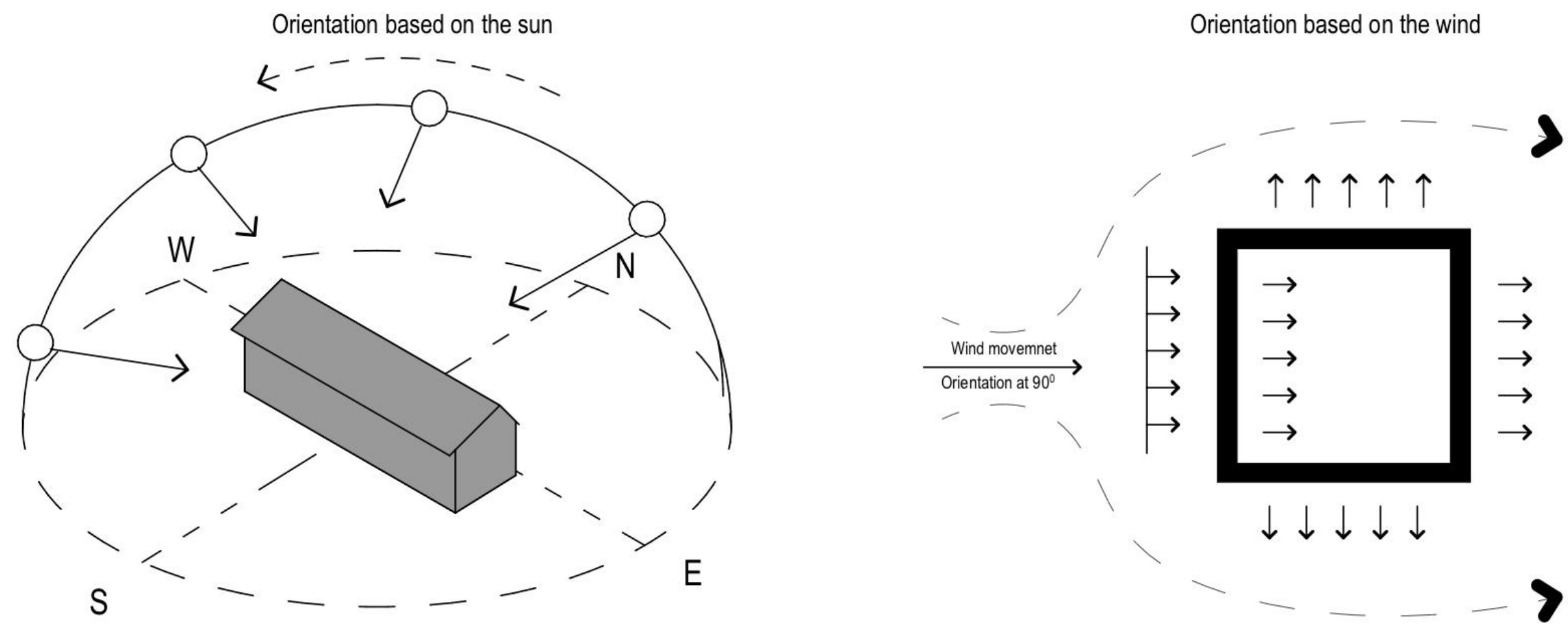

Figure 2. 3: Building orientation based on sun and wind. (Image source: Author).

\subsubsection{Natural Ventilation}

Natural ventilation refers to the provision of indoor comfort with the strategic location of windows, doors or other openings for enhancing air movement without fans or other auxiliary cooling systems (Mahoney et al., 1971). Airflow is generally created by the difference in pressure caused by wind and temperature differences between the interior and exterior of a building. Natural ventilation is governed by the following principles (Butera et al., 2015; Mahoney et al., 1971):

- Air generally moves from higher to lower pressure zones

- When wind hits a building, it creates low pressure along the leeward sides and areas parallel to its direction

- A stack effect (Figure 2.4) is triggered when indoor air temperatures are higher than outdoor temperatures

- Wind-induced air movement patterns are based on the relative position and size of openings. It is recommended that openings for air outlets are higher and wider than the proposed inlets. 
Chapter 2 | Environmentally sustainable design methods

- When air outlet and inlet openings are aligned, optimum cross ventilation is achieved. If the inlet and outlet are aligned in the wind direction, the air passes through without any significant impact. Similarly, if the wind movement is parallel to the openings, there is no significant air movement in the space.

- If spaces have openings adjacent to the wind, the use of wing walls significantly increases natural ventilation.

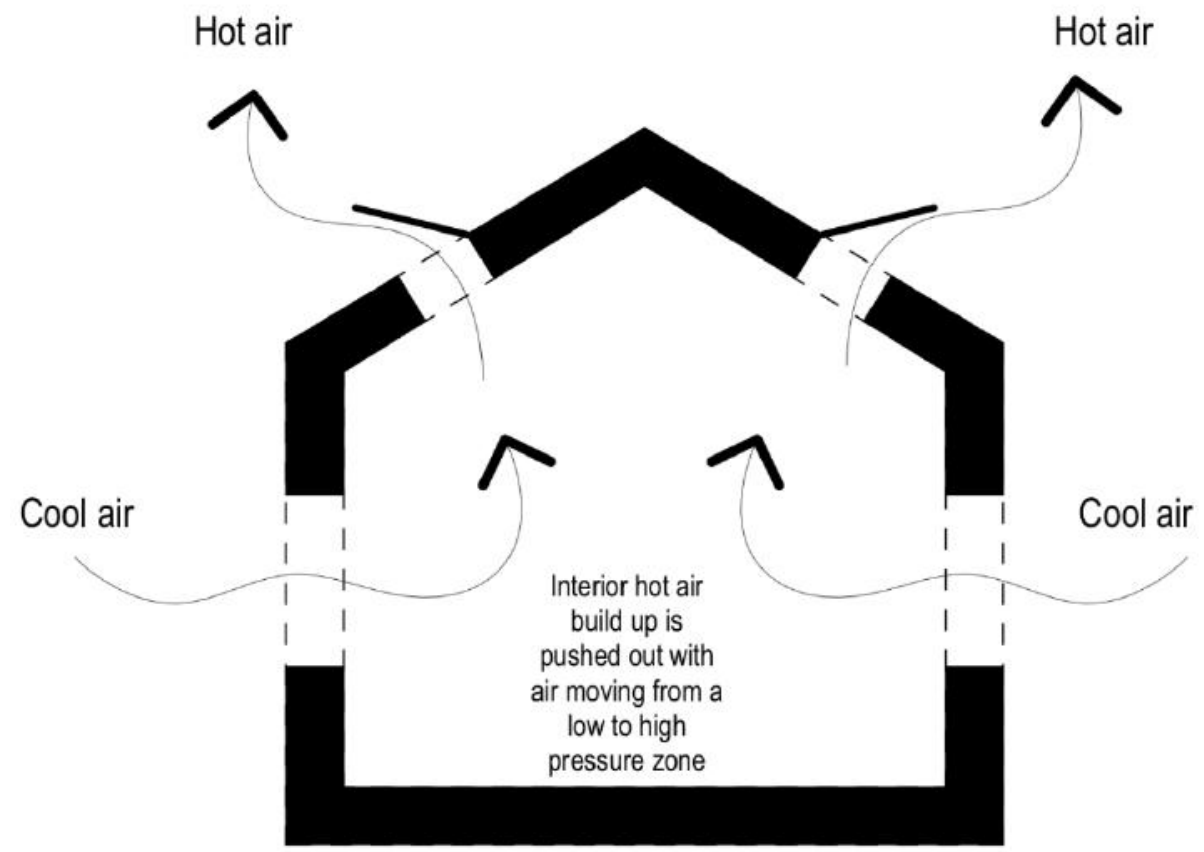

Figure 2. 4: Stack ventilation (Image source: Author)

With the proper building orientation, window sizes and location, and roof venting (Figure 2.4), indoor spaces could benefit from the stack effect, that is, air moving from the higher to lower pressure zones due to temperature difference between the indoors and outdoors. Similarly, in instances where optimal solar orientation might not be the preferred orientation for wind, the use of wing walls (Figure 2.5) becomes an effective tool (Butera et al., 2015).

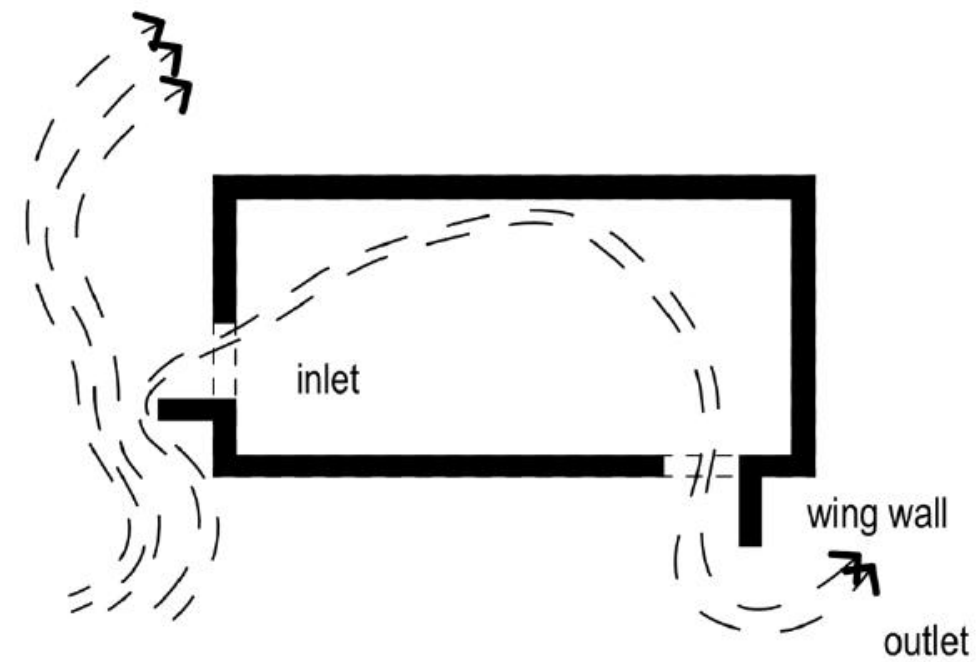

Figure 2. 5: Wing wall (Image source: Author) 
Chapter 2 | Environmentally sustainable design methods

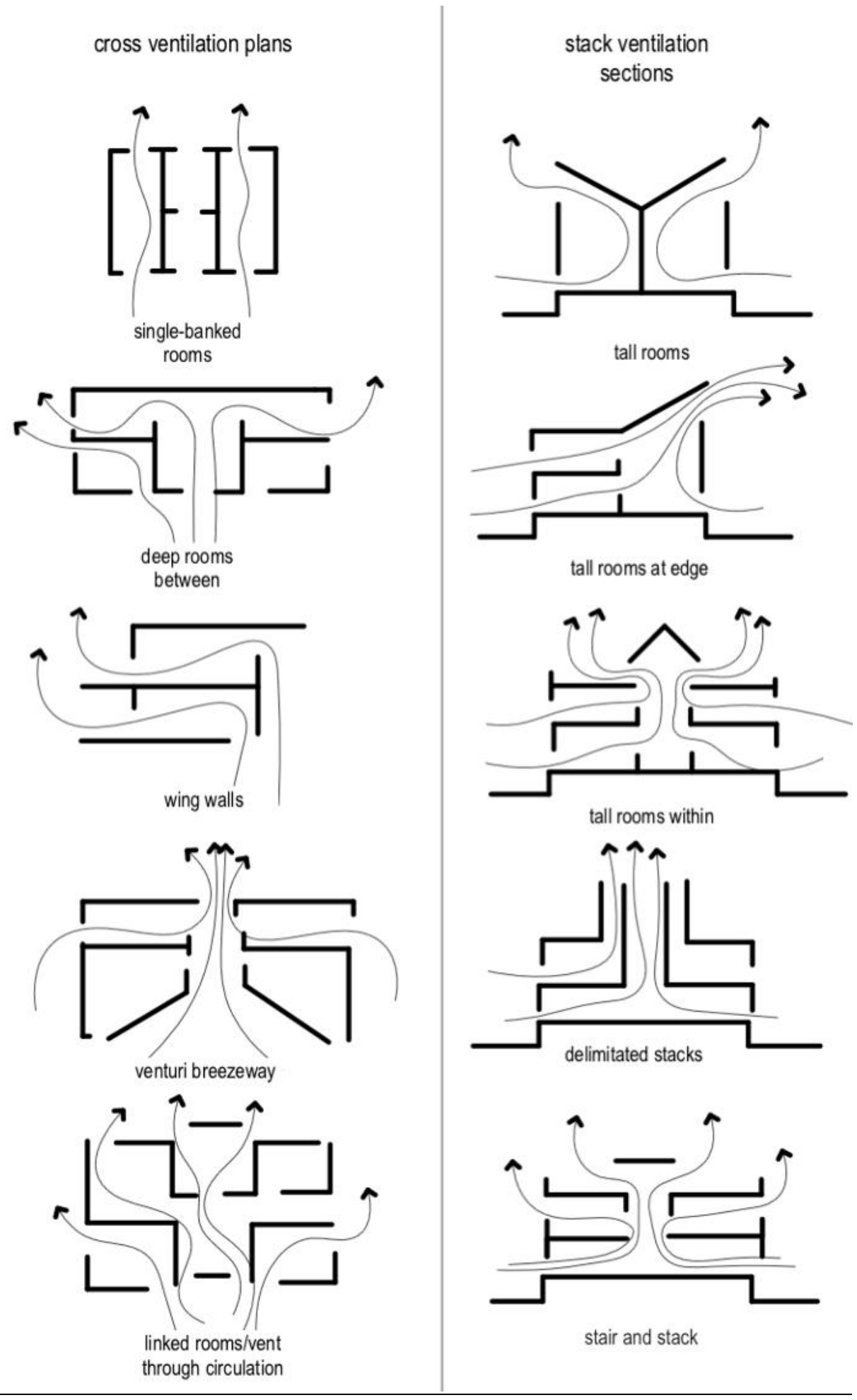

Figure 2. 6: Typical floor plans and sections for improving cross-ventilation and stack ventilation. Drawn by Author and adapted from (DeKay \& Brown, 2014).

The importance of natural ventilation cannot be over-emphasised; for this reason, wall and roof openings (Figure 2.6) should be designed to admit the required quantity of natural light and ventilation without overheating interior spaces (Adunola, 2017). Achieving this requires a combination of different design strategies such as the strategic location of apertures based on the site analysis for adequate cross ventilation; adequate vegetative landscaping for shading; responsive envelopes such as wing walls and window hoods for buffers; and the thermophysical properties of the building materials for heat insulation and radiation as required (Olgyay, 2015). In terms of vegetative landscaping, the use of vegetation delivers shading and freshness throughout the year. Natural vegetation provides natural freshness and a buffer from the sun, reduces noise and pollution, and modifies the ambient temperature and relative humidity for improving overall comfort for building occupants (Akande, 2010). As noted by Butera et al., (2015), in addition to the combined strategies listed above, openable windows and glazing should be shaded from direct sun and be 20-40\% of the wall area. This lets in natural light whilst reducing heat gain into the building. Windows and doors (both internal and external) should be supplemented with overhead windows or openings where possible to allow for stack ventilation. Figure 2.6 provides a graphic representation to configure interior spaces for optimising cross ventilation and stack ventilation. 


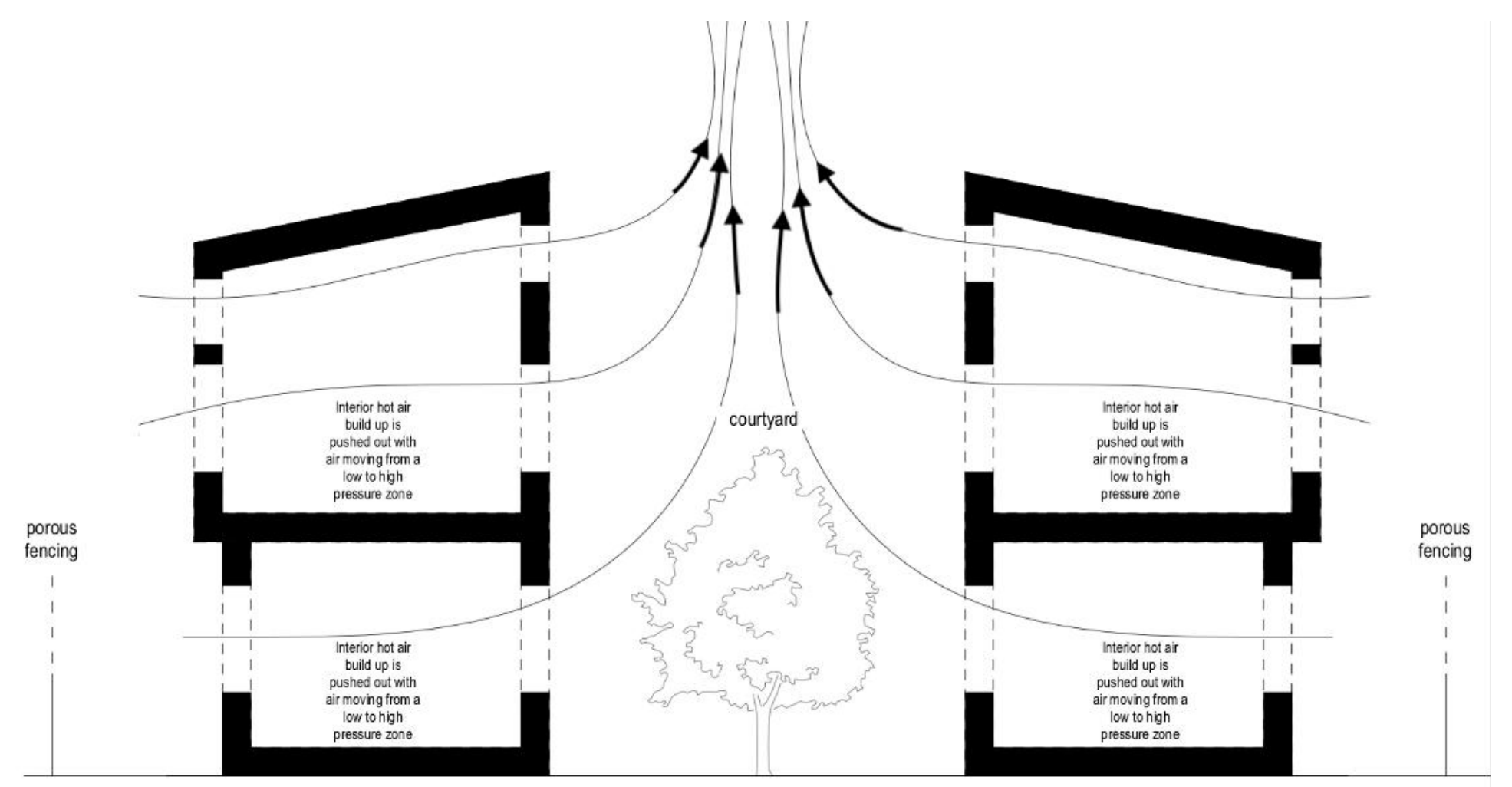

Figure 2. 7: Natural ventilation through courtyard and porous fencing (Image source: Author)

The use of cross ventilation becomes challenging in some dwellings due to their compactness. As shown in the photographs in Section 5.4.1, these compact houses might struggle to benefit from cross-ventilation due to their proximity to neighbouring buildings. However, with courtyards (Figure 2.7), indoor spaces could still benefit from natural ventilation (Mahoney et al., 1971). Courtyards also create flexible indoor/outdoor spaces for space migration by the building occupants in response to the ambient climate. In addition to using courtyards, the overall thermal performance of the building could be improved by raising the building from the ground (Figure 2.8) to allow for adequate air circulation through the foundation for cooling the floor (Amasuomo \& Baird, 2016b; Mahoney et al., 1971).
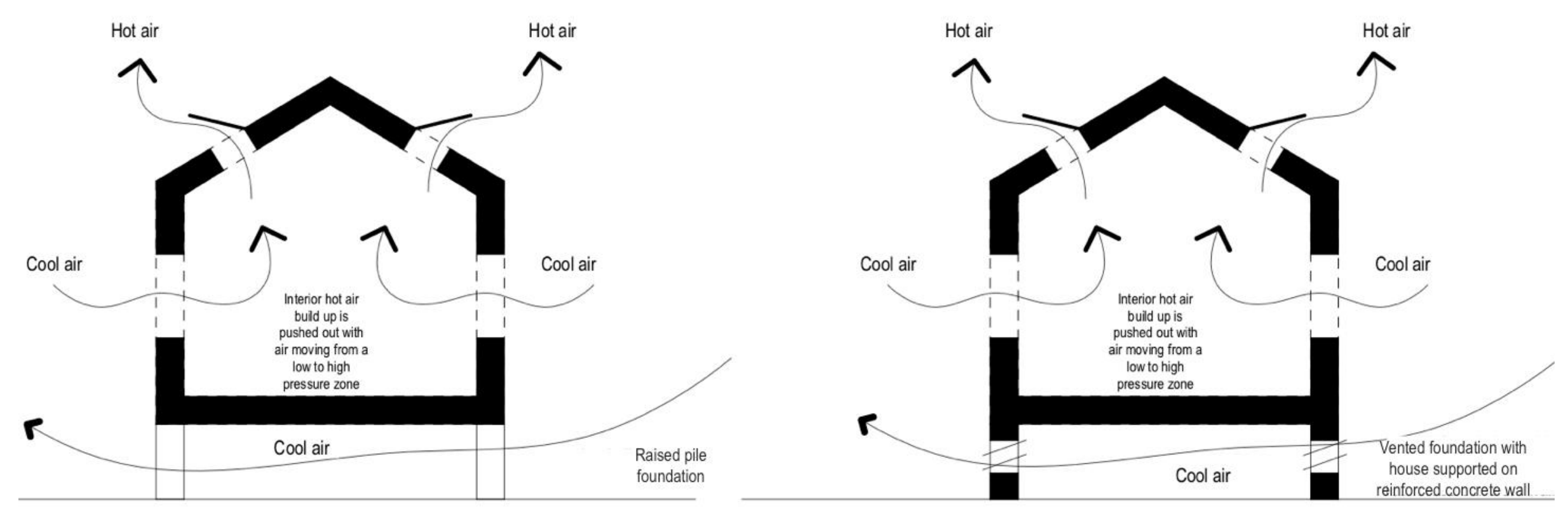

Figure 2. 8: Pile foundation and vented foundation (Image source: Author)

According to Mahoney et al. (1971), a vented foundation or building on stilts improves air circulation under the building and enhances internal thermal comfort. Since buildings in Nigeria are constructed using concrete block walls and foundations (Abraham, Michael, James, \& Michael, 2016), they could be supported using concrete or steel columns/piles or using a vented foundation instead of the standard raft foundation (Figure 2.8).

\subsubsection{Building Envelope}

Responsive envelopes are designed to prevent heat gain into a building through ventilation, shading techniques, and the building material's thermophysical properties (Butera et al., 2015). It also includes the use of vented wall cavities, vented roofs, green edges, window fins, raised foundations, etc. This study has divided the building envelope into two main components for the provision of thermally comfortable indoor spaces through responsive building envelopes: the building walls and roofs. 
Chapter 2 | Environmentally sustainable design methods

Walls: The walls constitute a significant portion of a building envelope. They heat up and transmit heat into the building if it is not well protected from the sun. The walls could be protected using shared shade (using shade from neighbouring structures), overhead shade (using overhead awnings, pergolas, or louvred systems), shading umbrella (providing shade for a courtyard or patio by shaping surrounding structures to cast shadows), green edges (similar to vegetative landscaping for providing shade and cooling incoming breezes), vertical and horizontal fins (DeKay \& Brown, 2014). According to Givoni (1976) the thermophysical properties of the wall determine its ability to control and resist heat gain into the building. The level of resistance could be improved by increasing the wall thickness, shading, adopting cavity wall systems, using well-insulated walls, using radiant barriers, and applying light finishes to the exterior to improve reflectivity. However, the overall effectiveness of the wall depends on the level of protection (Figure 2.9) it receives from the ambient climatic parameters.

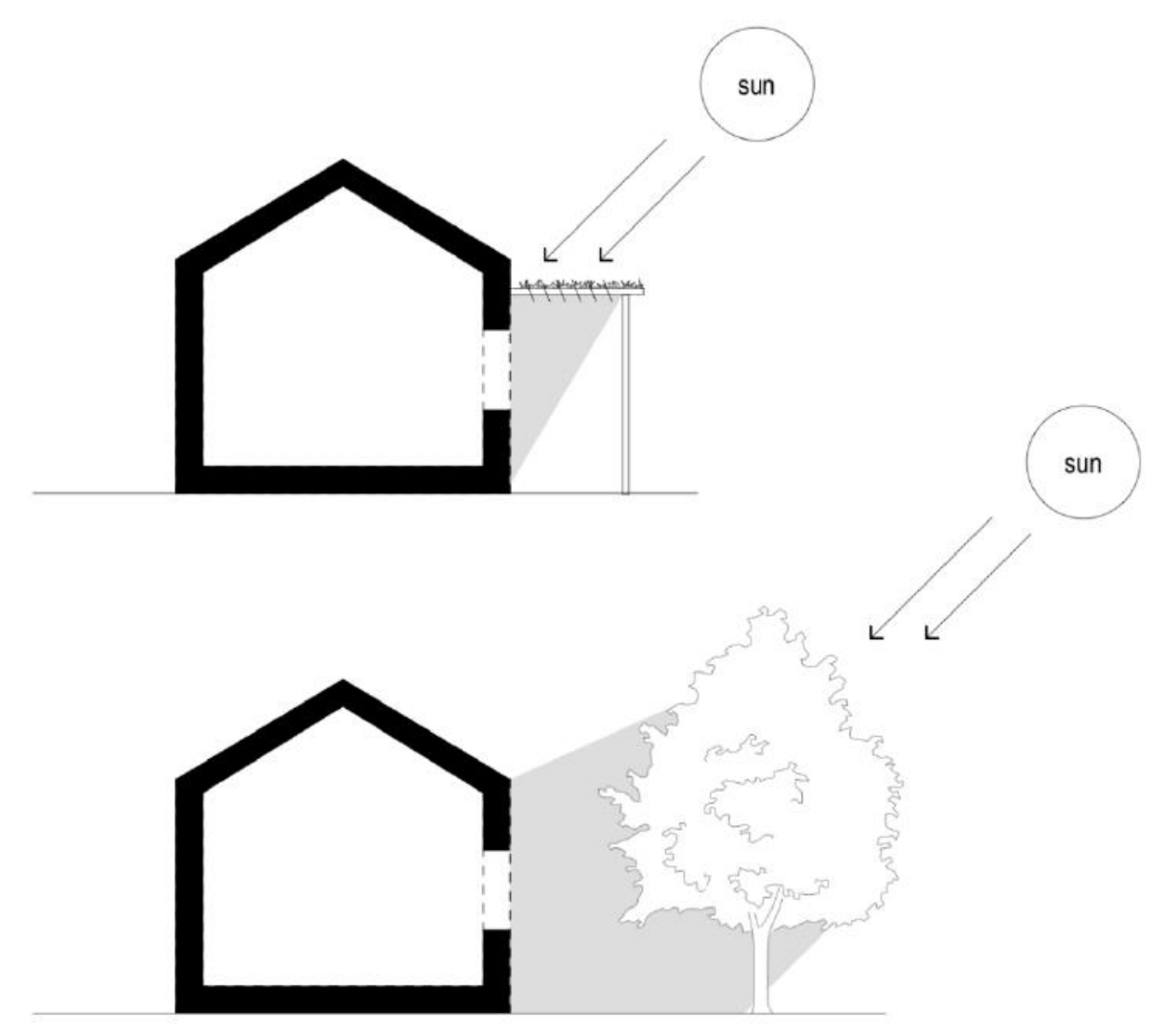

Figure 2. 9: Wall and window shading (Image source: Author)

The appropriate wall thickness varies based on the wall specification; however, the overall thickness should be determined by the site analysis, which establishes the building morphology and orientation. A combination of good thermal mass and resistance improve indoor thermal comfort. Brick, concrete blocks, and clay/mud walls add to building efficiency by reducing the heat transfer through a wall (Givoni, 1976; Okafor, 2018). As noted above, the overall effectiveness of the building envelope would be improved by shading, ventilated walls (Figure 2.10), and raised foundations where possible (Figure 2.8).

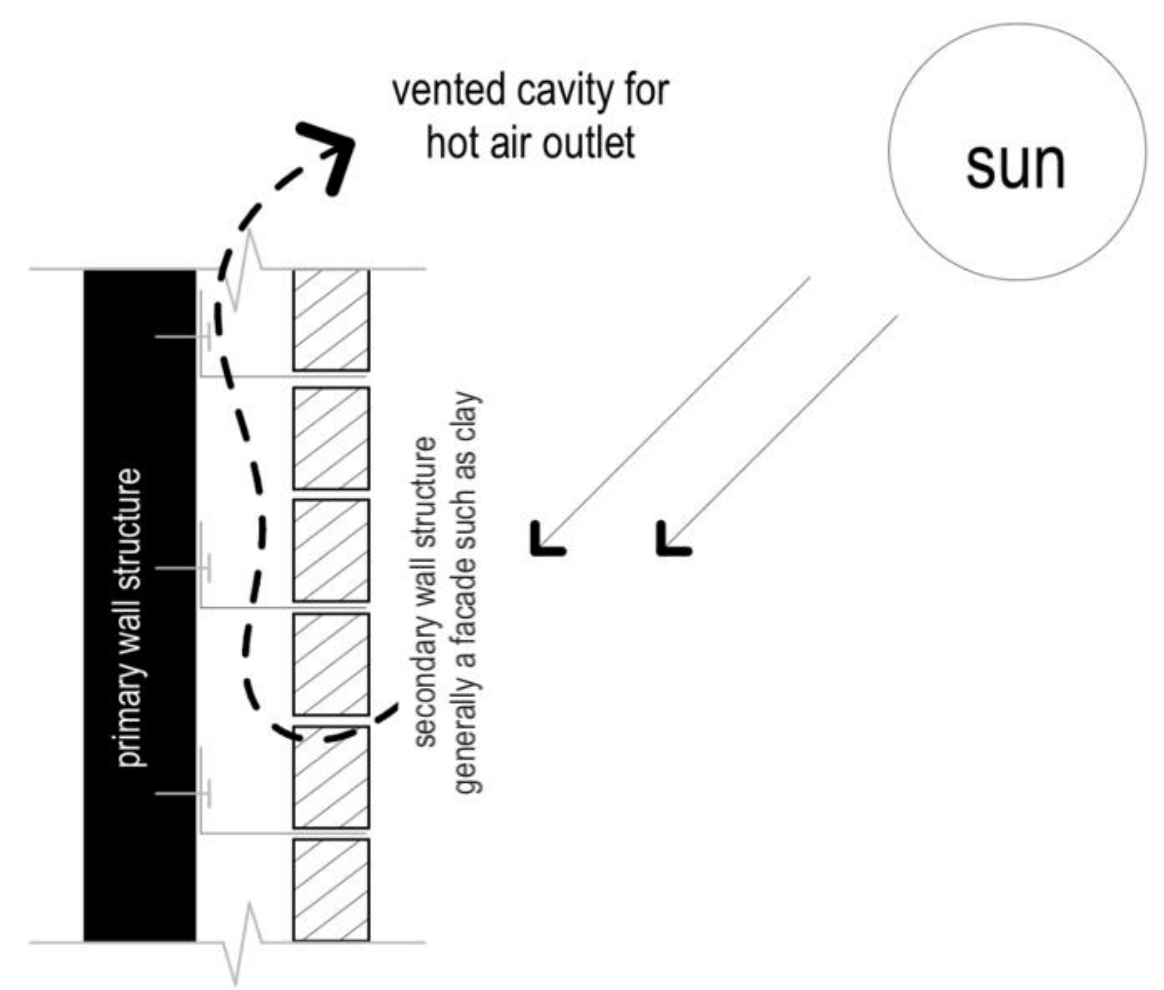

Figure 2. 10: Vented cavity (Image source: Author) 
However, expensive, ventilated walls (Figure 2.10) provide an effective means of reducing radiant heat gain into the building (Butera et al., 2015). With ventilated walls, the overall thickness of the primary wall could be reduced (DeKay \& Brown, 2014). This is because, in hot humid climates like Nigeria that experience low nocturnal and diurnal ranges, thermal storage is not required (Mahoney et al., 1971). An alternative to ventilated walls could be structural insulated panels. Despite not being commonly adopted in Nigeria, it has been reported to provide good insulation and radiative properties when finished with light colours (Harris et al., 2019; Ogundiran \& Adedeji, 2012). This suggests that structural insulated panels could be an excellent supplement to the conventional concrete block wall systems.

Roofs: The roof receives the highest exposure to solar radiation. It absorbs the heat from the sun and transmits this heat into the building, creating thermal discomfort for occupants. The roof's thermal performance is one of the most critical to the attainment of indoor thermal comfort (DeKay \& Brown, 2014). The overall thermal performance of a roof depends on the thermophysical properties of the material and its external finish (Butera et al., 2015). In hot, humid climates like Nigeria, a double ventilated roof is recommended because the outer skin absorbs the heat based on its reflectivity and provides shade to the inner layer. The reflectivity of the outer skin should be as high as possible using a light finished lightweight material with low thermal capacity (Olgyay, 2015).

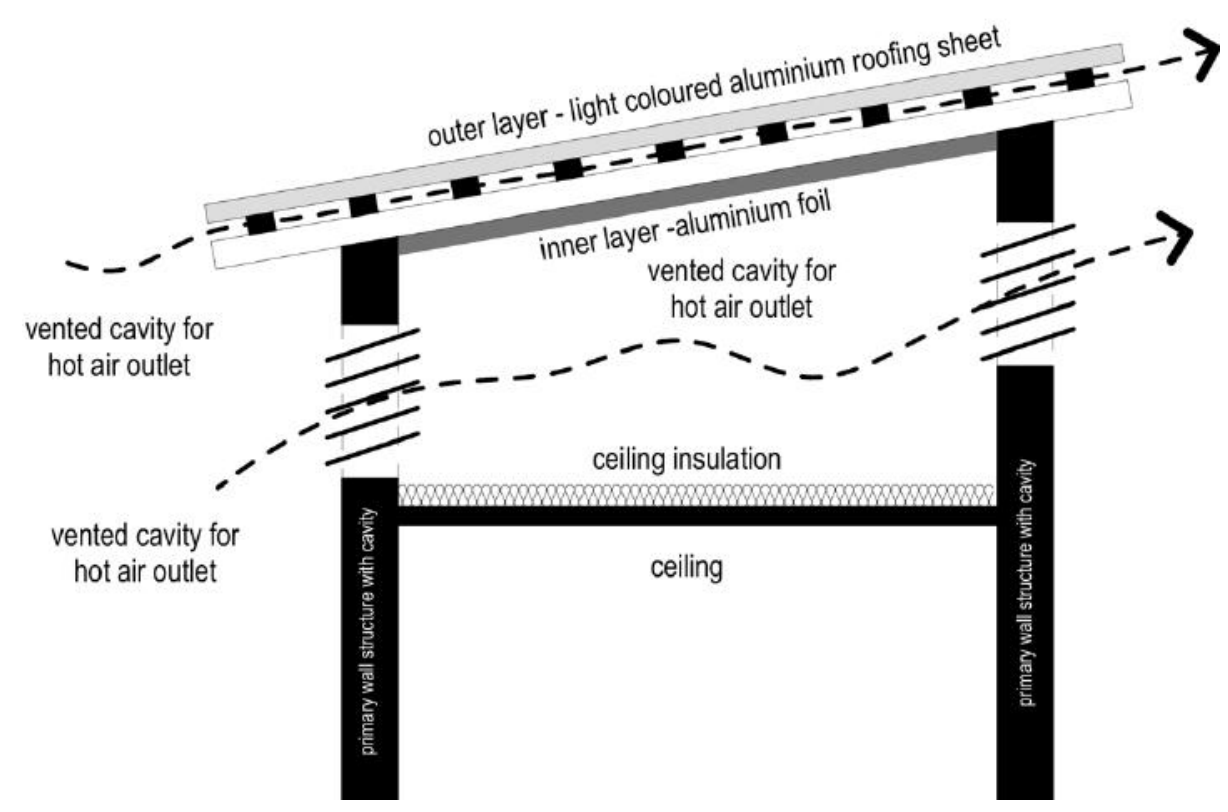

Figure 2. 11: Vented roof cavity (Image source: Author)

In double-skinned ventilated roofs (Figure 2.11), the heat build-up between both skins and the space between the roof and the ceiling is removed by the airflow through the roof space (DeKay \& Brown, 2014). Such roof spaces are generally vented using inlet and outlet openings facing the prevailing wind. Like the principle of stack ventilation (Butera et al., 2015), the outlet should be larger than the inlet, with both openings placed at different heights in order to attain optimum ventilation through the stack effect.

\subsubsection{Energy Generation and Optimisation}

The above strategies could be supplemented with low energy cooling appliances like ceiling or table fans in extremely hot weather conditions. In instances like this or during the absence of power from the national grid, as commonly experienced in Nigerian (Abanihi et al., 2018), onsite renewable power generation systems are required. These systems must be sized and located appropriately based on the site analysis and anticipated energy demand load in the proposed building (Elinwa et al., 2020). Given that in Nigeria, the average hours of sunshine are between 6 and 8 hours during the wet season and as much as 10 hours during the dry season (NIMET, 2020), solar panels can conveniently generate the required energy demand in a building (Bamisile et al., 2017). In addition to using solar panels, other energy-efficient devices could be adopted, such as solar hot water systems and energy-efficient appliances.

\subsubsection{Summary of Environmentally Sustainable Design Methods Implementation}

The above sections provided an explicit but straightforward set of strategies for ESD implementation, with emphasis on the provision of thermal comfort and energy efficiency. It was acknowledged that the adoption of ESD might be faced with some constraints such as narrow sites, fencing, and extreme climatic conditions. However, recommendations were provided for navigating these constraints, such as the use of courtyards and porous fencing. These methods are effective when achieving cross ventilation becomes challenging due to long and narrow sites with fencing and neighbours on either side. Similarly, in extreme climatic conditions, renewable energy 
Chapter 2 | Environmentally sustainable design methods

cooling could supplement natural cooling techniques. In summary, the selected simple methods for improving natural ventilation and energy efficiency include:

- A detailed site analysis

- Adequate building orientation based on the site analysis

- Cross ventilation

- Strategic location and size of openings, windows and glazed facades based on the site analysis (this should include vents or louvres above internal and external doors to enhance airflow)

- Stack ventilation or vertical ventilation

- Courtyard systems

- Porous fencing (where absolute privacy is required, this could be achieved by vegetative landscaping along boundaries/fencing)

- Vented foundations

- Light finished vented walls

- Walls with light finishes for reflectivity and overall good thermophysical properties (this could also include structural insulated panels or wall insulation)

- Light finished double-skinned roofs with high reflectivity

- Vented roofs

- Shading techniques: shared shade (using shade from neighbouring structures), overhead shade (using overhead awnings, pergolas, or louvred systems), shading umbrella (providing shade for a courtyard or patio by shaping surrounding structures to cast shadows), green edges (similar to vegetative landscaping for providing shade and cooling incoming breezes), vertical and horizontal fins

- Where possible, loose permeable plans to enhance air circulation

The checklist in the subsequent section is developed based on the above methods and the green building assessment tools (Section 2.1).

\subsection{An adapted checklist for the physical survey of selected buildings in Nigeria}

Subsequent sections have defined ESD and provided a breakdown of how ESD could be adopted in residential buildings for improving thermal comfort. This section aims to develop a checklist that would be used in conducting physical surveys of selected buildings in Stage 3 of this study. The proposed checklist is an offshoot of Section 2.3 \& 2.4, and the Green Star SA - Multi-Unit Residential v1. The NGBC is a prospective member of the WGBC, and conducts its assessment through the GBCSA. GBCSA currently certifies commercial buildings, retail facilities, public and educational buildings, and multi-residential buildings (GBCSA, 2019). Hence the Green Star SA - Multi-Unit Residential v1 has been adapted to suit a stand-alone residential building in Nigeria.

In the interests of practicality and importance within the Nigerian context, the scope of the checklist is focused on the provision of indoor thermal comfort and renewable energy generation (Table 2.3). For example, ventilation under indoor environmental quality has been encapsulated into the provision and strategic location of fenestrations. In this vein, louvre windows are favoured over other window types: according to Alassar (2017), the use of louvre windows enhances air movement whilst reducing the penetration of solar radiation and keeping moisture out. Louvre windows are up to $95 \%$ open for air ingress, casement windows are generally $50 \%$ open for air ingress, while casement windows generally re-direct the prevailing air/breeze.

In order to create efficient buildings and optimise the effects of any assessment tool, houses should be planned from conception to counteract climatic extremes (Atanda \& Olukoya, 2019; Mahoney et al., 1971). 


\section{Chapter 2 | Environmentally sustainable design methods}

Table 2. 3: Checklist for the physical survey of selected buildings. Based on: (Amasuomo et al., 2017; BRANZ, 2017; Dantata \& Alibaba, 2018; DeKay \& Brown, 2014; GBCSA, 2019; Givoni, 1976, 1994; Hyde, 2000; Mahoney et al., 1971; Olgyay, 2015; Wu, Liu, Li, \& Hsieh, 2005).

\begin{tabular}{|c|c|c|c|c|c|}
\hline \multirow{3}{*}{$\begin{array}{r}\text { Title } \\
\text { Indoor Enı } \\
\text { Ventilation }\end{array}$} & \multirow{2}{*}{$\begin{array}{l}\text { Aim of credit } \\
\text { ironmental Quality }\end{array}$} & \multirow[t]{2}{*}{ Credit criteria summary } & \multicolumn{2}{|l|}{ Checklist } & \multirow[t]{2}{*}{ Benefits } \\
\hline & & & & & \\
\hline & $\begin{array}{l}\text { To recognise designs } \\
\text { that provide sufficient } \\
\text { outside air to reduce } \\
\text { the build-up of indoor } \\
\text { pollutants and } \\
\text { moisture. }\end{array}$ & $\begin{array}{l}\text { Habitable rooms must be } \\
\text { naturally ventilated. } \\
\text { Adequate natural ventilation is } \\
\text { achieved through cross } \\
\text { ventilation. } \\
\text { Habitable rooms greater than } \\
4 \mathrm{~m}^{2} \text { are provided with } \\
\text { manually controllable } \\
\text { background openings such as } \\
\text { trickle ventilators or similar. }\end{array}$ & $\begin{array}{l}\text { Ventilation } \\
\text { Cross Ventilation in habitable } \\
\text { rooms. } \\
\text { The application of window } \\
\text { nets/insect screen disrupts cross } \\
\text { ventilation. Where possible, these } \\
\text { should be removed. The presence of } \\
\text { window screens/nets affects the rate } \\
\text { of airflow through the windows } \\
\text { Window types: Unlike other } \\
\text { windows, louvre windows enhance } \\
\text { air movement whilst shading direct } \\
\text { solar radiation into dwellings } \\
\text { Vent opening arrangements to } \\
\text { enhance air movements and stack } \\
\text { ventilation }\end{array}$ & $\begin{array}{l}\text { - Vent opening above } \\
\text { internal/external doors } \\
\text { - Vent opening/window } \\
\text { above exterior windows } \\
\text { - Low height partition/roll- } \\
\text { back walls } \\
\text { - Windcatcher }\end{array}$ & $\begin{array}{l}\text { - Enhances breeze penetration } \\
\text { into the building } \\
\text { - Promotes stack ventilation } \\
\text { for cooling } \\
\text { - Promotes cross-ventilation } \\
\text { with inlets facing the } \\
\text { prevailing wind and outlets in } \\
\text { the opposite direction of the } \\
\text { inlet }\end{array}$ \\
\hline Thermal comfort & $\begin{array}{l}\text { To ensure that } \\
\text { dwellings achieve } \\
\text { suitable levels of } \\
\text { thermal comfort for } \\
\text { occupants }\end{array}$ & $\begin{array}{l}\text { In the absence of active cooling } \\
\text { systems, dwellings must } \\
\text { ensure the following: } \\
\text { - Adequate natural ventilation } \\
\text { is provided via cross- } \\
\text { ventilation, stack ventilation or } \\
\text { other passive methods } \\
\text { - Adequate thermal mass } \\
\text { - Adequate control of solar } \\
\text { heat gains }\end{array}$ & $\begin{array}{l}\text { Adequate control of solar heat gains } \\
\text { can be achieved by using different } \\
\text { shading techniques } \\
\text { Cooling effect through flooring, } \\
\text { walls, etc. }\end{array}$ & $\begin{array}{l}\text { - Cooling and shading effect } \\
\text { using vegetation } \\
\text { - Concrete hood or baffles } \\
\text { - Large Roof overhang } \\
\text { - Overhead shade screens } \\
\text { - Flooring such as ceramic } \\
\text { tiles, terrazzo, or concrete } \\
\text { flooring provides cooling } \\
\text { effect for improving thermal } \\
\text { comfort }\end{array}$ & $\begin{array}{l}\text { - Reduces solar radiation by } \\
\text { providing shade for walls and } \\
\text { windows } \\
\text { - Promotes } \\
\text { evapotranspiration } \\
\text { - Modifies the ambient } \\
\text { temperature }\end{array}$ \\
\hline Natural Lighting & $\begin{array}{l}\text { To encourage designs } \\
\text { that ensure good } \\
\text { levels of natural light } \\
\text { within habitable } \\
\text { rooms. }\end{array}$ & $\begin{array}{l}\text { Between } 60-90 \% \text { of each } \\
\text { apartment achieves a } \\
\text { minimum daylight criterion of } \\
\text { no less than } 1.5 \% \text { of a daylight } \\
\text { factor or no less than } 150 \text { lux } \\
\text { of daylight illuminance } \\
\text { measured at finished floor } \\
\text { level }\end{array}$ & $\begin{array}{l}\text { Window area of no less than } 10 \% \text { of } \\
\text { the floor area. This is generally } \\
\text { achieved by having ample windows } \\
\text { in a space strategically located on } \\
\text { adjacent walls }\end{array}$ & $\begin{array}{l}\text { - Skylight } \\
\text { - Large windows with at least } \\
\text { two opposite walls of } \\
\text { habitable rooms }\end{array}$ & $\begin{array}{l}\text { - Provides sufficient indoor } \\
\text { lighting and reduces the need } \\
\text { for artificial lighting. } \\
\text { - Energy efficiency }\end{array}$ \\
\hline $\begin{array}{r}\text { Internal Noise } \\
\text { Levels }\end{array}$ & $\begin{array}{l}\text { To ensure that } \\
\text { apartments are } \\
\text { designed to maintain } \\
\text { appropriate internal } \\
\text { noise levels. }\end{array}$ & $\begin{array}{l}\text { The acoustic performance of } \\
\text { all wall and floor constructions } \\
\text { separating each apartment } \\
\text { achieves an airborne noise } \\
\text { isolation standard of Rw + Ctr } \\
\geq 55 \\
\text { However, this rule is not } \\
\text { applicable where less than } \\
30 \% \text { of the apartments share a } \\
\text { wall and/or floor/ceiling } \\
\text { element that separate } \\
\text { habitable areas of adjacent } \\
\text { apartments. }\end{array}$ & $\begin{array}{l}\text { Reducing sound transmission } \\
\text { requires a material with greater } \\
\text { mass and density. } \\
\text { Standard 19omm solid concrete } \\
\text { blocks or reinforced and stabilised } \\
\text { adobe bricks achieves an STC of 55, } \\
\text { which meets this requirement } \\
\text { (BRANZ, 2017). }\end{array}$ & $\begin{array}{l}\text { - Locally sourced reinforced } \\
\text { and stabilized adobe bricks. } \\
\text { - Wall insulation } \\
\text { - Roof insulation }\end{array}$ & $\begin{array}{l}\text { - Improves health and } \\
\text { wellbeing } \\
\text { - Provides good acoustic and } \\
\text { thermal-physical properties } \\
\text { for improved IEQ }\end{array}$ \\
\hline $\begin{array}{r}\text { Private Outdoor } \\
\text { Space }\end{array}$ & $\begin{array}{l}\text { To ensure that } \\
\text { apartments are } \\
\text { designed to improve } \\
\text { the inhabitants' } \\
\text { health and well-being } \\
\text { by providing private } \\
\text { outdoor space. }\end{array}$ & $\begin{array}{l}\text { For at least } 90 \% \text { of the } \\
\text { apartments, a private outdoor } \\
\text { space is provided that meets } \\
\text { the following: } \\
\text { - The outdoor space is } \\
\text { provided for the private use of } \\
\text { the occupant(s) only; } \\
\text { - The apartment is directly } \\
\text { adjacent to and accessible } \\
\text { from the associated dwelling. } \\
\text { - A minimum of } 1 \mathrm{~m}^{2} \text { of private } \\
\text { outdoor space is provided for } \\
\text { each occupant or at least } 6 \mathrm{~m}^{2} \\
\text { (whichever is greater). }\end{array}$ & $\begin{array}{l}\text { Private outdoor spaces like } \\
\text { courtyards improve air movement } \\
\text { into internal spaces and encourage } \\
\text { space migration and periodic } \\
\text { transformation of spaces during hot } \\
\text { periods. This is achieved by } \\
\text { ensuring indoor-outdoor flow into } \\
\text { the courtyard. }\end{array}$ & $\begin{array}{l}\text { - Courtyard } \\
\text { - Porch/balcony }\end{array}$ & $\begin{array}{l}\text { - Improves indoor thermal } \\
\text { comfort by promoting air } \\
\text { circulation through the } \\
\text { building interior } \\
\text { - Enhances indoor comfort and } \\
\text { reduces reliance on cooling } \\
\text { devices }\end{array}$ \\
\hline Energ & & & & & \\
\hline $\begin{array}{r}\text { Greenhouse Gas } \\
\text { Emissions - }\end{array}$ & $\begin{array}{l}\text { To ensure apartments } \\
\text { are designed to } \\
\text { minimise greenhouse }\end{array}$ & $\begin{array}{l}\text { This is demonstrated by } \\
\text { ensuring that greenhouse gas } \\
\text { emission will be reduced }\end{array}$ & $\begin{array}{l}\text { Materials with high thermal } \\
\text { resistance or mass to reduce the } \\
\text { admittance of heat. }\end{array}$ & $\begin{array}{l}\text { - Earth-air heat exchanger } \\
\text { - Air-air heat exchanger }\end{array}$ & $\begin{array}{l}\text { - Reduces heat gain into the } \\
\text { interior of a building either by }\end{array}$ \\
\hline
\end{tabular}




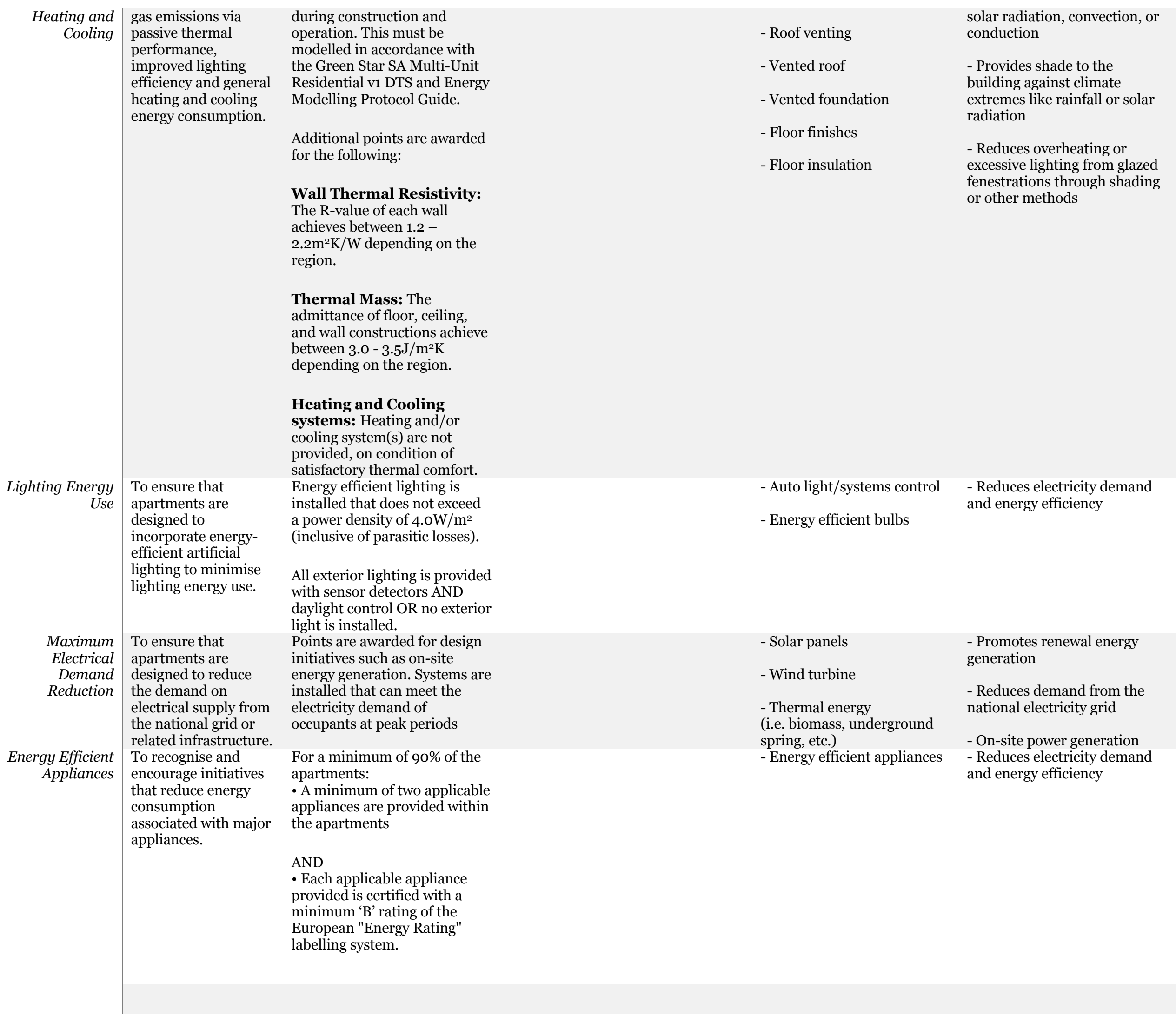

The adapted checklist is similar to that used in a study by Amasuomo et al. (2017). As observed during the model simulation in that study, the adoption of ESD is an iterative process where building elements have to be adjusted and substituted as required to optimise the desired output for achieving a comfortable indoor environment. These adjustments include increasing the width of the concrete block wall from $150 \mathrm{~mm}$ to $190 \mathrm{~mm}$ to improve its resistance, the addition of vents/windows above interior doors, increasing window sizes and including additional shading above windows. However, further exploration of a comprehensive assessment tool or checklist applicable to the Nigerian context is required. This comprehensive exploration needs to be conducted by the NGBC in conjunction with its affiliates. As stated, the purpose of this checklist is to develop a framework for conducting a non-invasive visual survey of the selected buildings in this study. The survey of selected buildings is not the primary aim of this study, which is to understand the possible barriers preventing ESD adoption in Nigeria. 
Chapter 2 | Environmentally sustainable design methods

\subsection{Chapter conclusion}

Based on the benefits of ESD, which includes enhancement of thermal comfort and energy efficiency (Okafor, 2018), it was essential to provide a chapter summarising the basic ways through which ESD could be adopted for ensuring thermal comfort and energy efficiency. This chapter provided basic and straightforward strategies that could easily be adopted in Nigeria due to its simplicity. In order to improve its explicitness, diagrams were also provided showing how to conduct a basic site analysis for building orientation, benefits and ways of adopting shading techniques, roof and wall venting, ventilated foundations, natural ventilation techniques, and courtyard designs.

The subject of environmentally sustainable design is broad; hence the scope of this study has been tailored towards natural ventilation and energy efficiency techniques for improving indoor thermal comfort and energy generation. This is because the literature review and the results from stages 1, 2, and 3 of the study have highlighted the importance of thermal comfort and its relationship to energy generation, the natural environment, global warming and climate change. It is acknowledged that in some cases, the adoption of ESD could be challenging, for example, on narrow sites or those with solid fencing; however, recommendations were provided for navigating these constraints, such as the use of courtyard systems and porous fencing with vegetative screening if privacy is required. These are basic recommendations that could be developed further to establish the best ways for addressing constraints to the effective adoption of ESD. The next chapter provides a review of the Nigerian response to ESD to establish if any, the barriers to the adoption of ESD. 
Chapter 3 | Nigerian response to environmentally sustainable design

Chapter 3 | Nigerian response to environmentally sustainable design 


\subsection{Introduction}

Increased global advocacy, erratic electricity supply and climate change have prompted the need for environmentally sustainable design in the Nigerian building industry (Nwokoro \& Onukwube, 2011). This chapter begins with an overview of the three Nigerian climates and geographical coverage and then proceeds to review the current environmentally sustainable design practices in Nigeria to establish its adoption level. This review would assist the study in selecting and investigating the level of ESD adoption in the four selected states representing the three geopolitical zones and climates in subsequent chapters. Finally, this chapter discusses the possible barriers to ESD from a national and global context.

\subsection{The Nigerian climate and geographical coverage}

Nigeria is located on the southern coast of West Africa. It has a total population of over 200 million, with a population density of 193 people per $\mathrm{km}^{2}$, a total landmass of approximately $925,796 \mathrm{~km}^{2}$, over 250 ethnic groups, and over 520 native languages (NBS, 2019). Nigeria is divided into six geopolitical zones based on geographical location, ethnicity, and shared political history and culture. They include North Central (NC), North East (NE), North West (NW), South West (SW), South East (SE), and South-South (SS) (NBS, 2019). There are three main climates in Nigeria; equatorial in the south, tropical in the middle belt, and arid in the north. However, Nigeria is generally classified as a hot tropical climate, and like most tropical climates, it has only two seasons. These are the rainy season and the dry season, both characterised by high temperatures and high relative humidity (Ugbah et al., 2020). The rainy season is generally from April to October and is influenced by the airmass from the South Atlantic Ocean. The southern part of the country receives an annual rainfall exceeding 2,500 mm/10oinch as compared to northern and central regions with 1,150-1500mm/50-60inch (NIMET, 2019). The dry season typically begins mid-October to early March, with dry peak conditions between early December and late February (WMO, 2015). The length of daylight does not vary significantly, staying within 12 hours throughout the year (Table 3.1). The average hours of sunshine are between 6 and 8 hours during the wet season and as much as 10 hours during the dry season (Elum \& Momodu, 2017).

There has been an increasing trend in temperature across Nigeria from the mid- $20^{\text {th }}$ century to date. Temperatures have increased from $0.2-0.5^{\circ} \mathrm{C}$ in the high ground areas of northern Nigeria (Jos, Kaduna and Kano) and southwest Nigeria (Oyo and Ondo) and to $0.9-1.9^{\circ} \mathrm{C}$ in the other regions of Nigeria (Gough et al., 2018). There is high relative humidity in the country ranging from $41 \%$ to $100 \%$ throughout the year, rarely dropping below 21\% (NIMET, 2019). The average maximum temperature figures between $1980-$ 2019 (Table 3.1) across the country ranged from $30^{\circ} \mathrm{C}-42^{\circ} \mathrm{C}$, with states like Abia, Awka Ibom, Bayelsa, Enugu, Imo, and Rivers State experiencing temperatures of $30^{\circ} \mathrm{C}-31^{\circ} \mathrm{C}$. The highest figures recorded $\left(40^{\circ} \mathrm{C}-42^{\circ} \mathrm{C}\right)$ were in Adamawa, Borno, Kebbi, and Sokoto, respectively (NIMET, 2020). The lowest temperatures are general experienced at night, with temperature distribution across the country ranging from $12^{\circ} \mathrm{C}-20^{\circ} \mathrm{C}$ (Table 3.1). The lowest temperatures were recorded in Jigawa, Kano, and Plateau state, respectively. Table 3.1 provides a breakdown of the average climatic conditions in Nigeria to provide an overview of the climatic parameters across its 36 states. It also provides a breakdown of the six different geopolitical zones in Nigeria showing the interrelationship between the climate and geopolitical zones.

A review of the climatic parameters across the different states (Table 3.1) highlights relatively similar temperatures across most states, high temperatures experienced in most states even during the coolest periods, low wind speed, high humidity, and long hours of daylight. In addition to other factors like wind and humidity, high temperatures are dominant climatic factors affecting thermal comfort in tropical climates like Nigeria (Okafor, 2018). Thermal discomfort increases significantly in the afternoons due to the impact of solar radiation leading to further high indoor temperatures in poorly designed buildings (Adunola, 2014). The typical wind speeds vary from $5 \mathrm{kmh}$ to $20 \mathrm{kmh}$. Wind speeds are more intense in northern states due to the mountainous terrain, however, parts of the south and other mountainous regions like Cross Rivers also experience similar wind speeds (NIMET, 2019). According to Adunola (2017) the wind speed drops significantly in indoor spaces of residential dwellings, ranging from $0.75 \mathrm{kmh}$ to $1.0 \mathrm{kmh}$. This drop in indoor wind speed is due to insufficient cross ventilation and other techniques for improving natural ventilation/air circulation. These techniques include the use of courtyards, strategic positioning of windows/fenestrations, building orientation towards the prevailing wind, the use of corridors and stairwells to promote ventilation, wind towers, and stack ventilation techniques (Gough et al., 2018; Guedes, 2013). In relation to the adoption of ESD for addressing thermal discomfort, the relatively uniform temperatures and minor seasonal variations across the country (Table 3.1) make the application of ESD more straightforward. The following sections provide an overview of the Nigerian response to ESD, starting with a review of traditional architecture to contemporary architecture. 
Chapter 3 | Nigerian response to environmentally sustainable design

Table 3. 1: Average climate statistics in Nigeria between 1980 - 2019 based on states/geopolitical zones

(NIMET, 2020; Weatherspark, 2019)

GZ STATES AVERAGE TEMPERATURE (OC)

\begin{tabular}{|c|c|c|c|c|c|c|c|c|c|}
\hline & & & & \\
\hline & & Max. & Min. & Max. & Min. & Max. & Min. & Max. & Min. \\
\hline $\mathrm{SE}$ & Abia & 30 & 19 & 9 & 5.4 & 100 & 52 & 12.25 & 12.6 \\
\hline $\mathrm{NE}$ & Adamawa & 42 & 17 & 12.8 & 6.6 & 100 & 2 & 12.40 & 12.6 \\
\hline SS & Akwa Ibom & 31 & 21 & 8.4 & 6.2 & 100 & 69 & 12.25 & 12.6 \\
\hline SE & Anambra & 32 & 19 & 12.4 & 6.7 & 100 & 42 & 12.29 & 12.6 \\
\hline $\mathrm{NE}$ & Bauchi & 38 & 14 & 14.7 & 8 & 98 & 0 & 12.44 & 12.6 \\
\hline SS & Bayelsa & 31 & 21 & 10 & 6 & 100 & 74 & 12.25 & 12.6 \\
\hline $\mathrm{NC}$ & Benue & 34 & 17 & 12.8 & 6.9 & 100 & 10 & 12.35 & 12.6 \\
\hline $\mathrm{NE}$ & Borno & 42 & 14 & 20.8 & 11.6 & 97 & O & 12.56 & 12.6 \\
\hline SS & Cross River & 33 & 18 & 12.2 & 6.6 & 100 & 83 & 12.25 & 12.6 \\
\hline SS & Delta & 32 & 19 & 12.1 & 6.5 & 100 & 47 & 12.29 & 12.6 \\
\hline $\mathrm{SE}$ & Ebonyi & 32 & 18 & 11.9 & 6.5 & 100 & 34 & 12.29 & 12.6 \\
\hline SS & Edo & 31 & 19 & 8.1 & 4.7 & 100 & 59 & 12.30 & 12.6 \\
\hline SW & Ekiti & 32 & 18 & 11.1 & 6.4 & 100 & 25 & 12.34 & 12.6 \\
\hline $\mathrm{SE}$ & Enugu & 31 & 18 & 12.3 & 6.8 & 100 & 32 & 12.30 & 12.6 \\
\hline $\mathrm{NC}$ & $\begin{array}{r}\text { Federal } \\
\text { Capital } \\
\text { Territory }\end{array}$ & 35 & 17 & 9.4 & 5.9 & 100 & 6 & 12.39 & 12.6 \\
\hline $\mathrm{NE}$ & Gombe & 38 & 14 & 16 & 8.1 & 100 & 0 & 12.44 & 12.6 \\
\hline SE & Imo & 31 & 20 & 10.5 & 6.2 & 100 & 57 & 12.27 & 12.6 \\
\hline NW & Jigawa & 39 & 12 & 11.2 & 5.8 & 97 & 0 & 12.49 & 12.6 \\
\hline NW & Kaduna & 35 & 13 & 17.1 & $7 \cdot 3$ & 100 & $\mathrm{O}$ & 12.44 & 12.6 \\
\hline NW & Kano & 39 & 12 & 11.3 & 5.7 & 96 & 0 & 12.50 & 12.6 \\
\hline NW & Katsina & 38 & 14 & 17.9 & 8.9 & 100 & $\mathrm{O}$ & 12.54 & 12.6 \\
\hline NW & Kebbi & 40 & 18 & 13.4 & 6.6 & 100 & $\mathrm{O}$ & 12.52 & 12.6 \\
\hline $\mathrm{NC}$ & Kogi & 35 & 19 & 11.8 & 6.8 & 100 & 17 & 12.35 & 12.6 \\
\hline $\mathrm{NC}$ & Kwara & 35 & 18 & 13.8 & 7.7 & 100 & 12 & 12.37 & 12.6 \\
\hline SW & Lagos & 33 & 23 & $13 \cdot 3$ & 7 & 100 & 82 & 12.30 & 12.6 \\
\hline $\mathrm{NC}$ & Nasarawa & 35 & 17 & 9.7 & 6.2 & 100 & 7 & 12.37 & 12.6 \\
\hline $\mathrm{NC}$ & Niger & 34 & 16 & 12.4 & 6 & 100 & 3 & 12.41 & 12.6 \\
\hline SW & Ogun & 34 & 22 & 10.8 & 5.8 & 100 & $\begin{array}{l}\mathbf{u} \\
73\end{array}$ & 12.32 & 12.6 \\
\hline SW & Ondo & 33 & 19 & 6.4 & 3.9 & 100 & 61 & 12.32 & 12.6 \\
\hline SW & Osun & 34 & 18 & 11 & 6 & 100 & 36 & 12.35 & 12.6 \\
\hline SW & Oyo & 34 & 20 & 10.4 & 5.5 & 100 & 62 & 12.33 & 12.6 \\
\hline $\mathrm{NC}$ & Plateau & 33 & 12 & 14.7 & 8.2 & 60 & $\mathrm{O}$ & 12.42 & 12.6 \\
\hline SS & Rivers & 31 & 22 & 9 & $5 \cdot 3$ & 100 & 75 & 12.24 & 12.6 \\
\hline NW & Sokoto & 40 & 17 & 17 & 8.3 & 100 & 0 & 12.54 & 12.6 \\
\hline $\mathrm{NE}$ & Taraba & 37 & 16 & 13.9 & 7.1 & 100 & 2 & 12.39 & 12.6 \\
\hline $\mathrm{NE}$ & Yobe & 40 & 14 & 17.5 & 8.8 & 100 & $\mathrm{O}$ & 12.49 & 12.6 \\
\hline NW & Zamfara & 38 & 15 & 17.7 & 8.2 & 100 & $\mathrm{O}$ & 12.51 & 12.6 \\
\hline
\end{tabular}

\section{Notes:}

GZ-Geopolitical zones

North Central (NC), North East (NE), North West (NW), South West (SW), South East (SE), and South-South (SS)

\subsection{Architectural dynamics in Nigeria}

The architectural dynamics in Nigeria have evolved from the traditional architecture of mud houses with thatch roofs (Figure 3.1) to the contemporary architecture of concrete masonry block wall and aluminium roofing sheets. This evolution from traditional to contemporary architecture began in the late 1940 s and became prevalent during the post-colonial era (Lodson, Ogbeba, \& Elinwa, 2018). Generally, the architecture in Nigeria can be divided into two main eras. The first of these is the pre-colonial era from medieval times to the 1940s, characterised by traditional architecture (this era is currently referred to in this study as traditional architecture). The second is the post-colonial era, from the 1960 s to the present, which was initially characterised by a combination of traditional and colonial influence (a more bioclimatic approach) and later evolved to a less bioclimatic approach (Immerwahr, 2007; Okafor, 2018) (this era is referred to in this study as contemporary architecture). 
Chapter 3 | Nigerian response to environmentally sustainable design

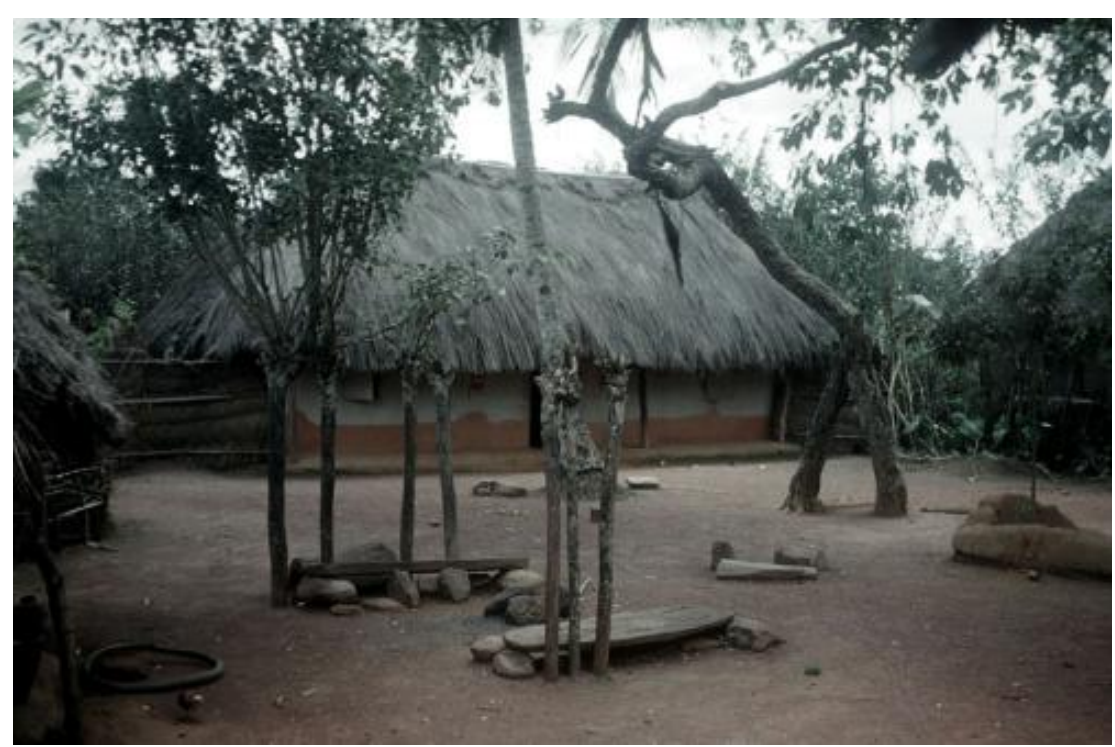

Figure 3. 1: Typical vernacular Nigerian architecture with clay and thatch roof in a compound setting (Image source: Author)

A review of the architectural dynamics in Nigeria reveals a vernacular architectural system that responded to the climate, surrounding environment, and the cultural and settlement patterns all over the region (Elleh, 1997). The climatic conditions in Nigeria stimulated two necessities: thermal insulation and ventilation, each of which was met by the judicious selection of locally available natural materials and techniques. These included the use of thick-walled timber and mud structures for providing thermal mass and ventilation (Amasuomo \& Amasuomo, 2016c). According to Folkers (2019), the vernacular architecture was an organic and cosmogonic design that accommodated the time cycle of generations all tied to the cour, also known as the courtyard, with the dwellings as the independent structures peripheral to the cour (Figure 3.2). The morphology was a manifestation of spiritual beliefs, a balance with nature, and the cognisance of community inclusion and centrality (Beswick, 2010). The taxonomy of house forms included round, oval, square and rectangular plans, free-standing with diameters greater or equal in height house, often with terraces, and building units arranged peripheral to the courtyard (Denyer, 1978). The courtyard offered a wealth of opportunity for seasonal and daily migration, with the shady recesses serving as buffer zones. The emphasis on fortification and protection inevitably also affected the spatial composition.

An example is the Kasbah, an indigenous housing style in northern Nigeria developed during the mid - $7^{\text {th }}$ century, which was made of stone and earth (clay) with the interiors well furnished with glazed stones and tiles (Elleh, 1997). The thick stone walls afforded the desired mass effects. In southern region, houses were built of indigenous bamboo and decorative tied mat, which were used for the roofs, doors and walls. These materials provided insulation to heat gain whilst aiding airflow due to their porous nature (Denyer, 1978).

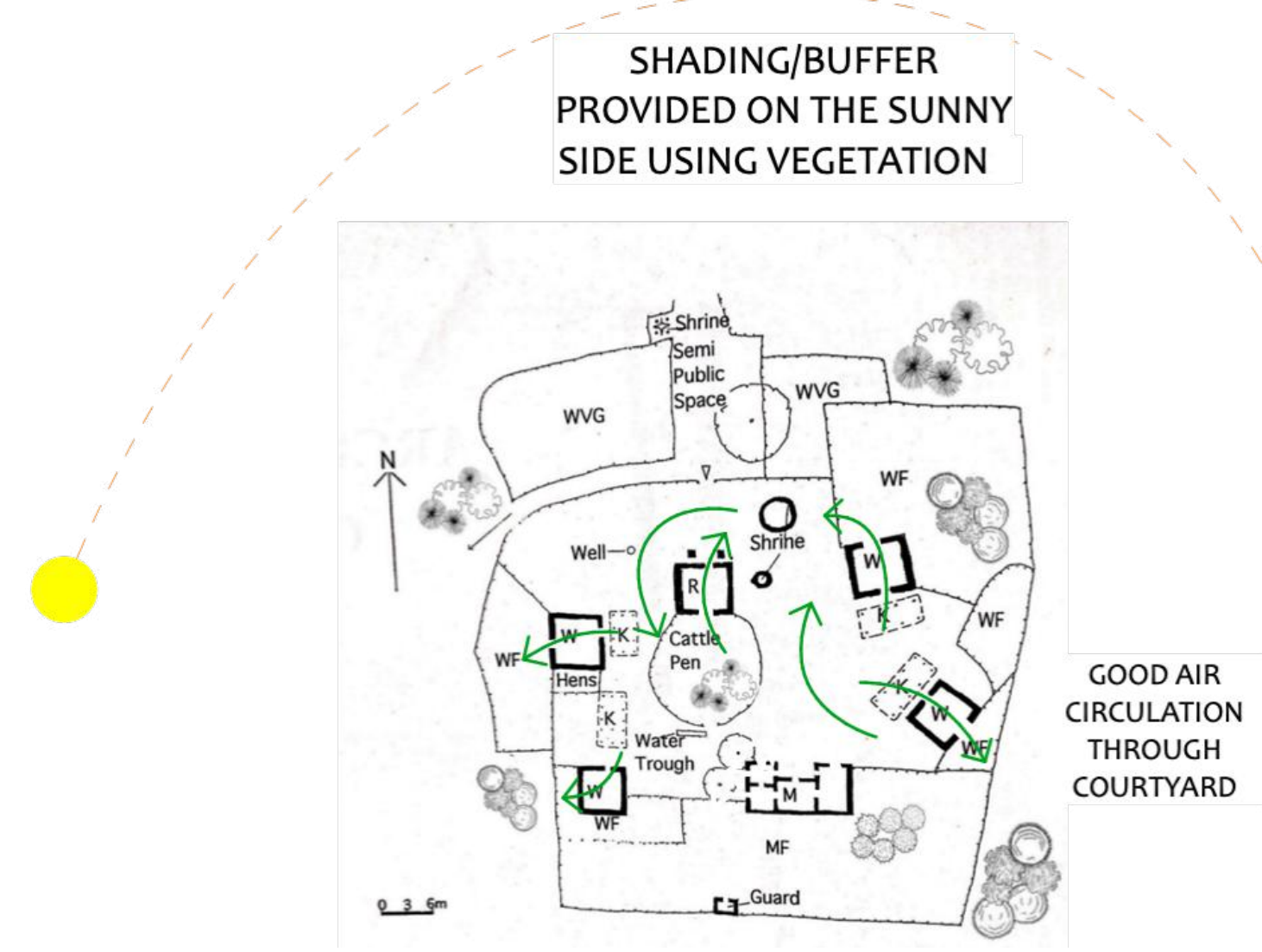

KEY: women's room - W, women's food store - WF, women's vegetable garden - WVG, kitchen- K, reception room - R, and men's food store - MF

Figure 3. 2: Typical building site and spatial composition of a Nigerian traditional compound showing airflow movement.

Adapted from (Elleh, 1997). 
In the south-eastern region, vernacular architecture adopted a minimalist building construction comprised primarily of locallysourced vegetative materials. The vernacular buildings had several ventilation and thermal resistance characteristics. The houses were built of palm thatch (Figure 3.1) with relatively steep hipped roofs, well interwoven (using significant amounts of sennit) with windows and doors (Elleh, 1997).

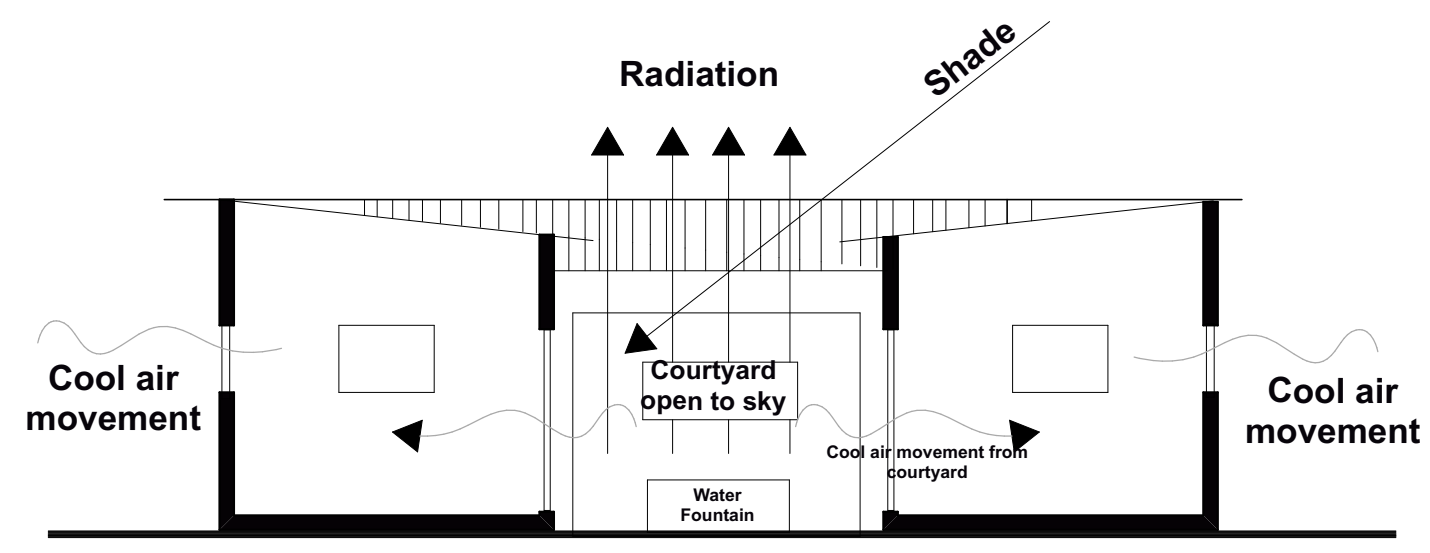

Figure 3. 3: The courtyard principle (Amasuomo \& Baird, 2016b)

Close observation of the architecture in Nigeria and other hot humid tropical climates shows a close correspondence between architectural features and climate. Despite the contrasting physiography, there is significant similarity in the building morphology across the tropical regions. Conspicuously, this was not only a response to similar climatic challenges, but the availability of local building materials as can be seen in the use of thatch across the regions (Ejiga, Obi, \& Osasona, 2012). Vernacular buildings were not only a reflection of precise and detailed knowledge of the local climatic conditions but an excellent understanding of the characteristics of the locally available building materials (Okafor, 2018). The spatial composition was an adaptation to the warm humid climate and the socio-cultural requirements of large families. Arguably, these types of residences can be regarded as balanced shelters in terms of their ability to intercept the adverse and take advantage of the environment (Okafor, 2018; Olgyay, 2015).

By contrast, contemporary buildings in Nigeria directly respond to colonialism, modernism, and socio-cultural changes. Some examples of these responses include the desire for smaller families and its effect on the proliferation of compact houses and the adoption of colonial design principles such as the maxim of form and function (Immerwahr, 2007; Okafor, 2018). The period immediately after colonisation (between the 1960 s and 1980s) consisted of first-generation Nigerian indigenous architects (PrucnalOgunsote, 2013). According to Immerwahr (2007), architectural emphasis in this era was on the importance of climate with a primary focus on ventilation, shading, humidity, and the general theoretical works on tropical architecture. Although the architects of this era were still interested in the overall building aesthetics and norms, the bioclimatic architectural approach remained the primary focus. The result of this approach led to the exploration of basic geometrical arrangements as they related to form and function, with central inner courtyards (Figure 3.3) and strategic location of fenestrations for enhancing air circulation and thermal comfort within indoor spaces (Elleh, 1997). The principle of form and function (form follows function or function follows form) was coined in the $19^{\text {th }}$ and $2 \mathrm{O}^{\text {th }}$ century, with architect Louis Sullivan as one of the pioneers. The principle of form follows function implies that the building form or shape is determined by the function or purpose of that building or space. Conversely, the principle of function follows form implies that the overall function of a space is determined by the building form (Alihodzic, Murgul, \& Vatin, 2014; Guimera \& SalesPardo, 2006). Despite the focus of the principle on building appearance or use of space, its application could either improve or impair user comfort and the efficiency of the building (Huang, Ma, \& Zhang, 2019; Papageorgiou, 2016). This principle was adopted not just for achieving aesthetics or spatial circulation but for improving thermal comfort by the first generation architects in Nigeria during the early post-colonial era (Immerwahr, 2007). However, this architectural ideology slowly degenerated with the younger and contemporary architects (Okafor, 2018). According to Prucnal-Ogunsote (2013), in recent years, contemporary architecture is gaining more traction among the younger generation of architects with less emphasis on the bioclimatic architectural approach. Nonetheless, according to Agboola and Zango (2014) the subject of form and function as it relates to the general building form, aesthetics, transition through spaces, and ease of circulation in the design, still remains a fundamental part of design and construction in contemporary Nigeria. However, studies suggest less emphasis on how building form and function can ensure maximum thermal comfort and energy efficiency (Alwetaishi, 2016; Umar, Yusuf, \& Mustapha, 2019). 
Traditional architecture revealed a commendable level of performance when compared to modern building technologies (Kiamba, Rodrigues, \& Lau, 2014; Okafor, 2018; Priyaa, Sundarraja, Radhakrishnana, \& Vijayalakshmia, 2012). However, some of its disadvantages included low durability, poor technology and fire risk for thatched roofs and wooden structures. Nonetheless, these building methods were particularly efficient in energy conservation and thermal performance (Mariarty \& Svar, 1976; Okafor, 2018). Traditional architectural systems sought to prevent the adverse impact of the ambient climatic conditions and utilised the advantageous at the correct time and in appropriate quantities for improving indoor thermal comfort (Okafor, 2018). Traditional systems and building techniques had challenges: Aniakor (1979), for example, notes that, during heavy rains, mud walls that were not adequately protected by the roof collapsed, and flooding continually eroded mud foundations. Also, humidity created excessive moisture and dampness that encouraged pests and affected the performance of the roof. Traditional systems and building techniques were imperfect but were exemplary in the provision of thermal comfort in an environmentally friendly and energy-efficient manner. For the review of traditional and contemporary architecture in Nigeria, this study divides the building envelope into five sections based on the primary components: site, structure, spatial composition, skin, and systems. These sections highlight those methods in each era that failed to provide indoor thermal comfort and renewable energy generation and highlight those that succeeded.

\subsubsection{Traditional architecture in Nigeria}

Traditional architecture adopted a bioclimatic approach using traditional building materials like locally sourced mud/clay and the provision of courtyards to ensure indoor thermal comfort (Ejiga et al., 2012; Okafor, 2018). Traditional architecture was a communal endeavour, and the house was a reflection of the ideological, economic, and social position of the broader urban context (Dmochowski, 1988). In Nigerian traditional culture, homeowners held the roles of client, architect, and builder. Whenever they decided to build a family home, they informed their friends and relatives, who assisted with construction (Elleh, 1997). During the design and construction process, they were conscious of the environmental conditions and utilised locally sourced building materials and techniques in an innovative fashion that reflected their local knowledge and expertise. The completed family home incorporated ESD to take advantage of the favourable climatic/environmental conditions and mitigate the unfavourable (Elleh, 1997; Okafor, 2018). The subsections below provide a review of traditional architecture in Nigeria based on the five components.

\subsubsection{Site and microclimate}

Traditional architecture incorporated trees, plantings, and green hedges into the landscape. This provided good shading to the building during sunny days, provided outdoor shelter during rainy days, and allowed for good optimal utilisation of on-site resources. Above all, the vegetative nature of the typical ambient environment and land use was crucial to the formation, growth, and consolidation of the traditional settlement in Nigeria (Dmochowski, 1988). In most parts of Nigeria, the typical traditional neighbourhood was characterised by a continuous stretch of open grassland with trees over the lush undulating hills and level sites (Aniakor, 1979). Elleh (1997), traditional builders had mastered the science of building orientation (Figure 3.2) from years of practice which allowed the buildings to take advantage of the climatic parameters. This involved the use of landscaping as a buffer from the sun. Positioning buildings around the courtyard also provided an additional buffer from the sun, especially when the courtyard was used as a communal space.

\subsubsection{Structure}

The complexity of traditional architecture was due to the different social and cultural factors that influenced the building culture and settlement patterns (Elleh, 1997). The regional building culture conformed to the environment in ingenious ways based on locally sourced natural building materials and climate. The morphology was a manifestation of spiritual beliefs, a balance with nature, and a cognisance of community inclusion and centrality (Folkers \& Van Buiten, 2019). The building structure of the traditional house consists of three main categories: the wall structure, roof structure, and apertures.

Wall structures: Most traditional buildings consisted of wooden poles (for structural support), mud, and fibres with a combined approximate thickness of 30omm. In some cases, the façade was painted with different colours for aesthetics. The fibres interwoven with the mud provided tensile strength in the mud brick. The compressive strength of the mud and the fibres prevented deformation to the mud, thus preserving its appearance, shape, and resistance to climatic effects (Binici, Orhan, \& Tahir, 2005). Heat transfer into the building takes place either through conduction, radiation, convection, and evaporation or condensation, and the traditional mud wall structure addressed the problem of heat transfer by moderating the amount of heat flow into the building depending on the external temperature in relation to the internal temperature (Givoni, 1976). This regulated the indoor thermal conditions and 
provided comfort for occupants. A study by Chel and Tiwari (2009) using the $\mathrm{Q}_{\text {wall }}(\mathrm{UA})_{\text {wall }}\left(\mathrm{T}_{\text {sol, wall }}-\mathrm{Tr}\right)$ equation to determine heat transmission through a mud wall showed that during summer months, internal temperatures were within the range of $26-28^{\circ} \mathrm{C}$ for an external temperature range of $26-40^{\circ} \mathrm{C}$. This was due to the thermal resistance and heat capacity of the mud wall. In Cameroon, a neighbouring country to Nigeria, (Nematchoua \& Orosa, 2016) performed a numerical calculation to evaluate the indoor air quality in old mud brick buildings and new concrete block buildings. The results showed a clear agreement with (Chel \& Tiwari, 2009) who found indoor temperatures were higher in the new buildings. Nematchoua and Orosa (2016) calculated a mean temperature difference of $2^{\circ} \mathrm{C}$ when compared to the old buildings. The essential thermo-physical properties of mud are its thermal resistance $(R)$ and the heat capacity $(Q)$, often expressed as $Q R$ of the building material (Givoni, 1976). In some regions, materials with a low heat capacity $(Q)$ and a high thermal resistance $(R)$ are advisable since the diurnal range is negligible, and the night-cooled mass is not generally needed for passive cooling.

Roof structure: The thatched roof system was common in most parts of Nigeria because of its good heat insulation, shading effect with the roof overhang, low cost, and local availability. Its primary disadvantage was its low durability, inflammability, and attraction to pests, rodents, and birds (Denyer, 1978; Folkers \& Van Buiten, 2019; Mariarty \& Svar, 1976). The thatched roof consists of laying bundles of palm reeds over each other to create an impermeable shell of waterproofing. Each thatch layer is about $300 \mathrm{~mm}$ thick, and gravity from its $45^{\circ}$ slope carries the rain down the roof (Denyer, 1978). With the increased thickness, thermal resistance and capacity of the thatched roof, solar radiation into the building is reduced (Givoni, 1976). As noted by Aniakor (1979), environmental factors dictated the use of highly pitched thatched roofs that could quickly shed the rainwater during the rainy season, expanding when it rains to prevent the entry of water and shrinking during the dry season to allow cool air into the house. Despite its lightweight nature, the thatched roof was effective.

Apertures: Most traditional buildings had small apertures, with door sizes of approximately $1800 \mathrm{x} 750 \mathrm{~mm}$ and $950 \mathrm{x} 950 \mathrm{~mm}$ for windows (Denyer, 1978). This concept was a systematic adaptation to abate sunlight penetration into the building, thus reducing the greenhouse effect inside dwellings. The symmetrical location of the small windows (typically one window per room) was to provide daylight and ventilation whilst reducing the level of solar radiation into the building (Elleh, 1997; Kumar \& Pushplata, 2013). The small window sizes also provided visual screening and privacy, and were sometimes closed at night (Ajibola, 1997; Olgyay, 2015). However, the small windows adopted in traditional buildings had some challenges, one of which was the effect on cross ventilation if there was no second opening. In such instances, pressure buoyancy and stack ventilation were utilised with air movement from the high to the low-pressure sections and through the air pores in the thatch roof, thereby providing comfortable indoor spaces (Elleh, 1997).

\subsubsection{Spatial composition}

It was customary to practise polygamy until the late 1960s, following colonisation, and in 2010 when it officially became illegal in Lagos and most states in Nigeria (Olufemi, 2019). This practice of polygamy resulted in the creation of larger homes due to extended families (Arthi \& Fenske, 2018; Chinwuba, 2015). In order to accommodate large families, the compound housing system was ubiquitous (Aniakor, 1979). The compound house consisted of several rooms clustered around the courtyard, which served as the focal point for social and religious gatherings. The size of the compound housing was directly proportional to the family's wealth, with larger families resulting from polygamy being a sign of wealth, respect, and high social standing (Arthi \& Fenske, 2018). This meant that the spatial configuration differed based on the social class, with the less affluent having smaller and less compact clusters, which was better for air circulation (Agboola \& Zango, 2014). The buoyancy of the circulation and transitional spaces enhanced airflow through the courtyards into the rooms.

In some cases, the women's kitchen, which consisted of a four-sided mud structure about $1.5 \mathrm{~m}$ above ground, was located in the courtyard. This meant that household tasks like cooking could extend from the kitchen to the courtyard if required. Other household tasks like laundry and dishes were done in the courtyard, thereby taking advantage of evaporative cooling during sunny afternoons (Denyer, 1978; Mahoney et al., 1971). During hot afternoons, shady courtyards also provided passive cooling, and during high nocturnal temperatures, occupants adopted the space migration principle by sleeping in the courtyards. The landscape elements of the compound house served as a shield from the sun, creating comfortable ambient temperatures (Aniakor, 1979; Elleh, 1997). The spatial configuration of the traditional house ensured that at any given time, thermal comfort was achieved. 


\subsubsection{Skin}

In traditional Nigerian architecture, wall finishes were primarily limited to the external walls but were an important architectural feature. The surfaces that received decorations and additional finishes included corridors, kitchen areas, and walls that enclosed the room units (Aniakor, 1979). Clay as a decorative material was used for finishing the walls and was applied either by hand, sponge or other soft materials to achieve the desired effects. This decoration was a sign of wealth and represented traditional and religious themes and motifs (Elleh, 1997). In most cases, the finishes consisted of light-coloured paints, which, in addition to the thermophysical properties of the wall material, had radiative advantages and enhanced indoor thermal comfort.

\subsubsection{Systems}

Traditional architecture adopted passive systems for ensuring indoor thermal comfort. Amongst many, these systems included the strategic location of windows; energy-efficient living patterns; building layout and orientation; number, size, location, and types of apertures; envelope shading devices; the thermophysical properties of the building materials; and courtyard, which provided buoyancy in airflow throughout the building (Elleh, 1997). Traditional systems and building techniques were not generally technologically advanced in renewable energy generation and had their challenges. However, traditional methods were exemplary in providing thermal comfort in an environmentally friendly and energy-efficient manner.

\subsubsection{Contemporary Architecture in Nigeria}

Contemporary architecture has evolved from an era of traditional influence to the current period of Western influence. By contrast to traditional architecture, which adopted a more environmentally friendly bioclimatic approach to architecture from the conceptual stages to completion and occupancy, contemporary architecture in Nigeria is less environmentally friendly (Allu \& Elimisiemon, 2017; Dalibi et al., 2017). The subsections below provide a review of contemporary architecture in Nigeria based on the five components of site and microclimate; structure; spatial composition; skin; and systems.

\subsubsection{Site and microclimate}

In contemporary buildings, open compounds, neighbourhood access, outdoor spaces and building access to climate resources at the neighbourhood or urban scale have been replaced by impervious paving with little landscaping and plantings, high rise buildings, and fencing that prevents access to wind and natural lighting (Paul \& Zango Modi, 2014a). As shown in Table 3.2, when compared to the traditional architecture of good landscaping that enhanced thermal comfort, contemporary architecture could learn a lot from traditional architecture. According to a study by Idowu, Junaid, and Humphrey (2018), a well-designed house with porous fencing would achieve a good level of air circulation. However, if houses are poorly designed with solid perimeter fencing, the level of air circulation within a residential dwelling is negatively affected.

The compact configuration of contemporary buildings makes it challenging to prevent the adverse impact of the ambient climatic conditions or the utilisation of advantageous conditions at the appropriate time and in appropriate quantities (Olgyay, 2015). The provision of good site landscaping and proper building orientation is essential to achieving thermal comfort and environmentally friendly buildings (DeKay \& Brown, 2014; Givoni, 1976; Mahoney et al., 1971). According to Ude, Umeh, and Ukwunna (2017), there are limited restrictions on the maximum building coverage or height on a site to allow for sufficient setbacks and vegetative landscaping to enhance shading and maximise airflow.

\subsubsection{Structure}

Population increases and the impacts of colonisation have accelerated the use of Western building techniques in Nigeria. These techniques pose difficulties when adopted inappropriately. The contemporary urban fabric consists of hollow concrete blocks (CHB) and solid concrete blocks (SCB). The building structure of the contemporary house consists of three main categories: the wall structure, roof structure, and apertures, as detailed below.

Wall: Concrete block is favoured amongst contemporary builders and designers due to its thermophysical properties, durability, and accessibility. With a thermal resistance of $0.37 \mathrm{~m}^{2} .{ }^{\circ} \mathrm{C} / \mathrm{W}$ and heat capacity of $Q=0.25 \mathrm{kcal} / \mathrm{kg} .{ }^{\circ} \mathrm{C}$, the standard concrete block sizes in Nigeria are $150 \mathrm{~mm}$ wide $\mathrm{x} 225 \mathrm{~mm}$ high $\mathrm{x} 450 \mathrm{~mm}$ long (usually for single storey buildings) and $225 \mathrm{~mm}$ wide $\mathrm{x} 225 \mathrm{~mm}$ high $\mathrm{x}$ $450 \mathrm{~mm}$ long (usually for multiple storey buildings). The thermal capacity of the concrete block makes it energy efficient, however, if 
not properly finished or well shaded, the reflectivity of the exterior painting could affect the amount of heat absorbed by the exterior walls. Shading is an effective method for preventing overheating through purposeful landscaping, large roof overhangs, and window hoods whilst increasing air movement into indoor spaces (Alausa, Adekoya, Aderibigbe, \& Nwaokocha, 2013). In addition to concrete blocks, a few contemporary buildings have also adopted interlocking brick systems, formwork panels, and structural insulated panels. An analysis of structural insulated panels revealed certain advantages when compared to other materials like concrete blocks. These included minimal material waste and faster construction time; flexibility in design; fewer labour requirements; cost savings; and better sustainability potential (Ogundiran \& Adedeji, 2012). However, there is a lack of mainstream adoption of structural insulated panels due to a lack of supply and poor awareness of their thermal performance benefits among the various stakeholders in the building industry (Ogundiran \& Adedeji, 2014).

Roof structure: To overcome the shortcomings of thatched roofing, corrugated mild steel roofing sheets gradually replaced the thatched roof. However, with its subsequent corrosion, these roofing sheets were subsequently replaced with profiled aluminium roofing sheet which is durable, lightweight, and impervious to biological deterioration and corrosion (Oloruntoba, Oluwole, \& Oguntade, 2009). Despite its advantages, its low thermal resistance, fading of the reflective surface, and heat conduction posed a thermal challenge (Mijinyawa, Adesogan, \& Ogunkoya, 2007). Lack of ventilation between the roof and the ceiling, as found in most contemporary buildings, reduces the effect of ceiling boards during times of high solar radiation (Odunfa, Ojo, Odunfa, \& Ohunakin, 2015). The aluminium roofing system has to be vented and be light coloured for it to be thermally effective. When vented, the heat gain into the indoor space is significantly reduced since the absorbed heat is lost through the vent by convection.

Apertures: Achieving satisfactory ventilation in contemporary buildings have proven problematic partly due to high temperatures, low wind velocity, window placements and types, burglar-proofing for security, and insect screens (Omonijo et al., 2013). These elements typically prevent optimum indoor thermal comfort unless auxiliary cooling devices are used (Adunola \& Ajibola, 2016; Ajibola, 1997). In addition to proper building orientation, windows must be shaded if possible and provided at different heights so that the excess indoor pressure remains at the upper openings where air flows out, and air ingress is built at the lower level, prompting an inward airflow for indoor thermal comfort.

\subsubsection{Spatial composition}

Contemporary buildings have adopted the Western compact spatial composition. Despite being appropriate in cold climates where heat loss is reduced by its compactness, this spatial composition seems unsuitable in Nigeria, where airflow and heat gain are of primary significance (Adebamowo, 2013; Olgyay, 2015). The desire for smaller families and monogamy also has a relative effect on the contemporary compact spatial composition. Arguably, with the kitchen situated within the living area, the heat generated during cooking also raises the indoor temperature and potential thermal discomfort (Lawal \& Ojo, 2011; Moriarty, 1980; Odunfa et al., 2015). However, the applicability of the compound housing system in these modern times would not be cost-effective given the price of land sections, building construction and population growth. Notwithstanding, with innovative techniques, thermal comfort can still be achieved in compact spaces.

\subsubsection{Skin}

Contemporary buildings have replaced the painted clay external finishes with an array of external finishes, which include cementsand rendering/plastering; ceramic tiles; paint finishing on rendered walls; and schist/stone finish (Iwuagwu \& Chioma, 2015). In addition to the structural mass, the thermal efficiency of these finishes is directly proportional to the surface absorbance. When solar radiation hits the building surface, a portion of the energy is absorbed by the surface, and the rest is reflected. Smaller floor areas with greater absorption tend to have warmer indoor spaces. The absorbance of a material depends on the colour, finish, and type of material, hence lighter surfaces tend to reduce the amount of solar radiation absorbed by decreasing the radiative heat gain into the indoor space (DeKay \& Brown, 2014; Givoni, 1976; Olgyay, 2015). Dark colours have a solar absorbance of between 0.90 - 0.98 with a solar reflectance of between $0.02-0.10$, and therefore dark coloured roofs and wall finishes, as found in some contemporary buildings in Nigeria, are more likely to lead to high indoor temperatures. Conversely, lighter colours, as found on cement-sand rendering/plastering, polished aluminium reflectors, light-coloured ceramic tiles, and red bricks, have a solar absorbance of between 0.51 - 0.70 with a solar reflectance of between 0.25 - 0.49 (DeKay \& Brown, 2014; Lawal \& Ojo, 2011). A comparison of traditional and contemporary architecture shows that whilst most traditional buildings had lighter colours and greater mass that increased the 
Chapter 3 | Nigerian response to environmentally sustainable design

thermal performance of the structure and reduced, some contemporary buildings have also been designed to achieve an equivalent performance with lighter colours and thermally resistive structures.

\subsubsection{Systems}

Systems, controls, and energy generation is the final stage and constitutes the selection of mechanical systems, controls, and on-site energy generation systems such as wind turbines, photovoltaic panels, and other renewable energy sources (DeKay \& Brown, 2014). According to Givoni (1994), this stage should only be required when every other bioclimatic approach has been utilised. Contemporary buildings in Nigeria have not completely incorporated systems, controls, or energy generation. The lack of mainstream adoption could result from a lack of information, lack of comprehensive tools and data, the perception of cost and trend, and lack of technical skills (Akadiri, 2015; Dalibi et al., 2017). Adopting sustainable systems, controls, and energy generation can significantly improve thermal comfort whilst reducing the cost of energy and protecting the environment. With the right knowledge and systems, a contemporary household can generate its own energy and be self-sufficient (DeKay \& Brown, 2014; Torcellini, 2006).

Table 3. 2: A summary comparison of traditional and contemporary building envelopes

\begin{tabular}{|c|c|c|c|c|}
\hline & \multicolumn{2}{|c|}{ TRADITIONAL ARCHITECTURE } & \multicolumn{2}{|c|}{ CONTEMPORARY ARCHITECTURE } \\
\hline & Advantages & Disadvantages & Advantages & Disadvantages \\
\hline \multirow[t]{2}{*}{$\begin{array}{l}\text { 1. SITE AND } \\
\text { MICROCLIMAT } \\
\text { E }\end{array}$} & $\begin{array}{l}\text { - Interwoven with } \\
\text { trees, plantings, and } \\
\text { green hedges }\end{array}$ & $\begin{array}{l}\text { - Can be land-intensive } \\
\text { - Land use with } \\
\text { population growth can } \\
\text { be unstainable in } \\
\text { urban areas }\end{array}$ & $\begin{array}{l}\text { - Hardscaping, which } \\
\text { generally requires less } \\
\text { maintenance, is water } \\
\text { efficient and reduces } \\
\text { erosion }\end{array}$ & $\begin{array}{l}\text { - Lack of vegetative shading } \\
\text { and evapotranspiration }\end{array}$ \\
\hline & $\begin{array}{l}\text { - Good shading to } \\
\text { the building during } \\
\text { sunny days and } \\
\text { outdoor shelter }\end{array}$ & $\begin{array}{l}\text { - Lack of privacy and } \\
\text { security }\end{array}$ & $\begin{array}{l}\text { - Security and privacy } \\
\text { using high solid fencing }\end{array}$ & $\begin{array}{l}\text { - If buildings are not well } \\
\text { oriented, it could prevent } \\
\text { optimum utilisation } \\
\text { of on-site resources }\end{array}$ \\
\hline \multirow{3}{*}{$\begin{array}{l}\text { 2. STRUCTURE } \\
\text { WALL }\end{array}$} & & & & \\
\hline & Mud wall & & Concrete Blocks & \\
\hline & $\begin{array}{l}\text { - Thermal resistance } \\
=0.77 \mathrm{~m}^{2} .{ }^{\circ} \mathrm{C} / \mathrm{W}\end{array}$ & - Low durability & - Better durability & $\begin{array}{l}\text { - Approximately half the } \\
\text { thermal resistance of mud } \\
\text { wall }=0.37 \mathrm{~m}^{2} .{ }^{\circ} \mathrm{C} / \mathrm{W}\end{array}$ \\
\hline \multirow[t]{2}{*}{ ROOF } & Thatched Roof & & Aluminium Roof & \\
\hline & $\begin{array}{l}\text { - Good insulation (R- } \\
\text { value of R26.6) } \\
\text { - Air cavity/vents } \\
\text { aiding air movement }\end{array}$ & $\begin{array}{l}\text { - Low durability } \\
\text { - Harbours insects } \\
\text { - Fire risk }\end{array}$ & $\begin{array}{l}\text { - Good reflectivity and } \\
\text { lightweight }\end{array}$ & $\begin{array}{l}\text { - Poor insulators if dark } \\
\text { coloured } \\
\text { - Where venting is not } \\
\text { provided in the roof space, } \\
\text { air movement is prevented } \\
\text { - Poor insulating ceiling } \\
\text { boards }\end{array}$ \\
\hline \multirow[t]{2}{*}{ 3. APERTURES } & \multicolumn{2}{|c|}{ Small side hung timber windows } & \multicolumn{2}{|c|}{ Aluminium sliding and casement windows } \\
\hline & $\begin{array}{l}\text { - Allowed for } \\
\text { pressure, buoyancy } \\
\text { and stack ventilation }\end{array}$ & $\begin{array}{l}\text { - Small openings on } 10 \\
-15 \% \text { of the wall area } \\
\text { affect cross ventilation }\end{array}$ & $\begin{array}{l}\text { - Large openings on } 25- \\
50 \% \text { good for ventilation } \\
\text { if well placed }\end{array}$ & $\begin{array}{l}\text { - The use of window nets. } \\
\text { - Large openings without } \\
\text { proper shading increase solar } \\
\text { radiation through the } \\
\text { building }\end{array}$ \\
\hline \multirow{2}{*}{$\begin{array}{l}\text { 4. SPATIAL } \\
\text { COMPOSITION }\end{array}$} & \multicolumn{2}{|l|}{ Compound Housing } & \multicolumn{2}{|l|}{ Compact Housing } \\
\hline & $\begin{array}{l}\text { - Well-spaced, loose } \\
\text { open plan to allow air } \\
\text { movement } \\
\text { - Natural } \\
\text { conditioning }\end{array}$ & $\begin{array}{l}\text { - Poor security } \\
\text { - Poor protection } \\
\text { against insects, } \\
\text { mosquitoes, and pest } \\
\text { - In some cases, poor } \\
\text { hygiene }\end{array}$ & $\begin{array}{l}\text { - Adequate security } \\
\text { - Well suited for } \\
\text { contemporary families }\end{array}$ & $\begin{array}{l}\text { - Interrupted air movement } \\
\text { due to compactness } \\
\text { - Mechanical cooling } \\
\text { requirements }\end{array}$ \\
\hline \multirow[t]{2}{*}{ 5. SKIN } & \multicolumn{2}{|c|}{ Clay finishes, Paint finishes on clay } & \multicolumn{2}{|c|}{$\begin{array}{l}\text { Ceramic tiles, Paint finishing on rendered walls, and } \\
\text { Schist/stone finish }\end{array}$} \\
\hline & $\begin{array}{l}\text { - Light colour } \\
\text { finishes had radiative } \\
\text { advantages }\end{array}$ & $\begin{array}{l}\text { - Poor durability and } \\
\text { longevity }\end{array}$ & $\begin{array}{l}\text { - Depends on the external } \\
\text { colour of the finishes and } \\
\text { thermophysical property } \\
\text { of the substrate }\end{array}$ & $\begin{array}{l}\text { - Dark coloured finishes } \\
\text { generally have higher heat } \\
\text { absorption and low } \\
\text { reflectivity }\end{array}$ \\
\hline 6. SYSTEMS & $\begin{array}{l}\text { - Energy-efficient } \\
\text { and environmentally } \\
\text { friendly systems }\end{array}$ & - Poor durability & $\begin{array}{l}\text { - Energy and cost-efficient } \\
\text { over time }\end{array}$ & - High initial cost \\
\hline $\begin{array}{l}\text { 7. BUILDING } \\
\text { OWNER'S } \\
\text { ROLE }\end{array}$ & $\begin{array}{l}\text { - Acted as the } \\
\text { designer and builder. } \\
\text { Adopted ESD based } \\
\text { on their local } \\
\text { knowledge }\end{array}$ & & $\begin{array}{l}\text { - Delegated the role of the } \\
\text { building team }\end{array}$ & $\begin{array}{l}\text { - In some cases, lack good } \\
\text { knowledge of ESD }\end{array}$ \\
\hline $\begin{array}{l}8 . \\
\text { ARCHITECT'S } \\
\text { ROLE }\end{array}$ & $\begin{array}{l}\text { - The building owner } \\
\text { assumed the role of } \\
\text { an architect }\end{array}$ & & $\begin{array}{l}\text { - Responsible for the } \\
\text { design process, including } \\
\text { adopting ESD }\end{array}$ & $\begin{array}{l}\text { - In some cases, lack good } \\
\text { knowledge of ESD }\end{array}$ \\
\hline
\end{tabular}


Chapter 3 | Nigerian response to environmentally sustainable design

\subsubsection{Comparison of traditional and contemporary architecture}

A review of traditional and contemporary architecture in Nigeria shows a significant shift. This is expected given modernisation and other social-cultural factors such as the desire for smaller families. Despite this shift, it is observed that in both eras, the building envelope has been designed to modify and prevent the direct effects of the external climatic variables such as solar radiation, rain, humidity, and wind whilst providing a habitable dwelling. However, the significant difference between traditional and contemporary architecture in Nigeria is the quantitative effect of the building envelope which is determined by the thermophysical properties, the spatial composition of the envelope, and how the building envelope adapts to the ambient climatic parameters, specifically in the provision of thermal comfort (Akande et al., 2015; Ejiga et al., 2012; Givoni, 1976). Compared to contemporary architecture, traditional architecture seems to have a better thermal performance for ensuring indoor thermal comfort (Umar et al., 2019). However, as shown in Table 3.2, traditional architecture has its challenges, suggesting that it should not be replicated in its entirety, but its advantages adapted as much as possible to meet modern demands. In summary, vernacular methods should be studied but not copied because many were developed under circumstances that have now been superseded. Nevertheless, with the right knowledge and systems, contemporary buildings can still take advantage of ancient wisdom to arrive at better and cheaper solutions.

\subsection{The Nigerian response to environmental sustainability}

As part of a memorandum of understanding with other African nations during the UN-HABITAT conference on the Green Building Rating System (GBRS), which was held in Nairobi in 2010, the Nigerian government and building stakeholders have taken steps to encourage a sustainable built environment (Adebowale, Adekunle, Joseph, Ankeli, \& Dabara, 2017; Waniko, 2014). Most significant to the building industry was the creation of the Green Building Council of Nigeria (GBCN). As mentioned, GBCN is newly developed and still on a prospective membership level of registration with the World Green Building Council (WGBC) as of January 2014. In the meantime, the GBCN is working in collaboration with The Green Building Council of South Africa (GBCSA) to manage and allow certification through its current rating (Prucnal-Ogunsote et al., 2018). Currently, there are a few LEED-certified buildings in Nigeria, most of which are commercial buildings. They include; Number 4 Bourdilon, a 25-floor luxury residential development, which is still under construction; the Heritage Place in Ikoyi, Lagos; the NOX building in Abuja; P\&G Nigeria MDO Warehouse; RFA HSClassroom North in Abuja; and RFA HS- Classroom South in Abuja (LEED, 2019a; Prucnal-Ogunsote et al., 2018).

GBCN membership is currently restricted to firms and corporate entities, with 50 members (Adekunle Onabekun, GBCN). GBCN does not have an active website, hence most of the information on $\mathrm{GBCN}$ has either been retrieved from direct contact, journal articles, or media publications. According to the GBCN member brochure, GBCN is a private sector initiative for promoting environmentally sustainable development within the Nigerian context by encouraging and recognising building designs and constructions that have adopted appropriate principles of environmental efficiency (NIQS, 2019). The primary aims and objectives of GBCN are to:

- Raise the public and professionals' awareness on the benefits of a green, safe, and sustainable built environment.

- Encourage professionals within the building industry to adopt a green, comfortable and affordable approach during design and construction.

- Encourage training and technological development within the green building practice.

- Develop a green building rating and assessment tool for the building industry.

- Effectively promote research and development of relevant theories and principles that would benefit green building development.

- Cooperate with similar organisations within and outside of Nigeria, especially those within Africa and the WGBC. (NIQS, 2019).

In addition to the GBCN, other institutions and projects have been established in the private and public sectors to promote a more sustainable built environment in Nigeria. Some of the widely documented efforts include:

\subsubsection{The implementation of Sustainable Development Goals (SDG)}

According to the UN (2017), as part of the SDG, the Nigerian government appointed a Senior Special Assistant to the President on SDG. This office is responsible for ensuring coherency between development plans, policies and strategies. Additionally, an Inter- 
Chapter 3 | Nigerian response to environmentally sustainable design

Ministerial Committee on SDG, which includes ministries, departments, and agencies, has been established to ensure a multi-layer and multi-cluster institutional framework for enhancing coordination between the SDG and the public and private sectors. Some significant challenges documented by the SDG committee include:

- Over dependency on the oil and gas sector for revenue generation, power generation, and job creation

- Poor infrastructural and technological development

- Economic decline in the country due to unstable global oil prices and humanitarian crises in northern Nigeria

The Nigerian government is yet to achieve most of the goals stipulated in the United Nations SDG. A significant failing is Nigeria's continued dependence on the fossil-powered national grid instead of affordable and cleaner energy promised by the government (IEA, 2019). Despite the alarming rate of environmental degradation due to rapid urbanisation and population growth in the country, currently estimated at 200 million and rising at a $2.8 \%$ growth rate, little has been done to ensure environmental sustainability (Bamisile et al., 2017; Dalibi et al., 2017). With the current trend, it is projected that building demand and $\mathrm{Co}_{2}$ emission will double over the next decade (UN, 2017; UNEP, 2012). According to HBS (2015), climatic responsive and passive building design is a vehicle through which affordable housing can be provided for the housing deficit of 17 million units in Nigeria. A Passive House Prototype project executed by the USAID and The African Diaspora Marketplace (ADM 11) Business plan to provide a sustainable design response to the acute housing problem highlighted some issues such as a lack of public and private partnership, material unavailability, limited knowledge, and economic and social-political barriers. This provides an insight into the possible reasons why ESD has not been ultimately adopted in Nigeria (HBS, 2015).

Climate change and the pressing concerns of the environment are nudging both the public and private sector in Nigeria onto a more sustainable path. However, there is little emphasis on the built environment and the erratic electricity supply in Nigeria and its relation to the provision of healthy and comfortable built spaces within the Nigerian built environment (Waniko, 2014). The Energy Policy established in April 2003 by the Energy Commission of Nigeria (ECN) primarily centred on aspects of energy consumption in agriculture, transportation, and the industrial sector with little emphasis on energy generation and consumption in the building arena (Kawuwa, Sani, Mustapha, \& Ishaku, 2015). According to a survey conducted by Otegbulu (2011) on several buildings in Lagos, Nigeria, residential buildings like the Dolphin Estate had neither proper fenestration nor any sustainable means of generating electricity, leaving the residents without proper ventilation during the constant blackouts (Otegbulu, 2011). The current electricity supply is estimated at around 5000MW, meeting only a tiny fraction of the electricity demand in Nigeria. However, studies have shown that sustainable electricity generation on a large scale or attached to buildings can generate over 427,00oMW (Giwa et al., 2017; IIED, 2012). This shows that stakeholders in the built environment have not fully explored the potential of sustainable energy in Nigeria.

\subsection{Energy consumption in Nigeria}

Most societies' economic growth and development can be linked to the availability and optimum utilisation of the energy resources at their disposal. Energy provides economic growth and plays a critical role in the commercial and residential sector for providing lighting, cooling, and basic necessities (Aliyu et al., 2015). The provision of electricity from the national grid has been insufficient in Nigeria, with electricity available to only approximately 40-50\% of the Nigerian populace (Abanihi et al., 2018; IIED, 2012). In addition to the residential sector, this issue has greatly affected the industrial sector, with the Manufacturers Association of Nigeria claiming to spend more than NGN18 billion (USD11,340 million) weekly on diesel/petrol powered generators (Aliyu et al., 2015). Establishing the energy use patterns and electricity consumption in Nigerian households has proven difficult because some households do not have electricity meters, or faulty meters mean that electricity bills are an unreliable method of establishing household electricity consumption. However, household survey data suggests that the average Nigerian household consumes approximately 670kWh (18-27kWh/day) per month at the cost of NGN23.6o/kWh from the national grid (IIED, 2012; Olaniyan, McLellan, Ogata, \& Tezuka, 2018; Roche, 2017). Table 3.3 provides a breakdown of the average household electricity consumption in Watts (W). 
Chapter 3 | Nigerian response to environmentally sustainable design

Table 3. 3: Appliance categorise and power rating (Olaniyan et al., 2018)

\begin{tabular}{|c|c|c|c|c|c|c|}
\hline \multirow{2}{*}{$\mathbf{S} / \mathbf{N}$} & \multirow{2}{*}{ Category } & \multirow{2}{*}{ Appliance } & \multicolumn{4}{|c|}{ Power Rating (Watts) } \\
\hline & & & Range & Mean & Mode & Median \\
\hline 1 & \multirow{3}{*}{ Lighting } & Incandescent lamps & $60-100$ & 80 & 80 & 80 \\
\hline 2 & & Fluorescent lamps & $9-18$ & 10 & 9 & 9 \\
\hline 3 & & Compact fluorescent & $3-85$ & 11 & 5 & 8 \\
\hline 4 & \multirow{12}{*}{ Cooking } & Rice cooker & $450-1500$ & 946 & 1000 & 1000 \\
\hline 5 & & Water dispenser & $500-670$ & 607 & 640 & 640 \\
\hline 6 & & Food blender & $250-700$ & 323 & 300 & 300 \\
\hline 7 & & Refrigerator & 225 & 225 & 225 & 225 \\
\hline 8 & & Freezer & $277-386$ & 286 & 277 & 277 \\
\hline 9 & & Toaster & $700-1300$ & 754 & 750 & 750 \\
\hline 10 & & Coffee machine & $700-1300$ & 983 & 700 & 1000 \\
\hline 11 & & Microwave oven & $600-1550$ & 814 & 700 & 800 \\
\hline 12 & & Boiling ring & 1000 & 1000 & 1000 & 1000 \\
\hline 13 & & Electric kettle & $800-3000$ & 1832 & 2000 & 1800 \\
\hline 14 & & Hot plate & $1000-1500$ & 1215 & 1000 & 1000 \\
\hline 15 & & Electric cooker/oven & $1000-2000$ & 1215 & 1000 & 1000 \\
\hline 16 & \multirow{6}{*}{ Entertainment } & Mobile phones (charging) & $2-4$ & 3 & 3 & 3 \\
\hline 17 & & TV & $70-339$ & 205 & 205 & 205 \\
\hline 18 & & PC (desktop) & $80-120$ & 100 & 100 & 100 \\
\hline 19 & & Radio & 60 & 60 & 60 & 60 \\
\hline 20 & & CD/DVD player & 17 & 17 & 17 & 17 \\
\hline 21 & & PC (laptop) (charging) & $60-250$ & 155 & 155 & 155 \\
\hline 22 & \multirow{5}{*}{ Laundry } & Washing machine & $200-460$ & 228 & 200 & 200 \\
\hline 23 & & Iron & $800-2400$ & 1254 & 1200 & 1200 \\
\hline 24 & & Hair dryer & $850-2200$ & 1069 & 1000 & 1000 \\
\hline 25 & & Vacuum cleaner & $700-2300$ & 1709 & 1600 & 1600 \\
\hline 26 & & Water heater & $1500-5000$ & 1916 & 1500 & 1500 \\
\hline 27 & \multirow{2}{*}{ Cooling } & Fan & $47-140$ & 80 & 75 & 75 \\
\hline 28 & & Air conditioner & $845-12,500$ & 1872 & 1200 & 1230 \\
\hline
\end{tabular}

Increasingly households in Nigeria rely entirely on fuel generators or complement the power from the national grid with generators (Oseni, 2012). Fuel generator sets are harmful to human health and the environment, with several cases of generator explosion and respiratory crises resulting from fuel-powered generator incidents in Nigeria (Arogundade, 2015; Awofeso, 2011; Elinwa et al., 2020). It is estimated that the average electricity consumer spends approximately $7 \%$ of per capita income on electricity either from generators or the national grid, which equates to $18-27 \mathrm{kWh}$ per capita per month for an average household of five people in the different geopolitical zones in Nigeria. This translates to two light bulbs, a fridge or freezer for five hours, television for four hours, radio for one hour, CD player for two hours, a fan for five hours and an iron for 20-30 minutes per day (Olaniyan et al., 2018).

Considering the erratic electricity supply from the national grid, renewable energy sources like solar panels have been proposed as a better alternative to the national grid or fossil powered generators (Aliyu et al., 2015). However, the relatively high capital cost instead of the long-term financial benefits of renewable energy sources like solar panels have proven to be a barrier (Dalibi et al., 2017). Investing in an average generator set in Nigeria selling for NGN 40,00o, which excludes the cost of petrol (NGN145/litre) and maintenance, seems preferable to purchasing a solar home system (SHS) at the cost of NGN 200,00o. Studies have shown that most consumers opt for cheaper short-term options due to specific barriers such as cost, limited knowledge, and other social-political issues such as public perception and unfavourable government policies (IIED, 2012; NBS, 2019). Compared to the lifetime cost of running generators, estimated at NGN217/kWh, SHS becomes more cost-efficient in Nigeria on a lifetime basis costing an average of NGN72/kWh (including storage and maintenance cost) (Roche, 2017). According to Waniko (2014), building owners are more interested in the capital cost and less interested in the whole life operating cost of a building.

Given that the initial cost of sustainable design methods is more expensive than the typical unsustainable methods, most building owners find them less appealing. Due to the high initial cost, the Off-grid pay-as-you-go solar power system initiative was established by the Nigerian telecommunication company MTN in collaboration with a Netherlands firm Nova Lumos (GSMA, 2016). Since establishing this initiative, there has been a relative increase in the adoption of photovoltaic systems for electricity generation to power household appliances (Signify, 2019). However, as Elinwa et al. (2020) more work is required to encourage more households to adopt photovoltaic systems. Figure 3.4 provides a summary of the projected cost of energy from different sources. Results show that based on the cooling, ventilation, lighting and general domestic requirements, the average Nigerian household can achieve a positive Energy Balance Index of $5 \mathrm{~kW} /$ day since the average SHS can generate about $15 \mathrm{~kW} /$ day given that the average hours of 
Chapter 3 | Nigerian response to environmentally sustainable design

sunshine in Nigeria are between 6 and 8 hours during the wet season and as much as 10 hours during the dry season (Giwa et al., 2017; IIED, 2012; WMO, 2015). A survey by Wojuola and Alant (2017) on the public perception of renewable technologies in Nigeria showed that due to limited understanding of the environmental and cost benefits of ESD, there is a lack of mainstream adoption of renewable energy sources.

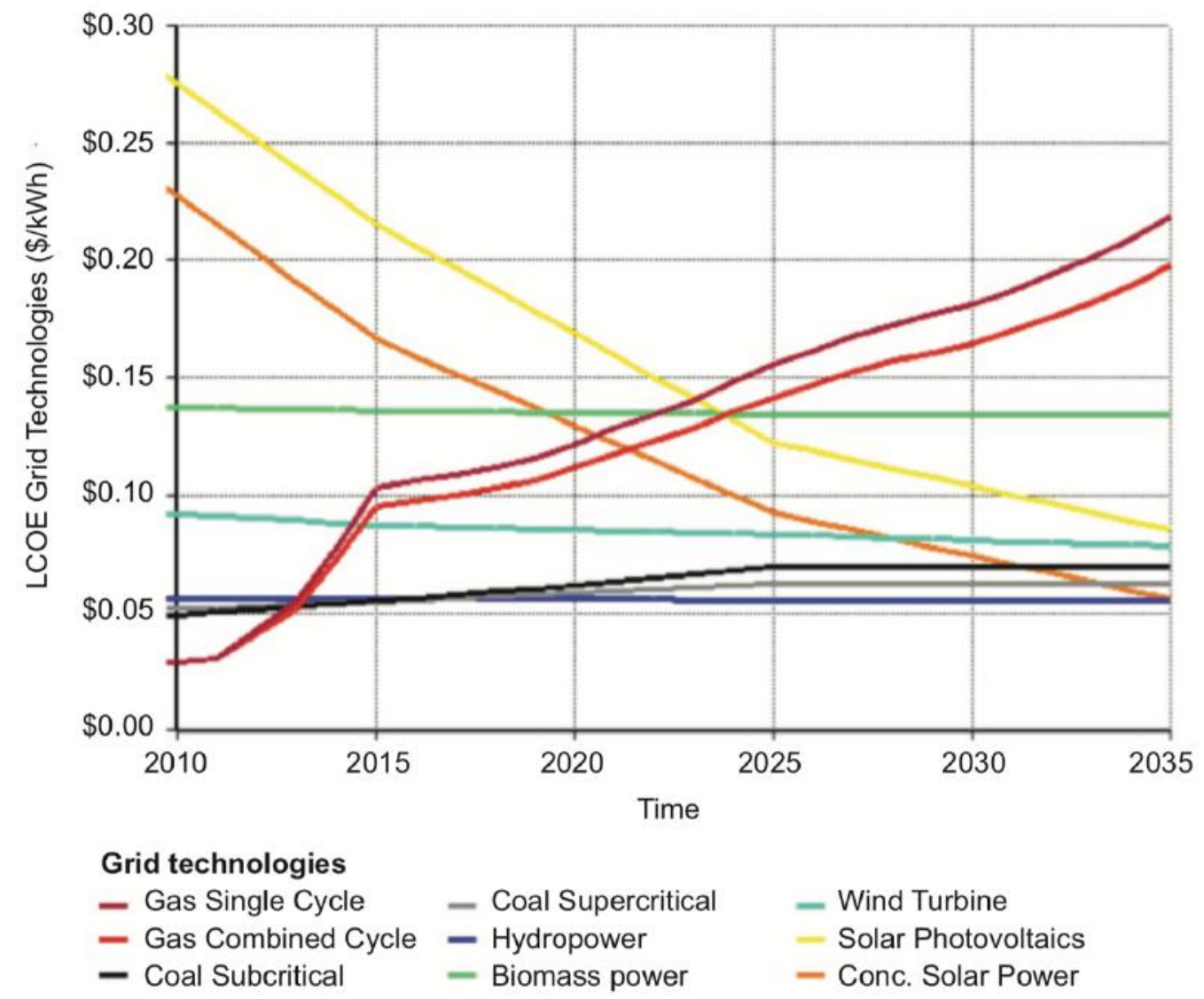

Figure 3. 4: A summary of the projected cost of energy from different sources Nigeria (IIED, 2012)

\subsection{The National Building Code}

The Building Code sets the minimum standards and requirements for building design and construction to ensure quality, safety, and proficiency in the Nigerian building industry (Dauda, 2012). The condition of the built environment has received the attention of the government and stakeholders in the building industry. This led to the establishment of the first National Building Code (NBC) in Nigeria in 2006, which was aimed at 'protecting the built environment' through resilient buildings (Anejo, 2008). The enactment of the NBC is a positive step towards a sustainable built environment in Nigeria. Aspects of the NBC currently provide basic guidelines for ensuring thermally comfortable indoor spaces, such as installing windows on at least two opposite walls in a room for enhancing cross ventilation (ARUP, 2016). However, some experts within the building industry have stressed the need for a revamp of the current building code (Kawuwa et al., 2015). Some of the issues highlighted include; reinforcing the need for its use, the need for energy efficiency and environmental sustainability clause, and strategies for the implementation and enforcement of the building code (Atanda \& Olukoya, 2019). The need for its use and enforcement becomes critical, specifically during the application for a building permit. In Nigeria, obtaining a building permit is a prerequisite for construction, specifically in districts where the government insists on full compliance to the NBC, urban and regional planning regulations. Commencing a building construction without a permit results in severe fines. Unlike some parts of the world like New Zealand, where a Licensed Building Practitioner can sign off an architectural plan and apply for a building permit (MBIE, 2019), in Nigeria only registered architects with The Architects Registration Council of Nigeria (ARCON) can sign off an architectural plan required for building permit application (Ayotamuno \& Owei, 2015; LASPPPA, 2019). This reinforces the role of an architect in the adoption of ESD.

Against this backdrop, the Ministry of Power, Works and Housing launched the Building Energy Efficiency Guidelines, which is intended for all professionals in the building industry and is designed to enhance a sustainable built environment (Adebowale et al., 2017). These guidelines are yet to be included in the NBC (Atanda \& Olukoya, 2019). Currently, the NBC is primarily divided into four parts, as shown in Table 3.4. 
Chapter 3 | Nigerian response to environmentally sustainable design

Table 3. 4: National Building Code (Atanda \& Olukoya, 2019)

\begin{tabular}{lll} 
PARTS & STAGES & SECTIONS \\
\hline PART ONE: & & Section 1: Citation and commencement \\
\hline & & Section 2: Interpretations, definitions and abbreviations \\
\hline & Section 3: Organisation, committees and roles \\
\hline $\begin{array}{l}\text { PART TWO: TECHNICAL } \\
\text { (PROFESSIONALS) }\end{array}$ & Section 4: Building design classifications \\
\hline & Pre-design stage & Section 5 Building construction classifications \\
\hline & Design stage & Section 6: Environmental and general building requirements \\
\hline & & Section 7: Architectural design requirements \\
\hline & & Section 9: Service engineering design requirements \\
\hline PART THREE: & Construction stage & Section 10: Building materials and components requirements \\
ENFORCEMENT & & \\
\hline & & Section 11: Building construction requirements \\
\hline & Post-construction stage & Section 12: Post-construction requirements \\
\hline $\begin{array}{l}\text { PART FIVE: SCHEDULES } \\
\text { AND REFERENCES }\end{array}$ & & Section 13: Control of building works \\
\hline & & Section 14: Referenced standards \\
\hline
\end{tabular}

A survey was conducted by Dauda et al., (2012) to evaluate the adequacy of the NBC for achieving a sustainable built environment in Nigeria. The survey indicated that Architects, Engineers, and Contractors (AEC) were concerned about the inadequacy of the current NBC towards encouraging a more sustainable built environment. Based on the results from the survey, and similar studies (Atanda \& Olukoya, 2019; Kawuwa et al., 2015; Mu'Azu, 2011; Windapo, 2006), the following was concluded:

- Environmentally sustainable measures in the NBC (2006) are insufficient.

- The current legislation regarding the sustainable protection of the built environment is not enforced.

- There are some variations between the newly established NBC (2006) and the already existing building legislation in some states. Regardless of these differences, the building regulations are not effectively enforced.

- The enactment of the NBC (2016) is a step in the right direction towards achieving a sustainable built environment; however, certain flaws and challenges must be addressed for it to be effective.

- There is an urgent need for effective promotion and awareness campaigns to inform professionals of the necessity to comply with sustainable construction measures.

- The need for a well-structured enforcement system towards compliance with sustainable measures cannot be overemphasised. A structured system free from corruption and nepotism is required.

\subsection{Professional bodies' facilitation role towards a sustainable built environment}

Some professional institutions in Nigeria have made efforts towards encouraging energy efficiency and environmental sustainability. ARCON has organised conferences and awareness programmes such as the Architects Colloquium, held in April 2016 in Abuja. The conference was aimed at Urbanization and Sustainable Built-Environment in Nigeria, highlighting the role of architects in attaining a sustainable built environment (ARCON, 2016). The role of ARCON is to register architects and regulate the practice of architecture in Nigeria.

Recognising the need for a sustainable built environment, The Nigerian Institute of Architects (NIA) held a training and certificate course in Energy Efficient Building Design, which aimed to provide energy-efficient design strategies (NIA, 2017). The NIA was founded as an association for fostering support and cooperation amongst architects in Nigeria. Following the GBCN annual general meeting held on $28^{\text {th }}$ June 2017 , NIQS sent out a letter to all its members encouraging them of the benefits and need to join the NGBC (NIQS, 2019). Given the growing concerns and relevance of ESD, professional bodies like NIA, ARCON, NIQS, and COREN still need 
Chapter 3 | Nigerian response to environmentally sustainable design

to do more towards enhancing a sustainable built environment in Nigeria. This could include making ESD a core part of the Continual Professional Development program (Akinola et al., 2018; Nduka \& Ogunsanmi, 2016). Figure 3.5 provides an insight into the efforts made by the different professional bodies in Nigeria. Notably, NIA was the most active in promoting a sustainable built environment (Waniko, 2014).

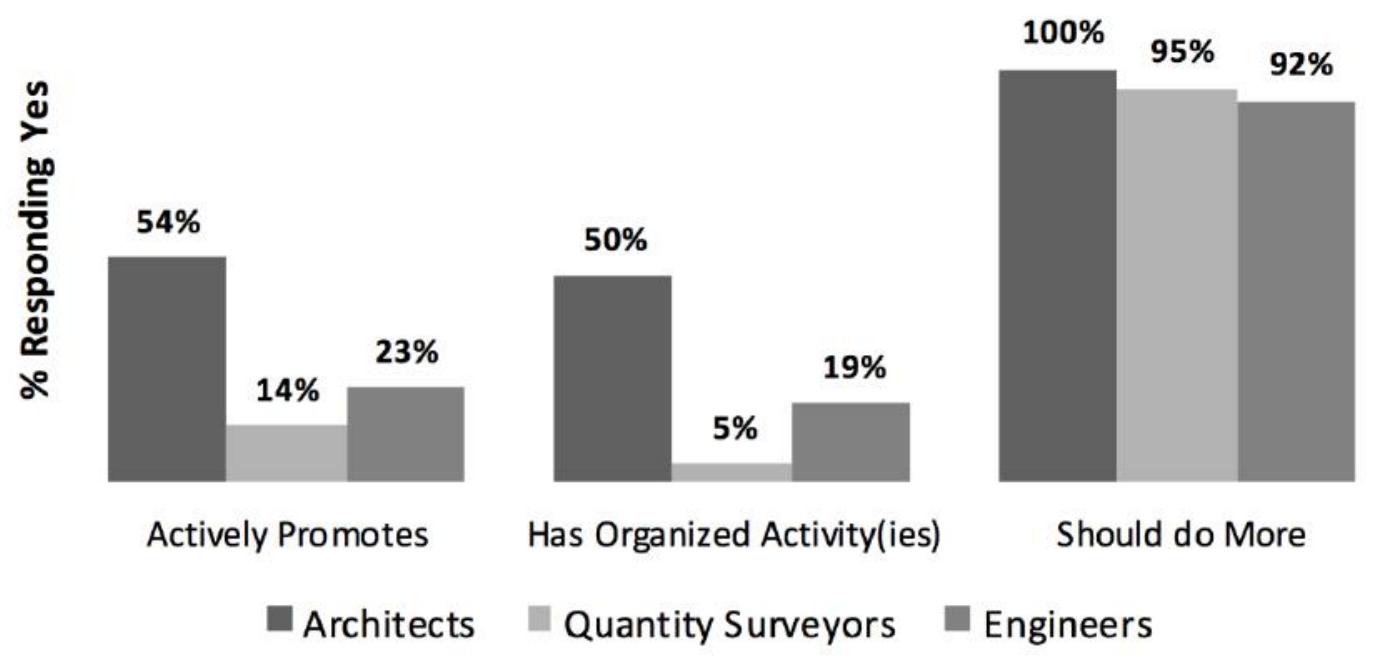

Figure 3. 5: Professional bodies' responses towards ensuring a sustainable built environment (Waniko, 2014)

\subsection{Environmentally sustainable design practices in Nigeria}

90.9\% of participants involved in a 2010 study by Obafemi Awolowo, University of Nigeria, considered ESD essential to the built environment; however, only $54.5 \%$ of respondents (including architects, engineers, and quantity surveyors) had a fair knowledge of ESD (Oladokun, Gbadegesin, \& Ogunba, 2010). This was validated by a similar survey conducted by Waniko (2014) on 78 professionals (Figure 3.6) from the building industry in Nigeria. The study discovered that most of the surveyed professionals were familiar with some aspects of ESD, and less than 22\% had received any form of education or training on ESD. Similarly, most of the respondents were not familiar with building rating systems, however, 70\% indicated a willingness to acquire more knowledge about ESD and subsequently adopt it in their work (Waniko, 2014). Waniko (2014) also identified that 49\% of the respondents felt the professional bodies are to be blamed for the lack of widespread implementation of ESD (Figure 3.7).

In Nigeria, architects are leading other professionals in terms of ESD awareness (Figure 3.6). This creates a strategic opportunity for architects to expand on this knowledge for when the demand for sustainability increases. According to ARCON (2019), the role of an architect in Nigeria is influenced by the definition of Architecture which "is the art and science of the theory and practice of design, erection, commissioning, maintenance, management and coordination of allied professionals inputs into a building, or groups of buildings forming a comprehensive institution, establishment or neighbourhood as well as any other organised space, enclosed or opened, required for human and other activities”. Therefore, the architect's role serves as a medium for the planning, design, construction, and maintenance of the built environment that is functional, appealing, culturally relevant, healthy, and sustainable. To achieve this, the architect's professional services include planning and urban design, preliminary design and feasibility studies, design and construction documentation and coordination of the entire construction team, construction economics, contract administration and monitoring, and project management (Allu \& Elimisiemon, 2017)

Architects are fundamental throughout the design process and should become more familiar with ESD, setting precedents for others to follow. Most of the studies and existing literature have been conducted from a broader employment spectrum, including architects, builders, engineers, etc., without emphasis on a particular profession. 


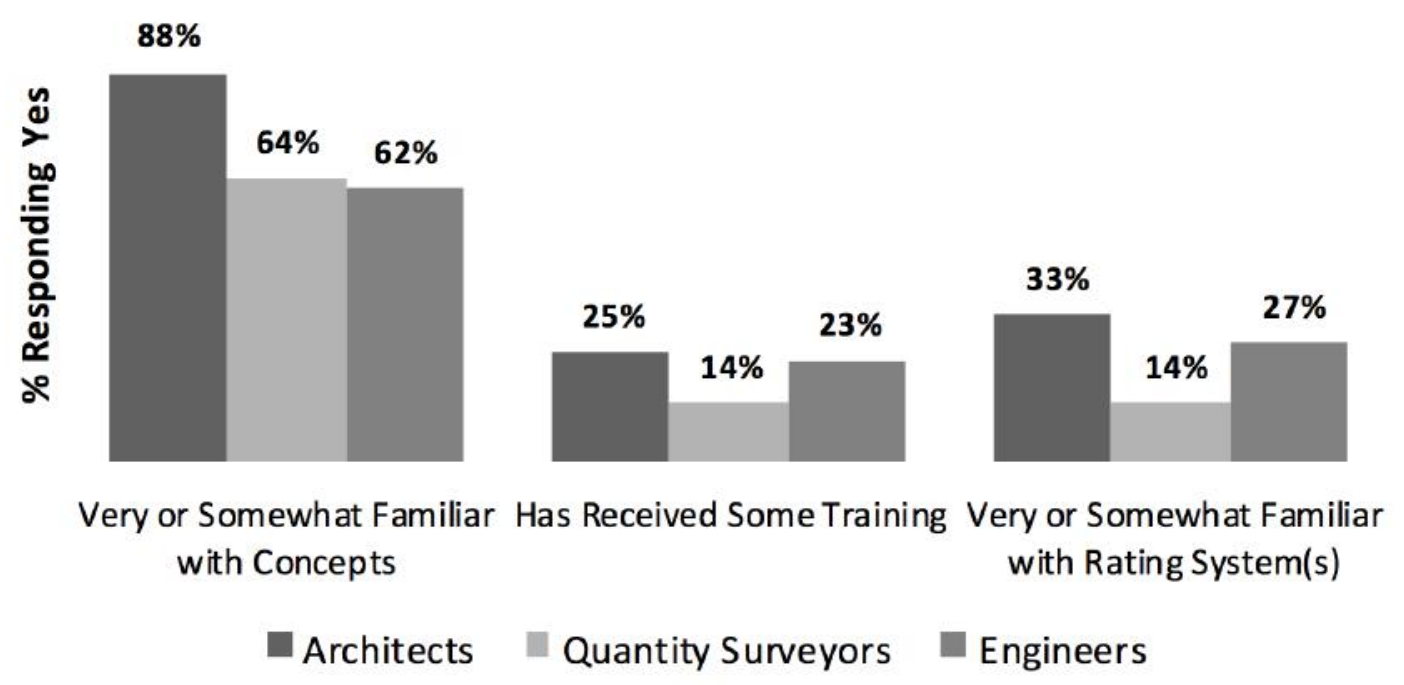

Figure 3. 6: Perception of building professionals towards ESD (Waniko, 2014)

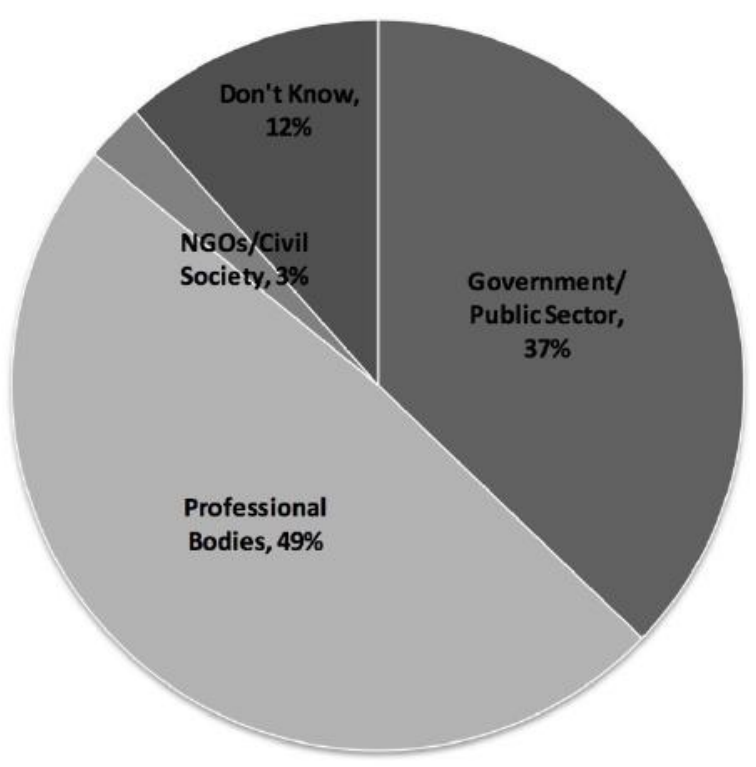

Figure 3. 7: Who is responsible for promoting ESDs in Nigeria? Adapted from (Waniko, 2014).

Dahiru, Dania, and Adejoh (2014) conducted a study to determine the Nigerian building industry's understanding of ESD; problems of ESD practice; benefits of ESD; the level of importance attached to the benefits; and the level of awareness of ESD. 95\% of respondents agreed that current building practice had a negative impact on the environment. In terms of the application of ESD, only $13 \%$ had adopted certain features of ESD. In terms of an integrated synergistic design process, 95\% of the respondents had not participated in the design production as part of a team, while only $5 \%$ indicated they had participated. Regarding ESD prospects in Nigeria, 85\% of respondents strongly agreed with the prospects of ESD (Dahiru et al., 2014). In a similar study by Abolore (2012) on the built environment perception on ESD in Nigeria, the results mirrored those of Dahiru et al. (2014), who found that $64.6 \%$ of the professionals (including architects, engineers, and surveyors) in the building industry were interested in ESD, 27.7\% were undecided, 7.7\% were not interested, and only $9.2 \%$ had adequate knowledge of ESD. In terms of the built environment perception towards ESD in Nigeria, Dahiru et al. (2014), reported that the concept was well accepted by 9.2\%, 67.7\% believed in the prospects but doubted the swift implementation, $13.8 \%$ believed ESD frameworks in Nigeria were not adequately structured, and $9.2 \%$ were undecided as to the concept of ESD in Nigeria. In terms of gaining substantial knowledge on ESD, $15.4 \%$ relied on published articles, websites, and newspapers, $10.8 \%$ believed that the bulk of knowledge should come from seminars and conferences, $12.3 \%$ relied on professional experience, and $61.6 \%$ believed that educational and higher learning institutions should be responsible for improving the knowledge of ESD in Nigeria (Dahiru et al., 2014). Overall the survey indicated an insufficient level of ESD implementation in Nigeria, with 60\% of the respondents either unaware of, or has failed to implement ESD measures to a significant extent. Some of the identified constraints included cost, lack of technological development, lack of awareness, social factors, poor governance and building codes.

According to similar studies by Abolore (2012), 12.3\% of the respondents stated that the lack of implementation was due to a lack of enforcement, 18.5\% indicated a lack of government intervention, $47.7 \%$ stated that it was due to poor education and lack of experience, 12.3\% cited economic factors, $4.6 \%$ blamed passive culture, and $4.6 \%$ were undecided as to what was responsible for the lack of implementation. This figure raises concerns about the architectural education system in Nigeria. Ogunrayewa et al. (2012), the National Universities Commission (NUC) stipulates the curriculum contents and specific subjects of study in schools of architecture in Nigeria and has been charged with overhauling the system. However, results have shown a curriculum deficiency, specifically in 
Chapter 3 | Nigerian response to environmentally sustainable design

the area of sustainability. Currently, there are various courses categorised into seven broad modules for architectural education by the NUC and parallel institutions, one of which is environmental studies, which briefly addresses sustainability (Allu, 2014). However, despite being taught about sustainability in this environmental study module which is less than $5 \%$ of the credit unit, arguably, most architectural students may be unable to apply the principles in practical terms if they are not encouraged to adopt aspects of sustainability studies in the architectural studio coursework, which is $40 \%$ of the credit units (Allu, 2016). According to Allu and Elimisiemon (2017), there is a need for architectural pedagogy in Nigeria to improve the integration of sustainability in the university curriculum and research and adopt it holistically in the university system. A similar study (Akeel, Bell, \& Mitchell, 2017) conducted on the Nigerian engineering educational curriculum suggests that the existing curriculum does not properly address sustainability. This implies that the issue is not unique to the architectural pedagogy. These constraints are not unique to the Nigerian context, as highlighted in similar studies concerning ESD application in the African continent (Ayarkwa, Acheampong, Wiafe, \& Boateng, 2017; Chan, Darko, Olanipekun, \& Ameyaw, 2018). The following section provides a review of the potential barriers to ESD.

\subsection{A review of the barriers to environmentally sustainable design practice}

Before embarking on a review of the Nigerian context, this study reviews the global perspective to establish any barriers that might be relevant to the Nigerian context.

In the United States of America (USA), the barriers to ESD adoption identified include the high cost of green building products and materials; cost premium; long payback duration; limited contractors; a tendency to retain existing practices; a lack of government incentives; and a lack of knowledge, skill and expertise (Table 3.5) (Chan et al., 2018). Irrespective of these barriers, a moderate level of growth in green activities are projected in the USA due to efforts by the government and private sectors such as LEED and regulatory implementation (DDA, 2018). The adoption of green practices is expected to grow from $32 \%$ to $45 \%$ by 2020 . The primary driver for the green market in the USA is client demand. Similarly, the need for an improved IEQ is widely recognised by $78 \%$ of respondents in the USA as a primary reason for adopting sustainable features in building construction (DDA, 2018).

In the United Kingdom (UK), a lack of client demand; cost; unavailability of green building products and materials; a dearth of information and awareness; lack of knowledge, skill and expertise; and insufficient building regulations were the primary barriers preventing widespread adoption of sustainable design methods (Darko \& Chan, 2017; Winston, 2010). In the UK, approximately 27\% of projects adopt green principles, with an expected growth of up to 40\% by 2021 (DDA, 2018). Like the USA, client demand is seen as a significant driver to going green, and many recognise lowering greenhouse gas emissions and environmental regulations as their primary motivation (DDA, 2018).

In Australia, cost; lack of information and awareness; lack of government incentives; inadequate building codes and regulations; lack of skill and expertise; and poor relationships between stakeholders were found to be the primary barriers to ESD adoption (Bond, 2011; Love, Niedzweicki, Bullen, \& Edwards, 2012; NZGBC, 2015). In Australia, 63\% of the Green Building Council of Australia (GBCA) members reported adopting sustainable methods in 60\% of their projects, with IEQ, client, and market demands as the primary drivers (DDA, 2018).

South Africa currently has some building projects adopting sustainable methods, with an expected positive growth by 2021 (DDA, 2018). Lower operating costs, healthier homes, and improved occupants' health and wellbeing are seen as the primary drivers promoting sustainable design practices in South Africa (DDA, 2018). In Ghana (Table 3.5), a geographical neighbour to Nigeria, the critical barriers to ESD identified were: lack of client demand for ESD; higher initial cost; unavailability of green building products and materials; lack of public awareness; lack of knowledge, skill and expertise; lack of information; lack of government support and incentives; inadequate building codes and regulations; lack of demonstration projects; conflict of interest amongst stakeholders; and a lack of green building rating tools (Chan et al., 2018; Djokoto, Dadzie, \& Ohemeng-Ababio, 2014). 
Chapter 3 | Nigerian response to environmentally sustainable design

Table 3. 5: Top five barriers to sustainable building technologies in Ghana in comparison to US, Canada, and Australia

(Chan et al., 2018)

\begin{tabular}{|c|c|c|c|c|}
\hline $\begin{array}{l}\text { Top five barriers to sustainable } \\
\text { building technologies in Ghana }\end{array}$ & Ghana & US & Canada & Australia \\
\hline $\begin{array}{l}\text { - High cost of sustainable } \\
\text { technologies }\end{array}$ & (rank 1) & (rank 2) & (rank 3) & (rank 2) \\
\hline - Lack of government incentives & (rank 2) & (rank 5) & (rank 6) & (rank 6) \\
\hline - Lack of financing schemes & (rank 3) & (rank 6) & (rank 13) & (rank 15) \\
\hline $\begin{array}{l}\text { - Unavailability of sustainable } \\
\text { technology suppliers }\end{array}$ & (rank 4) & (rank 14) & (rank 25) & (rank 13) \\
\hline $\begin{array}{l}\text { Lack of institutes and facilities } \\
\text { for research and development } \\
\text { of sustainable technologies }\end{array}$ & (rank 5) & (rank 11) & (rank 13) & (rank 23) \\
\hline
\end{tabular}

Table 3.5 shows a link between the barriers experienced in the different countries highlighted above. However, common issues are experienced in Nigeria, Ghana, and neighbouring African countries (Table 3.6). This could be broadly due to the lack of practical rating tools, inadequate regulations, lack of government support, limited knowledge on the benefits and means of adopting ESD, and a lack of societal demand (Ayarkwa et al., 2017; Oyefusi \& Adeyemo, 2019).

Table 3. 6: A summary of the top barriers identified in different African countries.

Country

Heilman (2016) Tanzania

Identified barriers

- Lack of awareness and understanding of the concept of sustainable design methods

- Absence of building codes and guidelines for promoting sustainable design

- Existing curricula in higher institutions do not encourage sustainability

- The perception and ego of developers and designers

- Perception of cost

- Lack of professional ethics

- The assumption that sustainable design is expensive

- Lack of understanding of the benefits of sustainable design

- Inadequate information of the economic benefits and opportunities of sustainable construction

- Lack of incentives for encouraging sustainable design and construction

\begin{tabular}{|c|c|c|}
\hline (Ayarkwa et al., 2017) & Ghana & $\begin{array}{l}\text { - Lack of client demand } \\
\text { - Lack of financial incentives } \\
\text { - Lack of legislation for encouraging sustainable } \\
\text { development } \\
\text { - Lack of awareness }\end{array}$ \\
\hline (Were, 2015) & Kenya & $\begin{array}{l}\text { - Lack of legislation and enforcement of sustainable } \\
\text { construction } \\
\text { - Lack of incentives from the government for encouraging } \\
\text { sustainable design and construction } \\
\text { - Lack of awareness }\end{array}$ \\
\hline (Oyefusi \& Adeyemo, 2019) & Nigeria & $\begin{array}{l}\text { - Lack of legislation and policies for enhancing sustainable } \\
\text { design and construction } \\
\text { - Perception of cost } \\
\text { - Lack of awareness and public enlightenment of the benefits } \\
\text { of suitability } \\
\text { - The technical and technological barrier }\end{array}$ \\
\hline
\end{tabular}

As noted above, in the USA, Canada, and Australia, client demand, adequate regulations, environmental consciousness, and awareness are the primary drivers of sustainability. However, this seems to be lacking in Nigeria, with results showing a lack of demand, inadequate regulations, and lack of general awareness (Elum \& Momodu, 2017; Wojuola \& Alant, 2017). This suggests that efforts in Nigeria need to be tailored towards improving awareness, client demand, and enacting adequate regulations for improving sustainability. 
Chapter 3 | Nigerian response to environmentally sustainable design

\subsection{Chapter conclusion}

This chapter began with a review of the Nigerian climate and geographical coverage to establish its climatic and geographical context. It discussed the high temperatures experienced in most states, even during the coolest periods, low wind speed, high humidity, and the potential impact on thermal comfort. Due to these climatic constraints, building occupants had to rely either on the building's ability to provide thermal comfort through its design, or auxiliary cooling systems, with the literature review suggesting a reliance on auxiliary cooling systems. However, given the erratic electricity supply from the national grid, occupants resorted to fuel generator sets for powering auxiliary systems. Fuel-powered generators are harmful to health and the environment through their contribution to carbon emission. This reinforced the need for environmentally sustainable methods for providing thermal comfort, energy generation, and a sustainable built environment in Nigeria. By expanding on ESD, a review of the architectural dynamics in Nigeria was conducted, revealing that the concept of sustainability reaches back to the medieval era. However, after the post-colonial era, there has been a shift from a more climatic responsive design approach to a less climatic and unsustainable approach. Some of which includes the reliance on auxiliary cooling, poor building orientation and ventilation

The review also investigated the current efforts in Nigeria towards ensuring a sustainable built environment, with results suggesting that the government and related institutions have made some efforts but that there is still significant work to be done. Some of these efforts include creating the Green Building Council of Nigeria (GBCN), the National Building Code (NBC) and the government's promise to achieve the sustainable development goals stipulated by the United Nations.

In relation to the literature so far, the problems of climate change, thermal discomfort and power generation have been discussed. ESD as a possible solution to these issues has been proffered as a viable solution, however, the literature review has shown a lack of mainstream adoption due to knowledge, technology, economic, social, and political barriers. It was also discovered that some of these barriers are not unique to Nigeria but could be experienced in other countries around the globe. Despite efforts such as the NGBC, Nigeria does not have an active rating tool or an effective NBC as found in most developed countries. This makes the Nigeria case open for further investigation with particular reference to architects and building owners regarding their perceptions of the barriers preventing ESD adoption. The next chapter provides a review of the theoretical models and research methods for understanding the possible barriers preventing ESD adoption in Nigeria. 
Chapter 4 | Design and methodology of study

Chapter 4 | Design and methodology of study 


\subsection{Introduction}

As already established, while there are real advantages to using ESD, it seems that these are not commonly applied. Against that general backdrop, this chapter investigates the barriers preventing the adoption of ESD. Given that the architect's and building owner's role is vital in shaping the built environment, it is essential to investigate the architect's and building owner's reasons for not adopting ESD or their perceived barriers to ESD adoption. To examine these barriers, this chapter provides a review of the theoretical model for barrier identification. It concludes with a mixed-method research approach suitable for investigating the potential barriers to ESD.

\subsection{A review of the theoretical models for barrier identification}

This section aims to review the theoretical models for understanding the possible barriers preventing ESD adoption in Nigeria. Having reviewed existing literature, it was found that some theoretical models exist for barrier identification within the field of psychology, socioeconomics, and the broader discourse of sustainable development. These models include transition dynamic framework or transition management, theory of reasoned action (TRA), technology acceptance model (TAM), the model of psychological barriers to behaviour change, and the model for barrier identification. However, having reviewed these models, it was identified that the model for barrier identification was most suitable for this study. According to Walliman (2017), the selected model in any study must adequately address the research problem whilst providing answers to the research questions and an in-depth understanding of the research aims and objectives

\subsubsection{Model of barrier identification by Trudgill}

The Trudgill (1990) model of barrier identification and classification suggest that the barriers hindering the development of a sustainable built environment may be classified into six categories: agreement, knowledge, technology, economic, social, and political barriers (Figure 4.1). The model of barrier identification provides a good structure for addressing the research aims and objectives because of its comprehensiveness. The following sections provide a review of Trudgill's model in relation to other studies conducted on the barriers preventing ESD adoption.

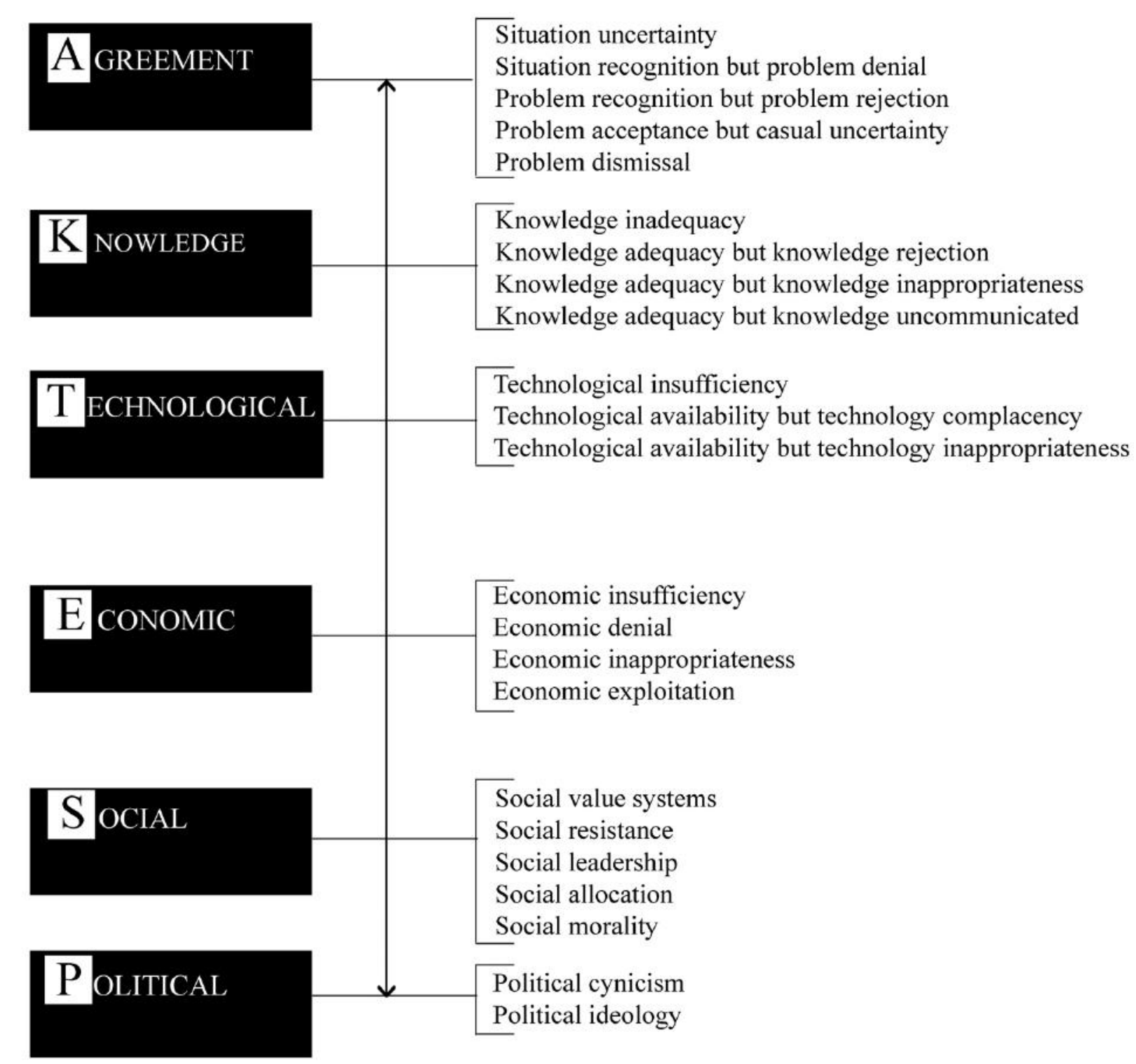

Figure 4. 1: Model on barrier identification and classification (Trudgill, 1990). 
Chapter 4 | Design and methodology of study

\section{- Agreement as a barrier to ESD}

The agreement barrier in any setting can ultimately involve a disagreement about the specific environmental goals of the society; the diversity on the scope and importance of environmental problems and solutions, specifically how solutions should be implemented into the society; and disagreements of what constitutes a problem. According to Trudgill (1990), for a sustainable built environment to be realised, there should at least be some level of agreement on the prevalent problem. In Nigeria, existing studies have highlighted the impacts of climate change and global warming and the resulting adverse effects on the environment and indoor thermal comfort (Amasuomo \& Amasuomo, 2016a; Elum \& Momodu, 2017; Okafor, 2018). Due to rising temperatures, building occupants are often faced with reducing heat gain in the building. The inability of the building to keep out heat usually leads to occupants' being in thermal discomfort and using mechanical devices to provide relief (Okafor, 2018). In relation to Trudgill's (1990) model, some level of commitment towards a resolution and a consensus on the problem of thermal discomfort in the internal spaces of residential buildings must be reached before a solution can be proposed. This framework adopts the position that in an attempt to achieve a better environment, there is a consensus that prevalent barriers exist and that they need to be addressed. A study conducted by AsekunOlarinmoye et al., (2014), illustrated that most respondents exhibited a good level of agreement on the problem of climate change and global warming when it comes to addressing the issue of rising temperatures, flooding etc. however, a disagreement ensued when it came to reducing the anthropogenic factors that influence climate change and global warming.

Expanding on this, Gifford (2011) stated that the issue of agreement, as opposed to denial, could also be a troubling barrier for ESD adoption. This is because a positive transformation cannot occur so long as climate change and the resulting impact are not seen as a problem. For instance, let us assume a general agreement is reached on the issue and a commitment established towards addressing the problem; research has shown that in most cases, solutions offered for environmental problems only uncover other aspects of the problem requiring resolution. This could include economic or socio-cultural issues (Howes et al., 2017). These socio-cultural problems include people feeling that climate change and sustainability are paramount, but only a few are engaged in adequate mitigating actions or behaviours to reduce negative environmental impact (Booth, Hammond, Lamond, \& Proverbs, 2012; Gifford, 2011; Howes et al., 2017). Gifford (2011) stated that structural barriers such as agreement, knowledge, technology, economy, social and political, or a poor environmentally sensitive structure are part of the answer as to why these behaviours occur. However, psychological factors also act as a barrier through the behavioural choices that would either facilitate or impede ESD adoption.

The issue of agreement as a barrier is somewhat prevalent within the Nigerian context, with some Nigerians still not recognising nor accepting the urgency for pro-sustainable actions and the resulting impact these could have on the environment and health (Atanda \& Olukoya, 2019; Irouke \& George, 2016; Nwabueze \& Egbra, 2016). A study by Wojuola and Alant (2017) on the public perception of renewable energy in Nigeria showed that in some cases, people might agree on a problem and pursue a possible solution, however, lack of awareness constantly affects people's decisions and poses a barrier to attaining a sustainable built environment. The results in Chapter 5 provide insight into architects' and building owners' perceptions of ESD to establish if the agreement barrier is prevalent in Nigeria and how that impacts the adoption of ESD.

\section{- Level of knowledge as impediments to the adoption of ESD}

The lack of knowledge on environmentally sustainable design methods has been reported in several studies as a barrier to ESD adoption in Nigeria (Akinola et al., 2018; Dalibi et al., 2017; Elum \& Momodu, 2017). As noted, a lack of knowledge on the benefits of a sustainable built environment can significantly impact an individual's ability to make a pro-sustainable decision. In some cases, there might be a general agreement and commitment towards ensuring a sustainable built environment, however, the knowledge and awareness of the right way forward might be unknown (Trudgill, 1990). The issue of knowledge as a barrier to ESD is extensive. It covers not only formal education as it relates to the provision of knowledge, but also includes the role of professional institutions, government and the media in the propagation of sustainability. According to Howes et al. (2017) the knowledge barrier could be divided into three broad themes: firstly, lack of comprehensive research into environmental problems or solutions in the case of energy production, carbon dependence, and bio-security; secondly, general misconceptions on the cause of environmental issues; and thirdly, inadequate understanding with regards to the impacts of environmental policies.

Similarly, Trudgill (1990) summarises the knowledge barrier into three main categories. First, knowledge in the form of evidence about the causes of environmental problem may or may not exist, and in the event of its existence, there may be contradicting interpretations of its adequacy. Secondly, problem clarification or solution is usually gained through scientific processes, and achievement may prove difficult in practical societal circumstances; this may be because the knowledge is not holistic enough; hence, 
despite being clear in scientific terms, it may not be in layperson's terms. Thirdly, knowledge might be perfectly appropriate and valuable but may be communicated poorly to individuals who need it to make rational decisions (i.e. clients and policymakers). This implies that the propagation of sustainability should extend beyond the confines of the university or other formal learning institutions to include adequate education of the public through informal methods. This improves public awareness of the benefits and importance of sustainability and can cause a cultural shift towards a more pro-sustainable environment (Trudgill, 1990).

Having insufficient knowledge about tackling environmental issues or an inability to seek knowledge that is not widely available, may be additional hurdles in implementing a sustainable built environment. Existing studies in the Nigerian context showed that individuals who were knowledgeable about sustainability were more environmentally conscious and more likely to adopt ESD (Wojuola \& Alant, 2017). Individuals with less knowledge about sustainability were less conscious and less likely to adopt ESD due to unwillingness to use methods that were not mainstream, specifically those that are slightly expensive (Elum \& Momodu, 2017; Wojuola \& Alant, 2017). According to Elum and Momodu (2017) lack of knowledge in the Nigerian context negatively affects the public perception of sustainability and the possibility for positive policy reforms for encouraging a sustainable built environment in Nigeria. For the knowledge barrier to be abated in Nigeria, the educational curriculum needs to be broadened to promote sustainable development, specifically for architectural education and related professions (Allu, 2016). Similarly, Nwabueze and Egbra (2016) noted that informal and formal education through the media and institutions is greatly needed for improving public awareness on the benefits and need for a sustainable environment to elicit a cultural change towards sustainability. This study research aim and objectives have been tailored to understand better the impact of knowledge as a barrier to ESD adoption in Nigeria.

\section{- Level of technological development as an impediment to the adoption of ESD}

In addition to a lack of knowledge, the existence and appropriateness of technology could also become a barrier. According to Trudgill (1990), lack of technology rarely seems to be a significant problem. If the problem has been established and the knowledge is available, devising a technology for solving the problem becomes more straightforward. However, the problem now becomes the appropriateness of the developed technology or the source of the technology. As stated by Pearce and Ivana (2012), the technological barriers include appropriate technology seen as inferior or inadequate (mainly locally-sourced technologies such as vernacular architectural methods); cultural appropriateness; issues of technical robustness; transferability and suitability within the current social and economic systems; and lack of funding and support from the public and private institutions. According to Wojuola and Alant (2017) technological barriers identified in Nigeria include a lack of sustainability measurement tools; lack of exemplary and demonstrative projects; absence of guidance; lack of technical ability; and chronic shortage in skill and labour to implement sustainable construction. These barriers are considered technical because they directly impact and play a role in implementing a sustainable built environment (Ametepey, Aigbavboa, \& Ansah, 2015). In the event of technological availability, two primary issues exist:

- Complacency: people become fixated on the available technology, despite its impact on health and the environment. Trudgill (1990) uses the term' technological fix' to describe this fixation. Research has indicated, for example, that, despite the cost of air-conditioners and running generators, most Nigerians are still fixated on using these devices as opposed to passive cooling techniques (Opara \& Kfuban, 2014; Roche, 2017).

- Knowledge and ability to operate renewable technology: despite a general agreement and a good understanding of the benefits of ESD, the adoption of ESD could still face some opposition. This resistance may be due to a lack of knowledge to adopt renewable energy technologies (Chan, Darko, \& Ameyaw, 2017). Wojuola and Alant (2017) found a positive correlation between perceived usefulness, ease of use, and willingness to use renewable technology. Essentially, lack of information on how renewable technologies work, cost, and the inability to operate them may negatively affect renewable technologies. In some instances, these technologies could include basic features such as stack ventilation or windcatchers. 
Chapter 4 | Design and methodology of study

\section{- Economic factors as an impediment to the adoption of ESD}

Economic and cost-related factors such as the high initial cost of renewable and efficient technologies and lack of financial incentives from the government and financial institutions have been reported as impediments to ESD adoption in Nigeria (Dalibi et al., 2017). According to Trudgill (1990), the primary factors within the economic barrier are how and who pays and what are the benefits. In terms of the how and who pays, this revolves around the financial structure of any given society, which Gifford (2011) refers to as a structural barrier. Low-income earners, for example, are typically unable to purchase solar panels because of the cost, specifically when there are no financial incentives or loans. In such situations, Gifford (2011) recommends that the structural barrier has to be eliminated before addressing any other barrier. A comparative analysis showed that while most barriers to ESD may vary between developed and developing countries, the initial cost of ESD remains a barrier globally (DDA, 2018). Cost is considered a barrier specifically because the initial cost of most renewable and efficient technologies is higher than its inefficient counterparts; industry practitioners report a $10-20 \%$ increase in construction cost (Chan et al., 2018). In developing countries like Nigeria, where incomes are low and inflation high, the slightly higher cost of ESD could also affect its affordability, specifically when there are limited financial incentives and support from the government and financial institutions (Dalibi et al., 2017).

In terms of the economic benefits of ESD, this involves an awareness of the long-term benefits over the short-term benefits associated with renewable and efficient technologies. Trudgill (1990) refers to the short versus long term benefit as the time-scale factor. Existing studies in the Nigerian context illustrate that most people were discouraged from adopting renewable and efficient technologies because of the slightly higher initial cost, opting instead for, for example, a generator set that requires a high running cost (Roche, 2017). For Nigerians who can afford to purchase and constantly run a generator set, there is a higher possibility that they will opt for renewable and efficient technologies if they are knowledgeable about the long-term financial benefits (Aliyu et al., 2015). In Nigeria, the idea of renewable and efficient technologies is relatively new, making it difficult to convince stakeholders in the construction industry to adopt them, specifically those who are not knowledgeable of their benefits. A study in Nigeria showed that those respondents who were not knowledgeable about ESD were less likely to adopt them because of the perceived financial risk (Wojuola \& Alant, 2017). According to Trudgill (1990) when the time scale factor becomes a barrier, people need to be constantly educated about the long-term benefits.

\section{- Social factors as an impediment to the adoption of ESD}

Social factors have been known to impact the adoption of ESD, especially in culturally driven societies like Nigeria (Dalibi et al., 2017). According to Trudgill (1990), environmental issues are socially determined and should be squarely resolved by tackling social issues. In parallel, environmental issues like thermal discomfort can cause stress, therefore tackling environmental problems in an integrated fashion either through design or policy is paramount and beneficial to society. Lorenzoni, Nicholson-Cole and Whitmarsh (2007) argue that the solutions to environmental change are as crucial as the democratic process and that there has to be an "engagement" that reflects a personal connection with environmental issues; to be effective, this engagement must be devoid of any financial motive. A lack of individual engagement encourages political salience, hinders the enactment of favourable environmental policies, and decreases the ability for public and private institutions to fund and promote sustainability. Macnaghten and Jacobs (1997) also argue that achieving environmental sustainability becomes difficult unless individual engagement is resolved. Once the social aspect of engagement has been resolved, the political sphere will be encouraged to enact favourable policies and incentives. Schultz et al.'s (2007) study on the constructive, destructive, and reconstructive power of social norms on residents of a community towards adopting an environmentally friendly behaviour revealed that residents' willingness or otherwise to reduce the amount of household energy consumption was strongly influenced by the normative information they received. It was observed that high-energy-consuming households reduced their energy consumption when they were informed about the low-energy consumption of their neighbours. This theoretical account reflects the dramatic impact social norms have on the adoption or lack of adoption of ESD. It also explains the impact a lack of knowledge and information could have on an individual's motivation or amotivation to adopt ESD. Similar studies show a strong correlation between awareness and the public acceptance and adoption of ESD in Nigeria (Akinola et al., 2018; Giwa et al., 2017; Wojuola \& Alant, 2017). The success of an environmentally sustainable society begins with the society. It depends on the support and participation of the general public, specifically at the local level (Macnaghten \& Jacobs, 1997; Trudgill, 1990). Hence, for ESD to be completely adopted in Nigeria, there must be an acknowledgement and widespread identification and support by the general public, which would affect the building regulations and encourage stakeholders in the building industry to act appropriately. 


\section{- Political factors as an impediment to the adoption of ESD}

The adoption of ESD to mitigate thermal discomfort problems and energy generation issues in Nigeria has also been impeded by poor governance. Environmental sustainable issues have not been adequately addressed because of Nigeria's lack of political enablement (Gberevbie, Joshua, Excellence-Oluye, \& Oyeyemi, 2017). This enablement involves enacting policies to encourage a more sustainable built environment (Abisuga \& Okuntade, 2020; Zhang \& Wang, 2017). This encouragement could also be in the form of actions that will support the reduction of social, economic and environmental degradation; extensive human and financial resources to support environmental conservation; training of professionals; public enlightenment campaigns on causes and solutions; and the implementation of such enactments by physical and social scientists committed to generating scientific information which will add to the creation, implementation and continual modification of environmental policies and programs (Trudgill, 1990). This implies that at every stage, the problem, causes, and solutions to environmental issues are understood and effectively communicated both in physical and social terms. Macnaghten and Jacobs (1997), also indicate that the success of environmental sustainability relies on the widespread identification and support from the government, the private sector and the local level. For instance, for an agreement to be reached on the need to adopt ESD, there has to be some level of awareness of the benefits of ESD by stakeholders. Similarly, the technological barrier is closely related to the availability of the right knowledge to develop, adopt and maintain renewable and energyefficient technologies. With an awareness of the long-term economic benefits of ESD, people are more likely to adopt these methods. Finally, the social and political factors are closely associated. With public knowledge and support for ESD, the government is more likely to enact favourable policies to encourage a more sustainable built environment in Nigeria.

Trudgill's (1990) structural theoretical model of barrier identification is relevant to the present study because it outlines the barriers to sustainability from an encompassing perspective that could be adopted, not just in architecture but in any related field. The theoretical model states that there must be a consensus for a sustainable built environment to be achieved. The level of knowledge, technological development, economic, social and political barriers that impede the development of a sustainable built environment must be eliminated to a reasonable extent. In this study, the structural theoretical model of agreement, knowledge, technology, economic, social, and political barriers have been considered for further investigation within the Nigerian context.

In relation to the literature so far, the problems of climate change, thermal discomfort and power generation have been discussed. ESD as a possible solution to these issues has been proffered as a viable solution, however, the literature review suggests a lack of mainstream adoption due to the barriers mentioned in the previous paragraphs. It was also discovered that some of these barriers are not unique to Nigeria but could be experienced in other countries around the globe. Despite efforts such as the NGBC, Nigeria does not have an active rating tool or an effective NBC as found in most developed countries. This makes the Nigeria case open for further investigation with particular reference to architects and building owners in terms of their perceptions of the barriers preventing the adoption of ESD. The following sections provide a mixed-method research approach suitable for investigating the potential barriers to ESD. 


\subsection{Research method}

The previous section conceptualised the problem by providing a hypothesis for the barriers preventing ESD adoption in Nigeria. The literature review suggested various barriers that may prevent architects and building owners from adopting environmentally sustainable design methods (ESD). They include a lack of technological development, cost of building construction and operation, public perception, poor governance, and a lack of knowledge on the benefits and means of adopting ESD. To examine these barriers, the study is divided into three stages (Figure 4.2):

Stage 1: Distribution of questionnaires to registered architects in Nigeria

Stage 2: Interviews with registered architects in Nigeria

Stage 3: Distribution of questionnaires to building owners in Nigeria and a visual survey of their respective buildings

\section{Quantitative}

Distribution of questionnaires to architects. Architects selected based on homogenous sampling.

2 Qualitative

Interviews with architects to provide deeper insight and validate responses from stage 1 . Architects selected based on homogenous sampling.

\section{Quantitative \& Case Study}

Distribution of questionnaires to building owners to establish general awareness and perception of ESD. Respondents selected using cluster sampling.

The use of a checklist to conduct a physical survey of buildings. This includes establishing the level of ESD adoption in the buildings through a visual survey of the building and asking the owners questions when in doubt. Cases selected using cluster sampling.

Figure 4. 2: Stages for the mixed-method research design (Image Source: Author)

In stages 1 and 2 of the study, the survey was conducted on the members of the Architects Registration Council of Nigeria (ARCON). Most of the registered architects in Nigeria generally work in architectural firms or as sole practitioners, and a significant majority of the firms are usually small-scale practices (Ibem, Aduwo, \& Ayo-Vaughan, 2017; Ibem, Akinola, Erebor, Tolani, \& Nwa-uwa, 2018). In stage 3 of the study, it was essential to review existing residential buildings in Nigeria with sustainable or green certification. To achieve this, the study initially planned to sample LEED-certified residential buildings in Nigeria, however, there is only one LEEDcertified residential building in Nigeria, and that is yet to be completed. In re-outlining the case study, the study implemented a purposeful sampling technique for selecting buildings and their respective owners. This decision was made based on the following criteria:

- Regulated settlements with good infrastructures. This is because such settlements are more likely to have buildings designed by architects that would have gone through the building consenting process.

- Specific locations with housing developments built after the enactment of the National Building Code (NBC) in 2006. This is because houses constructed during this period would be required to comply with the building code.

- Cost, time and availability of resources for the study in those locations.

- The selected states to represent at least three out of the six geopolitical zones in Nigeria (Table 3.1).

Based on these criteria, the scope of the study in stage 3 was limited to four states (Figure 4.4): Bayelsa and Rivers (representing the South-South geopolitical zone), Lagos (representing the South-West geopolitical zone), and Abuja (representing the North Central geopolitical zone). Located in the southern part of Nigeria, Bayelsa State was created out of Rivers State in 1996, and as a result, there has been ongoing new residential development due to the oil riches. A relative number of the populace are civil servants and fall under the middle-class social stratification (NCDMB, 2019; NYTimes, 2011). According to Williams (2008), Port Harcourt, the capital of 
Rivers State, is a major seaport (Figure 4.4) with a vast presence of multinational firms and the petroleum industry, with modern residential developments. It has a mix of different social classes. Rivers State and Bayelsa State were conveniently close in proximity to each other. Located in the south-west, Lagos and its adjourning conurbations are the largest city in Nigeria and one of the fastestgrowing in the world. It is the commercial hub of Nigeria with the highest GDP and a significant financial centre in Africa. It is also considered the gateway to innovations in Nigeria (BBC, 2018). In contrast, Abuja is the capital of Nigeria and the centre of national affairs. There are ongoing public and private investment in housing infrastructures in Abuja. It is Nigeria's administrative and political centre and a key capital in the African continent due to Nigeria's political influence in the continent. It is located in the middle belt (i.e. central part of Nigeria) and considered one of the fastest-growing cities in Africa. The master plan of Abuja and its building regulations is deemed to be preeminent in Nigeria, and it exemplifies the results of recent building regulations and policies (Elleh, 2001), thus it is well suited for this study. Like the other states mentioned above, it has a mixed social stratification. In addition to the above criteria, the study could not survey other states in the Eastern and Northern parts of Nigeria due to political and security unrest in those regions.

In order to understand the possible barriers preventing the adoption of ESD, the study adopted a mixed-method research approach. This method involves using multiple strategies ranging from surveys, interviews, and case studies, providing adequate checks and validation whilst complimenting each strategy. This chapter outlines the development of a mixed-method research approach purposefully designed to overcome the restraints specific to each method.

\subsection{Mixed-method research approach}

This research aims to uncover barriers to ESD adoption in Nigeria from the architects' and building owners' perspectives. In order to achieve this, the selected research approach should address the research aims, objectives, and questions. As noted by Walliman (2017), it is essential for the researcher to choose a method that meets the specific aim and objectives of the study. The proposed method must provide answers to the questions posed by the research, whilst mindful of the funding for the research, personal skills, training, and safety of the researcher. According to Groat and Wang (2013), there are different research strategies within the field of architecture with differences in their method of data collection, sample sizes, integration, and analysis of the collected data at one or more stages in a specific study, with data collected concurrently or sequentially to address the research aims and objectives (Creswell \& Plano, 2011; Tashakkori \& Charles, 2010). Considering the complexity of investigating the respondents' perceived barriers towards the adoption of ESD and based on this study's specific aims and objectives, a mixed-method research approach was most suitable to provide the required results. According to Harford (2008), a person's interest or lack of interest in a topic will theoretically affect their response. Therefore, an approach to obtain unbiased evidence from respondents is needed. The mixed-method research approach was selected due to its proficiency in confronting the complexities surrounding a respondent's cognitive rationale whilst expanding on the scope and improving the analytical power of the study (Sandelowski, 2000).

Researchers in various fields, including architecture, are increasingly encouraging a mixed-method research approach in which multiple methods are integrated into one study both quantitatively and qualitatively. This integrated method provides appropriate checks and validation against the shortcomings in either the quantitative or qualitative approach while concurrently enabling benefits to complement each other (Groat \& Wang, 2013). According to Greene (2007), the mixed method is advantageous in fields involving a dynamic interplay with creative practice in highly practical areas. These fields, such as architecture, depend upon the dynamic relationship between "thinking/knowing and acting/doing" (Greene, 2007; Groat \& Wang, 2013). A mixed-method research approach is defined as the collection, analysis, and integration of both quantitative and qualitative data at one or more stages in a specific study with data collected concurrently or sequentially to address a single research problem. The mixed-method design presents a complete integration of two or more research designs (Creswell \& Plano, 2011; Tashakkori \& Charles, 2010). In this study, the mixed method was designed to conduct a quantitative, qualitative, and case study in comparable sequences with an approximately equal level of emphasis. According to Sandelowski (2000), a mixed-method study is concretely operationalised at the technique level. That is, at the level of sampling, data collection, and analysis. This is not an integration of paradigms of inquiry, but rather paradigms are reflected in the techniques the study chooses to combine and how and why they were the desired choice. As noted by Groat and Wang (2013) the advantages of this approach are the ability for each research design to complement the other through this systematic combination. This combination allows for innovative uses of various techniques for multifaceted purposes (Creswell \& Plano, 2011). These include: 
- Triangulation, to achieve/ensure verification of data, or convergent validation

- Complementarity, to clarify, explain or elaborate on the results of the analysis

- Development, to serve as a guide in using additional sampling, data collection and analysis technique (Greene, Caracelli, \& Graham, 1989; Sandelowski, 2000).

For this study, methodological triangulation is used in sequence. This begins with the distribution of questionnaires to architects to establish their views on ESD and the perceived barriers to its optimum adoption (i.e. quantitative method), followed by an interview with architects to validate the data collected through the distribution of questionnaires to architects (i.e. qualitative). This is followed by distributing questionnaires to building owners to establish the general awareness and perception of ESD (i.e. quantitative method) and a visual survey of their respective buildings using the developed checklist (i.e. case study). According to Morse (1991), the combination of different methods at different stages through triangulation ensures validation of the survey data.

One of the most crucial features of a mixed-method research approach is distinguishing between a qualitative and quantitative inquiry. While the qualitative approach typically involves purposeful sampling to heighten understanding of the information-packed case, the quantitative approach involves probabilistic sampling to permit statistical inferences to be made (Patton, 2014). While purposeful sampling is tailored toward the development of idiographic comprehension for the generalisation of individual cases, probability sampling is tailored towards nomothetic comprehension from the generalisation of samples to populations (Sandelowski, 2000). Notwithstanding key differences, each technique is combined in this study to deepen the insights generated. This is achieved by adopting homogenous and cluster sampling to generate different fundamental data sets, as will be described below.

\subsubsection{Homogenous sampling}

Homogenous sampling involves the sampling of cases or data sets based on their similarities to each other. Cases are chosen from a small homogeneous sample to provide an in-depth understanding of the sample (Patton, 2014). In this study, for example, the homogeneous sample comprises architects in the Nigerian context to understand specific barriers preventing ESD adoption. Suri (2011a), the homogenous sampling helps overcome the frequent criticism of 'mixing apples and oranges' whilst improving meaningful comparison within the study design and conceptual scope. In addition, this sampling technique is particularly suitable for participatory syntheses, within which the synthesis co-synthesises research with practitioners about a phenomenon with a direct impact on their practice (Suri, 2007).

In this study, homogenous sampling is undertaken in stages 1 and 2. Based on the results from stage 1, further observations and interviews were conducted on the homogenous sample for stage 2. To achieve a range of responses, the participants in stage 2 were different from those who participated in stage 1. For stage 2 of this study, participants were recruited by contacting the accredited members on the ARCON list practising in Lagos, Abuja, Rivers, and Bayelsa State with telephone numbers listed but not email addresses. Despite being a homogenous sample, it was envisaged that the results from the study would be divided into three main groups: architects who are knowledgeable about ESD and adopt them frequently; architects who are knowledgeable about ESD but do not adopt them frequently; and architects who have limited knowledge about ESD. In the process of sampling for complementarity, the study will inevitably obtain information on convergent validity and also achieve the triangulation purpose (Sandelowski, 200o). In addition, a statistical test of homogeneity was conducted to ensure no violation of homogeneity.

\subsubsection{Cluster sampling}

This sampling technique is employed when there is a large pool of potentially rich information with no apparent reason to choose one case over another in the specified group or when the researcher cannot source information about the population as a whole but can obtain information about clusters (Walliman, 2017). In certain instances, it is almost impossible to conduct a purposeful sampling tailored towards an in-depth study of cases due to a large number of available options (Uzoagulu, 2011). In this study, these challenges were envisaged, and therefore cases will be chosen from each cluster representing specific neighbourhoods within the selected states that meet the criteria as stipulated in Section 4.3. Within each neighbourhood, numbers representing different house addresses were drawn from a random number table. Each drawn case was required to meet the specified criterion in all purposeful sampling (Sandelowski, 2000). This method enabled the study in stage 3 to provide a good description of the cases and establish barriers to ESD and the level of ESD adoption in the Nigerian residential sector (Tashakkori \& Charles, 2010). 


\subsection{Focus population}

The population of the study was comprised of two groups. The first group consisted of the 2,815 accredited architects in Nigeria based on the current register of accredited architects published by ARCON (2015). These architects were either employed in the private sector (architectural firms), public sector (government organisations like ministries, etc.), or the educational sector (university and polytechnic lecturers, or employment in the estate and works department). The second group were the building owners who have their properties in Abuja, Lagos, Rivers, and Bayelsa. A population of 142 building owners was used for the study selected through cluster sampling.

\subsection{Ethics and data collection}

Ethical approval was obtained from Victoria University of Wellington's (VUW) Human Ethics Committee before the commencement of the survey. An electronic copy of the ethics application form, information sheet for participants, and consent forms for the various stages of the study, architects' questionnaire and interview questions (Appendix A), building owners' questionnaire and survey checklist (Appendix B) were sent to the VUW's Human Ethics Committee. The ethics application for the pilot study was sent in May 2017, stage 1 and 2 was sent in September 2017, and stage 3 in November 2017. After meeting the committee's request for minor amendments such as changing the letterhead for all documents, stating that the interview would be recorded, and including consent for photos and measurements, approval to conduct the pilot study was received in July 2017, stages 1 and 2 in November 2017, and stage 3 in December 2017 respectively (Appendix C). Once ethics approval had been obtained, each stage of the study was activated. The following sections provide an overview of the different stages.

\subsection{Pilot study}

A pilot study was conducted among a sample of architects and building owners in Nigeria. The pilot study was divided into six categories based on barriers identified in the literature review, the model of barrier identification (Trudgill, 1990), and questionnaires used for similar studies (Baird, 2010; Christie, 2010; Shari, 2011; Wittmann, 1998). The six categories include agreement, knowledge, technology, economic, social and political barriers. Using a six-point Likert-type scale, each category was tested to establish if the proposed survey would sufficiently address the research aims and objectives. In addition, the purpose of the pilot study was to gather a preliminary understanding of the Nigerian architects' and building owners' perceptions of ESD and test the hypothesis already established in the literature review. In particular, the objectives were:

- Highlight and test the validity of the questionnaire

- Ensure clarity and unambiguity in the questionnaire

- Check the effectiveness and relevance of the research

- Estimate the expected cost and duration of the main survey

- Ascertain the response rate from Nigerian architects and building owners

The initial plan for the pilot study was to distribute the questionnaires to 20 people, however, following poor response rates, it was distributed to 38 people. These individuals were not used for the main study. The initial decision to conduct the survey on a sample size of 20 people was based on studies that had validated a survey of five people as a reasonable number in terms of efficiency (Lancaster, Dodd, \& Williamson, 2004; Nielsen, 2000). The original sample size was similar to those used in Christie's (2010) and Shari (2011). The study was administered to 10 practising architects and seven building owners in Nigeria on the $23^{\text {rd }}$ of July 2017 , with only two responses within two weeks. Following this poor response, the questionnaires were sent out to 11 more practising architects and ten building owners. With consistent follow-ups, 18 responses were received, making a total of 20 completed questionnaires within two months, representing a $55 \%$ response rate. This provided an insight into the response rate that would be expected in subsequent stages. The questionnaires for the pilot study were sent out via email using Qualtrics. The data was analysed on Qualtrics, QDA Miner, and SPSS. In addition to the distribution of questionnaires, the pilot study also conducted interviews with 5 participants selected using a non-random sampling technique. The sample size chosen consisted of doctorate students at the Victoria University of Wellington who have practised architecture in Nigeria. 


\section{Chapter 4 | Design and methodology of study}

\subsubsection{Question content and sequence}

The questionnaire was divided into six fundamental categories: agreement, knowledge, technology, economic, social and political barriers. Each of these sections was sequentially linked to ensure consistency. As Dillman et al. (2009), noted there are five distinct types of question content: attributes, beliefs, knowledge, attitudes, and behaviour. These features were all incorporated into the survey. The questionnaire consisted of structured and open-ended questions. Structured questions with scaled responses are appropriate for when respondents are required to evaluate a particular problem (Fink, 2015), as in this study, where participants are asked to identify barriers to ESD. The open-ended questions were used to identify a range of possible responses (Dillman et al., 2009) and address those aspects that were possibly not covered in the questionnaire. In addition, the open-ended questions formed a good foundation for stage 2 of the study, which was the interview with architects.

\subsubsection{Notes from the pilot study}

It was acknowledged that the time, finance, administrative and constant follow up imposed significant constraints on the study. Despite efforts to boost the study by phone calls, snowballing, and sending out the questionnaire directly to respondents, the response rate was $55 \%$ over two months for a sample size of 37 surveys. One reason could be attributed to the length of the questionnaire, which took some respondents about 40 minutes to complete. Hence for the subsequent questionnaire, the length was reduced by 50\%. According to Dillman et al. (1999), in their study on the Principles for Constructing Web Surveys, a seven-step principle was encouraged, one of which was ensuring the questions are as short as possible, direct and straightforward, and the entire web interface is friendly. Hence, subsequent questionnaires adopted these principles. Overall, the results from the pilot study indicated that the proposed study in Chapter 5 would sufficiently address the research aims and objectives.

\subsection{Research design}

The purpose of data collection using a mixed-method technique is to develop answers to the research questions by expanding on the quantitative and qualitative methods of enquiry, thus improving the analytical power and validity of the results (Sandelowski, 200o; Shari, 2011; Teddlie \& Yu, 2007). Therefore, to address the research questions, the method of data collection was divided into three stages:

Stage 1: Distribution of questionnaires to registered architects in Nigeria

Stage 2: Interviews with registered architects in Nigeria

Stage 3: Distribution of questionnaires to building owners in Nigeria and a visual survey of their respective building

\subsection{STAGE ONE: Distribution of questionnaires to architects}

This stage aims to understand the architects' perspectives on the barriers preventing the adoption of ESD in Nigeria. The objective is to:

- Establish the prevalent barriers to ESD in Nigeria in accordance with the model for barrier identification and the overall research questions. Categories respondents in an objectively comparable way to identify if age, gender, experience or educational background influences the adoption of ESD in Nigeria

\subsubsection{Survey design}

The quantitative data was collected via a questionnaire survey, employing a self-developed and pilot-tested instrument. The final questionnaire was based on the discovery from the pilot study. The development of the questionnaire and the analysis of the result involved a 4-phase sequential step (Figure 4.3). Quantitative survey research has proven to be one of the preferable options for collecting accurate data for describing a sample size too large to observe directly (Salant, 1994). 


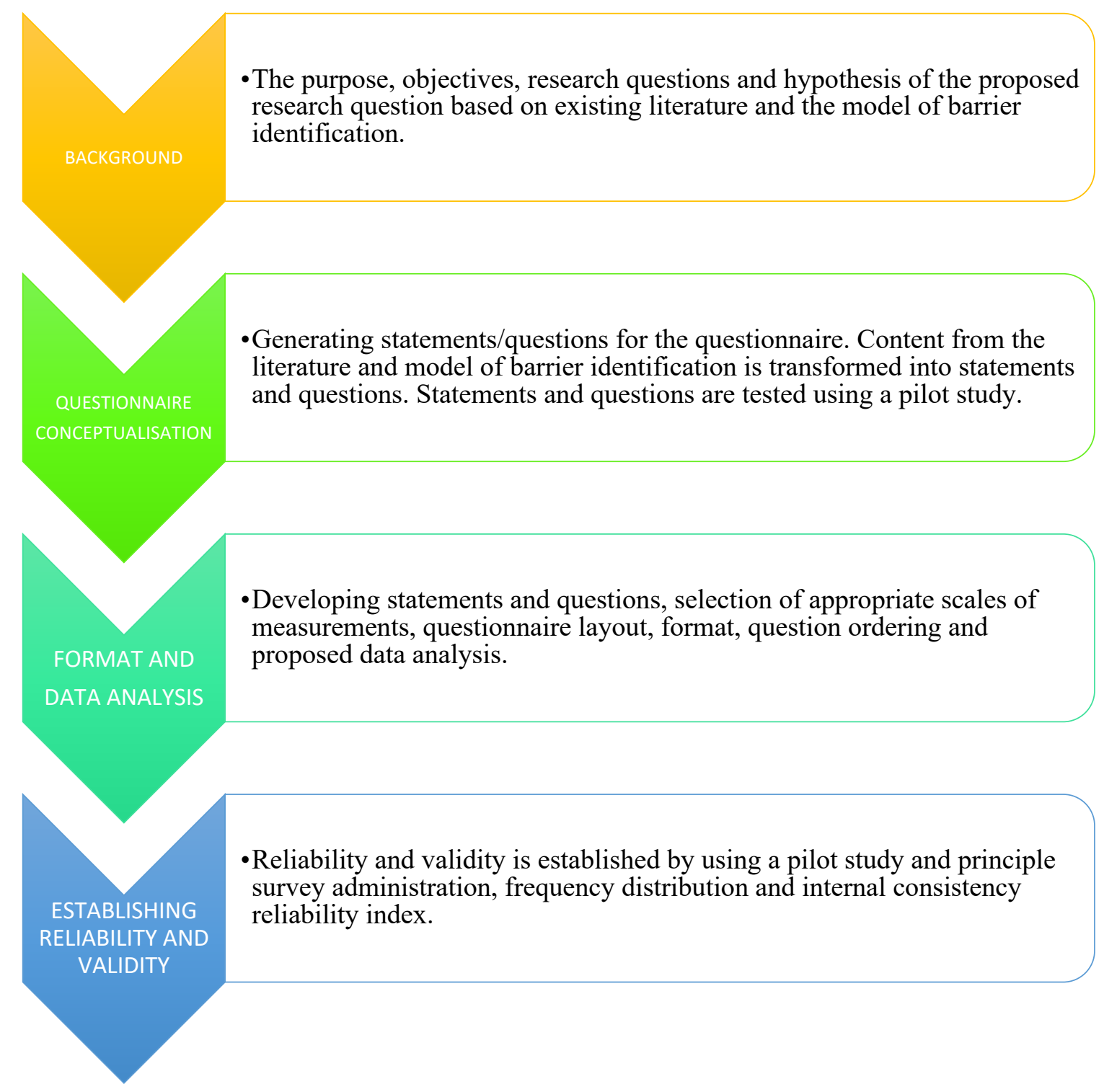

Figure 4. 3: Sequential step for developing a questionnaire. Adapted from (Norland-Tilburg, 1990; Radhakrishna, 2007).

The developed questionnaire using Likert-type scale questions was divided into seven main sections based on the theory of barrier identification: agreement, knowledge, technology, economy, social, political, background. The terminologies environmentally sustainable design, sustainable appliances/technologies, and energy efficiency were used throughout the survey without a direct recurring definition because it is the study's objective to explore the architects' perceptions on the subject of ESD in the Nigerian context. According to Preston and Colman (2000), in current practice, it is generally advised to use Likert-type scales and other attitudinal and opinion measures, consisting of either five, six, or seven response categories. However, conflicting views exist on the reliability of either the five, six, or seven response categories. However, a few studies have reported higher reliabilities for 5-point scales as opposed to two, three, four, six, or seven (Cox, 1980; Finstad, 2010; McKelvie, 1978). According to these studies, a 5-point scale rather than a 6 or 7 point scale was preferable for a number of reasons, including its ability to compare reliability coefficients with similar studies; allow respondents to interpolate effortlessly (i.e. attempt a response amongst two isolated values presented); and the appearance is more accessible for respondents. On the contrary, other studies show no significant disparity in terms of the internal structure of means, standard deviation, internal consistency/reliability, measurement error, factor loading, or item correlations (Dawes, 2008; Leung, 2011). Current studies are not clear on using mid-point categories on Likert scales (Courtenay, 1985). For instance, some researchers believe mid-point options enhance scale reliability, whilst others claim mid-point options could result in satisficing, while others suggest no significant difference in various scale points (Krosnick, 1996; Leung, 2011; Madden, 1978). Given the ongoing debate with no right or wrong method, Dillman et al., (2009) suggest that determining an appropriate length of scale should depend on what is best for the study and if the scale is unipolar or bipolar. A 6-point Likert-type scale was utilised in this study using a bipolar scale that measures the different gradations. A 6-point bipolar Likert-type scale was most appropriate for this study because of its ability to avoid cluster response at the mid-point, as expected in five or seven response categories.

The questions were structured to avoid cluster responses at mid-point or undecided response because of the negative impact on the overall results. For instance, questions relating to the level of ESD adoption by a respondent were expected to provide a response indicating if respondents frequently adopt ESD or not, as such mid-point or undecided responses are inappropriate for such questions. The reliability and validity of the survey items were established using a pilot study and internal consistency reliability index to determine the accuracy and precision of the measuring instrument. 
4.9.2 Sample design

The amount of variation that prevails in a population characteristic varies from one population to another. The larger the variations, the larger the sample size required to establish a population estimate (Fowler, 2002; Shari, 2011). As mentioned earlier, members within the sample population were relatively homogeneous given that they are all practising architects, therefore an 80/20 split was appropriate (Bryman, 2008; Fink, 2015). Table 4.1 provides a summary of the sample sizes required for various population sizes. Since the target respondents for this study were accredited architects in Nigeria, there are 2815 fully registered architects in Nigeria based on the register of accredited architects published by (ARCON, 2015). Of the 2815 fully registered architects, there were only 586 emails provided on the register, of which 182 were no longer active. This meant that the study only had access to 404 possible respondents.

A sampling error of $\pm 5 \%$ was implemented for this study because validity and reliability were established using other sources of data collection (i.e. interviews with architects, building owners' survey and visual survey of buildings). Based on the figures highlighted in Table 4.1, using an 80/20 split and a $\pm 5 \%$ sampling error, the representative population was 219 out of the 2815 accredited architects. Following the administration of the survey, a total of 130 responses was received, which accounts for a $59 \%$ response rate. According to a study by Baruch (1999), as opposed to the conventional population, a low response rate of $30 \%$ is expected when dealing with top to mid-level management staff like registered architects. Therefore, a response rate above $50 \%$ is considered acceptable for statistical analysis and generalization.

Table 4. 1: Sample sizes needed for different population sizes and characteristics at the $95 \%$ confidence level, at three levels of precision (Dillman et al., 2009; Shari, 2011)

\begin{tabular}{|c|c|c|c|c|c|c|}
\hline \multirow{3}{*}{$\begin{array}{l}\text { Population } \\
\text { size }\end{array}$} & \multicolumn{6}{|c|}{ Sample Size for the $95 \%$ Confidence Level } \\
\hline & \multicolumn{2}{|c|}{ $\pm 10 \%$} & \multicolumn{2}{|c|}{ $\pm 5 \%$} & \multicolumn{2}{|c|}{ $\pm 3 \%$} \\
\hline & $\begin{array}{l}50 / 50 \\
\text { Split }\end{array}$ & $\begin{array}{c}80 / 20 \\
\text { Split }\end{array}$ & $\begin{array}{l}50 / 50 \\
\text { Split }\end{array}$ & $\begin{array}{c}80 / 20 \\
\text { Split }\end{array}$ & $\begin{array}{l}50 / 50 \\
\text { Split }\end{array}$ & $\begin{array}{l}80 / 20 \\
\text { Split }\end{array}$ \\
\hline 100 & 49 & 38 & 80 & 71 & 92 & 87 \\
\hline 200 & 65 & 47 & 132 & 111 & 169 & 155 \\
\hline 400 & 78 & 53 & 196 & 153 & 291 & 253 \\
\hline 600 & 83 & 56 & 234 & 175 & 384 & 320 \\
\hline 800 & 86 & 57 & 260 & 188 & 458 & 369 \\
\hline 1,000 & 88 & 58 & 278 & 198 & 517 & 406 \\
\hline 2,000 & 92 & 60 & 322 & 219 & 696 & 509 \\
\hline 4,000 & 94 & 61 & 351 & 232 & 843 & 584 \\
\hline 6,000 & 95 & 61 & 361 & 236 & 906 & 613 \\
\hline 8,000 & 95 & 61 & 367 & 239 & 942 & 629 \\
\hline 10,000 & 95 & 61 & 370 & 240 & 965 & 640 \\
\hline 20,000 & 96 & 61 & 377 & 243 & 1,013 & 661 \\
\hline 40,000 & 96 & 61 & 381 & 244 & 1,040 & 672 \\
\hline 100,000 & 96 & 61 & 383 & 245 & 1,056 & 679 \\
\hline $1,000,000$ & 96 & 61 & 384 & 246 & 1,066 & 683 \\
\hline $1,000,000,000$ & 96 & 61 & 384 & 246 & 1,067 & 683 \\
\hline \multicolumn{7}{|c|}{$\begin{array}{l}\text { How to read this table: For a population with } 400 \text { members, whom we expect } \\
\text { to be about evenly split on the characteristic in which we are interested, we } \\
\text { need a sample of } 196 \text { to make estimates with a sampling error of no more than } \\
\pm 5 \% \text {, at the } 95 \% \text { confidence level. A " } 50 / 50 \text { split" means the population is } \\
\text { relatively varied or heterogeneous. An " } 80 / 20 \text { split" means it is less varied or } \\
\text { homogeneous; most people have a certain characteristic, a few do not. } \\
\text { Numbers in the table refer to completed sample sizes needed for various } \\
\text { levels of sampling error. }\end{array}$} \\
\hline
\end{tabular}

\subsubsection{Data collection}

A total of 130 responses were received through the distribution of the questionnaires to the architects using Qualtrics. Qualtrics is an internet-based subscription software platform where users can develop or upload a questionnaire, making it easy for users to collect extensive quantitative data from respondents. The platform generates a link to the questionnaire, which is sent out to selected respondents via email. Upon completing the questionnaire, the results are collated automatically in Qualtrics and can be transferred to SPSS for further statistical analysis. The benefit of distributing questionnaires electronically is that it is inexpensive and has a high response rate, with respondents completing the questionnaires at their convenience. However, its shortcomings include incomplete questionnaires and potential misunderstanding by respondents (Dillman et al., 2009). These shortcomings were addressed by using clear unambiguous questions, a pilot questionnaire, and providing the researcher's contact details. 
Chapter 4 | Design and methodology of study

4.9.4 Data analysis

All data was collected from Qualtrics, transferred to the SPSS software, and different methods applied to clean the data. These included possible code cleaning, contingency cleaning, and missing data cleaning (de Vaus, 2002; Shari, 2011). Both bivariate and univariate statistical procedures were used to analyse the results, with cross-tabulation and frequency counts to analyse the demographic information and awareness of ESD.

\subsection{STAGE TWO: In-depth, structured interviews with architects}

The aim of this stage was to gain further insight and capture the complexities surrounding the architects' perceptions and experiences and report the findings. While stage 1 provided quantitative results, little insight was gained about the cognitive rationale behind responses, hence a structured, recorded interview was deemed a preferable approach to generate essential data (Sandelowski, 200o; Vaismoradi, Turunen, \& Bondas, 2013). Qualitative data can either be obtained through interviews, physical observation, or document analysis. Within these methods, the physical interview has become a pillar of qualitative research (Sandelowski, 2000; Suri, 2011b). The interview structure depends on the level of control the interviewer wants to establish; this control can be exercised either through the type, number organization of the questions (Creswell, 2003). The study adopted a semi-structured interview to enable the interviewer to gain deeper insights whilst establishing some level of control. Using a semi-structured interview allowed questions to be prepared ahead of time so that the interviewer was prepared and competent during the interview (Cachia \& Millward, 2011; Irvine, Drew, \& Sainsbury, 2012). In addition, it allowed the participant freedom to voice their views whilst providing reliable and comparable qualitative data.

Traditionally, face-to-face interactions have been widely used and accepted as a preferred medium for conducting interviews, with telephone interviews considered less preferable (Farooq, 2015). However, research has not validated this view, making it anecdotal rather than proven (Cachia \& Millward, 2011). In most literature, face-to-face interviews have been encouraged because of the ability to maintain a rapport and create a comfortable environment for the interviewee. However, studies have also commended phone interviews since the interviewee has greater control over the conversation; it is time and cost-effective and fits perfectly into the busy schedule of participants; it sharpens the listening skills of the interviewer; enables the interviewer control over the conversation; allows note-taking without distracting the interviewee; provides easy rescheduling benefits, and most participants opt for the phone interview due to security and privacy issues (Cachia \& Millward, 2011; Farooq, 2015; Irvine et al., 2012). Due to certain limitations like distance, cost, convenience and busy schedules of the participants, two of the interviews were conducted over the phone while others were conducted face-to-face. For the phone interviews, the information sheet for participants and the interview questions were sent to the participants in advance of the main interview. During the phone interviews, participants were already informed and comfortable, making the whole interview session seamless and faster than face-to-face interviews.

The interview questions were developed from the literature with facets from similar studies conducted by (Baird, 2010; Christie, 2010; Shari, 2011; Wittmann, 1998). The interview questions were divided into seven main sections based on the theory of barrier identification: agreement, knowledge, technology, economy, social, political, and respondents background, similar to the architects' questionnaire. A pilot study was conducted before the interview, involving 5 participants selected using a non-random sampling technique. The sample size chosen consisted of doctorate students at the university who have practised architecture in Nigeria. The sample size was parallel to similar research conducted by Shari (2011). This technique was appropriate at the preliminary stages of research to test the effectiveness of the interview questions.

4.10.1 Sample design

Establishing a sample size was challenging because there were no favoured precedents for a qualitative sampling of a relatively homogenous group. To resolve this challenge, in addition to the saturation sampling, the study adopted the concept of information power proposed by Malterud, Siersma, and Guassora (2016). Based on the information power concept, the sample size for a qualitative study must be defined by the study aim, sample specificity, established theory, quality of dialogue, and analysis strategy. If the study aim is narrow, combined with a single case, highly specific participants with solid knowledge of the subject, and the result analysed with an already existing theory, then the study requires the least number of participants. Assuming the saturation model, this could range from 12 and 15 participants, particularly when the sample is homogenous (Guest, Bunce, \& Johnson, 2006; Mason, 2010). Based on the information power model, this study requires the least number of participants considering that it adopts an 
already existing theory, and the aim is narrow with a focus on a specific homogenous sample. Based on this, a sample size of 20 was proposed, however, 21 architects were interviewed. While statistical significance cannot be attached to the qualitative data collected, it is considered sufficient to illustrate common perceptions and existing challenges experienced by the respondents. Furthermore, a sample size of 20 is generally acceptable for making population generalization and estimation in a qualitative study (Creswell, 2003; Salkind, 2009). The sample size is also consistent with similar studies conducted by Christie (2010) and Shari (2011). Participants for the interview were recruited by randomly contacting accredited ARCON members in Lagos, Abuja, Rivers, and Bayelsa State, whose names and telephone numbers were listed without email addresses. After the initial phone call to the participants, a mutually convenient interview time and venue was negotiated.

\subsubsection{Data collection}

Interviews were conducted over the phone and in various locations based on the respondent's preference (for example, at their office, home, or in a meeting room at work). The interviews for the physical interview were recorded on an audio recorder (i.e. iPhone) for later transcribing and coding. The interviews over the phone were recorded using a call recording app called TapeAcall, which records the entire telephone conversation. During the telephone interview, participants were also informed that the conversation was being recorded. During the physical and telephone interviews, notes were also taken. Participants worked at their preferred pace during the interview sessions.

\subsubsection{Data analysis}

The data from the interviews were analysed using content analysis because of its relatively low level of interpretation. According to Vaismoradi et al. (2013), qualitative descriptive approaches such as phenomenology, content and thematic analysis are best suited for studies that wish to use a relatively low level of interpretation, in contrast to hermeneutic phenomenology or the grounded theory.

The recordings and notes taken during the interview were transcribed into a Microsoft Word document. The transcribed data was reexamined while listening to the interview recordings and reviewing the interview notes to ensure the accuracy of the transcription. The Word document was later transferred to Qualitative Data Analysis software (QDA Miner) for coding and analysis using content analysis. QDA Miner is a qualitative data analysis software for coding textual data and annotating, retrieving and reviewing coded data. The program manages complex projects with large volumes of information and provides an exploratory tool to identify patterns in coding and establish relationships between the different codes by assigning numerical and categorical properties like colours and fonts. The completed analysis is stored in rich text and can be transferred to text, graph or table formats. Overall, the program provides an easy integration of qualitative and quantitative methods. Analysing the data using content analysis involved a systematic step-bystep process starting with a quick browse of all the transcripts and making notes based on the first impression. This followed a more in-depth reading of the transcripts to identify any hidden trends. According to Vaismoradi et al. (2013), this provides a practical way of improving rigour and ensuring a reliability check. After reading the transcripts carefully, relevant words, phrases, sentences and sections were labelled (i.e. coded). These labels were either activities, concept differences or any item that raised a flag. The relevant items were generally highlighted based on them being new, repeated, or the respondents specifically stating their relevance or having been noted in previous publications or existing theories or concepts. At the coding process stage, the goal was to remain open-minded and code as many items as possible whilst being mindful of preconceived theories, concepts, or underlying patterns (Patton, 2014). However, as noted by Brinkmann and Kvale (2015) the researcher has the final say on the choice of method and the reason for considering an item relevant.

After coding as many items as possible, each code was grouped under different themes based on identified trends and importance. During this process new codes were created or combined whilst being aware that in the end, some of the codes might be abandoned (Bryman, 2016). The themes were labelled with sub-themes under each theme based on their connection. Within these themes, it was essential to group them in terms of hierarchy, which was generally determined by the number of repetitions by the respondents. Based on repetition, it is possible to identify essential themes and start drawing some assumptions (Brinkmann \& Kvale, 2015). Following the conclusion of the above processes, each theme was reported in the result section by describing the individual themes and how they connect to other themes, existing studies, and the research aim and objectives. During the process, it was crucial to remain unbiased and speak with a neutral voice (Bryman, 2016). Chapter 5 provides the results and some discussion from the qualitative study. 


\subsection{STAGE THREE: Distribution of questionnaires to building owners and a visual survey of their buildings}

In stage 3, the study used two different strategies and two different data collection tactics involving the distribution of questionnaires to building owners and case studies consisting of a visual survey of their respective buildings. The significance of the combined methodological strategies and data collection tactics emanates from the research aim.

The exploration into barriers preventing ESD adoption within the confines of this research has two main actors, the architect and building owner. It was envisaged that stage 3 would provide a better understanding of the results from stages 1 and 2 through a data triangulation method to understand the views of the other actor (the building owner) who also play a significant role within the ESD discourse. This method was selected because of its ability to negate, decrease, and counterbalance the deficiency of a single strategy (Thurmond, 2001; Walliman, 2017). The results from stage 3 provide a better insight into the socio-political salience of the sustainable environmental discourse; firstly, by discovering how far its argument is indeed publicly acknowledged as a problem; secondly, by establishing the level of ESD awareness from the building owners' perspectives and level of ESD adopted in their respective buildings; and thirdly, by exploring the validity of the views postulated by architects as these relate to building owners.

As stated by Yin (2014), case study research is beneficial, specifically when the boundaries between phenomenon and the context are not clearly visible. Such analysis provides a systematic inquiry into events that aims to comprehensively describe a phenomenon of interest (Lara, 2001). Within the context of this thesis, the systematic inquiry investigates how architecture can be used as a tool for providing a sustainable environment. To establish this from a holistic perspective, the study adopts multiple strategies and tactics to understand both the architects' and building owners' view in relation to environmental sustainability (Table 4.2).

Table 4. 2: Combined case study research strategy

\begin{tabular}{ccc}
\hline Research Framework & Research Strategies & Data Collection Tactics \\
\hline \multirow{3}{*}{ Case Study } & Interpretive/Quantitative & $\begin{array}{c}\text { Physical analysis of } \\
\text { residential buildings }\end{array}$ \\
\cline { 2 - 3 } & Qualitative/Quantitative & $\begin{array}{c}\text { A survey of building } \\
\text { owners }\end{array}$ \\
\hline
\end{tabular}

In terms of its weaknesses, Groat and Wang (2013) suggest that while there is much to be gained from the case study combined strategy, researchers may be disenchanted by its high level of sophistication. This complexity may result in a potential lack of connection and coherence. This complexity was acknowledged and addressed in this study by maintaining the same underpinning model of agreement, knowledge, technology, economy, social, and political across each research method from stages 1 to 3 and following a detailed ESD checklist. This ensured consistency.

\subsubsection{Sample design}

Despite the relative homogeneity of mainstream buildings in Nigeria, it could be argued that specific individual preferences or localities play a fundamental role in the overall morphology of the buildings. However, in the interests of practicality, this study has narrowed its focus to specific cities in Nigeria. As Yin (2014) pointed out, the ability for case studies to make generalisations is not constrained by its singularity, however, its in-depth contextual immersion into a case makes it perfect for examining complex phenomenon. In a case study research strategy, establishing a particular sample size for statistic generalization is not necessary and can vary from 1 - 500 or more depending on the requirements of the research. Groat and Wang (2013) provide an illustration of two examples of a case study strategy in which one used a combined strategy with a sample size of 300 houses in multiple locations, while the other used a single location to explore the various socio-physical dynamics that contributed to the urban life in that particular location. According to Yin (2014) this is because the idea of a case study strategy is to provide an in-depth description and explanation of a case, rather than a random sample of cases. However, within this strategy lie two fundamental sampling concepts; choosing and studying a number of cases in multiple locations or studying multiple cases or subjects in a single location. As stated by Groat and Wang (2013), it is more important to uncover the complexity of a particular phenomenon than limit the theoretical soundness of research by looking shallowly into that phenomenon. Through purposeful sampling, it was important to investigate the adoption of ESD in the geopolitical zones to provide insights into the richness and depth of the various economic and socio-political factors within those zones. 
Based on these criteria, as noted in Section 4.3, the scope of the study was limited to four states: Bayelsa, Rivers, Lagos, and Abuja. In this study, emphasis was on the buildings that have gone through the formal process of obtaining a building permit because, as noted in Section 3.5, those buildings would require the services of an architect.

\subsubsection{Data collection}

Stage 3 involved the distribution of questionnaires to building owners and a physical survey of their respective building. For the building owners, the cluster sampling method was used. Cluster sampling occurs when the sample unit contains a group of elements instead of individual members or items in the population. The number of clusters sampled becomes a representation of the entire population (Osuala, 1991; Uzoagulu, 2011). The sampling technique is significantly easier to apply when a large population or a large geographical area is involved (Nworgu, 1991). However, a greater error is associated with cluster sampling technique than a simple random sampling of the same size, since the technique does not guarantee an equal number of subjects in each cluster (Osuala, 1991; Uzoagulu, 2011). Focusing on specific locations allows for a more careful formation of the research strategy in terms that represent both the building owner's view on the appropriateness of ESD and the mainstream architecture of buildings in Nigeria. The cluster sampling involved clustering the residential areas in each of the four towns, thereby limiting the scope to Lagos, Abuja, Rivers, and Bayelsa states (Figure 4.4). The study targeted specific districts with good infrastructure within the four towns. Each district was divided into five clusters and streets with houses were randomly selected from a random number table based on the house numbers. In Lagos, the Lekki district was selected; in Abuja, the Garki district; in Rivers, the Central Port Harcourt district; and in Bayelsa, the Central Yenagoa district.

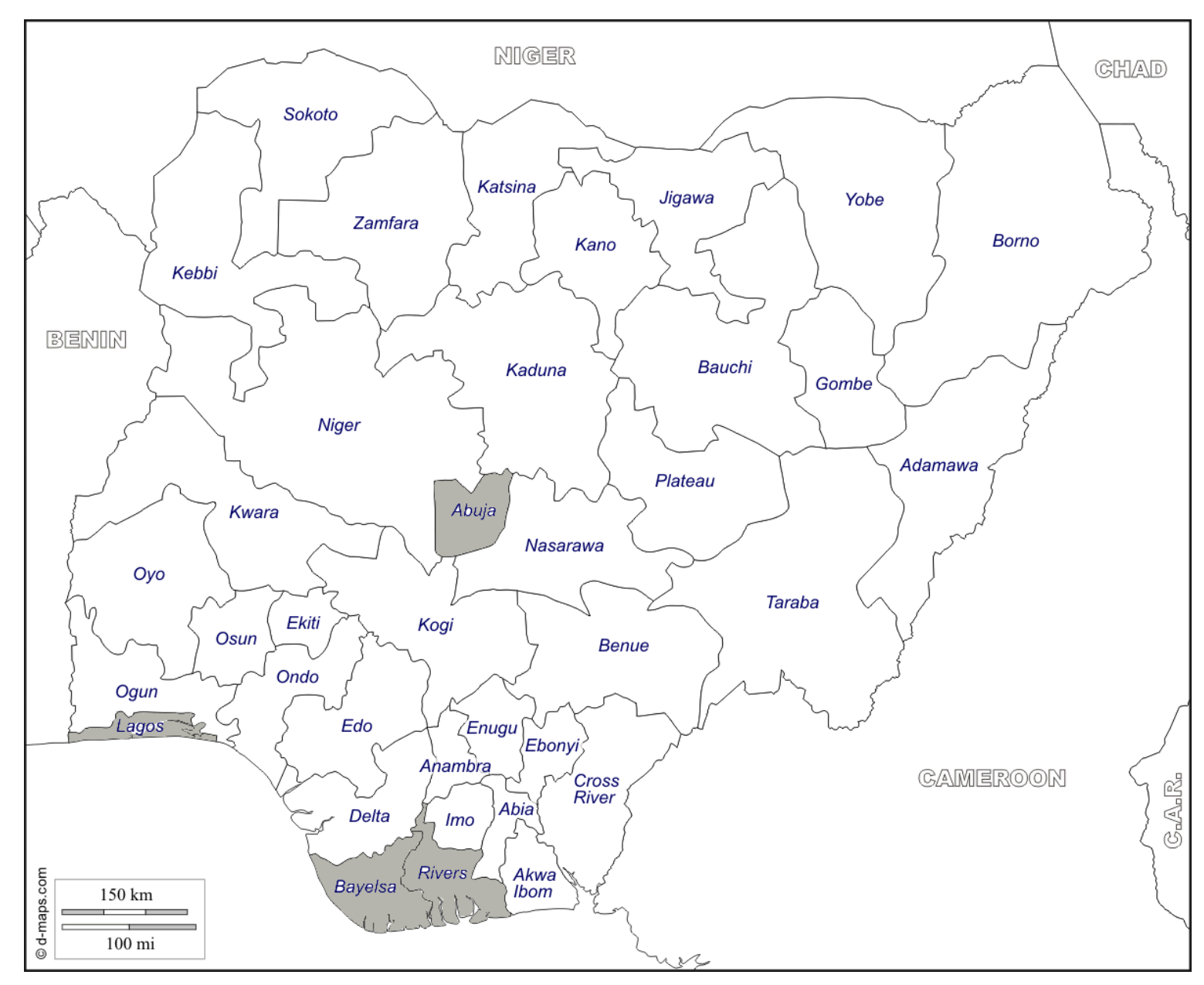

Figure 4. 4: Map of Nigeria showing the four locations selected for the case study. Image adapted from (D-Maps, 2019).

Using Google maps and the researcher's knowledge of the selected districts, building owners were randomly selected using a planned door-to-door walkthrough recruitment strategy. According to Flynn (2013), the door-to-door method is relevant to urban settings, assisting researchers to overcome the restraints of a telephone-based recruitment by enhancing direct contact with participants. For each building, with the building owner's consent, the checklist was completed (Appendix B) and photos were taken of the buildings with a visual examination of the building to document the level of ESD adoption in each. When in doubt during the building examination, building owners were asked for further clarification. In instances, for example, where it was impossible to see the roof to confirm the installation of solar panels, building owners confirmed the presence or absence of solar panels. It is important to note that the primary aim of this study is to establish the barriers to ESD and not the climatic or scientific parameters of the individual buildings. Section 3.2 provides an overview of the Nigerian climatic parameters. The researcher electronically completed the checklist on a tablet, while the building owners' completed the survey electronically on a different tablet. The data was uploaded directly to Qualtrics for later coding and analysis. The sample sizes were 42, 20, 50, and 30 participants for Lagos, Abuja, Rivers, and Bayelsa states, respectively, bringing the total sample size to 142. 


\section{Chapter 4 | Design and methodology of study}

\subsubsection{Data analysis}

The building owners completed the questionnaire electronically on Qualtrics and the data was transferred to SPSS. Similarly, the checklist was completed electronically on Qualtrics, with the data transmitted to SPSS for further statistical analysis. Different methods were applied to clean the data: possible code cleaning, contingency cleaning, and missing data cleaning (de Vaus, 2002; Shari, 2011). Both bivariate and univariate statistical procedures were used to analyse the results, with cross-tabulation and frequency counts to analyse the demographic information and awareness of ESD.

\subsection{Study limitations}

Although the study generally achieved the objectives of this thesis, it is acknowledged that the research was not conducted without limitations. Firstly, stages 2 and 3 of the study were confined to only 4 out of the 36 states in Nigeria (i.e. Lagos, Abuja, Rivers, and Bayelsa). Unlike the sampled population in stage 1, which covered more than four states, stages 2 and 3 did not. This means that in terms of providing a generalization of the barriers to ESD in stages 2 and 3 from the architects' and building owners' perspective in Nigeria, other factors could affect ESD, such as ethnicity and social-cultural background in the remaining 32 states.

Secondly, to meet the building owners, stage 3 of the study had to be conducted on weekends or after working hours, which limited the time spent surveying the respective buildings because respondents were already potentially tired after a long day at work. This affected the willingness of some of the respondents to take part in the study. In some instances, stage 3 of the study was rescheduled for the weekends or the preferred time of the respondent. It was the intention of the study also to collect climatic data in stage 3 , however collecting climatic data after working hours meant that houses were more likely to be cooler than houses surveyed during the day at the weekend when the sun was out. This made it challenging to collect climatic data/readings, limiting the study to a visual physical examination of the respective buildings. However, this did not impact the overall aim of the study, which was concerned with the respondents' perceptions of ESD.

Finally, there are three main climatic regions in Nigeria; equatorial in the south, tropical in the middle belt, and arid in the north. However, stage $2 \& 3$ was only conducted in the equatorial and tropical zones. The impact of regional climate on the architects' or building owners' decision to adopt or not adopt ESD was not measured in this study. However, this did not impact the overall aim of the study, which was not on climate but the architects' and building owners' perception of ESD. Existing studies (Akadiri, 2015; Chan et al., 2018; Edomah, 2016) have not identified regional climatic differences as a barrier preventing ESD adoption, which is the main aim of this study. Similarly, the results in Chapter 5 and literature review have not provided any evidence to show that the climatic differences across Nigeria had any impact on the barriers to ESD.

\subsection{Sampling error}

The results from this study are only estimates of actual population characteristics because the study only examined a sample and not the entire Nigerian population. The possible sampling error of $\pm 5 \%$ was implemented for this study because validity and reliability were established using other sources of data collection, as noted earlier. This assumption is acceptable since the survey aims to show trends in perceptions as opposed to fields such as biomedical research that might require a lower level of probability (Fink, 2015).

\subsection{Measurement error}

It is assumed that the measurement error in this study was kept to a minimum since respondents did not make any remark of uncertainties, and questions did not appear to be misinterpreted or misunderstood by respondents.

\subsection{Validation of the instrument for data collection}

The final instrument for data collection was validated using the pilot study and two experts in measurement and evaluation from the VUW's Statistical Consulting Services and one expert from the School of Architecture at VUW. During validation, the experts checked whether the items in the questionnaire were clear in wording and adequate and appropriate in addressing the problem and purpose of the study. The intent of validation of the instrument was to ensure that the items in the questionnaire were in line with the research questions and the hypotheses being tested. The comments of experts were used in modifying the final instrument used for data collection. In addition, a pilot study was conducted. 


\subsection{Reliability of the instrument}

The instrument's reliability was tested through a pilot study involving 20 architects and building owners, respectively, who were selected using a non-random sampling technique and were not part of the study, and interviews with 5 participants selected from the Victoria University School of Architecture who has practised in Nigeria. This technique was appropriate at the preliminary stages of the research to test the efficacy of the questionnaires and interview questions and reduce measurement error (Chambliss, 2009). The measurement errors represent the discrepancy between the respondent's attribute and their survey response (Groves, 1987; StatisticsSolutions, 2018). The participants for the pilot study were approached through email to participate in the online survey. The Qualtrics software generated a web link containing the questionnaire that was sent via email. The Cronbach Alpha Coefficient test was used to test the instrument's reliability for internal consistency because it provides a precise estimate of internal consistency and indicates how items correlate (Hamilton, 2006). The reliability coefficient for the architects' and building owners' in stages 1 and 3 averaged 0.85 and 0.79 , respectively, indicating that the instrument for data collection was reliable and internally consistent.

\subsection{Summary of chapter}

This chapter presented a summary of the research objectives, highlighting the requirements for a theoretical model and research method that could provide an in-depth understanding of why ESD is not being fully adopted in the Nigerian building industry. The resulting mixed-method research approach was selected with the intention that it could identify the extent and nature of both the architects' and building owners' motivation to either adopt or not adopt ESD. A mixed-method research strategy was incorporated to establish triangulation and validity, involving the distribution of questionnaires and interviews with architects and the distribution of questionnaires to building owners and a physical survey of their respective buildings. The next chapter reports the results from stages 1 to 3 . 
Chapter 5 | Results from Study

Chapter 5 | Results from Study 


\subsection{Stage One: The Architects perceived barriers preventing the adoption of Environmentally Sustainable Design}

The previous chapter provided a breakdown of the research methods adopted in stages 1, 2 and 3 of this study. A mixed-method research approach was recommended as a suitable method for achieving the research aims and objectives. Results from the investigation of the Nigerian architects' perceptions towards the implementation of environmentally sustainable design methods (ESD) based on the research questions are described and analysed in the following sections. The results are analysed using frequency distributions, Pearson's Correlation Coefficient, and Analysis of Variance (ANOVA). Internal consistency was established using the Cronbachs' alpha coefficient, which was at an average of 0.85 . This indicates robust internal consistency among the items and also suggests minor measurement error in the instrument. Preliminary discussion of the results are provided in this chapter; however, Chapter 6 provides a comprehensive insight into the results by establishing the links between the various studies and the research aims and objectives.

\subsubsection{Respondents' characteristics for Architects survey}

Demographic, education, and experience related characteristics are given in Table 5.1. Among the 130 surveyed architects, 68.5\% were aged between 20 and 40 years, $26.9 \%$ were aged between 41 and 60 years, and $4.6 \%$ were 60 years and above. The male respondents were $79.2 \%$, while the females were $20.8 \%$. These figures are consistent with studies conducted by (Enwerekowe \& Mangden, 2019; Ikoli, 2018), which illustrated a low representation of women in architectural practice in Nigeria. The underrepresentation of women in architecture extends throughout the public sector, consultancy and academia (Hosey, 2019; Tether, 2016).

More than half of the respondents had between 5 to 9 years of architectural experience, and the response rates were lower for the more experienced architects. The response rate based on years of experience is similar to the study conducted by (Akinola et al., 2018), which showed that most respondents had between 5 to 10 years of architectural experience. As would be expected, $70 \%$ of the respondents had a Master's in Architecture or an equivalent postgraduate qualification, $16.9 \%$ had a Bachelor's degree or equivalent in architecture, 9.2\% had a Doctorate degree in architecture, and 3.8\% had a Higher National Diploma in architecture. The higher response rate of respondents with a Master's degree or equivalent was expected because it is required for registration with the Architects Registration Council of Nigeria (ARCON, 2019). The disproportionality in the respondent's characteristics such as age, gender, years of experience, and qualification would not have a significant effect on the overall results and analysis of the study because it is expected and consistent with similar studies (Akinola et al., 2018; Ikoli, 2018) conducted within the Nigerian architectural industry. Appendix A provides a descriptive table showing the mean and standard deviations for the entire study.

Table 5. 1: Respondents' characteristics ( $\mathrm{N}=130)$

\begin{tabular}{|c|c|c|c|}
\hline Variable & Scale/category & $\mathbf{N}$ & $\%$ \\
\hline \multirow[t]{3}{*}{ Age } & $20-40$ & 89 & 68.5 \\
\hline & $41-60$ & 35 & 26.9 \\
\hline & 60 and above & 6 & 4.6 \\
\hline \multirow[t]{2}{*}{ Gender } & Male & 103 & 79.2 \\
\hline & Female & 27 & 20.8 \\
\hline \multirow[t]{5}{*}{ Years of architectural experience } & $5-9$ years & 77 & 59.2 \\
\hline & 10 - 19 years & 27 & 20.8 \\
\hline & $20-30$ years & 17 & 13.1 \\
\hline & $\begin{array}{l}30 \text { years and } \\
\text { above }\end{array}$ & 7 & 5.4 \\
\hline & Missing & 2 & 1.5 \\
\hline \multirow{4}{*}{$\begin{array}{l}\text { Highest level of educational } \\
\text { qualification }\end{array}$} & $\mathrm{PhD}$ & 12 & 9.2 \\
\hline & $\begin{array}{l}\text { MArch, M. SC, } \\
\text { M.TECH, MED, } \\
\text { B.ARCH }\end{array}$ & 91 & 70 \\
\hline & $\begin{array}{l}\text { B. SC, B.TECH, } \\
\text { BES, BA }\end{array}$ & 22 & 16.9 \\
\hline & HND & 5 & 3.8 \\
\hline
\end{tabular}




\subsubsection{Do architects agree on the need for environmentally sustainable design methods in Nigeria?}

The primary objective for this category was to establish if there is a consensus on the problem of thermal discomfort within the internal spaces of buildings. In addition, the results would show if the architects agree that it is an architectural problem that needs to be addressed. The architects were asked to select the option that best described their opinion on a scale of 1-6, with 1 representing "strongly disagree" and 6 representing "strongly agree". Descriptive statistics in Figure 5.1 show a general agreement on the problem of unsatisfactory electricity supply from the national grid and thermal discomfort in indoor spaces.

Figure 5. 1: Do the architects agree on the need for environmentally sustainable design methods in Nigeria? Please select the option that describes your opinion about the following statements on a scale of 1 to 6 , with 1 being strongly disagree and 6 being strongly agree

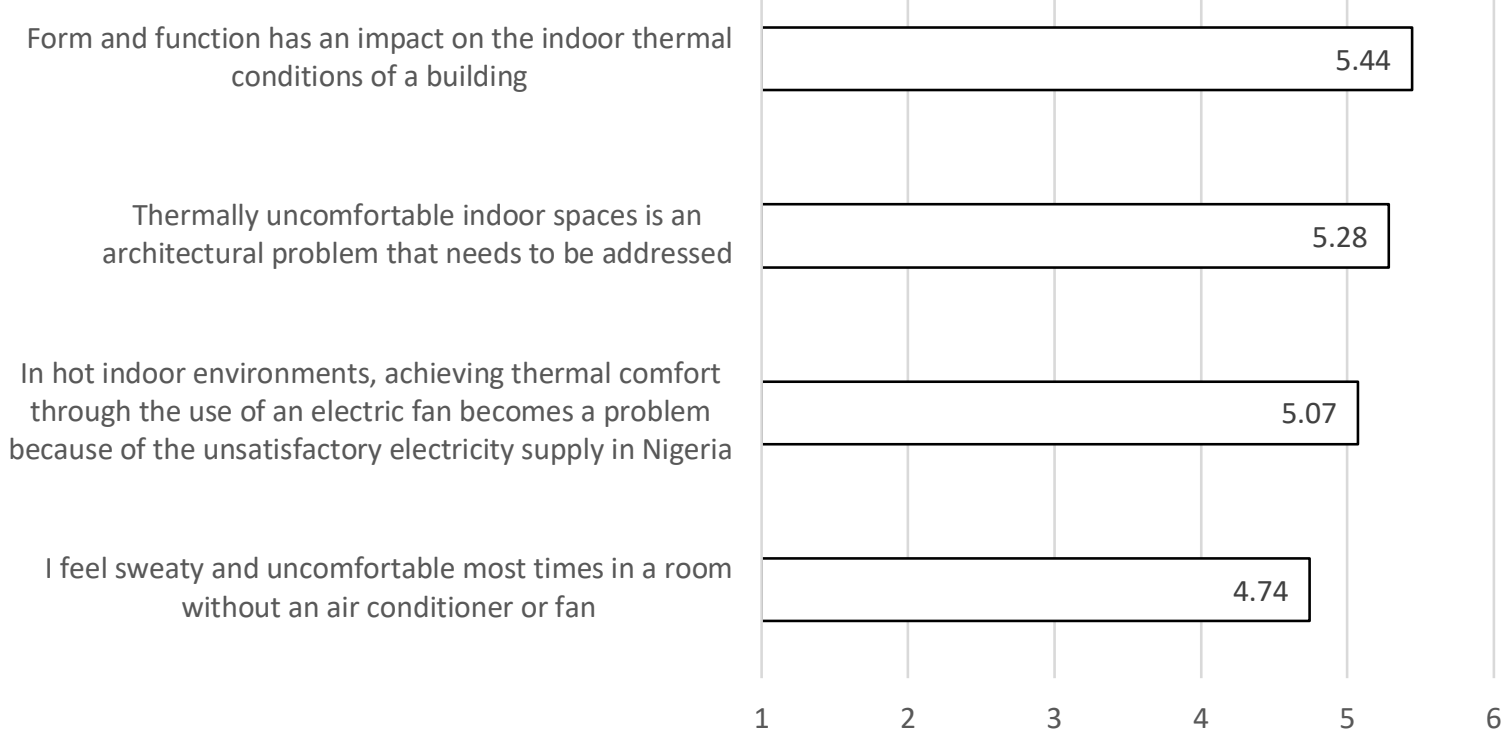

Mean Distribution 1 - Strongly disagree; 2 - Disagree; 3 - Somewhat disagree; 4 - Somewhat agree; 5 - Agree; 6 - Strongly agree $* 3.5$ Disagree, $>3.5$ Agree

\subsubsection{How knowledgeable is the Nigerian architect about environmentally sustainable design methods?}

This section aims to establish the level of ESD adoption and identify if a lack of knowledge is a possible barrier to ESD adoption in Nigeria. The result from this section gives an indication of the main features that appear to define Nigerian architecture. Figure 5.2 suggests that the respondents do not frequently adopt most environmentally sustainable design methods. However, cross ventilation was reported as the most frequently adopted ESD, while windcatchers were the least adopted.

A review of the results in Figure 5.2 reveals some interesting points. The results show that most architects reported providing cross ventilation in their respective designs and at the same time designed buildings with the intention of using air conditioners and fans. On the surface, this seems contradictory because it would be expected that the provision of natural ventilation would eliminate or at least reduce the need for mechanical ventilation (Figure 5.2). However, a further review of the results shows that the required techniques for improving the efficiency of cross ventilation are not frequently adopted: these include suitable building orientation, strategic positioning of windows, and courtyards (Figure 5.2). Hence, the need for mechanical ventilation. Failure to adopt appropriate techniques to enhance ventilation suggests that the respondents are either not knowledgeable of these techniques or knowledgeable but choose not to adopt them. The possibility of the architects intentionally choosing not to adopt these techniques is less likely, given that most architects acknowledged the problem of thermal discomfort (Figure 5.1). Stage 2 provides a better understanding of the architects' level of ESD awareness. 


\section{Chapter $5 \mid$ Results from Study}

Figure 5. 2: How knowledgeable is the Nigerian architect about environmentally sustainable design methods? Please select the option that describes your opinion about the following statements on a scale of 1 to 6 , with 1 being strongly disagree and 6 being strongly agree

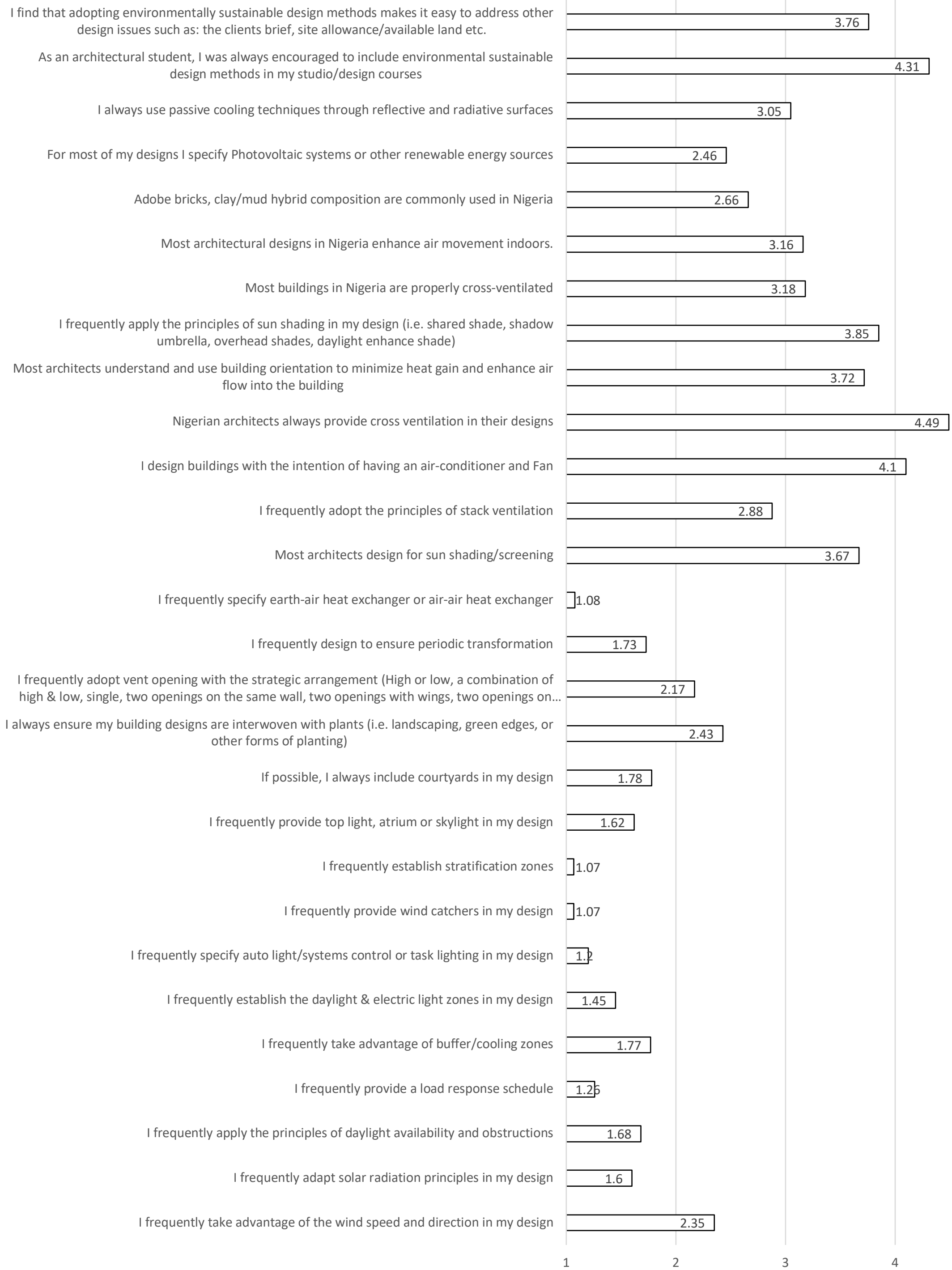

Mean Distribution 1 - Strongly disagree; 2 - Disagree; 3 - Somewhat disagree; 4 - Somewhat agree; 5 - Agree; 6 - Strongly agree ${ }^{*}<3.5$ Disagree, > 3.5 Agree 
Respondents reported positively that architects understood and utilised building orientation techniques, however, there was a negative response when asked about the fundaments of building orientation such as the principles of daylight availability and obstruction, periodic transformation, cooling and buffer zones, and solar radiation principles. This highlights some inconsistency because it is difficult to effectively adopt building orientation techniques without considering daylight availability and obstruction or solar radiation principles. This inconsistency could potentially be due to a lack of adequate understanding of the precept of building orientation.

Based on the mean, cross ventilation was the most adopted ESD. Further analysis was undertaken to ascertain the correlation between cross ventilation and other items within the knowledge category. The study explored whether architects' adoption of cross ventilation and shading principles in their designs related to the level of encouragement to adopt ESD offered to students in studio and design courses, for example. In other words, does an encouragement to adopt ESD at university improve the adoption of ESD by architects? A Pearson Correlation examined the relationship between "Nigerian architects always provide cross ventilation in their designs" (M $=4.49, \mathrm{SD}=0.80$ ) and "As an architectural student, I was always encouraged to include environmentally sustainable design methods in my studio/design courses" ( $\mathrm{M}=4.31, \mathrm{SD}=0.967)$. Preliminary analysis showed no violations in the assumption of normality, linearity, or homoscedasticity. The Pearson Correlation showed a positive, strong and statistically significant relationship between the variables $P(0.958)<0.05$ (Table 5.2). The positive relationship indicates that the higher level of responses in both variables is closely associated. In essence, respondents who reported that Nigerian architects always provide cross ventilation in their designs also reported that they were encouraged to adopt ESD in their studio/design courses. This suggests that architectural education has an impact on the level of ESD adoption.

Table 5. 2: Pearson Correlation between "Nigerian architects always provide cross ventilation in their designs" and "As an architectural student, I was always encouraged to include environmentally sustainable design methods in my studio/design courses"

\begin{tabular}{lllcc} 
& & $\begin{array}{c}\text { Nigerian architects always } \\
\text { provide cross ventilation in } \\
\text { their designs }\end{array}$ & $\begin{array}{c}\text { As an architectural student, I was always } \\
\text { encouraged to include environmentally } \\
\text { sustainable design methods in my } \\
\text { studio/design courses }\end{array}$ \\
\hline $\begin{array}{l}\text { Nigerian architects always provide } \\
\text { cross ventilation in their designs }\end{array}$ & Pearson Correlation & 1 & .005 \\
\cline { 2 - 4 } $\begin{array}{l}\text { As an architectural student, I was } \\
\text { always encouraged to include } \\
\text { environmentally sustainable design } \\
\text { methods in my studio/design }\end{array}$ & $\mathrm{N}$ & $\mathrm{N}$ & .005 & .958 \\
\cline { 2 - 4 } $\begin{array}{l}\text { Pearson Correlation } \\
\text { courses }\end{array}$ & Sig. (2-tailed) & .958 & 130 \\
\hline
\end{tabular}

Table 5. 3: Pearson Correlation between "I frequently apply the principles of sun shading in my design (i.e. shared shade, shadow umbrella, overhead shades, daylight enhance shade)" and "As an architectural student, I was always encouraged to include environmentally sustainable design methods in my studio/design courses"

I frequently apply the principles of sun shading in my design (i.e. shared shade, shadow umbrella, overhead shades, daylight enhance shade)

As an architectural student, I was always encouraged to include environmentally sustainable design methods in my studio/design courses

I frequently apply the principles Pearson of sun shading in my design (i.e. Correlation $.289^{* *}$ shared shade, shadow umbrella, Sig. (2-tailed) .001 overhead shades, daylight $\quad \mathrm{N}$ enhance shade) $\mathrm{N}$ As an architectural student, I Pearson was always encouraged to Correlation include environmentally Sig. (2-tailed) sustainable design methods in $\mathrm{N}$ my studio/design courses

**. Correlation is significant at the o.01 level (2-tailed). 
Similarly, the Pearson Correlation $P(0.289)<0.05$ (Table 5.3) also showed a positive and strong correlation between architectural education and shading principles. The result suggests that students who were encouraged to adopt ESD at university were more likely to adopt shading principles during their architectural practice. Based on the mean (Table 5.4), more detailed ESD for improving the delivery of natural lighting was infrequently adopted. This analysis aims to establish if a relationship exists within the responses for these items. In other words, is the low rate of adoption reported for the individual items a coincidence, or does it show a relationship/trend that architects do not understand or go a step further to enhance the natural lighting in their respective designs. To provide a better understating of the trends in the delivery of natural lighting, further analysis was conducted to establish the relationship between items in the knowledge category related to the provision of natural light. Table 5.4 provides the results of the correlation between the four variables:

Table 5. 4: Pearson Correlation of the relationship between four ESD variables that relate to the provision of natural light

\begin{tabular}{|c|c|c|c|c|c|}
\hline & & $\begin{array}{l}\text { V1. I frequently apply } \\
\text { the principles of } \\
\text { daylight availability } \\
\text { and obstructions }\end{array}$ & $\begin{array}{c}\text { V2. I frequently } \\
\text { establish the } \\
\text { daylight and electric } \\
\text { light zones in my } \\
\text { design }\end{array}$ & $\begin{array}{l}\text { V3. I frequently provide } \\
\text { top light, atrium or } \\
\text { skylight in my design }\end{array}$ & $\begin{array}{l}\text { V4. Most architects } \\
\text { understand and use building } \\
\text { orientation to minimise heat } \\
\text { gain and enhance airflow } \\
\text { and natural light into the } \\
\text { building }\end{array}$ \\
\hline \multirow{3}{*}{$\begin{array}{l}\text { V1. I frequently apply } \\
\text { the principles of } \\
\text { daylight availability } \\
\text { and obstructions }\end{array}$} & $\begin{array}{l}\text { Pearson } \\
\text { Correlation }\end{array}$ & 1 & $.805^{* *}$ & $.498^{* *}$ & $.420^{* * *}$ \\
\hline & Sig. (2-tailed) & & .000 & .000 & .000 \\
\hline & $\mathrm{N}$ & 130 & 130 & 130 & 130 \\
\hline
\end{tabular}

**. Correlation is significant at the 0.01 level (2-tailed).

A Pearson Correlation examined the relation between $V 1(\mathrm{M}=1.68, \mathrm{SD}=1.104) ; V_{2}(\mathrm{M}=1.45, \mathrm{SD}=0.907) ; \mathrm{V} 3(\mathrm{M}=1.62, \mathrm{SD}=$ 0.730); V4 (M = 3.72, $\mathrm{SD}=1.129)$ (Table 5.4). The relationships were positive, moderate in strength, and statistically significant $P<$ 0.05, except for the relationship between $\mathrm{V}_{3}$ and $\mathrm{V} 4$, which was statistically insignificant $P(0.167)>0.05$, showing that the provision of top light, atrium or skylight in design has no relationship with the architect's understanding and use of building orientation to minimise heat gain, enhance airflow and natural light into the building. This implies that the building orientation as it relates to the delivery of natural lighting was not generally considered during the placement of top light, atrium or skylight.

Table 5. 5: Pearson Correlation of the relationship between self-reported questions and general perception

\begin{tabular}{|c|c|c|c|c|c|c|c|}
\hline & & $\begin{array}{l}\text { V1. Nigerian } \\
\text { architects } \\
\text { always provide } \\
\text { cross } \\
\text { ventilation in } \\
\text { their designs }\end{array}$ & $\begin{array}{c}\text { V2. Most } \\
\text { architects } \\
\text { design for sun } \\
\text { shading/scree } \\
\text { ning }\end{array}$ & $\begin{array}{l}\text { V3. Most } \\
\text { architects } \\
\text { understand } \\
\text { and use } \\
\text { building } \\
\text { orientation to } \\
\text { minimise heat } \\
\text { gain and } \\
\text { enhance } \\
\text { airflow and } \\
\text { natural light } \\
\text { into the } \\
\text { building }\end{array}$ & $\begin{array}{c}\text { V4. I frequently } \\
\text { adopt vent opening } \\
\text { with the strategic } \\
\text { arrangement (High } \\
\text { or low, a } \\
\text { combination of high } \\
\text { and low, single, two } \\
\text { openings on the } \\
\text { same wall, two } \\
\text { openings with wings, } \\
\text { two openings on } \\
\text { adjacent walls, two } \\
\text { openings on } \\
\text { opposite walls) }\end{array}$ & $\begin{array}{l}\text { V5. I } \\
\text { frequently } \\
\text { apply the } \\
\text { principles of } \\
\text { sun shading } \\
\text { in my design } \\
\text { (i.e. shared } \\
\text { shade, } \\
\text { shadow } \\
\text { umbrella, } \\
\text { overhead } \\
\text { shades, } \\
\text { daylight } \\
\text { enhance } \\
\text { shade) }\end{array}$ & $\begin{array}{l}\text { V6. I frequently } \\
\text { apply the principles } \\
\text { of daylight } \\
\text { availability and } \\
\text { obstructions }\end{array}$ \\
\hline \multirow{3}{*}{$\begin{array}{l}\text { V1. Nigerian } \\
\text { architects always } \\
\text { provide cross } \\
\text { ventilation in their } \\
\text { designs }\end{array}$} & \begin{tabular}{|l} 
Pearson \\
Correlation
\end{tabular} & 1 & $.441^{* * *}$ & $.214^{*}$ & $.200^{*}$ & .172 & $.367^{* * *}$ \\
\hline & Sig. (2-tailed) & & .000 & .015 & .023 & .050 & .000 \\
\hline & $\mathrm{N}$ & 130 & 130 & 130 & 130 & 130 & 129 \\
\hline
\end{tabular}

**. Correlation is significant at the 0.01 level (2-tailed).

*. Correlation is significant at the 0.05 level (2-tailed). 
The knowledge category was divided into two main sections consisting of self-reported questions and generalisation. Analyses were conducted to establish the relationship between the responses from the self-reported questions (which began with "I always" or "I frequently") and the general perception (which began with "Most architects"). The analysis aimed to establish if the respondent's selfperception was consistent with what they suspect or expect from other architects as it relates to the adoption of ESD. In addition, it also shows a general consistency in which sustainable methods are generally adopted or not adopted. A Pearson Correlation examined the relation between $V_{1}(\mathrm{M}=4.49, \mathrm{SD}=0.809) ; V_{2}(\mathrm{M}=3.67, \mathrm{SD}=1.177) ; \mathrm{V}_{3}(\mathrm{M}=3.72, \mathrm{SD}=1.129) ; \mathrm{V} 4(\mathrm{M}=2.17, \mathrm{SD}=0.728) ; \mathrm{V} 5$ $(\mathrm{M}=3.85, \mathrm{SD}=0.965) ; \mathrm{V6}(\mathrm{M}=1.68, \mathrm{SD}=1.104)$ (Table 5.5). Overall, the relationships were positive, moderate and statistically significant $P<0.05$ between the variables. This indicates consistency between what the architects report to adopt personally in their respective designs and what they suspect other architects are adopting.

\subsubsection{Cross examination between "I frequently apply the principles of sun shading in my design and respondents' characteristics"}

The results in the knowledge category and the respondent's characteristics were cross-examined to establish if respondents' characteristics had any impact on their level of ESD adoption. The independent variables include age, gender, years of architectural experience, and level of qualification. The dependent variable "I frequently apply the principles of sun shading in my design" was selected because it is the self-reported item with the highest mean. The cross examination tested the null hypothesis that there is no significant difference between the dependent and independent variables. The results showed a significant relationship between the adoption of sun shading principles and age. However, the study concluded that there was no significant relationship between the adoption of sun shading principles and gender, years of architectural experience, and level of educational qualification (Appendix A). Given the statistically significant relationship between sun shading principles and age, the paragraph below provides an overview of the results.

To test the null hypothesis that the dependent variable ("I frequently apply the principles of sun shading in my design" - $M=3.85$, $\mathrm{SD}=0.965$ ) and independent variable age (see Table 5.1) are not statistically different, the one-way ANOVA was performed. The assumption of normality was evaluated and found tenable for all items. The assumption of homogeneity of variance was tested and found tenable using the Levene's Test $F(2,127)=0.067, \mathrm{p}=0.935$. The ANOVA (Table 5.6) was not significant, $\mathrm{F}(2,127)=0.366, \mathrm{p}$ $=0.694, \mathrm{n}^{2}=0.0057$. Thus, there was no significant evidence to reject the null hypothesis and the study concluded that there is a significant relationship between "I frequently apply the principles of sun shading in my design" and respondents' age. A review of the means plot (Figure 5.3) shows that respondents aged 60 and above are more likely to adopt sun shading principles in their respective designs. Inequality of sample size or distribution is not an issue because ANOVA simply checks the means of two or more groups to establish any significant difference between groups based on the means and not the sample sizes between the groups. The ANOVA is not distorted, so long as the assumption of independence or normality is not violated and there are no outliers present (Blanca, Alarcón, Arnau, Bono, \& Bendayan, 2018; Cuevas, Febrero, \& Fraiman, 2004). In other words, the sample sizes within the group have no effect on the reliability of the ANOVA.

Table 5. 6: Analysis of variance between Age and "I frequently apply the principles of sun shading in my design (i.e. shared shade, shadow umbrella, overhead shades, daylight enhance shade)"

\begin{tabular}{lccccc}
\hline & Sum of Squares & df & Mean Square & F & Sig. \\
\hline Between Groups & .689 & 2 & .344 & .366 & .694 \\
\hline Within Groups & 119.534 & 127 & .941 & & \\
\hline Total & 120.223 & 129 & & & \\
\hline
\end{tabular}




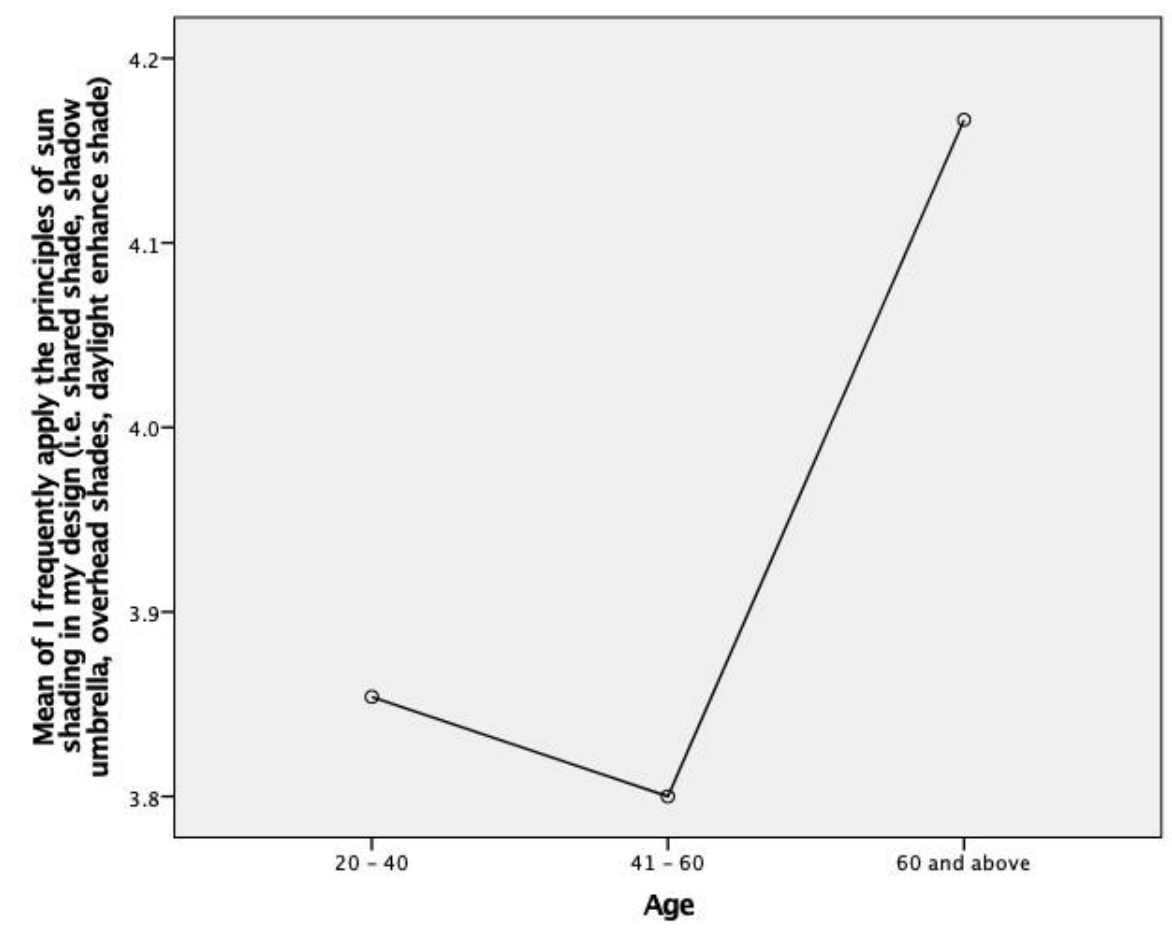

Figure 5. 3: Means plot of the relationship between respondents' Age and "I frequently apply the principles of sun shading in my design (i.e. shared shade, shadow umbrella, overhead shades, daylight enhance shade)"

5.1.3.2 Cross examination between "Most Nigerian architects always provide cross ventilation in their designs" and respondents'

\section{characteristics}

The results in the knowledge category and the respondent's characteristics were cross-examined to establish if respondents' characteristics had any impact on the level of ESD adoption. The independent variables include age, gender, years of architectural experience, and level of qualification. The dependent variable "Most Nigerian architects always provide cross ventilation in their designs" was selected because it is the respondent's perception of what is done by other architects with the highest mean. The cross examination tested the null hypothesis that there is no significant difference between the dependent and independent variables. The results showed a significant relationship between "Most Nigerian architects always provide cross ventilation in their designs" and age, gender, and level of educational qualification. However, the study concluded that there was no significant relationship between "Most Nigerian architects always provide cross ventilation in their designs" and years of architectural experience or level of educational qualification (Appendix A). Given the statistically significant relationship between "Most Nigerian architects always provide cross ventilation in their designs" and age and gender the sections below provide abreakdown overview of the results.

\section{- Age}

To test the null hypothesis that the dependent variable ("Most Nigerian architects always provide cross ventilation in their designs" $M=4.49, \mathrm{SD}=0.809$ ) and independent variable age (see Table 5.1) are not statistically different, the one-way ANOVA was performed. The assumption of normality was evaluated and found tenable for all items. The assumption of homogeneity of variance was tested and found tenable using the Levene's Test $F(2,127)=1.275, \mathrm{p}=0.283$. The ANOVA (Table 5.7) was not significant, $\mathrm{F}(2,127)=1.269$, $\mathrm{p}=0.285, \mathrm{n}^{2}=0.02$. Therefore, there is no significant evidence to reject the null hypothesis and the study concluded that there is a significant relationship between "Most Nigerian architects always provide cross ventilation in their designs" and age. A review of the mean plot (Figure 5.4) showed that respondents aged 60 and above agreed that "Most Nigerian architects always provide cross ventilation in their designs". However, this perception decreased with younger respondents.

Table 5. 7: Analysis of variance between respondents' Age and "Most Nigerian architects always provide cross ventilation in their designs"

\begin{tabular}{lccccc}
\hline & Sum of Squares & df & Mean Square & F & Sig. \\
\hline Between Groups & 1.655 & 2 & .828 & 1.269 & .285 \\
\hline Within Groups & 82.837 & 127 & .652 & & \\
\hline Total & 84.492 & 129 & & \\
\hline
\end{tabular}




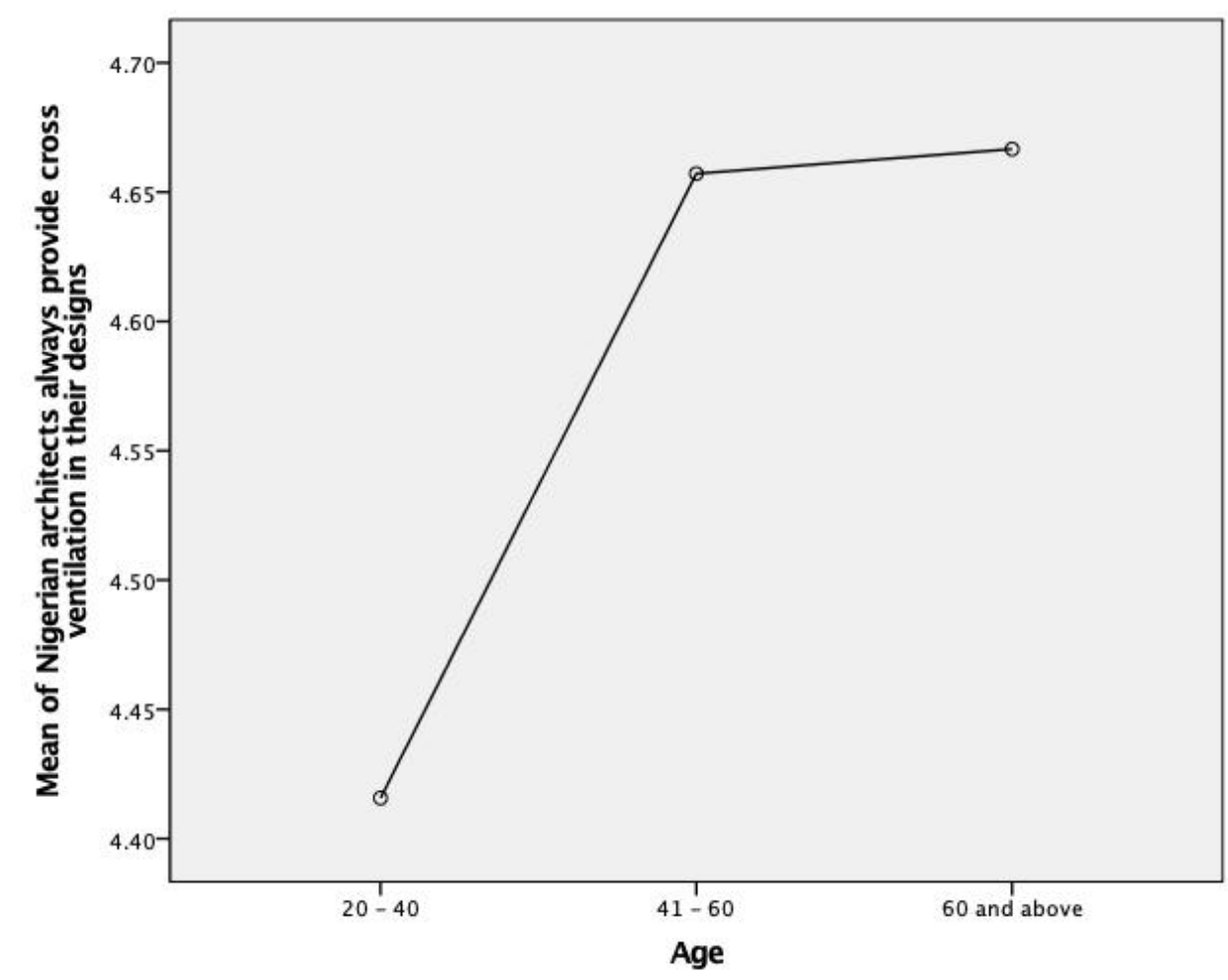

Figure 5. 4: Means plot of the relationship between respondents' Age and "Most Nigerian architects always provide cross ventilation in their designs"

\section{- Gender}

To test the null hypothesis that the dependent variable ("Most Nigerian architects always provide cross ventilation in their designs" $M=4.49, \mathrm{SD}=0.809$ ) and independent variable gender (see Table 4.1) are not statistically different, the one-way ANOVA was performed. The assumption of normality was evaluated and found tenable for all items. The assumption of homogeneity of variance was tested and found tenable using the Levene's Test $F(1,128)=1.165, \mathrm{p}=0.282$. The ANOVA (Table 5.8) was not significant, $\mathrm{F}$ $(1,128)=0.373, \mathrm{p}=0.542, \mathrm{n} 2=0.003$. Therefore, there was no significant evidence to reject the null hypothesis and the study concluded that there was a significant relationship between "Most Nigerian architects always provide cross ventilation in their designs" and gender. A review of the means plot (Figure 5.5) showed that male respondents were more likely to agree that "Most Nigerian architects always provide cross ventilation in their designs".

Table 5. 8: Analysis of variance between respondents' Gender and Nigerian architects always provide cross ventilation in their designs

\begin{tabular}{lccccc}
\hline & Sum of Squares & df & Mean Square & F & Sig. \\
\hline Between Groups & .246 & 1 & .246 & .373 & .542 \\
\hline Within Groups & 84.247 & 128 & .658 & & \\
\hline Total & 84.492 & 129 & & & \\
\hline
\end{tabular}

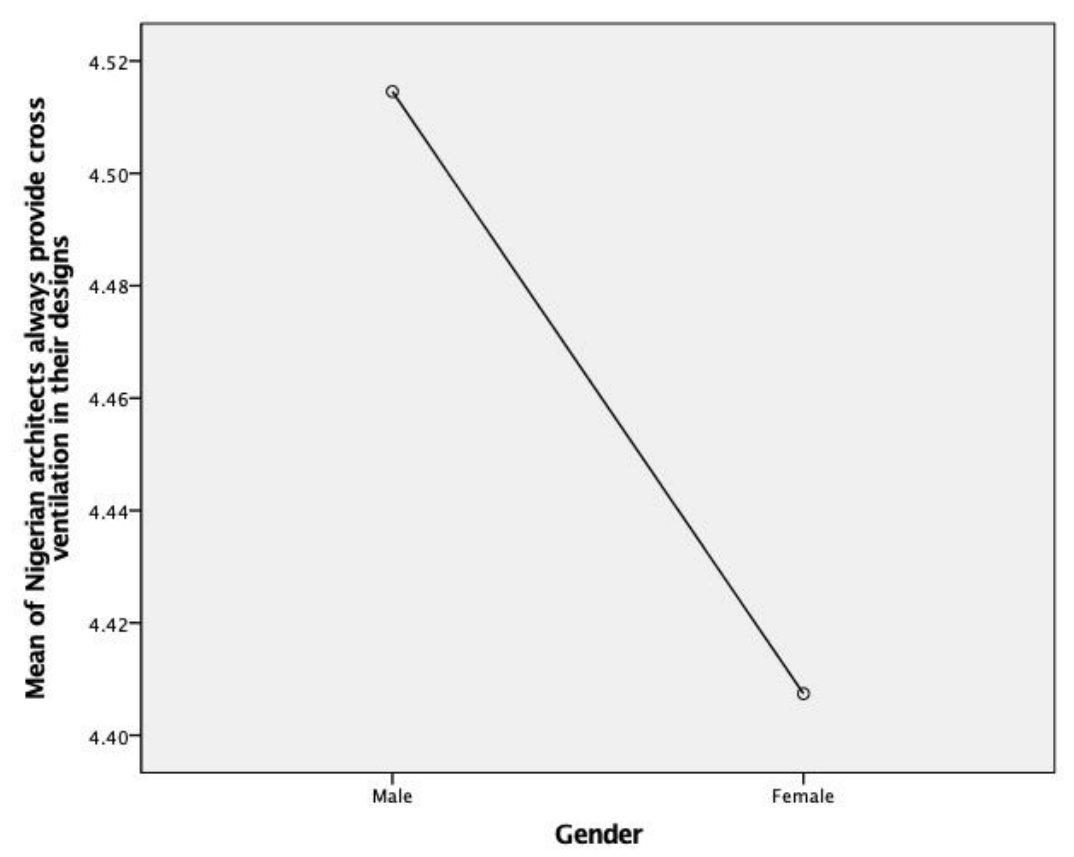

Figure 5. 5: Means plot of the relationship between respondents' gender and "Most Nigerian architects always provide cross ventilation in their designs" 


\subsubsection{Cross examination between age, years of experience, and the adoption of renewable energy sources}

\section{- Age}

To test the null hypothesis that the dependent variable "For most of my designs I specify photovoltaic systems or other renewable energy sources" - $M=2.46, \mathrm{SD}=1.083$ ) and independent variable age (see Table 5.1) are not statistically different, the one-way ANOVA was performed. The assumption of normality was evaluated and found tenable for all items. The assumption of homogeneity of variance was tested and found tenable using the Levene's Test $F(2,126)=0.043, \mathrm{p}=0.958$. The ANOVA (Table 5.9) was not significant, $\mathrm{F}(2,126)=0.228, \mathrm{p}=0.796, \mathrm{n}^{2}=0.003$. Therefore, there was no significant evidence to reject the null hypothesis and the study concluded that there was a significant relationship between the respondent's age and "For most of my designs I specify photovoltaic systems or other renewable energy sources". A review of the means plot (Figure 5.6) showed that younger respondents were more likely to adopt renewable energy sources in their respective designs.

Table 5. 9: Analysis of variance between respondents' age and "For most of my designs I specify photovoltaic systems or other renewable energy sources"

\begin{tabular}{cccccc}
\hline & Sum of Squares & df & Mean Square & F & Sig. \\
\hline Between Groups & .542 & 2 & .271 & .228 & .796 \\
\hline Within Groups & 149.474 & 126 & 1.186 & & \\
\hline Total & 150.016 & 128 & & & \\
& & & & & \\
\hline
\end{tabular}

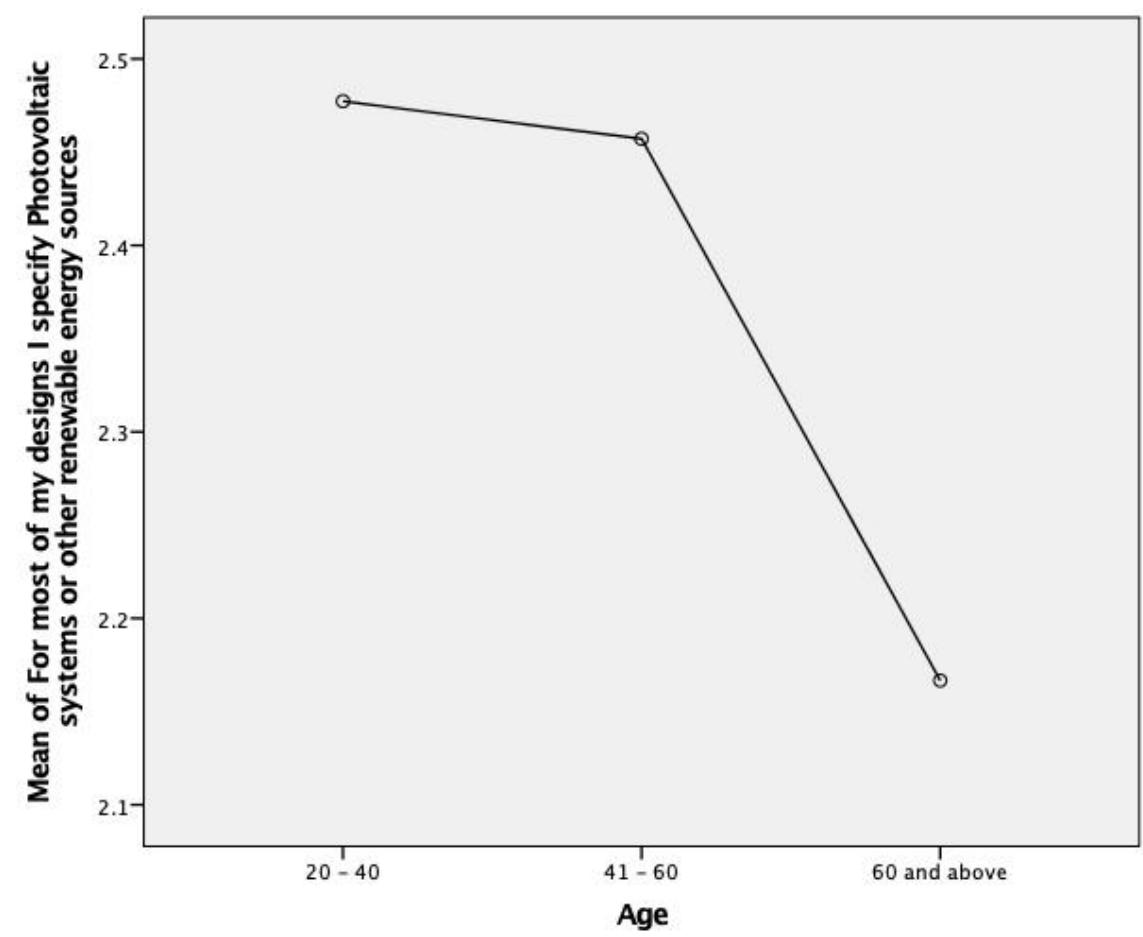

Figure 5. 6: Means plot of the relationship between respondents' age and "For most of my designs I specify photovoltaic systems or other renewable energy sources"

\section{- Years of architectural experience}

To test the null hypothesis that the dependent variable ("For most of my designs I specify photovoltaic systems or other renewable energy sources" - $M=2.45, \mathrm{SD}=1.089$ ) and independent variable years of architectural experience (see Table 5.1) are not statistically different, the one-way ANOVA was performed. The assumption of normality was evaluated and found tenable for all items. The assumption of homogeneity of variance was tested and found tenable using the Levene's Test $F(3,123)=1.827, \mathrm{p}=0.146$. The ANOVA (Table 5.10) was not significant, $F(3,123)=2.233, \mathrm{p}=0.088, \mathrm{n}^{2}=0.05$. Therefore, there was no significant evidence to reject the null hypothesis and the study concluded that there was a relationship between respondents' years of architectural experience and "For most of my designs I specify photovoltaic systems or other renewable energy sources”. A review of the means plot (Figure 5.7) showed that respondents with 10 - 19 years of architectural experience were more likely to specify renewable energy sources in their respective designs, with the level of positive responses decreasing with the more experienced respondents. 


\section{Chapter 5 | Results from Study}

Table 5. 10: Analysis of variance between respondents' years of architectural experience and "For most of my designs I specify photovoltaic systems or other renewable energy sources"

\begin{tabular}{lccccc}
\hline & Sum of Squares & df & Mean Square & F & Sig. \\
\hline Between Groups & 7.719 & 3 & 2.573 & 2.233 & .088 \\
\hline Within Groups & 141.698 & 123 & 1.152 & & \\
\hline Total & 149.417 & 126 & & & \\
\hline
\end{tabular}

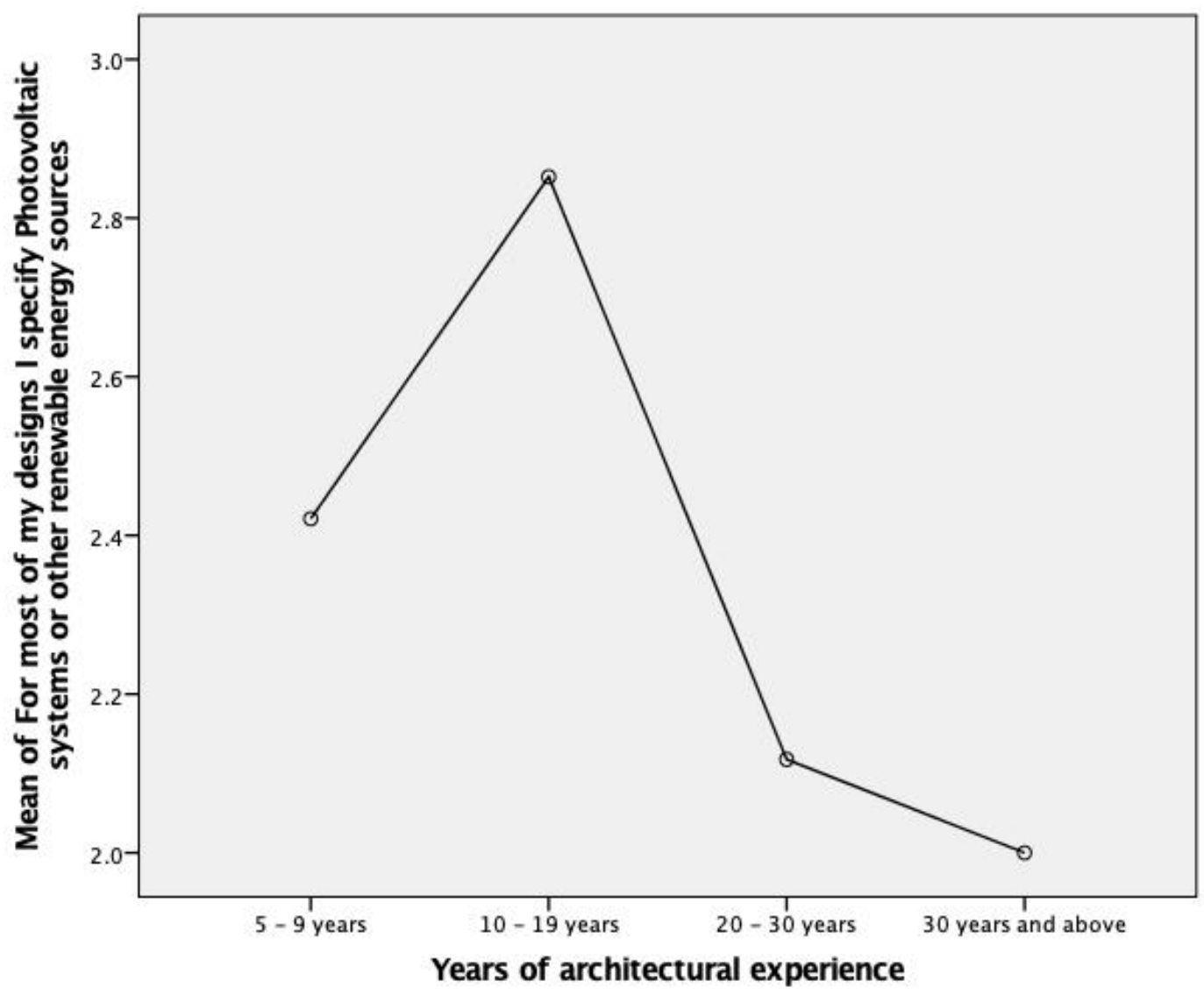

Figure 5. 7: Means plot of the relationship between respondents' years of architectural experience and "For most of my designs I specify photovoltaic systems or other renewable energy sources”

Overall, the results suggested that when compared to the younger architects, older architects were more likely to adopt a bioclimatic design approach. Similarly, despite the lack of adoption of photovoltaic systems or other renewable energy sources, Figure 5.7 shows that when compared to the older architects, younger architects were more likely to adopt passive architectural design approaches involving renewable and energy efficient technologies such as the specification of solar panels. This result is consistent with existing studies as noted in Section 3.3 .

\subsubsection{Relationship between items in the agreement and knowledge category}

Having provided several cross examinations within the knowledge category, the study conducted further analysis to ascertain the correlation between the agreement and knowledge category. One example was to determine whether respondents who reported that electricity supply is unsatisfactory were more likely to specify renewable energy sources. A Pearson Correlation examined (Table 5.11) the relation between "In hot indoor environments, achieving thermal comfort through the use of an electric fan becomes a problem because of the unsatisfactory electricity supply in Nigeria" $(M=5.07, \mathrm{SD}=1.149)$ and "For most of my designs I specify Photovoltaic systems or other renewable energy sources" ( $M=2.46, \mathrm{SD}=1.083)$. Preliminary analysis showed no violations in the assumption of normality, linearity, or homoscedasticity. However, the relationship was negative, weak, and statistically insignificant $P(0.719)>$ 0.05 . 
Chapter 5 | Results from Study

Table 5. 11: Pearson Correlation examining the relation between unsatisfactory electricity supply and the specification of renewable energy sources

\begin{tabular}{|c|c|c|c|}
\hline & & $\begin{array}{l}\text { In hot indoor environments, achieving } \\
\text { thermal comfort through the use of an electric } \\
\text { fan becomes a problem because of the } \\
\text { unsatisfactory electricity supply in Nigeria }\end{array}$ & $\begin{array}{c}\text { For most of my designs I specify } \\
\text { Photovoltaic systems or other } \\
\text { renewable energy sources }\end{array}$ \\
\hline \multirow{3}{*}{$\begin{array}{l}\text { In hot indoor environments, } \\
\text { achieving thermal comfort } \\
\text { through the use of an electric } \\
\text { fan becomes a problem because } \\
\text { of the unsatisfactory electricity } \\
\text { supply in Nigeria }\end{array}$} & Pearson Correlation & 1 & -.032 \\
\hline & \begin{tabular}{|l} 
Sig. (2-tailed) \\
\end{tabular} & & .719 \\
\hline & $\mathrm{N}$ & 130 & 129 \\
\hline \multirow{3}{*}{$\begin{array}{l}\text { For most of my designs I specify } \\
\text { Photovoltaic systems or other } \\
\text { renewable energy sources }\end{array}$} & Pearson Correlation & -.032 & 1 \\
\hline & \begin{tabular}{|l} 
Sig. (2-tailed) \\
\end{tabular} & .719 & \\
\hline & $\mathrm{N}$ & 130 & 130 \\
\hline
\end{tabular}

The result suggested that respondents who specify photovoltaic systems or other renewable energy sources most likely do so, not specifically for the provision of thermal comfort, but as a result of other factors like electricity generation to power household appliances as discussed in Section 3.5.

\subsubsection{Do we have the right technology to enhance the adoption of ESD?}

As indicated in Chapter 3, the lack of technological development in terms of the production and maintenance of energy efficient systems, stack ventilation systems, and other sustainable technologies could be a possible barrier to the mainstream adoption of ESD in Nigeria. The aim of the technology category is to establish if the absence of technology is a barrier and if Nigerians have the right expertise to manufacture and maintain energy generation and efficient systems. In addition, the results would give an indication as to whether a lack of knowledge has led to an over-dependence on readily available systems like air conditioners instead of being innovative in generating passive and sustainable means of attaining thermal comfort. As shown on Figure 5.8, most of the respondents somewhat agreed that there is shortage in manpower and skills to manufacture and maintain energy efficient appliances, and that the lack of technological development is a barrier to ESD in Nigeria. Similarly, respondents reported some level of dependence on mechanical ventilation.

Figure 5. 8: Do we have the right technology to enhance the adoption of ESD? Please select the option that describes your opinion about the following statements on a scale of 1 to 6 , with 1 being strongly disagree and 6 being strongly agree

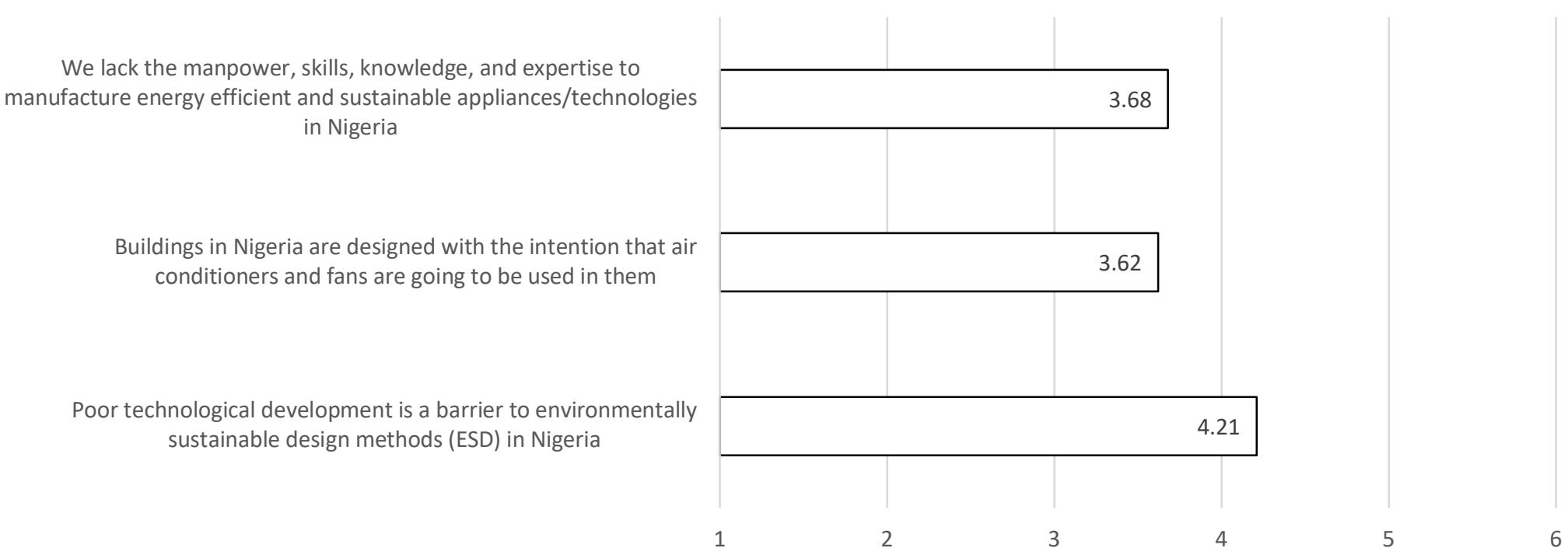

Mean Distribution 1 - Strongly disagree; 2 - Disagree; 3 - Somewhat disagree; 4 - Somewhat agree; 5 - Agree; 6 - Strongly agree ${ }^{*}<3.5$ Disagree, $>3.5$ Agree

To provide a better understanding of the results in Figure 5.8, further analysis was conducted to ascertain the correlation between the technology and agreement category. In this instance, "Buildings in Nigeria are designed with the intention that air conditioners and fans are going to be used in them" ( $\mathrm{M}=3.62, \mathrm{SD}=1.164)$ was related to "In hot indoor environments, achieving thermal comfort through the use of an electric fan becomes a problem because of the unsatisfactory electricity supply in Nigeria" $(\mathrm{M}=5.07, \mathrm{SD}=$ 1.149)? The aim of this analysis was to establish if mechanical ventilation is considered a more preferable means of achieving thermal 
comfort. A Pearson Correlation (Table 5.12) examined the relation between both variables and the relationship was positive and statistically significant $P(0.011)<0.05$.

Table 5. 12: Pearson Correlation between "Buildings in Nigeria are designed with the intention that air conditioners and fans are going to be used in them" and "I design buildings with the intention of having an air-conditioner and fan"

\begin{tabular}{l|l|c|c}
\multicolumn{2}{ll}{} & $\begin{array}{c}\text { In hot indoor environments, } \\
\text { achieving thermal comfort through } \\
\text { the use of an electric fan becomes } \\
\text { a problem because of the } \\
\text { unsatisfactory electricity supply in } \\
\text { Nigeria }\end{array}$ & $\begin{array}{c}\text { Buildings in Nigeria are } \\
\text { designed with the } \\
\text { intention that air } \\
\text { conditioners and fans are } \\
\text { going to be used in them }\end{array}$ \\
\hline $\begin{array}{l}\text { In hot indoor environments, achieving thermal } \\
\text { comfort through the use of an electric fan } \\
\text { becomes a problem because of the unsatisfactory } \\
\text { electricity supply in Nigeria }\end{array}$ & Pearson Correlation & 1 & $.223^{*}$ \\
\cline { 2 - 4 } & Sig. (2-tailed) & $\mathrm{N}$ & .011 \\
\hline
\end{tabular}

*. Correlation is significant at the 0.05 level (2-tailed).

Since the direction of the relationship between the variables was positive (Table 5.12), the higher response rates between the variables were associated (Cohen, 1988). In other words, respondents who agreed that in hot indoor environments, achieving thermal comfort through the use of an electric fan becomes a problem because of the unsatisfactory electricity supply in Nigeria, also agreed that buildings in Nigeria are designed with the intention that air conditioners and fans will be used in them. Architects who reported that achieving thermal comfort was a problem without mechanical ventilation were more likely to specify mechanical ventilation in their respective designs. This suggests that these respondents considered mechanical ventilation as the preferred means of achieving thermal comfort.

\subsubsection{Are economic factors a possible barrier to ESD?}

This category sets out to explore the impact of economic barriers (i.e. cost) on the mainstream adoption of ESD in Nigeria. As shown in Chapter 3, economic factors have been reported as a possible barrier to the adoption of ESD in Nigeria, specifically in terms of the purchase of energy efficient appliances and the lack of financial incentives from the public and private sectors. The results in Figure 5.9 illustrate that renewable energy sources could be slightly more expensive. In addition, respondents reported a lack of financial incentives for renewable energy sources. When compared to ESD, most of the respondents considered budget and cost a priority.

Figure 5. 9: Are economic factors a possible barrier to ESD? Please select the option that describes your opinion about the following statements on a scale of 1 to 6 , with 1 being strongly disagree and 6 being strongly agree 
The study investigated the relation between the economic and knowledge category. A Pearson Correlation examined both categories to establish if a correlation exists between those respondents who specified energy generation systems and those who reported that energy generation systems are expensive. The variables were "Environmentally sustainable design methods and renewable energy sources like solar panels are expensive" $(\mathrm{M}=3.59, \mathrm{SD}=1.105)$ and "For most of my designs I specify Photovoltaic systems or other renewable energy sources" ( $\mathrm{M}=2.46, \mathrm{SD}=1.083)$. The Pearson Correlation (Table 5.13) was positive and statistically significant $P$ $(0.311)<0.05$

Table 5. 13: Pearson Correlation between environmentally sustainable design methods and renewable energy sources like solar panels are expensive and "For most of my designs I specify Photovoltaic systems or other renewable energy sources"

\begin{tabular}{l|l|c|c}
\multicolumn{2}{l|}{} & $\begin{array}{c}\text { For most of my designs I } \\
\text { specify Photovoltaic systems } \\
\text { or other renewable energy } \\
\text { sources }\end{array}$ & $\begin{array}{c}\text { Environmentally sustainable } \\
\text { designs methods and renewable } \\
\text { energy sources like solar panels } \\
\text { are expensive }\end{array}$ \\
\hline $\begin{array}{l}\text { For most of my designs I specify } \\
\begin{array}{l}\text { Photovoltaic systems or other renewable } \\
\text { energy sources }\end{array}\end{array}$ & $\begin{array}{l}\text { Pearson } \\
\text { Correlation }\end{array}$ & 1 & $.311^{* * *}$ \\
\cline { 2 - 4 } & Sig. (2-tailed) & & .000 \\
\cline { 2 - 4 } & $\mathrm{N}$ & 129 & 129 \\
\hline
\end{tabular}

**. Correlation is significant at the 0.01 level (2-tailed).

Given that the Pearson Correlation was positive, the higher responses between the variables were associated. This suggests that respondents who agreed that solar panels are expensive also reported specifying them in their respective designs. In other words, respondents who specify photovoltaic systems or other renewable energy sources think they are expensive potentially because they are aware of the high initial capital cost.

\subsubsection{What is the public perception of ESD? Are they interested?}

This category evaluates the level of ESD adoption by Nigerian architects and the impact of social factors on the adoption of ESD. As in the previous questions, on a scale of 1-6, with 1 representing strongly disagree and 6 representing strongly agree, the architects were asked to rate the impact of social factors on the adoption of ESD in Nigeria. The results (Figure 5.10) show that the public perception towards ESD is inclined to a lack of interest.

Figure 5. 10: What is the public perception of ESD? Are they interested? Please select the option that describes your opinion about the following statements on a scale of 1 to 6 , with 1 being the lowest and 6 being the highest

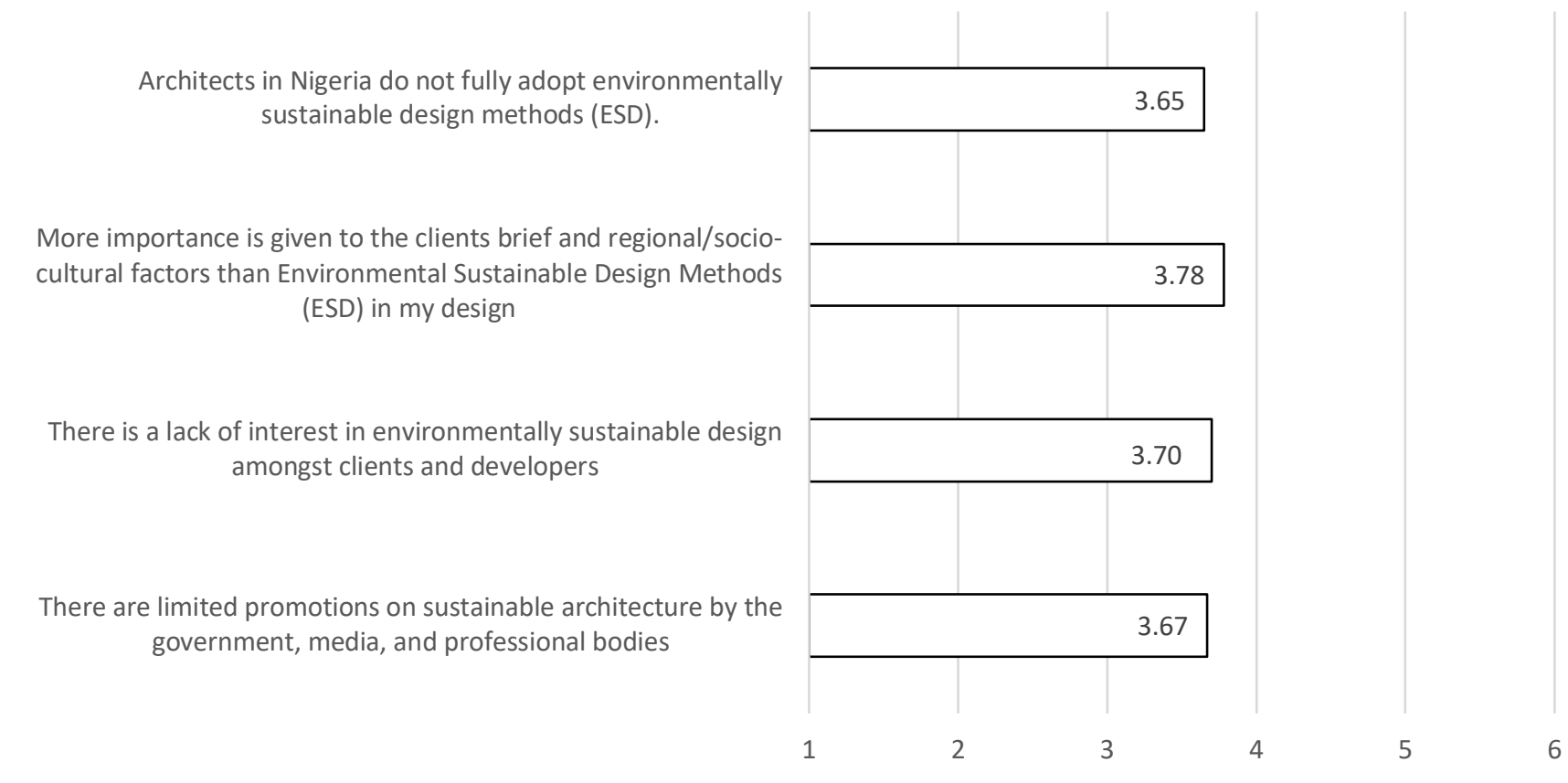

Mean Distribution 1 - Strongly disagree; 2 - Disagree; 3 - Somewhat disagree; 4 - Somewhat agree; 5 - Agree; 6 - Strongly agree ${ }^{*}<3.5$ Disagree, $>3.5$ Agree

To provide a good understanding of the results, further analysis was conducted to ascertain the correlation between the social and economic category. In this instance, the study was examining whether there was a relationship between the lack of interest among clients/developers $(\mathrm{M}=3.70, \mathrm{SD}=1.054)$ and the government/private sector not providing sufficient financial incentives and rewards 
for saving energy or using renewable energy sources like solar panels $(\mathrm{M}=1.89, \mathrm{SD}=1.051)$ ? A Pearson Correlation (Table 5.14) examined the relationship between both variables, and the relationship was statistically insignificant $P(0.958)>0.05$. This suggests that the client/developer's interest in ESD or lack of interest is not influenced by financial incentives and rewards from the government/private sectors.

Table 5. 14: Pearson Correlation between the lack of interest among clients/developers and the government/private sector not providing sufficient financial incentives and rewards for saving energy or using renewable energy sources like solar panels

\begin{tabular}{|c|c|c|c|}
\hline & & $\begin{array}{l}\text { There is a lack of interest } \\
\text { in environmentally } \\
\text { sustainable design } \\
\text { amongst clients and } \\
\text { developers }\end{array}$ & $\begin{array}{c}\text { The government and the private } \\
\text { sector provide sufficient financial } \\
\text { incentives and rewards for saving } \\
\text { energy or using renewable energy } \\
\text { sources like solar panels }\end{array}$ \\
\hline \multirow{3}{*}{$\begin{array}{l}\text { There is a lack of interest in environmentally } \\
\text { sustainable design amongst clients and } \\
\text { developers }\end{array}$} & Pearson Correlation & 1 & .069 \\
\hline & Sig. (2-tailed) & & .438 \\
\hline & $\mathrm{N}$ & 130 & 130 \\
\hline \multirow{3}{*}{$\begin{array}{l}\text { The government and the private sector provide } \\
\text { sufficient financial incentives and rewards for } \\
\text { saving energy or using renewable energy } \\
\text { sources like solar panels }\end{array}$} & Pearson Correlation & .069 & 1 \\
\hline & \begin{tabular}{|l|} 
Sig. (2-tailed) \\
\end{tabular} & .438 & \\
\hline & $\mathrm{N}$ & 130 & 130 \\
\hline
\end{tabular}

\subsubsection{Are there favourable ESD policies? If no, is that a possible barrier?}

Having examined the preceding research questions, the political category deals specifically with the issue of governance by evaluating the impact of existing policies and practices on the adoption of ESD in Nigeria. Like other groupings, respondents were asked to rate the efforts by the government and related institutions towards encouraging the mainstream adoption of ESD, specifically through their policies.

Figure 5. 11: Are there favourable ESD policies? If no, is that a possible barrier? Please select the option that describes your opinion about the following statements on a scale of 1 to 6 , with 1 being strongly disagree and 6 being strongly agree

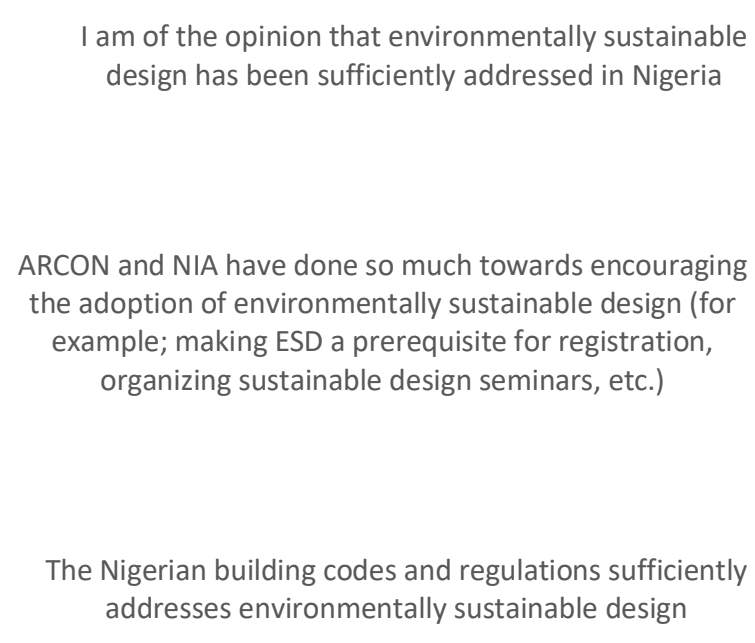
addresses environmentally sustainable design

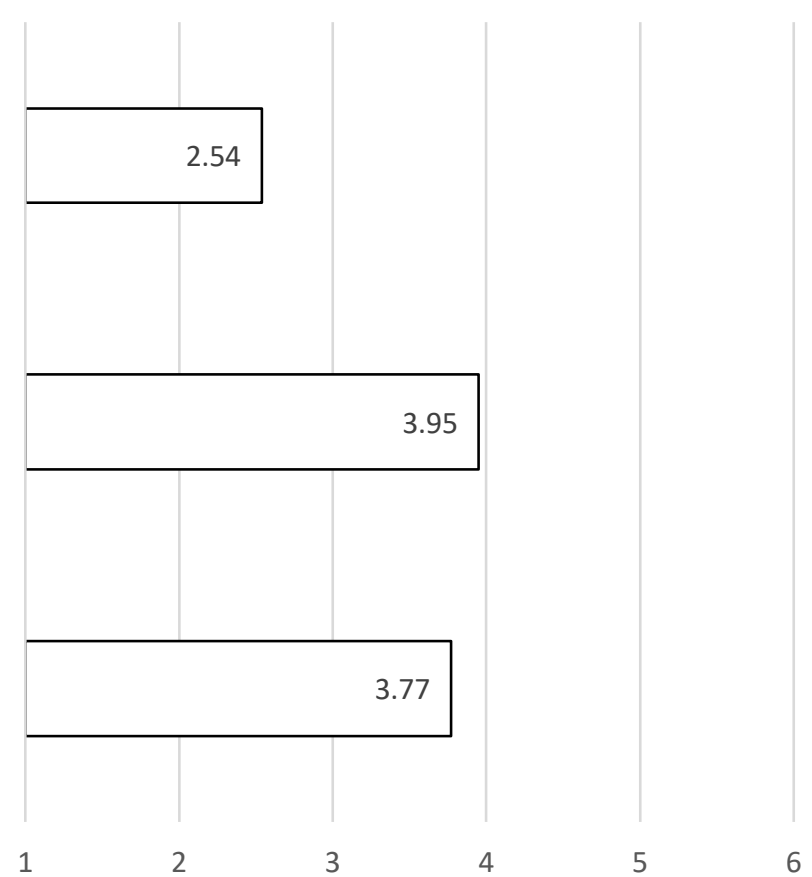

Mean Distribution 11 - Strongly disagree; 2 - Disagree; 3 - Somewhat disagree; 4 - Somewhat agree; 5 - Agree; 6 - Strongly agree ${ }^{*}<3.5$ Disagree, > 3.5 Agree

The results showed some level of effort by the government and related institutions towards encouraging the adoption of ESD in Nigeria. Respondents also reported, that irrespective of these efforts, ESD has not been sufficiently addressed in Nigeria. This shows that more work needs to be done by the government and related institutions like ARCON and NIA towards encouraging a sustainable built environment in Nigeria. 


\subsubsection{Summary of findings}

The results show an agreement amongst architects about the issue of thermal discomfort in indoor spaces (M-5.28), specifically in the absence of mechanical ventilation. Similarly, they noted that it was an architectural problem that needed to be addressed. Despite this agreement, the results show that most architects did not frequently adopt ESD such as photovoltaic systems, stack ventilation, courtyards, or windcatchers (Figure 5.2) for addressing the issues of thermal discomfort or electricity generation. This paucity in the adoption of ESD is due to architects having limited knowledge about ESD, lack of technological development, the high capital cost for ESD, and lack of interest by stakeholders in the building industry. It was reported that the government and its related institutions have made some efforts towards encouraging ESD. Nevertheless, the lack of mainstream adoption suggests that more work needs to be done by the public and private sectors to improve the adoption of ESD in Nigeria. Stages 2 and 3 of the study provide further insight into the reasons for a lack of mainstream adoption of ESD in Nigeria.

\subsection{Stage Two: Interview with Architects}

This stage sets out to gain a better understanding of the results from stage 1 and report the findings. In addition, stage 2 also forms a significant part of the triangulation process as stated in Chapter 4. A detailed outline of the sample design and data analysis technique adopted for stage 2 is provided in Chapter 4 . Of the 21 architects interviewed, 18 of the respondents were men and 3 were women. In terms of architectural experience, 9 respondents had between 20 - 29 years of architectural experience, 8 respondents had between 10 - 19 years of architectural experience, and 4 between 30 - 39 years of architectural experience. A total of 19 respondents had a Master's degree in Architecture (MArch), 2 had a Higher National Diploma in architecture (HND), and 1 had both a Master's and a Doctorate degree in architecture (PhD). During the interview, interviewees were not provided with a definition of ESD because it is the objective of the study to explore the architects' perception on the subject of ESD in the Nigerian context, based on their understanding of ESD. The results from the oral interview are presented in the following sections.

5.2.1 Research Question one: Do the architects agree on the need for environmentally sustainable design methods in Nigeria?

Interview question 1: What are the main factors you consider during your design?

To validate the response from question one in stage 1 and gain a better understanding of Nigerian architects' level of agreement on the problem of thermal discomfort and its correlation to ESD, participants were asked to discuss what they considered most important during a building design and describe what they commonly resolved with their respective designs. In analysing the data from the interview, eight themes emerged, which are discussed below. These themes were: function, form, sustainability, cost, clients' brief, environment, regulations and standards, and user comfort (see Appendix A).

Function was the most mentioned item by the participants. It was considered an important driver during a building design. Function or functionality is a broad terminology and can be sometimes confusing. However, when applying the content analysis approach as discussed in Chapter 4, the study was able to identify from further questioning of the respondents and data analysis that in most instances, the participants used the term function to describe space optimisation, indoor circulation, composition and order, structural stability and quality of building materials. Typical statements were:

\section{Form must follow function, I give more emphasis to the functionality of space}

Function is important, the building must be functional

This meant that functionality was not specifically adopted for environmentally conscious reasons, but to address the use and transition within spaces in a building. This is consistent with the results in stage 1 which showed that ESD relating to form and function such as periodic transformation of spaces and buffer/cooling zones was not frequently adopted. 


\section{Chapter $5 \mid$ Results from Study}

User comfort was the second most mentioned item. This reinforces the results from stage 1 on the problem of thermal discomfort. This suggests that, despite the need to address other factors such as cost, most participants considered the provision of user comfort an important factor. Most participants associated the attainment of user comfort to the provision of natural ventilation, thermal comfort, natural lighting and ventilation, cross ventilation, and the use of shading principles to ensure a comfortable indoor environment. Overall, this highlights the problem of thermal discomfort and the need to resolve it. Typical statements were:

During my design, I consider the weather, i.e. how we can utilise cross ventilation when mechanical systems are not working

Natural ventilation to ensure user comfort, because of the erratic power supply.

Form, as it relates to the building's aesthetics, appeal, and expression, was the third most mentioned item. According to participants, the aesthetics of a building most be bold, speak out and elevate the architecture of the neighbourhood where it is located. In most instances, the principle of "function follows form" was mentioned by some of the participants as an important driver during the conceptual stages of a building design project. Typical statements within this theme were:

Aesthetics of the building. When you design, your building most be bold and speak out

Function follows form

The clients' brief and the impact of social norms was the fourth most mentioned item. This correlates with form which addresses "fads" rather than ESD. This reinforces the results from stage 1 which noted the importance accorded to the client's brief during a design process and the resulting impact on ESD, specifically in instances where emphasis from the client is on fads.

.... the beautiful things they see influence people; they always want their buildings to look like what's the norm, hence the design influence

Cost of construction and maintenance was the fifth most important factor reported by the respondents, while sustainability, environmental factors, and building regulations were the least mentioned items. According to respondents, sustainable features and ESD consciousness could be beneficial in terms of long-term energy savings, but at the same time could be unfavourable in terms of the capital cost required to buy energy efficient systems.

...develop the clients' brief based on their economic ability to realize the brief

... we have started considering how we could tap into energy saving because of the power issues. Such as incorporating solar panels

The result indicates that most participants did not specifically work to adopt ESD, but naturally adopted some aspects of ESD in their respective designs. Environmental factors were mentioned in relation to conducting site analysis, while building regulations were in terms of building zoning requirements. In summary, results show that form and function had a strong influence on architects' decision-making processes. The need to address the aesthetics of a building could possibly be influenced by social influence. This implies that social factors could also be a determinant in the adoption of ESD, thus giving an indication of the role building owners play in the adoption of ESD. 
Chapter 5 | Results from Study

5.2.2 Research Question two: How knowledgeable is the Nigerian architect about ESD and what do they consider as a sustainable

design?

In order to validate Nigerian architects' knowledge and perception of ESD and establish the extent to which lack of knowledge could impede the adoption of ESD, interviewees were asked the following questions:

Interview question 2: What environmentally sustainable design methods are you most knowledgeable of and frequently adopt in your designs?

In stage 1, when the architects were asked to rate how often they adopted ESD and their opinion of how often other architects adopted ESD, the results showed that overall, architects rarely adopted most aspects of ESD. In interviews, architects were asked about what ESD they were most knowledgeable about and frequently adopted, to determine whether a lack of knowledge or interest may be barriers to adoption. The results showed that most architects were more knowledgeable about natural ventilation and lighting, and shading techniques, with few participants making reference to energy generation, recycling, and thermal insulation. This is consistent with results from stage 1 of the study. The following sections analyse the results, based on the identified themes.

Natural ventilation and lighting was most commonly cited. Most participants made references to cross ventilation, natural ventilation and lighting. This suggests that most of the respondents were more knowledgeable about and adopted these techniques in their respective designs. Typical statements from respondents in stage 2 include:

In my designs, I ensure that the building is cross-ventilated

We also ensure that every space has an opening to the external wall so you can have light and natural ventilation

Building shading and orientation was the second most cited factor. On the subject of shading, some respondents went further to give practical examples, highlighting an understanding of shading techniques. Comments from participants with a good understanding included:

I use fins to shade the windows and also landscaping to achieve adequate shading

The buildings are usually hot because they are not well oriented. If you place your windows on the North - East and South

- East, you would have good ambient temperature.

However, it was also observed that some respondents that made references to building shading and orientation techniques did not provide practical examples even when asked to give examples, potentially because they did not frequently adopt these techniques or did not have a good understanding of the techniques. As noted by some of the respondents:

In Nigeria we do not consider orientation even though we were taught at university

While I was at the University in Rivers State, I was taught how to calculate the comfort zones, but sadly ever since I left the university, I have not used it.

This indicates that some of the respondents who were knowledgeable about building shading and orientation adopted these principles; some were knowledgeable and did not frequently adopt them, as noted above due to the various potentially barriers, while others were not knowledgeable, as shown in the responses from interview question 3. This explains why in stage 1 (section 5.1.3) some of the respondents reported positively that most architects understood and utilised building orientation techniques, but negatively when asked about the fundaments of building orientation.

Energy generation and recycling was the third most cited factor. Within this theme, participants made reference to the adoption of renewable energy systems like solar panels, energy saving systems and recycling. Interestingly, one participant adopted rainwater harvesting techniques to address the issue of drought. Participants were knowledgeable about solar panels but reported infrequently specifying them in designs because of cost and maintenance issues. The provision of building insulation and investigation into reflectivity/radiative surfaces in their respective designs were also mentioned, however, they were the lowest cited factor. Typical 
Chapter 5 | Results from Study

statements in response to the question included the following;

We encourage our clients to use solar panels, that way energy is generated

Most recently, I also specify LED warm and white light to reduce energy consumption

I am doing a prototype building design for a church and for the design we are using rockwool insulation in the roof

The colour was light to reflect the sun rays as opposed to dark colours

Interview question 3: How did you know about ESD?

In response to the second question, most of the architects learnt about ESD from seminars and publications; followed by their architectural education in Nigeria; architectural education overseas; and professional experience. This is consistent with the results from stage 1 which showed a correlation between the adoption of ESD and architectural education, with some respondents in stage 1 reporting that they were encouraged to include ESD in their respective studio/design courses. However, a review of the results so far suggests that respondents were most likely encouraged to adopted specific aspects of ESD such as natural ventilation and shading as the respondents seem to be most knowledgeable and frequently adopt these methods. Typical statements from respondents included:

I acquired the knowledge about ESD after the university through seminars, reading books...

In my Nigerian university, we were also taught about cross ventilation and natural lighting

I learnt about ESD by reading books and from seminars by NIA and the internet

5.2.3 Do we have the right technology to enhance the adoption of ESD? If no, is that a possible barrier?

Interview question 4: Do you feel we have the right technology to enhance the adoption of ESD in Nigeria? If no, do you consider it a barrier preventing the adoption of ESD in Nigerian residential buildings?

The majority of respondents reported that technology was a barrier to ESD. According to these respondents, significant barriers include a lack of technological development in Nigeria and the reliance on imported energy efficient technologies which are generally expensive. However, a few of the respondents reported that technology was not a barrier to ESD, instead they emphasised that a lack of knowledge about ESD and socio-political issues was the primary barrier, rather than technology. A comparison of the results in stages 1 and 2 shows a close correlation, suggesting why technology was not strongly reported as a barrier in stage 1. Typical statements in response to the question included:

There is no technology, Nigerians are not doing anything to improve their technology, and everything is imported It is more of a socio-cultural problem and not technology

5.2.4 Are economic factors a possible barrier to ESD?

Interview question 5: Was cost a major determinant in the adoption or rejection of ESD? If no, what was the major determinant?

The results showed that the majority of interviewees considered cost and finance as a determinant and a barrier preventing the adoption of ESD, while a handful reported that cost and finance were not barriers to the adoption of ESD. According to this latter group, poor adoption of ESD was due to a lack of knowledge in ESD and social-political issues in Nigeria.

There is no finance, so people are not ready to experiment

If it's cheap, people will adopt it. People are looking for cost and durability

Economy is not a problem, but the perception of cost is the problem. If you look at the overall operational cost, you realize that it is cheaper

A lot of clients are not interested, whenever you talk about it, they are not concerned

Ifeel it is the mind-set people have about ESD 
Chapter 5 | Results from Study

In one of our projects, we had 20 solar panels at NGN2OO,OOO (USD 55O) each and after three years you are required to replace the batteries which in turn is a high cost of maintenance

The last comment from a respondent is consistent with the results in stage 1, which showed that respondents who have specified renewable energy sources like solar panels think they are expensive.

5.2.5 What is the public perception of ESD? Are they interested?

Interview question 6: What do you think is the public perception of ESD?

To validate the response from stage 1 and gain a better understanding on the public perception of ESD, respondents were asked to discuss public acceptance of, or resistance to, ESD. In analysing the interview data, three themes emerged: knowledge, lack of demand, and social norms.

The results showed that the majority of interviewees considered the lack of public knowledge and awareness as impediments/barriers to adoption of ESD, while the remainder reported that the lack of demand and current social norms were the primary barriers discouraging the adoption of ESD. This reinforces the results from stage 1 which indicated that social factors were impediments/barriers preventing the adoption of ESD in Nigeria.

There is a lack of demand due to a lack of awareness

In society, people lack awareness

People are not really aware, on a scale on 1-10, I would rate the level of awareness as "4"

ESD is rarely used because of a lack of awareness

If they are well informed, they will. The issue of ESD is for wellbeing, so if people are informed, they will welcome it. They will have questions for the architect

ESD is really complicated, and when you want to use louvres for example, people question its modernity. So, I try to make the louvres look modern by using wooden and aluminium slats to give them the modern effect

Interviewees' responses to the question indicated that social factors are barriers to ESD. An examination of the responses shows a close correlation between the knowledge and social categories.

5.2.6 Are there favourable ESD policies? If no, is that a possible barrier?

Interview question 7: Has the government enacted environmentally sustainable policies or played any role in educating the public in general or the building industry in particular on sustainability issues? What about the Nigerian Institute of Architects (NIA) and Architects Registration Council of Nigeria (ARCON)?

Unlike stage 1 of the study which showed limited promotion by the government and media, most of the interviewees in stage 2 reported that the government, National Building Code (NBC), and Building Consent Authorities do not encourage ESD. Based on the responses, the political barriers to ESD are divided into four themes: the issue of self-interest, lack of publicity, substandard building codes, and lack of enforcement. Conversely, a few interviewees reported that the government and the recently developed national building code encouraged ESD.

No government encouragement, all the affordable houses in Nigeria are done using the same old block technology The NBC and approval authorities are not professionals, so they are clueless and not informed

The BCA do not care, it is all about the money. They don't care about specification, materials, or the design. They are all interested in money 
Chapter 5 | Results from Study

Similarly, the majority of the interviewees emphasised that NIA and ARCON do not sufficiently encourage the adoption of ESD in Nigeria.

The only thing they have done is to review professional fees. They haven't done anything to improve the architects. NIA and ARCON are busy fighting each other; hence it's all about politics. They are not interested in progression

No, they haven't because of the friction between the NIA and ARCON

However, the minority reported that the NIA and ARCON have encouraged ESD through their annual seminars. Comments from respondents include:

Yes, NIA and ARCON have organised seminars to educate architects on ESD, so I believe the next generation would adopt it

NIA and ARCON have organised expos and seminars to showcase new products

5.2.7 Major findings of the study

Interview question 8: In your experience, what are the major obstacles to ESD?

For most of the architects, lack of knowledge was a fundamental barrier to ESD, while the remainder considered the government and its unfavourable policies, economic and social factors, and a lack of encouragement from NIA and ARCON as the primary barriers to the adoption of ESD in Nigeria. Typical statements in response to the question included:

...proper research will need to be promoted in Nigeria on how best our built environments can take advantage of the numerous benefits of ESD

The state government needs to have the political will to encourage ESD

Appendix A provides details of the complete results from the oral interview sessions. Based on the results from stages 1 and 2, the study identified three main barriers preventing the adoption of ESD in Nigeria:

- Knowledge (i.e. lack of awareness)

- Economic barrier (i.e. the initial cost of renewable energy sources, the durability, and maintenance cost of renewable energy sources)

- Social barrier (lack of demand and social norms)

The next section provides a better understanding of the above results by surveying the building owners and their respective buildings. 


\subsection{Stage Three: The building owner's perception of ESD}

As noted in Chapter 4, the aim of stage 3 is to provide a broader understanding of the results from stages 1 and 2 and gather relevant information on the building owner's perception of ESD and the level of ESD adoption in their respective buildings. Stages 1 and 2 showed a lack of interest in ESD amongst clients (i.e. building owners), stage 3 was intended to further explore this discovery. A review of the results from stages 1 and 2 highlighted three primary barriers to ESD: knowledge, economic, and social barriers (lack of demand and social norms). Stage 3 set out to establish if the building owners also perceived knowledge, economic and social factors as barriers to ESD in Nigeria, and whether there is a high demand for ESD among building owners.

The 142 respondents in stage 3 were all owners and occupants of the sampled buildings. The study found that most of the surveyed buildings (54\%) were four bedroom single-storey duplexes. The average household size was 5 people (including adults and children). These figures are consistent with similar previous studies (Adunola \& Ajibola, 2016; NBS, 2014; Oluwatayo et al., 2018). Information on the respondent's gender, age, and qualification was not collected because the questionnaires were generally completed by couples who had co-ownership of the building. Results from the investigation based on the objectives are described. Descriptive analysis and cross tabulation were carried out to investigate the perception and adoption of ESD. Specifically, the objectives were to establish:

\section{Section one}

- What the building owner considers most important during the design and construction of a building

- What is considered a problem

- What is the building owner's level of ESD awareness and the public interest in ESD?

\section{Section two}

- What defines the mainstream residential buildings in Nigeria, i.e. what is the level of ESD adoption? How is environmental sustainability addressed through its form, shape, and general morphology?

The internal consistency reliability of the items within this section was examined using the Cronbach Alpha coefficient test. The reliability estimates of the items within the grouping averaged 0.790, indicating strong internal consistency among items. Additionally, this result also suggests little measurement error in the instrument. Appendix B provides a descriptive table showing the mean and standard deviations. 


\section{Chapter 5 | Results from Study}

5.3.1 What the building owner considers most important during the design and construction of a building

The aim of this section is to establish what the building owner considers most important during the design and construction stages of their respective buildings. To provide answers, building owners were asked to select the option that best described their opinion on a scale of 1-6, with 1 being the least important factor considered during design and construction and 6 being the most important factor considered during the design and construction of their respective building.

Figure 5. 12: What the building owner considers most important during the design and construction of a building. On a scale of 1-6, with 1 being not important and 6 being extremely important, please rate the most important factors you considered during the design and construction of your house

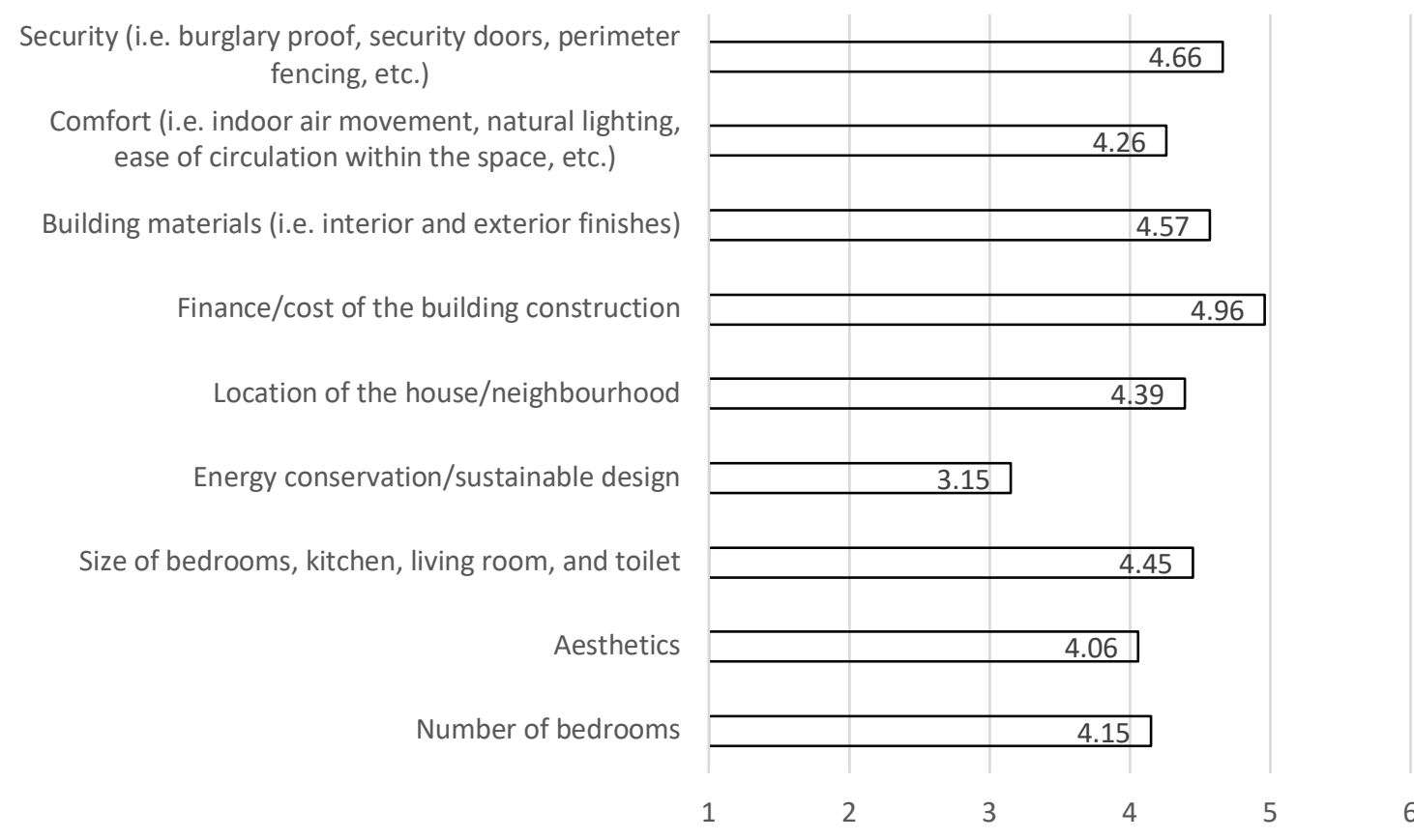

Mean Distribution $\mid$ 1 - Not important; 2 - Slightly important; 3 - Moderately important; 4 - Important; 5 - Very important; 6 - Extremely important * $<3.5$ Not important, $>3.5$ Important

The results in Figure 5.12 indicated that based on the mean, most of the items were somewhat important factors that the building owner considered during the design and construction of a building. Finance/cost of construction was the most important factor while energy conservation/sustainable design was the least important. Similarly, the building finishes and aesthetics, number and size of bedrooms, air movement and ease of circulation within the interior spaces were all considered very important during the design process. This is consistent with the results from stage 2 which showed that the main factors architects considered during a design process included finance/cost, aesthetics, natural ventilation and ease of transition within spaces. A review of the results in Figure 5.12 showed that respondents reported fairly positively in terms of comfort and fairly negatively in terms of ESD, despite the correlation between comfort and ESD. This suggests that building owners are not knowledgeable about energy conservation/sustainable design methods as a viable option for improving comfort. This is consistent with the results from Section 5.3.3 which showed that most building owners are not knowledgeable about ESD. 


\section{Chapter $5 \mid$ Results from Study}

5.3.2 The building owners' level of satisfaction with the building

The items within this grouping were developed as a scale to investigate the respondents' level of satisfaction within the internal spaces of their buildings and also highlight the aspects that pose a problem (Figure 5.13). In order to carry out this investigation, respondents were asked to rate their level of satisfaction or dissatisfaction with 1 being extremely dissatisfied and 6 being extremely satisfied.

Figure 5. 13: The building owners' level of satisfaction with the building. On a scale of 1-6, with 1 being extremely dissatisfied and 6 being extremely satisfied, how satisfied or dissatisfied are you with your house in terms of the following

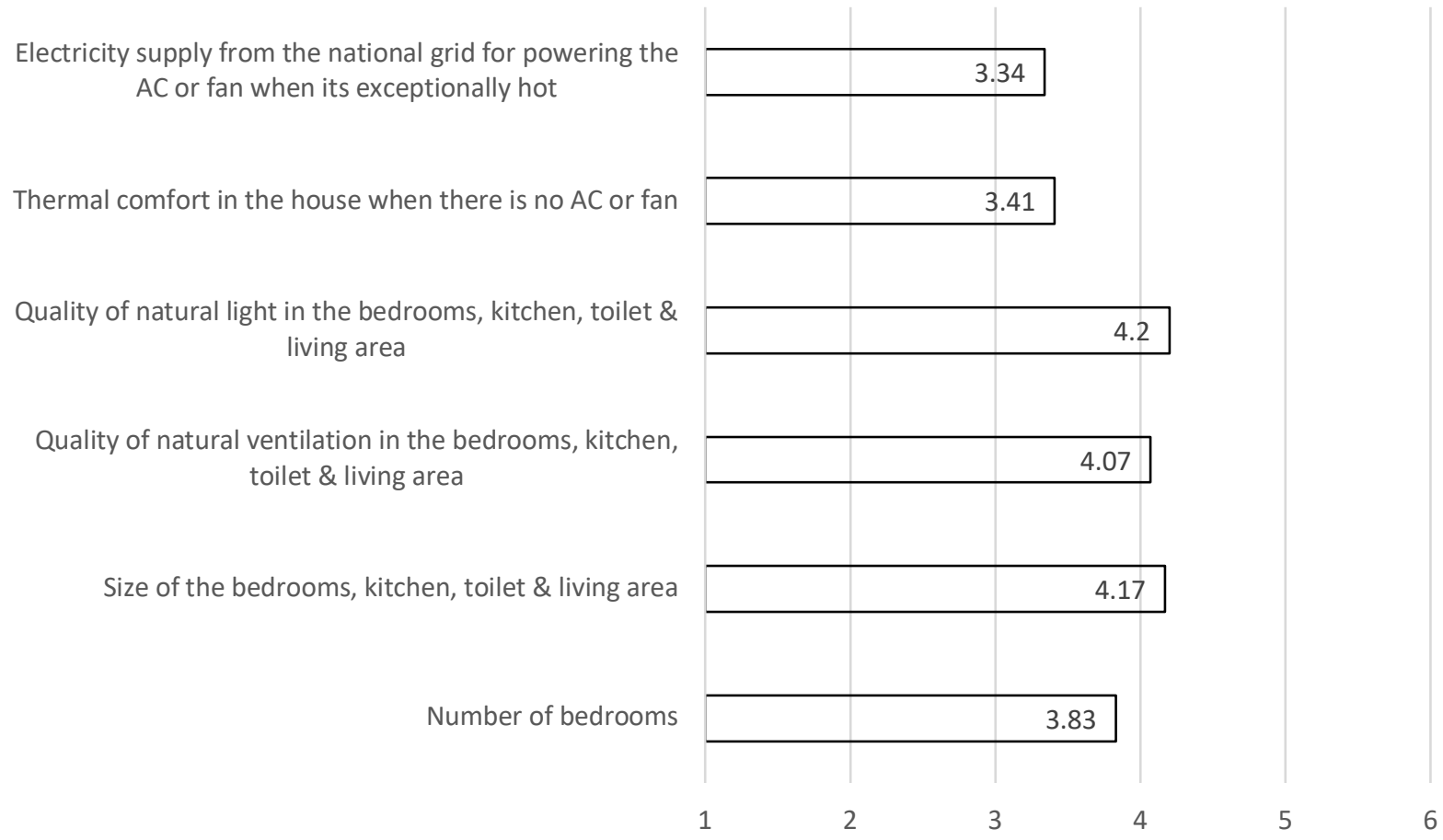

Mean Distribution 1 1 - Extremely dissatisfied; 2 - Very dissatisfied; 3 - Dissatisfied; 4 - Satisfied; 5 - Very Satisfied; 6 - Extremely Satisfied $*<3.5$ Dissatisfied, > 3.5 Satisfied

A review of the results above showed a low extent of thermal dissatisfaction in the absence of mechanical ventilation and a high extent of satisfaction with the quality of natural ventilation. This could be due to the shared assumption that mechanical ventilation is necessary for improving the quality of natural ventilation. This is consistent with the results from Section 5.1.3 which showed that most architects reported providing cross ventilation in their respective designs and simultaneously designed buildings with the intention of using mechanical ventilation, i.e. natural ventilation (i.e. cross ventilation and fenestrations) was supplemented with mechanical ventilation. Similarly, respondents reported being most satisfied with the quality of natural light within the internal spaces, and less satisfied with the provision of thermal comfort. This is consistent with the results from stage 1 (Section 5.1.3) which showed that most architects provided cross ventilation in their design but that buildings in Nigeria were not properly cross ventilated (Figure 5.2). This is possibly because most houses had window openings that provided natural lighting but did not adequately enhance thermal comfort, as noted in Section 5.1.3. Overall, building owners were fairly satisfied with aspects relating to size and the number of bedrooms. 
5.3.3 What is the building owner's level of ESD awareness and the public interest in ESD?

The items within this grouping are designed to establish the building owner's level of ESD awareness, the public interest in ESD, and investigate whether the government and private sector encourage ESD. The results in Figure 5.14 show a belief in the lack of effort from the government and private sector towards the provision of financial incentives for improving the adoption of ESD in Nigeria. The respondents also reported a low a level of interest in ESD by the public, a lack of demand and supply of ESD, and limited information and promotion of ESD in Nigeria. The building owners reported that they rarely adopted ESD and also that they were not fully knowledgeable about ESD.

Figure 5. 14: What is the building owner's level of ESD awareness and the public interest in ESD? On a scale of 1-6, with 1 being extremely low extent and 6 being extremely high extent, please rate the following statements
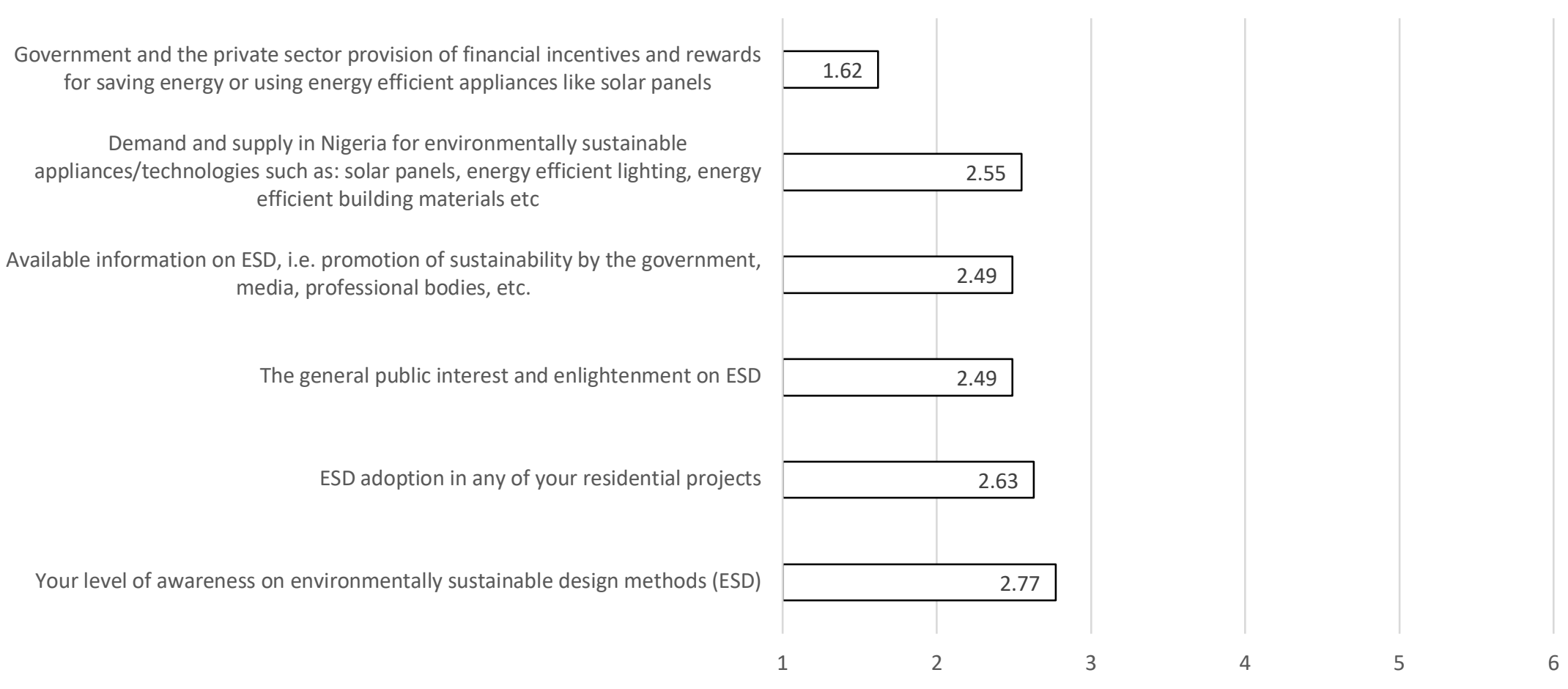

Mean Distribution 1 1 - Extremely low extent; 2 - Very low extent; 3 - Low extent; 4 - High extent; 5 - Very High extent; 6 - Extremely high extent * < 3.5 Disagree, $>3.5$ Agree

Given the consistency in the results above, the study conducted further analyses to ascertain any statistically significant correlation between the items in this category. Knowledge/awareness as a barrier to ESD was consistent throughout stages 1, 2, and 3 hence it was necessary to establish if the level of ESD awareness had any correlation with the adoption of ESD. A Pearson Correlation (Table 5.15) examined the relation between "Your level of awareness on environmentally sustainable design methods" (ESD) (M = 2.77, SD $=1.61)$ and "ESD adoption in any of your residential projects" $(\mathrm{M}=2.63, \mathrm{SD}=1.51)$. The relationship was positive, strong and statistically significant $P(0.871)<0.05$.

Table 5. 15: Pearson Correlation between "Your level of awareness on environmentally sustainable design methods (ESD)" and "ESD adoption in any of your residential projects"

\begin{tabular}{|c|c|c|c|}
\hline & & $\begin{array}{l}\text { ESD adoption in any of your } \\
\text { residential projects }\end{array}$ & $\begin{array}{c}\text { Your level of awareness on } \\
\text { environmentally sustainable design } \\
\text { methods (ESD) }\end{array}$ \\
\hline \multirow{3}{*}{$\begin{array}{l}\text { ESD adoption in any of your } \\
\text { residential projects }\end{array}$} & Pearson Correlation & 1 & $.871^{* * *}$ \\
\hline & Sig. (2-tailed) & & .000 \\
\hline & $\mathrm{N}$ & 142 & 142 \\
\hline \multirow{3}{*}{$\begin{array}{l}\text { Your level of awareness on } \\
\text { environmentally sustainable } \\
\text { design methods (ESD) } \\
\end{array}$} & Pearson Correlation & $.871^{* * *}$ & 1 \\
\hline & Sig. (2-tailed) & .000 & \\
\hline & $\mathrm{N}$ & 142 & 142 \\
\hline
\end{tabular}

**. Correlation is significant at the 0.01 level (2-tailed). 
As shown in the Pearson Correlation table (Table 5.15), the positive relationship indicates that the high level of awareness is closely associated with a high level of ESD adoption. Respondents who are aware of ESD are more likely to adopt it in their respective building projects. Similarly, a Pearson Correlation (Table 5.16) was conducted to establish if the low level of awareness (Figure 5.14) by building owners was as a result of the limited availability of information and promotion of ESD. The correlation showed a positive, and strong statistically significant relationship between the level of ESD awareness and the availability of information and promotion of ESD $P$ $(0.759)<0.05$

Table 5. 16: Pearson Correlation between "Your level of awareness on environmentally sustainable design methods (ESD)" and "Available information on ESD, i.e. promotion of sustainability by the government, media, professional bodies, etc."

\begin{tabular}{|c|c|c|c|}
\hline & & $\begin{array}{c}\text { Your level of awareness on } \\
\text { environmentally sustainable } \\
\text { design methods (ESD) }\end{array}$ & $\begin{array}{l}\text { Available information on ESD, i.e. } \\
\text { promotion of sustainability by the } \\
\text { government, media, professional } \\
\text { bodies, etc. }\end{array}$ \\
\hline \multirow{3}{*}{$\begin{array}{l}\text { Your level of awareness on } \\
\text { environmentally sustainable } \\
\text { design methods (ESD) }\end{array}$} & Pearson Correlation & 1 & $.759^{* * *}$ \\
\hline & Sig. (2-tailed) & & .000 \\
\hline & $\mathrm{N}$ & 142 & 142 \\
\hline \multirow{3}{*}{$\begin{array}{l}\text { Available information on ESD, } \\
\text { i.e. promotion of sustainability } \\
\text { by the government, media, } \\
\text { professional bodies, etc. }\end{array}$} & Pearson Correlation & $.759^{* * *}$ & 1 \\
\hline & Sig. (2-tailed) & .000 & \\
\hline & $\mathrm{N}$ & 142 & 142 \\
\hline
\end{tabular}

**. Correlation is significant at the o.01 level (2-tailed).

The positive relationship indicates that a high level of awareness is closely associated with a high level of available information. This suggest that respondents who reported that there is available information on ESD, also reported to have a good level of ESD awareness. Similarly, a Pearson Correlation (Table 5.16) was also conducted to establish if there was any statistically significant relationship between available information on ESD and the general public interest in ESD. The correlation showed a positive, strong and statistically significant relationship between the public interest in ESD and the availability of information and promotion of ESD $P(0.871)<0.05$.

Table 5. 17: Pearson Correlation between "The general public interest and enlightenment on ESD" and "Available information on ESD, i.e. promotion of sustainability by the government, media, professional bodies, etc.”

\begin{tabular}{|c|c|c|c|}
\hline & & $\begin{array}{l}\text { The general public } \\
\text { interest and } \\
\text { enlightenment on ESD }\end{array}$ & $\begin{array}{l}\text { Available information on ESD, i.e. } \\
\text { promotion of sustainability by the } \\
\text { government, media, professional } \\
\text { bodies, etc. }\end{array}$ \\
\hline \multirow{3}{*}{$\begin{array}{l}\text { The general public interest } \\
\text { and enlightenment on ESD }\end{array}$} & Pearson Correlation & 1 & $.871^{* * *}$ \\
\hline & Sig. (2-tailed) & & .000 \\
\hline & $\mathrm{N}$ & 141 & 141 \\
\hline \multirow{3}{*}{$\begin{array}{l}\text { Available information on } \\
\text { ESD, i.e. promotion of } \\
\text { sustainability by the } \\
\text { government, media, } \\
\text { professional bodies, etc. }\end{array}$} & Pearson Correlation & $.871^{* * *}$ & 1 \\
\hline & Sig. (2-tailed) & .000 & \\
\hline & $\mathrm{N}$ & 141 & 142 \\
\hline
\end{tabular}

Since the direction of the relationship between the variables was positive (Table 5.17), the higher response rates between the variables were associated (Cohen, 1988). In other words, respondents who agreed that the general public is interested and enlightened on ESD also agreed that there is available information on ESD: the public interest in ESD is statistically correlated to public awareness and enlightenment on ESD. 
5.3.4 During the building design consultation with your architect, did he or she inform you of any environmentally sustainable

design methods?

To expand on the building owner's level of ESD awareness, respondents were asked if the architect who designed their building informed them about environmentally sustainable design methods. The results (Figure 5.15) showed that 92\% of the respondents were not informed about ESD during consultation with their architect, while $8 \%$ of the respondents were. Given that the majority of the architects surveyed had limited knowledge about ESD (Section 5.1.3), there is less likelihood of them discussing ESD with a prospective client. Similarly, there is also a possibility that architects adopted certain principles that they were knowledgeable about like cross ventilation and shading techniques (Section 5.1.3) without specifically discussing these with their respective clients during the design consultation. RIBA (2019) report showed that architects who were quite knowledgeable and interested in sustainable design were more likely to bring up conversations about the benefits and importance of sustainable design with their respective clients. A lack of information or discussion with clients about ESD poses a barrier to ESD. As shown in Section 5.3.3, building owners who were informed about ESD, either through their architect, government, media, or professional bodies, were more likely to adopt ESD.

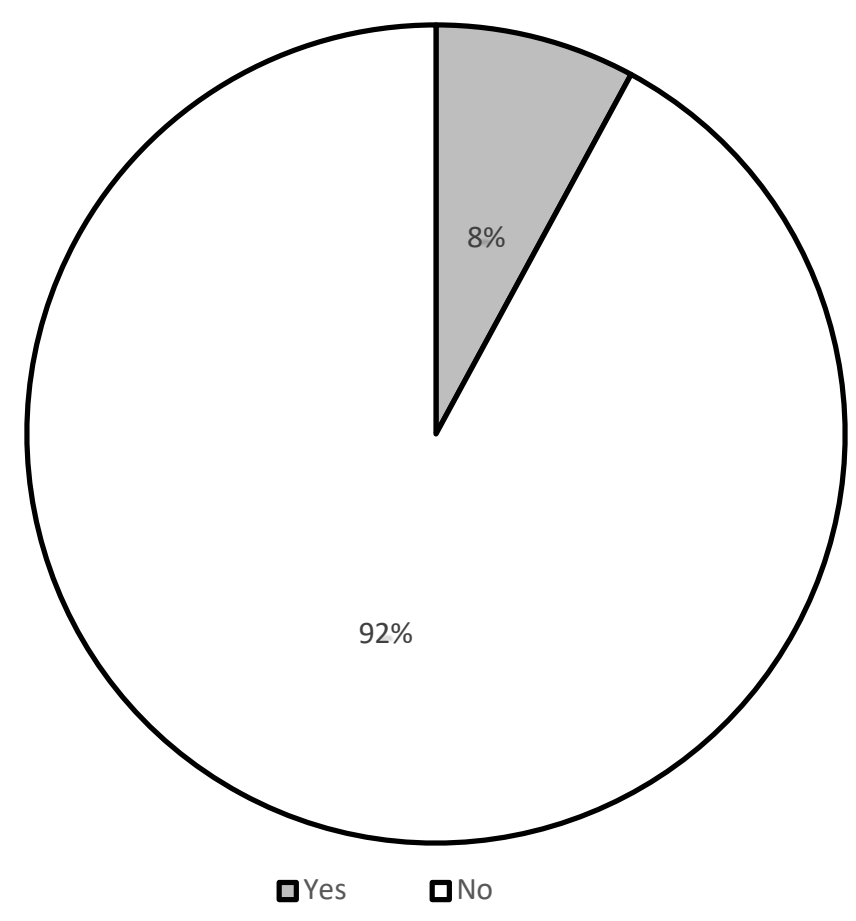

Figure 5. 15: During the building design consultation with your architect, did he or she inform you of any environmentally sustainable design method?

5.3.5 Most comfortable space in the house and why?

The questionnaire made provision for open-ended questions, with the aim of providing the researcher with insights into the completed questionnaire and opportunity to review the hypothesised barriers from previous sections. To achieve this, building owners were asked to discuss the spaces within their houses they considered to be most comfortable. The result showed that for some of the respondents the living room was considered the most comfortable, followed by the master bedroom and balcony. Typical statements from the respondents included:

Sitting area, it is spacious, well ventilated and airy

Family living room. The headroom gives you this free feeling and it is also cross ventilated

Sitting room: Greater privacy in the night when children have gone to sleep, listening to news and music

In analysing the data from the open-ended question, three themes emerged: ventilation, spaciousness, and relaxation/privacy. This is consistent with the results in Section 5.3.1 which showed that respondents reported comfort (i.e. ventilation, natural lighting, and circulation) and the size of spaces as important factors they considered during the design and construction of their respective houses. A review of the results showed that respondents were generally comfortable in the living/sitting room and not in the bedrooms or other spaces in the house. This reinforces the need for each space within a building to be properly designed to abate the problem of thermal discomfort through adopting sustainable design methods like natural ventilation techniques. 
Chapter 5 | Results from Study

5.3.6 Further Comments from Respondents

The respondents were asked to add any additional comments or suggestions in order to provide vital information on what may not have been covered in the questionnaire. In analysing the data from this section, three themes emerged: knowledge/awareness, political, and economic factors. Typical statements from the respondents included:

More public awareness is required

There is a need for public enlightenment and education on ESD. It should be adopted at the time of design and construction

Lack of space to incorporate ESD, houses are too closely built thereby reducing ventilation, there should be good town planning to provide enough space around buildings

reduced cost of installing solar panels because it is expensive to install them

These results are consistent with the results from stages 1, 2, and 3 which showed awareness, government policies, and cost as barriers preventing the adoption of ESD in the Nigerian housing sector. 


\subsection{Stage Three: Physical survey of their respective buildings}

The previous sections investigated the building owner's perception of ESD to identify possible barriers preventing the adoption of ESD in the Nigerian housing sector. Amongst others, knowledge/awareness, political, and economic factors were identified as barriers by the building owners. This section provides a breakdown of a visual physical examination conducted on the respondents' buildings. The aim of this is to establish what defines the mainstream residential buildings in Nigeria, i.e. what is the level of ESD adoption? This section is divided into six categories based on the checklist for physical survey of selected buildings (Section 2.6): ventilation/natural lighting, thermal comfort, cooling/internal noise levels, private outdoor space, lighting energy use/energy efficiency, and maximum electrical demand reduction. Some of the categories have been merged because some of the checklist items overlap.

\subsubsection{Ventilation/Natural lighting/Outdoor space}

The previous sections have discussed the provision of natural ventilation and lighting, with building owners considering these items essential towards the attainment of a comfortable indoor space, and architects reporting that they frequently provide cross ventilation in their designs. The aim of this section is validating this discovery.

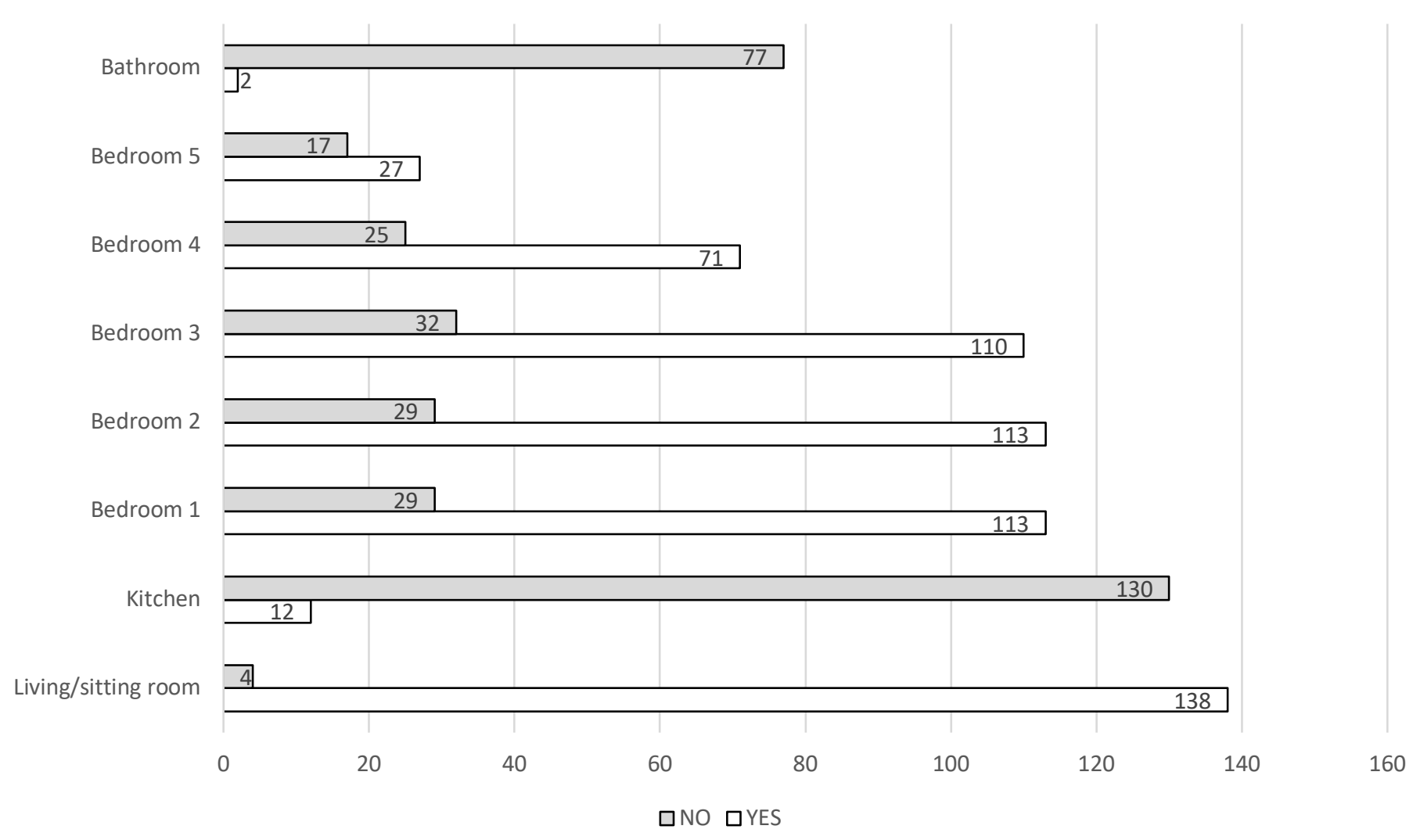

Figure 5. 16: Room spaces with cross ventilation

The results in Figure 5.16 show that most rooms in the surveyed houses had at least one window each on opposite walls. This is consistent with the results from stages 1 and 2 where architects reported providing cross ventilation in indoor spaces. However, as mentioned in Section 2.2, without the consideration of other factors, in some instances the simple placement of windows on opposite walls is ineffective in promoting cross ventilation. Conversely, the other methods (Figure 5.17) required for improving ventilation and natural lighting such as the strategic location of windows/vents and skylights were infrequently adopted in the surveyed houses. Most of the surveyed buildings had casement and sliding windows, with a limited proportion of louvre windows. As noted in Section 2.6, louvre windows are more advantageous in regions that rely on air movement for achieving thermal comfort. It was also observed that most houses were compact (Table 5.18). This also has some negative implications on achieving indoor thermal comfort, because permeable floor plan layout, as noted in Section 2.8 improve air circulation in indoor spaces. Finally, it was observed that most houses had window screens/nets. This is understandable because of the need to keep insects out however, as noted in Table 2.5 , this also reduces the ease of air ingress through windows. 
Table 5. 18: Photos from physical survey of selected buildings

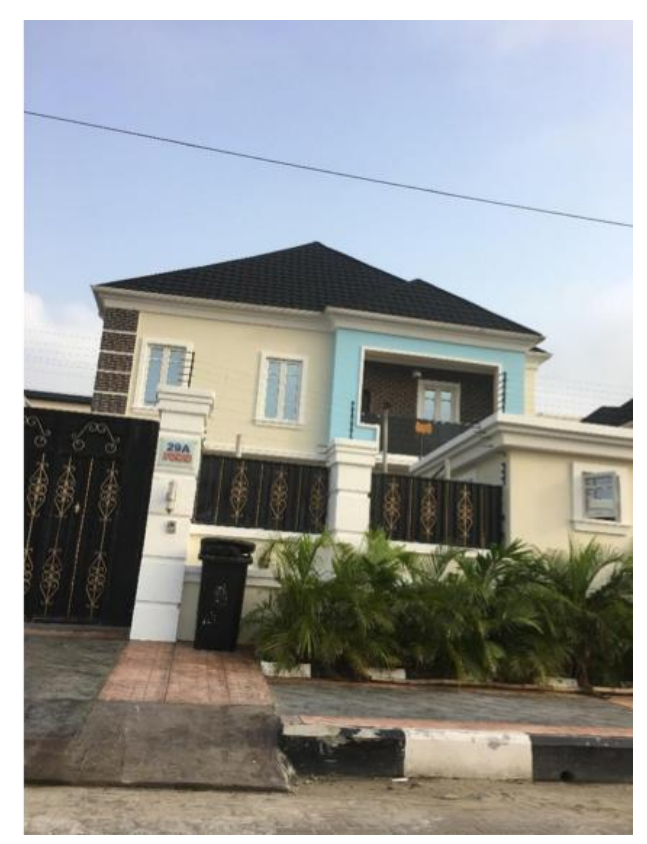

A residential dwelling in Lekki, Lagos, showing high perimeter fencing.

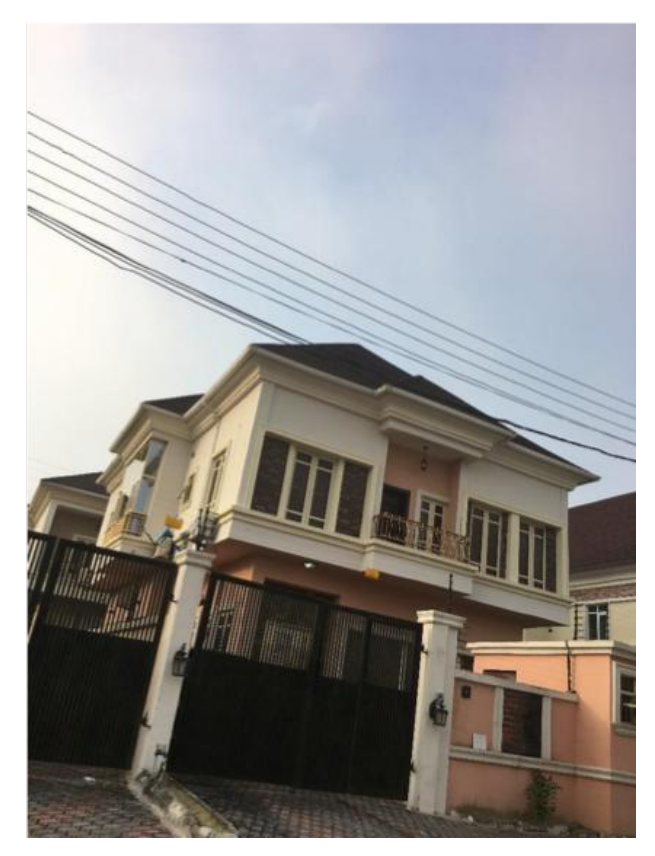

A residential dwelling in Garki, Abuja, showing compact housing with limited land space.

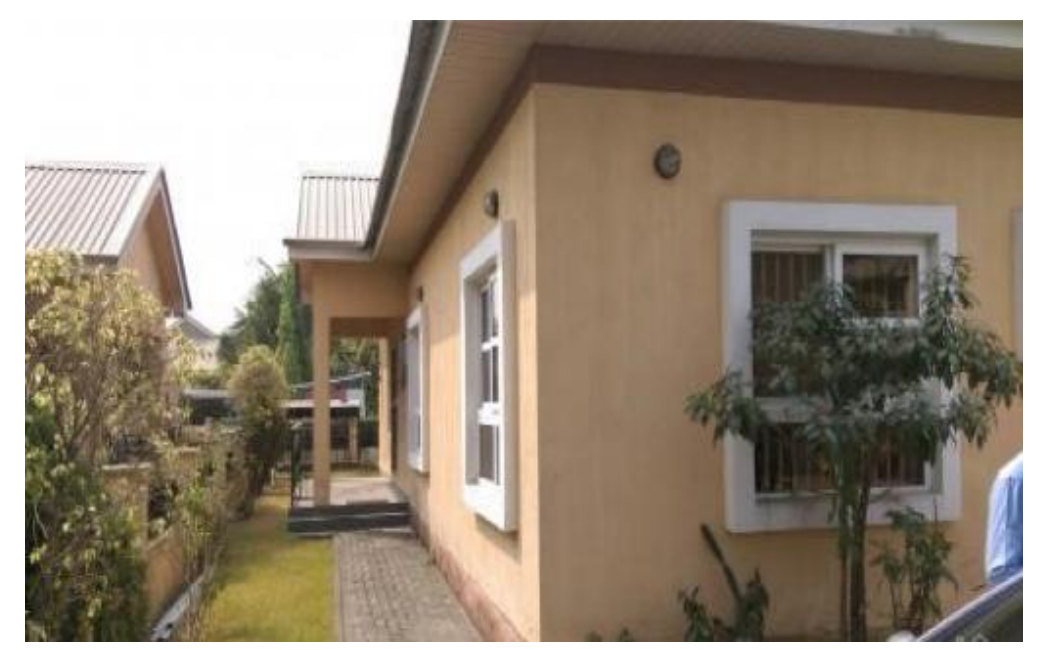

A single level residential dwelling in Port Harcourt, Rivers State, showing burglary proofing on windows and insect screening. 


\section{Chapter $5 \mid$ Results from Study}

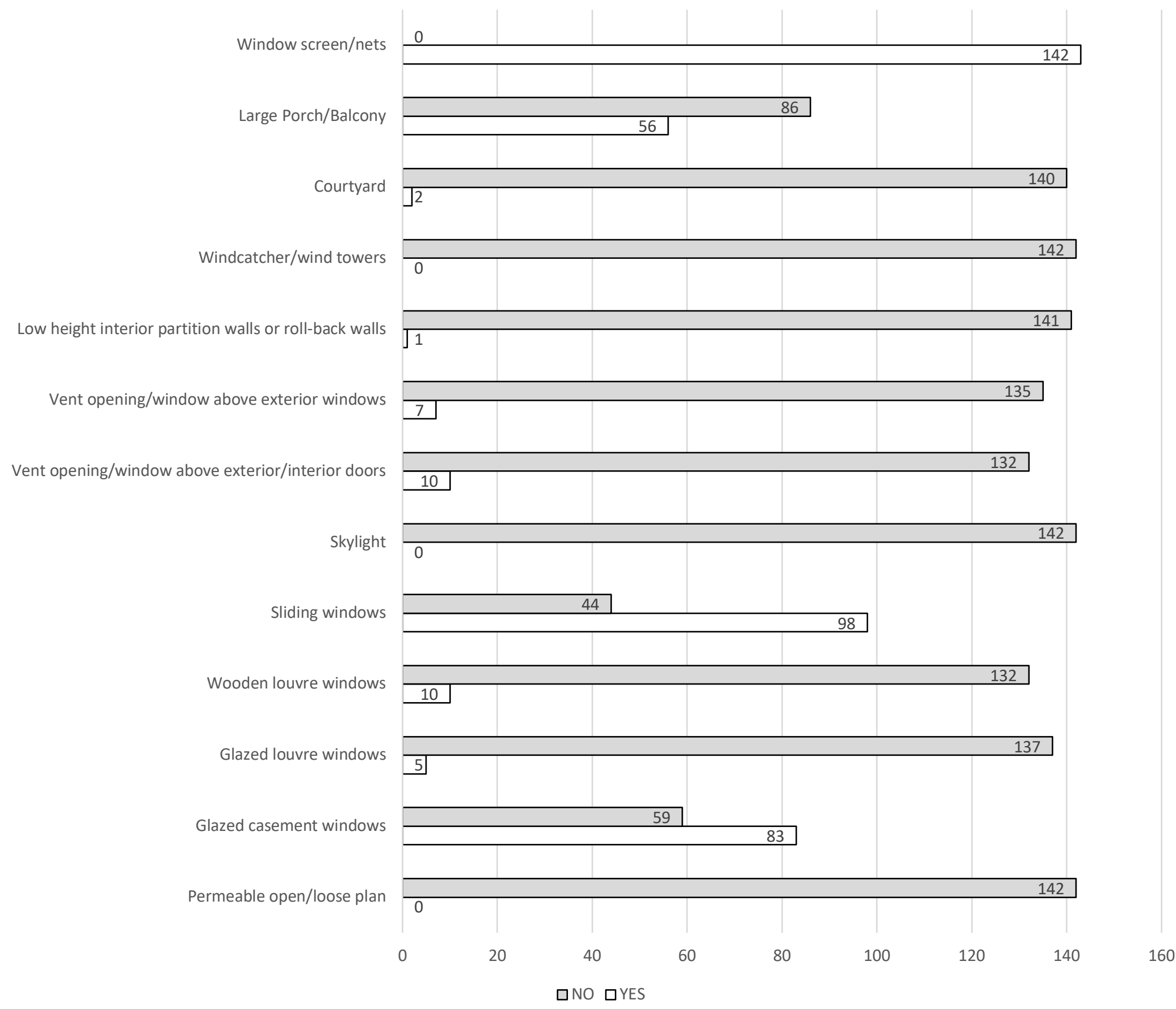

Figure 5. 17: Ventilation/Natural lighting/Outdoor space

5.4.2 Thermal comfort

This section examines whether different shading techniques have been adopted in the surveyed buildings to control solar heat gains. As shown in Figure 5.18 most of the items were infrequently adopted, with the exception of large roof overhangs for most of the surveyed buildings. Relating this to stages 1 and 2, this suggests that when architects reported their adoption of shading techniques, they were most likely referring to the use of roof overhangs and concrete hoods or baffles, as also noted in stage 2.

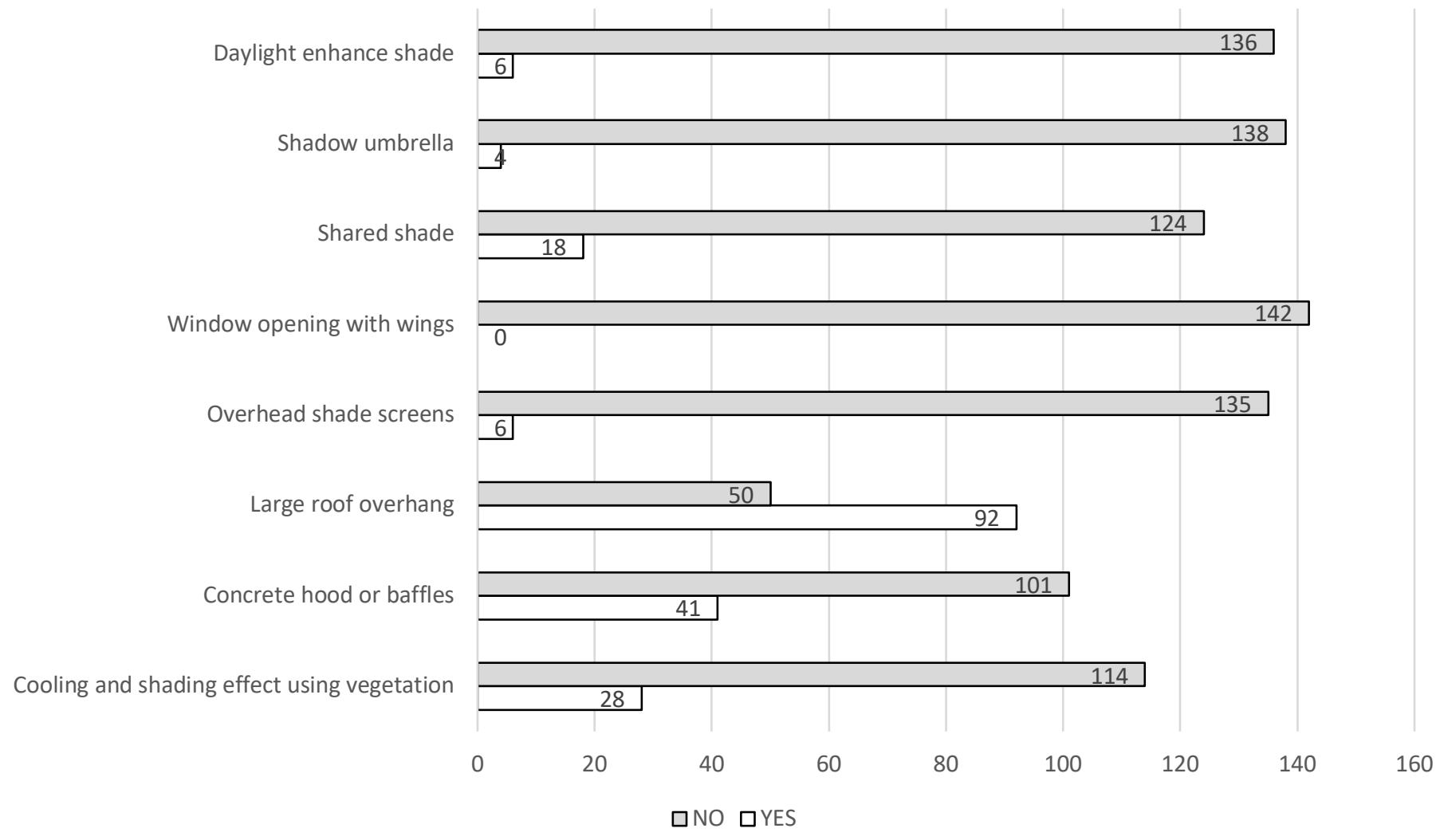

Figure 5. 18: Shading techniques 


\subsubsection{Cooling / Internal noise levels}

The primary objective of this section is to establish whether the surveyed buildings have features to improve thermal and acoustic performance. The data was collected through a visual examination and not a scientific examination, hence results are based on face value and discussions with building owners. The results (Figure 5.19) show that the surveyed buildings did not have floor, wall, or roof insulation, but instead relied on the density of the concrete block or brick walls for thermal and acoustic insulation. Most of the surveyed buildings had concrete block as the primary structure. There was no venting in the foundation, with limited venting in the roof and ceiling. None of the surveyed buildings had earth-air or air-air heat exchangers. It was also discovered that most of the surveyed buildings had ceramic floor tiles with limited carpet or vinyl flooring. As noted in Table 2.5, this is understandable because, amongst other benefits such as durability, ceramic tiles are known to provide a cooling effect.

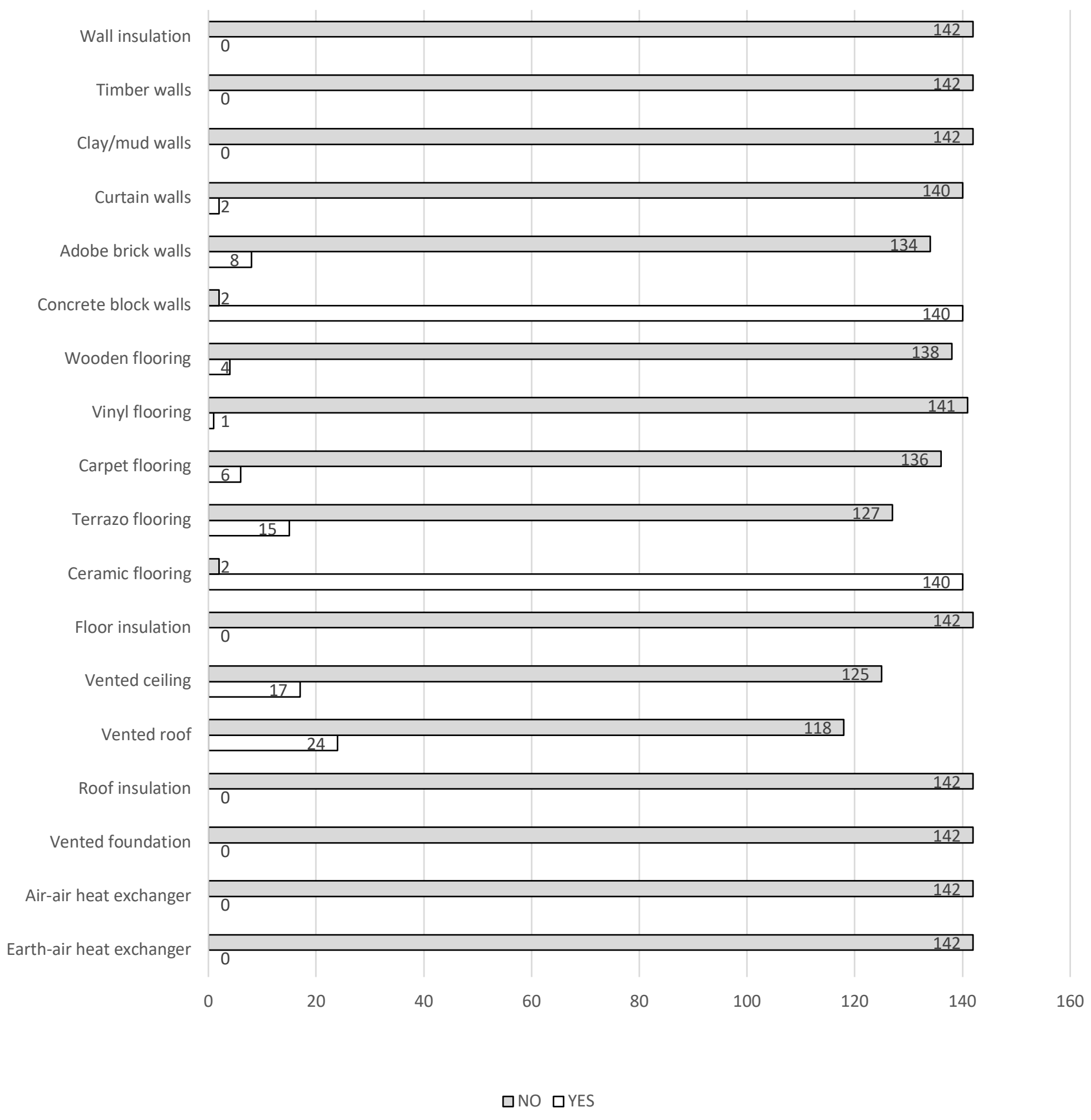

Figure 5. 19: Cooling /Internal noise levels 


\subsubsection{Energy efficiency and generation}

This section examines the adoption of basic energy efficient appliances in surveyed buildings and the presence of any on-site energy generation systems. The results (Figure 5.20) show that the national grid was the main source of energy generation in most houses, and all the surveyed buildings had fossil powered generators. A limited proportion of the surveyed buildings used solar panels for energy generation. This is consistent with the results from stages 1 and 2 which showed that most architects did not generally specify solar panel in their designs. Energy efficient lightbulbs were mostly adopted, with some houses having auto light systems (typically for outdoor automatic security sensor lights). All other systems on the checklist were rarely adopted.

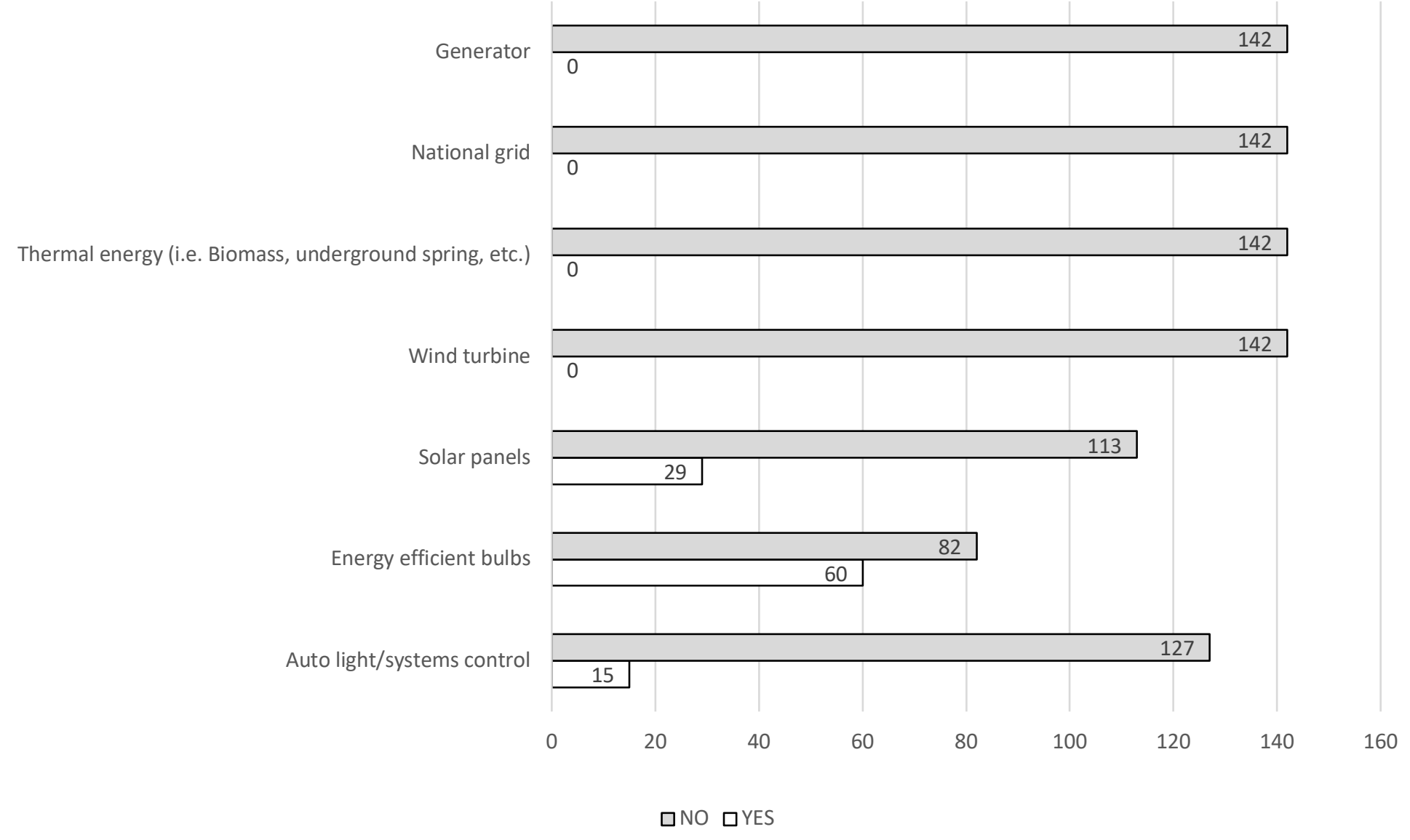

Figure 5. 20: Energy efficiency and generation

\subsection{A review of the results from the architects and building owners}

The results from stages 1, 2, and 3 provided an overview of the architects' and building owners' perceptions towards the adoption of ESD, highlighting barriers preventing the adoption of ESD in Nigeria. The aim of this section is to review results from the architects and building owners simultaneously, to emphasise any similarities in their responses on the issues identified in the preceding sections as they relate to the research questions. These include the issue of thermal discomfort, knowledge/awareness as it relates to provision of information on ESD, and the public interest in ESD.

\subsubsection{Thermal comfort in the house when there is no AC or fan}

A review of the results in Figure 5.1 shows that most architects agreed that they usually felt sweaty and uncomfortable in a room without an air conditioner or fan (M-4.74). Similarly, building owners reported some level of thermal discomfort when there was no mechanical ventilation (M-3.41). Despite the architects and building owners being asked about thermal comfort in different scenarios, the underlying factor remained the same, which was establishing the level of thermal discomfort in indoor spaces and the reliance on mechanical ventilation for achieving thermal comfort as opposed to ESD. These results are consistent with similar previous studies (Adaji et al., 2017; Adunola \& Ajibola, 2016), which showed that most residents typically felt thermally uncomfortable in their dwellings in the absence of mechanical ventilation. The studies showed that the average indoor temperature was between $30^{\circ} \mathrm{C}$ to $32^{\circ} \mathrm{C}$ with a maximum indoor temperature of $37^{\circ} \mathrm{C}$ and relative humidity between $15 \%-76 \%$. According to Adaji et al. (2017), the surveyed residents showed a preferred temperature range of $25^{\circ} \mathrm{C}-28^{\circ} \mathrm{C}$ with residents in naturally ventilated houses experiencing higher temperatures to those in mechanically ventilated houses. Overall, the results from this study and similar studies all show an agreement on the issue of thermal discomfort in residential dwellings in Nigeria. 
5.5.2 Limited information and promotions on sustainable architecture

The results in Figure 5.10 showed that some of the architects fairly agreed that there is limited information on sustainable architecture. A review of the results in Section 5.1.6 showed a mean response of M-3.67, which indicates that some architects are of the opinion that there is information on sustainable architecture. This is expected, given their training and experience in architecture. Alternatively, building owners reported that there is limited information on sustainable architecture. In contrast to results from the architects, building owners considered the lack of information an issue. The results in Section 5.3.3 showed a correlation between available information and the adoption of ESD, indicating that building owners who are informed about ESD were more likely to adopt it in their respective building projects. Despite the architects not considering the availability of information on ESD a significant issue, the results from Section 5.1.3 and from similar studies (Akinola et al., 2018; Allu \& Elimisiemon, 2017; Dalibi et al., 2017) showed that architects had limited knowledge about ESD.

\subsubsection{Public interest in ESD}

A review of Figure 5.10 shows that there was a fair level of agreement by the architects on the lack of public interest in ESD. Similarly, most of the building owners reported a low level of public interest in ESD. A review of the results in Section 5.3.3 showed a correlation between the lack of public interest and a paucity in the availability of information on ESD. This is consistent with a similar study by (Wojuola \& Alant, 2017) in the Nigerian context, which indicated that respondents were more likely to adopt sustainable design methods if they had prior knowledge and information on ESD.

\subsection{Summary of study}

The results from the study were presented in this chapter. They were presented in tables and figures with respect to the research objectives and questions. Stage 1 reported the results from the structured questionnaires sent out to the architects; stage 2 reported the results from the oral interview with architects; stage 3 reported the results from the structured questionnaires completed by building owners and the visual examination of their respective buildings. Results from each stage were compared for validation and further investigation using descriptive analysis, Pearson Correlation, and ANOVA.

In summary, Chapter 5 provided an investigation into the barriers preventing the adoption of ESD methods for the mitigation of thermal discomfort and energy generation problems in residential buildings in Nigeria. The results from the different stages were mostly consistent. In addition, they suggest little measurement error in the instrument and the overall authenticity of the results. The subsequent chapters conclude the thesis, discuss the findings from the results, and provide recommendations. 
Chapter 6 | Discussion and Implication

Chapter 6 | Discussion and Implication 


\subsection{Introduction}

Chapter 5 presented the results from the survey conducted on architects, building owners and their respective buildings. The key outcomes from Chapter 5 are the architects' and building owners' perceived barriers preventing the adoption of environmentally sustainable design methods in Nigerian residential buildings. This chapter discusses these findings further within the context of the research questions and based on other aligned studies in the Nigerian context. Whilst references are not normally part of the discussion, they were included for clarification. Below are the perceived barriers preventing the adoption of ESD methods in Nigerian residential buildings based on the research questions.

\subsection{Do the architects and building owners both agree on the issue of indoor thermal discomfort?}

One of the study's primary objectives was to establish if there was a general agreement on the issue of thermal discomfort in Nigerian residential buildings. To investigate this, it was necessary to establish the level of agreement on the problem of thermal discomfort, specifically in indoor spaces of Nigerian residential buildings. The study found that most architects $(M=5.28)$ agreed that thermal discomfort was a problem in Nigerian residential buildings. The results also showed that most of the architects $(M=4.74)$ agreed to feeling sweaty and uncomfortable in indoor spaces in the absence of mechanical ventilation. The research showed that most of the respondents relied on mechanical ventilation for achieving thermal comfort, with some building owners being thermally uncomfortable and dissatisfied in the absence of an $\mathrm{AC}$ or fan $(\mathrm{M}=3.41)$. However, the use of mechanical ventilation was affected by the erratic electrical supply from the national grid, meaning that respondents resorted to fuel generators for powering mechanical ventilation systems. This result is consistent with similar studies (Elum \& Momodu, 2017; Olaniyan et al., 2018) which showed that most households in Nigeria relied on fuel-powered generators for cooling and other domestic purposes.

A review of the results from the study revealed that most of the architects agreed $(M=5.28)$ that thermally uncomfortable indoor spaces were prevalent in Nigerian residential buildings and that this was an architectural problem that needed to be addressed. Similarly, it was observed that in addition to acknowledging the problem of thermal discomfort, architects also made some efforts to address the problem through design methods like cross ventilation and shading. However, a review of the results (Section 5.1.3) suggests that these methods were not well adopted, highlighting a gap in knowledge and a need for exploring the basic ways through which these methods could be adequately adopted. For example, during the architects' interview and physical survey of the selected buildings, it was noted that in the specification of cross ventilation and shading, architects did not generally consider other factors like climatic parameters and the strategic placement of windows.

The results from this study indicate that the agreement barrier (Section 5.1.2) does not necessarily exist within the Nigerian context and that the problem of thermal discomfort and inadequate power supply from the national grid is acknowledged. This presents an interesting discovery as it was initially hypothesised that a lack of agreement on the issue existed, which posed a possible barrier to ESD adoption. However, the study showed a paucity in the adoption of ESD and also found an agreement on the issue of thermal discomfort and inadequate power generation. This agreement does not mean a general consensus on the relevance and need to adopt ESD. The disconnect between an agreement (Section 5.1.2) on the issue and adoption/interest in ESD (Section 5.1.3, 5.1.6, and 5.3.3) stems from public perception and knowledge of ESD. As noted in Section 1.1 and Section 4.2, there are more concerns about extreme temperatures and fewer concerns about climate change or global warming because some Nigerians are not aware of ESD (Section 5.3.3) and the interrelationship between climate change and increasing temperatures, and the need for both issues to be addressed in an integrated way. This highlights a gap in knowledge and shows that ESD awareness and its need/relevance need to be investigated and other possible barriers.

\subsection{How knowledgeable is the Nigerian architect and building owner about ESD?}

Given that the respondents agreed on the issue of thermal discomfort and inadequate power generation, the research proceeded to evaluating the impact of knowledge as a barrier to ESD in Nigeria. The lack of knowledge as a barrier is not limited to the confines of formal or informal education but includes the subject of public awareness and perception and how that could lead to a cultural shift towards a more pro-sustainable environment in Nigeria. The study prompted consideration of whether the respondent's awareness of sustainability is enough to embrace sustainably effective solutions to designing, constructing, and living in buildings whilst being mindful of the environment. A review of the results from the architects and building owners showed that most of the respondents lacked general awareness about ESD as a practical solution, thus highlighting a gap in knowledge about ESD. Due to this gap in 
knowledge, respondents did not commonly adopt ESD as a solution, instead they relied on mechanical ventilation for achieving thermal comfort (Section 5.1.3) and fuel generators for power supply (Section 5.4.4) in the absence of electricity from the national grid. The lack of awareness of the benefits and means of adopting ESD presents a fundamental barrier to its adoption in Nigeria. The results showed that amongst all the environmentally sustainable design methods presented to the architects, cross ventilation was the item most frequently adopted.

Nonetheless, a review of the results showed that architects and building owners reported being thermally uncomfortable in the absence of mechanical ventilation and that architects did not take full advantage of cross ventilation to ensure optimum indoor thermal comfort, hence they designed buildings with the intention of using mechanical ventilation. As shown in Section 5.1.3 and the data collected during the physical survey (Table 5.18), ESD methods for improving the effectiveness of cross ventilation, such as building orientation, strategic positioning of windows, courtyards, and stack ventilation techniques, were infrequently adopted. This suggests that the architects had limited knowledge about natural ventilation and simply placed windows on either wall without proper investigation or understanding. This exercise simply ticked the box for ventilation and satisfied the requirement for building consent approval (Section 3.6). This is consistent with the literature review, which showed that residential buildings in Nigeria were generally designed without giving due consideration to the parameters responsible for improving natural ventilation. In addition to the lack of proper understanding and investigation of window placement during design, a review of the results and photographs (Table 5.18) also highlighted some possible impediments preventing the effectiveness of natural ventilation. Some of these impediments included limited land space for air circulation and high perimeter fencing due to the demand for security, which also impacted the level of air circulation within a residential dwelling. Both of these impediments are practical considerations that often take priority over ESD, however, with the right knowledge, each of these impediments could be addressed through ESD. Issues relating to inadequate air circulation and poor natural ventilation could have been addressed by conducting a detailed site analysis and proper building orientation as noted in Section 2.4.

A review of the trends in the self-reported items and general perception of ESD in Section 5.1.3 revealed that older architects were more likely to adopt basic ESD principles that align with bioclimatic architecture, while younger architects were more likely to adopt renewable energy sources like photovoltaic systems in their designs, as noted in Section 3.3 and Section 5.1.3.3. This is consistent with a similar study by Akinola et al. (2018), which showed that some respondents (primarily younger architects) were knowledgeable about renewable technologies. As noted by one of the architects during the interview session in stage 2 of this thesis, 'there have been seminars to educate architects on ESD, so I believe the next generation would adopt it'. This implies the possibility of widespread adoption of renewable energy-efficient systems in the near future, as an increasing number of younger architects enter the field. The trend of older architects being more inclined towards a bioclimatic architectural approach is consistent with the architectural dynamics in Nigeria. A review of existing literature (Section 3.3) and the results from this study (Section 5.1.3) show that the architectural dynamics have slowly evolved over time from a more bioclimatic approach of adopting natural ventilation techniques and courtyard systems, to a modern approach that adopts modern technologies. In addition to other factors, some of the reasons for this shift, as noted in Section 3.3, include societal values and systems being increasingly inclined to the Western way of living, which in some instances may not be suitable for Nigerian climatic conditions. One of these instances is the desire for compact living, due to smaller families and affordability, as opposed to a more open living arrangement which enhances natural ventilation and increases the air circulation within a building.

An analysis of the results from stage 1 and 2 of the study showed that most of the surveyed architects reported that form and function had an impact on the provision of indoor thermal comfort. However, studies show that in recent times in the Nigeria context the principle of form and function is mostly adopted in terms of aesthetics or circulation within interior spaces, and rarely for the provision of thermal comfort (Agboola \& Zango, 2014; Umar et al., 2019). Additionally, the prevalent use of the principle was credited to the respondents' time at university when architectural students were encouraged to adopt the principle of form and function during the design conceptualisation process. This suggests that architectural education had an impact on professional practice on the subject of form and function since respondents still adopted this principle after the university. On the subject of ESD, most of the respondents reported that they were encouraged to adopt ESD as architectural students. However, unlike form and function, the results showed that most of the architects did not completely adopt most aspects of ESD. According to the results and existing literature, architects frequently adopted form and function and did not frequently adopt most aspects of ESD because of the demand for form and function and the architectural educational scope being limited to only certain aspects of ESD. In terms of the demand for form and function as it relates to the building aesthetics and functionality (Frampton, 1985; Hendrix, 2015), the results (Section 5.2.1 and 5.3.1) suggest 
that most of the respondents considered it an important factor during design and construction. The demand from clients for buildings to have interesting forms, be fashionable, and functional, explains why architects were more likely to hold onto this principle, even after their architectural education. In terms of architectural education, the results (Section 5.1.3) suggest a significant correlation between architectural education and the adoption of certain aspects of ESD like cross ventilation and shading principles. In other words, respondents who reported that they were encouraged to adopt ESD at university also noted that as practising architects, they always provided cross ventilation and shading principles (Section 5.1.3). However, in terms of other aspects of ESD, the results showed a lack of adoption. This could potentially be due to students being taught about environmental sustainability as a separate course, and tending to infrequently apply that knowledge during design conceptualisation in architectural design courses (Allu, 2016). Alternatively, lack of adoption could be due to an emphasis on cross ventilation and shading principles in architectural education, at the expense of training in other ESD principles. This finding is consistent with the literature review (Section 3.8) which showed that architectural education in Nigeria needs to expand its scope to fully adopt all available facets of ESD in architectural design courses. This should most importantly include all facets of ESD that relate to the provision of thermal comfort and power generation.

The correlation between architectural education and the adoption of certain aspects of ESD indicates that in addition to demand by building owners, architects were more likely to adopt the aspects of ESD adequately covered during their architectural education. Nonetheless, the results also showed that in some instances, irrespective of their architectural education, if there is a lack of demand from building owners, architects were less likely to completely adopt ESD. The lack of demand highlights the role and importance of the building owner towards the enhancement of a sustainable built environment. During interviews some architects stated that, despite being taught at university about calculating comfort zones and building orientation, they rarely adopted these principles. Better education of the public would assist in the acceptance of ESD and encourage the architects to adopt ESD. However, as stated by Irouke and George (2016), it is the professional's responsibility to ensure building designs are as environmentally friendly as possible, given the current issue of climate change, global warming, and the demand for energy. This highlights the role and duty of an architect towards the attainment of a sustainable built environment.

\subsection{Do we have the right technology to enhance the adoption of ESD? If no, is that a possible barrier?}

The results from the study showed that some of the architects adopted low technological solutions such as natural ventilation, thermal mass, and shading. However, respondents infrequently adopted efficient and renewable energy systems. The architects reported that technological development was a barrier to the adoption of ESD and that there was a shortage in the required skills to manufacture and maintain sustainable technologies in Nigeria. The technological barrier was generally reported in terms of a lack of technological innovations within the Nigeria building industry for enhancing a more sustainable built environment. The lack of technological innovations also includes poor site analysis, inadequate building orientation, and poor building envelopes, which, as shown in Section 2.4, are essential technological tools required for enhancing thermal comfort and renewable onsite power generation.

The lack of technological innovations has also led to a lack of skilled labour and expertise to manufacture energy-efficient systems like solar panels for generating electricity, and as a result, these items are imported from overseas (Melodi \& Famakin, 2015). A review of existing literature and the results from the study identified the lack of sustainability measurement tools, lack of exemplary 'demonstrative projects', absence of guidance, lack of technical ability, and shortage in skill and labour to implement sustainable construction, as the barriers within the technology category. A review of the results highlights a correlation between the lack of technological innovation in Nigeria and the need for extensive education, research and development on environmental sustainability to close the current gap in knowledge. A resolution to the issue of technological dearth in Nigeria would involve taking steps towards developing sustainable services and products in the Nigerian building industry. This would include a critical review of vernacular technologies and how they could be modified to meet modern residential demands. Such demands include the need for more compact living, smaller building sections, and extreme climatic conditions. Section 2.4 provided a basic outline of some technological tools such as detailed site analysis and responsive building envelopes for ensuring thermal comfort, energy efficiency, and enhancing a more sustainable built environment in Nigeria.

\subsection{Are economic factors a possible barrier to ESD?}

The findings from the study showed that architects and building owners considered cost an important factor during building design and construction. This is expected as the success of any building project in part depends on the availability of finance to fund the project. Based on the results, most of the architects reported that more importance is giving to cost than ESD. Similarly, most of the 
building owners considered the cost of building construction as the most important factor during the design and construction of their respective houses. Essentially, the cost of construction becomes a barrier if the specification of ESD inflates the construction cost. As noted by architects in stage 2 of the study, the specification of energy-efficient and renewable systems could sometimes increase construction costs, making this unappealing. According to Waniko (2014) most Nigerians are more concerned about the initial cost as opposed to the long-term financial benefits, making some aspects of ESD like solar panels and other energy-efficient systems less attractive. As noted in the literature review and the results from the study (Section 5.2.4), the high initial cost of ESD becomes a potential barrier to the adoption of energy-efficient and renewable systems in Nigeria because some individuals might not be able to afford the high upfront cost. However, for those who can afford the upfront cost, there are long-term financial benefits.

It is understandable that the specification of energy-efficient and renewable systems or adopting a more bioclimatic approach such as window fins and overhead shades could affect the initial construction cost, however, the long-term benefit for energy efficiency generally outweighs the initial cost (Section 2.3). According to Roche (2017), given the rising cost of fuel and maintenance for generator sets in Nigeria, the use of ESD becomes more cost-efficient in the long term. Unfortunately, architects and building owners appear to have limited knowledge on the benefits of ESD or do not spend the time to conduct personal research into the financial and environmental benefits of ESD. For architects, this could involve a post-occupancy evaluation of any completed project where renewable energy systems and bioclimatic architectural approach were adopted to establish the long-term cost benefits. If the architect or building owner is not convinced of the long-term benefits, there is a likelihood that they could become fixated on the initial cost instead of the long-term benefits. As noted by Wojuola and Alant (2017), prior knowledge and information about ESD positively influences an individual towards adopting ESD. Similarly, as shown in Section 5.3.3 respondents who were knowledgeable about ESD were more likely to adopt it in their respective building projects.

\subsection{What is the public perception of ESD? Are they interested?}

A review of the results showed that respondents were concerned about the problem of thermal discomfort and inadequate power generation in Nigeria. They generally considered indoor environmental comfort an important factor during design and reported to be more comfortable in indoor spaces that were airy, spacious, and cross-ventilated (Section 5.3.5). However, a review of the results on the public perception of ESD showed that architects somewhat agreed (Section 5.1.6) that there was a lack of interest in environmentally sustainable design amongst clients and developers, while the building owners reported a low extent of public interest and enlightenment on ESD (Section 5.3.3). Despite the results showing a lack of interest in ESD, Adunola and Ajibola (2016) investigation on the use of spaces within the average Nigerian household highlighted some subconscious willingness and effort to adopt some basic energy-efficient methods for addressing thermal discomfort. These included adaptive techniques like changing clothing, opening windows, space migration, taking a bath or having a cold drink. This suggests that building occupants were knowledgeable and interested in basic energy-efficient methods for mitigating the problem of thermal discomfort and power generation. However, in terms of slightly more advanced sustainable architectural technologies, there appears to be a lack of enlightenment and interest, as shown in this study and similar studies (Akinola et al., 2018; Wojuola \& Alant, 2017). This explains why, in instances where adaptive techniques were unsuccessful, occupants resorted to mechanical ventilation for achieving thermal comfort. In addition to other factors such as cost, ease of use, maintenance and durability, the public perception of ESD in Nigeria has been significantly affected by the knowledge barrier (Wojuola \& Alant, 2017). As shown in Section 5.3.3, respondents who are aware of ESD were more likely to adopt it in their respective building projects. This is supported by the literature review, which showed that a lack of adequate information about unfamiliar technology significantly affects the public acceptance of such technology. As shown in Section 5.3.1, respondents considered comfort an important factor but not ESD, notwithstanding the correlation between comfort and ESD. This suggests that building owners were not aware of the inextricable link between comfort and ESD and that the primary objective of ESD is the provision of comfort and energy efficiency. The lack of demand or awareness about ESD by the building owner and the resulting impact on the adoption of ESD highlights the role and importance of the building owner's awareness and commitment towards the advancement of a sustainable built environment in Nigeria.

\subsection{Are there favourable ESD policies? If no, is that a possible barrier?}

Political barriers to ESD revolve around governance, specifically, the government and affiliated institutions' enactment of favourable policies and efforts to ensure a more sustainable built environment. The results in Section 5.2.6 and existing studies (Chapter 3) shows that the government has made some efforts through the NBC. Also, it was reported that ARCON and NIA had made some efforts towards encouraging ESD adoption through organising seminars. However, a further review of the results from building 
owners and the interview sessions with architects highlighted that more work is required by the government and professional institutions. As shown in Section 5.2.6, interviewees reported on the potential barriers to ESD within the political sector. These included the issue of self-interest, lack of publicity, substandard building codes, and lack of enforcement. Similarly, it was noted that the dispute between ARCON and NIA was inhibiting the progression of the architectural profession towards environmental sustainability. Respondents also reported poor town planning regulations that sometimes affected the adequate orientation and placement of buildings for effective utilisation or control of the climatic conditions. As noted in the literature review (Section 3.3.2.1), there are inadequate restrictions such as the maximum building coverage or height on a site for ensuring adequate building setbacks and vegetative landscaping for optimising shading and air circulation. The political motivation or amotivation to encourage ESD stems from the perceived practical or ideological advantage such change has on the political institution in terms of votes or societal value systems (Trudgill, 1990). Policy change requires the support of the Nigerian society, however as shown in the previous sections, there appears to be a lack of public interest and support for ESD. This highlights the role of the government and the inextricable link between the role of the building owner/public and the government towards ensuring a sustainable built environment in Nigeria.

\subsection{Implication}

This thesis was initially intended for architects, with the scope of the study limited to the distribution of questionnaires and interviews with architects. However, following the preliminary results from the pilot study, it was apparent that, in addition to other factors, the architects' perceived barriers to the adoption of ESD included prevailing social barriers. These social barriers primarily involved the building owners' (i.e. part of the public) perception of ESD. Following this discovery, the study expanded its scope to include the building owners and a physical survey of their respective buildings. The underlying assumptions/hypothesis on the barriers were tested on the architects, the building owners, and their respective buildings.

So far, most studies (Table 1.1) in Nigeria have either focused on the architects or building owners/clients in a single state and in most cases ,have not adopted any theoretical model for simultaneously understanding the architects' and building owners' perceived barriers to ESD. By conducting a case study of buildings and their respective owners simultaneously in four different states and a country-wide survey involving the distribution of questionnaires to registered architects in Nigeria, the results from stage 2 and 3 of the study encapsulate regional and socio-political factors within the three geopolitical zones, while stage 1 addressed this nationally. This is something that would be omitted in studies limited to specific states. The comprehensive nature of the results increases the empirical evidence on the barriers to ESD in Nigeria. To expand on this evidence, the model of barrier identification was adopted and reinforced by a mixed-method research technique consisting of a quantitative, qualitative, and case study approach to adequately identify the barriers to ESD in Nigeria. Existing studies (Table 1.1) have fallen short of comprehensiveness because they either adopted a quantitative or qualitative research approach, making it difficult to counterbalance the shortcomings of either method. The results from the mixed-method study and the adoption of the model of barrier identification ensured logical consistency in explaining the barriers to ESD in Nigeria, both from the architects' and building owners' perspectives.

The structure and order of the identified barriers by this study suggest that the respondents (i.e. architects and building owners) did not generally consider agreement (Section 5.1.2) as a barrier to the adoption of ESD. Rather, they considered lack of technological development, limited knowledge, economic, social and political factors as barriers to ESD in Nigeria. Further investigation into these barriers suggests that the lack of technological development; social barriers as they relate to public perception; and the economic barrier as it relates to the cost of construction, were considered as impediments to the adoption of ESD. Similarly, political barriers, as they relate to governance and the enactment of favourable ESD policies, were considered barriers. Generally, the results from the architects and building owners were consistent and showed that the lack of awareness on the benefits of ESD and ways of appropriately adopting ESD was the primary impediments to the adoption of ESD in Nigeria (Figure 6.1).

Education is the process of acquiring knowledge either through formal or informal training, while awareness extends beyond the confines of education to promote a cultural change and sensitivity in the individual and public perception on a given topic, which within the context of this study, is sustainable design (Flavian, 2016; Roeser \& Peck, 2009). A general lack of awareness was at the top of the hierarchy, with its lack having a profound influence on other barriers. This suggests an urgent need to revamp architectural education in Nigeria towards encouraging sustainability, so that architects are trained to have a good understanding of sustainability and how their role interacts with other stakeholders in the building industry towards ensuring a sustainable built environment in Nigeria. This education should also extend beyond architectural education to include awareness campaigns by the government and 
non-government institutions on the benefits of sustainable design, so that more people are informed and educated on the subject. Despite still being at the formative stages whilst awaiting accreditation from the World Green Building Council, the Green Building Council of Nigeria would ideally also assist in promoting and educating the building industry on practical context base methodologies for encouraging a more sustainable built environment in Nigeria.

The knowledge barrier creates a link between structural and psychological barriers. A review of Section 4.2 provides background to the structural barrier versus psychological barrier, in which it was noted by Gifford (2011) that, despite its unlikelihood, structural barriers such as climate-adverse infrastructure have to be completely eliminated wherever possible before addressing the psychological barrier. Gifford's (2011) view is consistent with the results from this study which shows that at least some aspects of the structural barrier need to be eliminated before addressing the psychological barrier. This structural barrier includes the lack of information and awareness about ESD in Nigeria (Section 5.3.3), which in turn affects the general perception of ESD (Gifford, 2011; Wojuola \& Alant, 2017). For instance, as shown in Section 5.3.3, respondents who were knowledgeable about ESD were more likely to adopt ESD in their respective projects. In contrast, respondents who were less knowledgeable were less likely to adopt these methods. An absence of sufficient information about unpopular systems such as ESD considerably affects public perception and reduces public acceptance of such systems (Wojuola \& Alant, 2017). Suggesting that if structures are not enacted to encourage and propagate information on ESD, the psychological barrier evolves in the form of a lack of acceptance or demand. The structural and psychological barrier must be dealt with simultaneously for real progress to prevail within the Nigerian built environment.

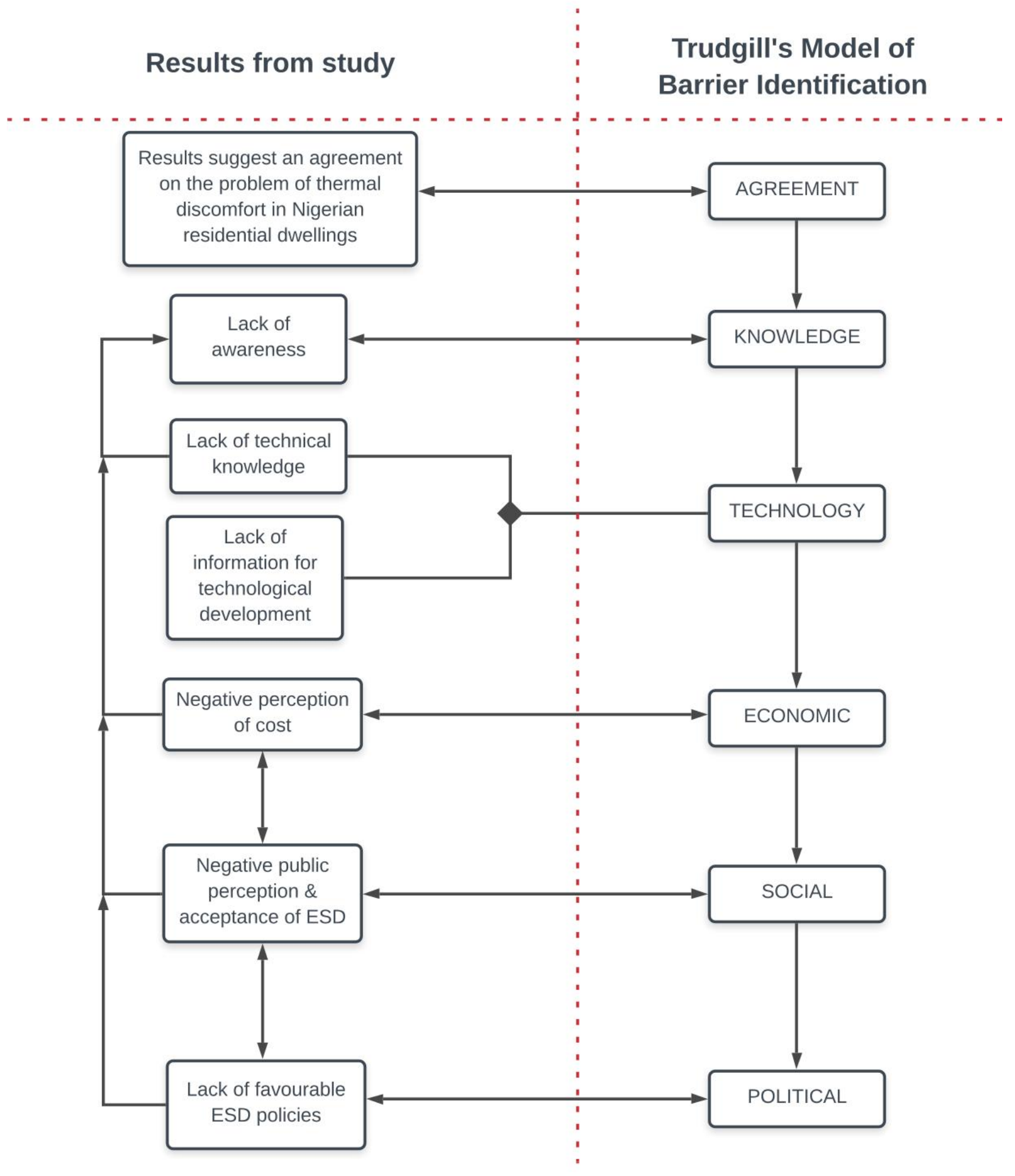

Figure 6. 1: A comparison of Trudgills' model and the Nigerian context. Adapted from (Trudgill, 1990). 
According to Gifford (2011), the barriers to environmental sustainability is a combination of structural (i.e. lack of knowledge and systems to enhance awareness and adoption of ESD) and psychological barriers (social norms and public perception). The connection/concurrence exists in a situation where the lack of awareness about ESD and its benefits leads to a continual refusal to adopt ESD. According to Gifford (2011), this continual refusal can also be influenced by social norms and comparisons, perceived risk, cost, discredence, ideologies, limited behaviour, and cognition. This view is similar to that identified in findings from previous studies (Agboola \& Zango, 2014; Ejiga et al., 2012; Okafor, 2018) as it relates to the Nigerian context, which showed that, prior to modernisation, vernacular buildings were more energy efficient and thermally comfortable, through the use of local knowledge, materials, and techniques. However, modern buildings seem to be the reverse, because Nigerians are becoming increasingly materialistic, fad driving, less rational, and less environmentally conscious (Agboola \& Zango, 2014). As noted by a respondent (Section 5.2.1) "the beautiful things they see influence people; they always want their buildings to look like what's the norm, hence the design influence".

Relating these findings to Trudgill's (1990) model of barrier identification, it appears that the problem of agreement is not necessarily a barrier in the Nigerian context, however knowledge, technological, economic, social, and political factors remain barriers. To address this, Trudgill (1990) suggests a recycling technique starting with situation awareness and ending with problem resolution, and in the event of the problem not being resolved, the cycle begins again from the top at the situation awareness stage. However, the findings from this study revealed that in the Nigerian context (Figure 6.1) the cycle begins with knowledge, social, political, economic, technology, implementation. The critical recycling stage exists between knowledge and social factors, in which, despite refusal/resistance, architects must educate and encourage themselves, clients, and the public. As shown in Figure 6.1, having crossed the barrier of agreement on the problem and establishing an overall problem acceptance, the endeavour to work towards the resolution of environmental problems and the full adoption of ESD begins with addressing the knowledge barrier (Figure 6.1). Squarely addressing barriers to ESD depends on active involvement and commitment from the government and related institutions, building owners, and the architect.

The role of the government includes the enactment of an integrated sustainable development policy at the national and state level for enhancing the adoption of ESD. This would include a revamp of the current National Building Code (NBC) to cover every aspect of sustainability, specifically as it relates to the provision of thermal comfort and renewable energy generation. This should be followed by strict enforcement during building consent/permit application and also imposing fines during construction for non-compliant buildings. In addition, the role of the government includes continual coordination with related institutions such as the educational sector, ARCON, NIA and GBCN for improving research, development, and continual education on the benefits and methods for ensuring a sustainable built environment. ARCON, NIA, and GBCN should tailor their efforts towards the continuous professional development of their members on ESD.

The role of the building owner is crucial to the adoption of ESD and ensuring a sustainable built environment in Nigeria. This is because owners make most of the decisions before and during construction and influence the overall construction and postconstruction processes. In addition, through the Nigerian democratic process, they also have the ability to influence the government towards enacting favourable sustainable policies. Similarly, the decision made by a building owner could have a significant impact on their neighbours and the overall social cultural context. This was evident in Section 4.2 , where it was observed that high-energy consuming households reduced their energy consumption when they were informed about the low-energy consumption of their neighbours. This theoretical account explains much about the role of the building owner and the dramatic impact on social norms as these relate to the adoption or lack of adoption of ESD. Clearly, building owner and building occupants need to be constantly informed and educated on the benefits and means of adopting ESD.

The role of the architect is also crucial, given their involvement in the design process from inception to completion. The architect does not only provide designs, but also plays an advisory role to the building owner during the design and construction process. In some instances, the architect's role also involves providing professional advice to the government on matters relating to the built environment, either individually or through an institute (i.e. ARCON, NIA or GBCN). The architect's knowledge, experience and commitment towards ESD is crucial. A review of the results so far suggests a gap in knowledge about ESD, with results from the questionnaires, interviews and survey of buildings showing that some basic ESD principles for improving thermal comfort and energy efficiency were infrequently adopted. 


\section{Chapter 6 | Discussion and Implication}

Based on the results, it is projected that once the knowledge barrier is resolved, it will become easier to address other barriers. Despite its importance, addressing knowledge alone would not necessarily ensure the widespread adoption of ESD. Economic, social cultural, and political factors also have a significant role to play. If the knowledge barrier is addressed and there is still no improvement, the endeavour of inquiry then proceeds to provide a detailed review of countries where the issue of knowledge has been addressed and possibly investigating other economic, social-cultural, and political barriers in the Nigerian context; one of which could include the willingness of the building owner to pay. As shown in Section 3.9, identified barriers are not unique to Nigeria, hence the potential resolution technique in Nigeria could be applicable in other countries. 
Chapter 7 | Conclusion and Recommendation

Chapter 7 | Conclusion and Recommendation 


\subsection{Conclusion}

The problem of thermal discomfort has been prevalent in Nigerian residential dwellings due to inadequate and unsustainable design methods, with studies suggesting an increase in thermal discomfort if current trends continue in the Nigerian building industry. To provide a possible solution to this problem, the thesis started by outlining the problem of thermal discomfort, specifically within Nigerian housing stock, and the architect's role in ensuring thermally comfortable indoor spaces whilst reducing the building impact on the natural environment and the dependence on fuel-powered mechanical systems. The initial aim of this thesis was to develop a sustainable design tool for improving thermal comfort that could be easily adopted by architects and understood by anyone interested in environmentally sustainable design methods (ESD), however, this changed after the review of existing literature suggested that sustainable design tools already existed for the Nigerian context. In response, the thesis then investigated why these tools were not widely adopted and the possible barriers to its adoption. This investigation began as an evaluation of architects' perceptions of ESD in Nigeria but later expanded to include the building owners due to their influence in the decision-making processes related to building design and construction.

In order to understand possible barriers to the adoption of ESD, the thesis investigated the barriers preventing the mainstream adoption of ESD in Nigeria. Based on the model for barrier identification by Trudgill (1990), and similar studies conducted within the Nigerian context (Akinola et al., 2018; Oyefusi \& Adeyemo, 2019; Waniko, 2014; Wojuola \& Alant, 2017), the hypothesised barriers included a lack of agreement on the problem; the lack of knowledge on a solution to the problem; lack of available technology and finance to address the problem; and the dominant social and political factors preventing the adoption of ESD in residential buildings in Nigeria. Out of this discovery emerged the question: What are the primary barriers preventing the mainstream adoption of ESD in Nigeria? This question is founded on the underlying assumption/hypothesis that the barriers identified in the literature review were significantly different from the barriers experienced in Nigeria. To provide a better understanding of the possible barriers, six research questions were developed:

- Do the architects and building owners both agree on the issue of indoor thermal discomfort?

- How knowledgeable is the Nigerian architect and building owner about ESD?

- Do we have the right technology to enhance the adoption of ESD? If no, is that a possible barrier?

- Are economic factors a possible barrier to ESD?

- What is the public perception of ESD? Are they interested?

- Are there favourable ESD policies? If no, is that a possible barrier?

A survey consisting of three stages was conducted on architects (stage 1\&2), building owners, and their respective buildings (stage 3). Stage 1 involved the distribution of questionnaires, while stage 2 involved interviews with architects. The distribution of questionnaires enabled the study to gather a range of information and provide a general overview of various ESD frequently adopted by Nigerian architects. The interviews with architects validated and provided greater insights into the results from stage 1 . Such insights included what architects generally considered important during a design process and the general perception of the barriers to ESD in Nigeria. Overall, the results from the questionnaires and interviews were similar and consistent. Stage 3 involved distributing questionnaires to building owners to establish the general awareness and perception of ESD. In addition, a checklist was used to conduct a physical survey of their respective buildings to establish the level of ESD adoption. The results from stage 3 provided further understanding of the barriers reported by the architects and also highlighted the ESD reported to be frequently adopted by architects in stages 1 and 2. The results from the survey are divided into six categories as noted in the literature review: agreement, knowledge, technology, economic, social, and political factors.

- Agreement: There was a general agreement by the architects and building owners on the problem of poor natural ventilation in residential dwellings and the resulting impact of thermal discomfort.

- Knowledge: The results suggested that most of the architects and building owners had limited knowledge about ESD. The architects and building owners reported that the lack of awareness of the means and benefits of adopting ESD was a fundamental barrier preventing the widespread adoption of ESD in Nigerian residential buildings.

- Technology: The results from stages 1 and 2 of the study showed that architects considered the lack of technological development as a barrier preventing ESD adoption in Nigeria. 
- Economic: The high initial cost associated with ESD was a barrier to the use of ESD, however, individuals who were wellinformed about the long-term cost benefits of ESD due to its low operational cost were more likely to see beyond the high initial cost.

- Social: The findings from the study on the public perception of ESD showed that, overall, there was an equal level of acceptance and rejection of ESD, as reported by architects and building owners. The rejection of ESD was accounted to a lack of interest and the lack of knowledge/awareness by the Nigerian public on the benefits of ESD.

- Political: The outcomes from the study showed that, overall, government policies did not generally encourage or enforce the adoption of ESD, hence more work needs to be done by the government through its policies. Similarly, it was suggested that professional bodies like ARCON and NIA need to clearly define their roles to avoid friction between the organisations. They must act professionally and in an unbiased manner to advance and grow the profession through a mandatory continuous professional development program concerning sustainability for all members.

A review of the results from all three stages of the study indicated that the lack of knowledge on the means of adopting ESD was the primary barrier to the adoption of ESD in Nigeria. This was unexpected as an initial review of existing literature during the early stages of the thesis suggested that sustainable design tools already existed for the Nigerian context. With the pressing demand for a sustainable environment and given the consensus on the problem of poor natural ventilation and power generation in Nigeria, there is a significant opportunity for architects to utilise the potentials of ESD. This could include the creation of affordable exemplar projects where ESD is fully adopted. The success of such projects would serve as an educational tool for stakeholders in the building industry and the general public.

\subsection{Recommendations and future research opportunities.}

The results from the study showed that among the six barriers, the knowledge barrier (a lack of awareness), social barrier (a lack of public interest), political barrier (a lack of enactment of favourable environmental sustainable policies), technological barrier (a lack of technological development), and the cost barrier were constantly cited by architects and building owners as barriers to the adoption of ESD in Nigeria. At this stage, actions to overcome these barriers should be aimed at enacting policies to encourage and improve the dissemination of information and education on ESD through formal and informal mediums. By doing so, it is assumed that public interest in ESD would be encouraged, which would help in resolving the other barriers.

\subsubsection{Recommendations}

Since the results from the study suggested that the main barriers to ESD stem from a lack of knowledge, lack of demand, and lack of policies for encouraging a sustainable environment in Nigeria, actions to overcome these barriers should be aimed at enacting policies for ensuring environmental sustainability by creating an enabling environment where awareness and information on the benefits and ways for adopting sustainable measures can strive. This action could begin with the Nigerian government setting up a department dedicated to research and development of ESD for Nigeria by developing on some of the strategies outlined in Section 2.4, and the implementation and continual modification of policies and programmes for ensuring a sustainable built environment in Nigeria. This department needs to coordinate with educational institutions, NGBC, BCA, ARCON, NIA, and related organisations, to:

- Improve the NBC to ensure that the building code sufficiently addresses ESD, and that ESD is enacted into the constitution and enforced regionally and nationally as part of climate change related activities.

- Promote sustainable education, formally through academic curricula from primary to tertiary schools, and continuous professional development programmes were required and informally through media platforms.

- Provide the required encouragement and guidance through appropriate adoption of ESD in all existing and proposed public building projects. This should include funding, where possible, through financial incentives and subsidies for individuals who wish to use renewable energy sources.

Coordination between the proposed department and related organisations could also include extensive research into sustainable alternatives for generating electricity and solving electricity generation and supply problems in Nigeria. The electricity from the national grid has been insufficient in Nigeria, with the erratic electricity available to approximately 40-50\% of the Nigerian populace (Section 1.2). This insufficiency results from the mounting pressure on the national grid due to the increasing population and demand 


\section{Chapter 7 | Conclusion and Recommendation}

for cooling in buildings. If buildings are designed to be thermally comfortable and at the same time generate their renewable energy, the mounting pressure on the national grid would be reduced significantly. As an example, The Manufacturers Association of Nigeria (MAN) spends more than NGN18 billion weekly on diesel/petrol powered generators (Section 3.5), however, the use of renewable energy systems could significantly reduce operational cost.

Resolution of the above provides an excellent chance to promote widespread adoption of ESD due to the inter-relationship and dependence of the other barriers on the knowledge and social-political barriers. It is envisaged that the adoption of ESD will increase and regulations updated to include ESD within the next decade. Similarly, knowledge and understanding of sustainable technologies will evolve, and there will be widespread interest and adoption of ESD in the mainstream building sector in Nigeria.

\subsubsection{Further studies}

Based on the results from this study, there are opportunities to improve the widespread adoption of ESD in Nigeria. The following research suggestions would be well suited for this purpose within the Nigerian building industry.

- Knowledge and awareness - more detailed research could be conducted to understand the knowledge barrier. This could include optimal ways to educate the Nigerian public on ESD. The architectural educational sector could be revamped to completely adopt ESD into their pedagogy.

- Extensive research - This could be conducted by establishing a small pilot community initiative, where public education on ESD adoption could be taught and supported by academic researchers.

- Retest the model for barrier identification by Trudgill (1990) within the Nigerian context - following a reasonable spread of knowledge and awareness on ESD, further research could be conducted to establish if the political, technological or economic barriers are dependent on knowledge and social factors and also investigate the building owner's willingness to pay for ESD. 


\section{References}

Abanihi, V. K., Ikheloa, S. O., \& Okodede, F. (2018). Overview of the Nigerian Power Sector. American Journal of Engineering Research 7(5), 253-263.

Abdul Majid, N. H., \& Hussaini, I. U. (2015). Energy development in Nigeria and the need for strategic energy efficiency practice scheme for the residential building sector. Management of Environmental Quality: An International Journal, 26(1), 21-36. doi:10.1108/MEQ-10-2013-0117

Abdulac, S. (1982). Traditional Housing Design in the Arab Countries. In M. B. Sevcenko (Ed.). Cambridge, Massachusetts. Abdulla, F. A., Al-Shareef, A.W. (2009). Roof rainwater harvesting systems for household water supply in Jordan. Desalination, 243(1-3), 195 -207. doi:10.1016/j.desal.2008.05.013

Abisuga, A. O., \& Okuntade, T. F. (2020). The current state of green building development in Nigerian construction industry: Policy and implications. In Z. Gou (Ed.), Green Building in Developing Countries (pp. 129-146). Cham, Switzerland: Springer.

Abisuga, A. O., \& Okuntade, T. F. (2020). The current state of green building development in Nigerian construction industry: Policy and implications. In Green Building in Developing Countries (pp. 129-146). Cham, Switzerland: Springer.

Abolore, F. A. (2012). Comparative Study of Environmental Sustainability in Building Construction in Nigeria and Malaysia. Journal of Emerging Trends in Economics and Management Sciences 3(6), 951-961.

Abraham, A., Michael, T., James, O., \& Michael, B. (2016). An Assesment of Foundation Design of Buildings in Lagos. safety, 2(6). Adaji, M., Watkins, R., \& Adler, G. (2015). An Investigation into Thermal Comfort in Residential Buildings in the Hot-Humid Climate of sub-Saharan Africa: A Field Study in Abuja-Nigeria.

Adaji, M., Watkins, R., \& Adler, G. (2017). Indoor Thermal Comfort for Residential Buildings in the Hot-Humid Climate of Nigeria during the dry season. Paper presented at the Passive Low and Energy Architecture: Design to Thrive, Edinburgh, UK. Adebamowo, M. A., Oginni. (2013). Do Architects Design for Thermal Comfort? A Case Study of Some Houses in Lagos. International Review of Social Sciences and Humanities 5(1), 255 - 264.

Adebisi, G. O., Onuwe, J. O., \& Sani, A. M. (2015). Assessment of Biomimcry Design Concept Adoption in Architecture: Towards a Sustainable Built Environment in

Nigeria. Journal of Environmental Science, Toxicology and Food Technology, 9(4), 41-46.

Adebowale, A. P., Adekunle, A., Joseph, O., Ankeli, A., \& Dabara, D. (2017). The need for green building rating systems

development for Nigeria: The process, progress and prospect. Academic Journal of Science, 7(2), 34-44.

Adedeji, M. D., Taiwo, A.A., Olotuah, A.O., \& Fadairo, G. (2011). Architectural education and sustainable human habitat in Nigeria. WIT Transactions on Ecology and the Environment, 167, 89-99.

Adegbile, M. (2012). Nigerian architectural education in a sustainable age. Paper presented at the Sustainable Futures: Architecture and Urbanism in the Global South, Kampala, Uganda.

Adejuwon, J. (2008). Vulnerability in Nigeria: A national-level assessment. Climate change and vulnerability, 2,198 - 217.

Adunola, A. O. (2014). Evaluation of urban residential thermal comfort in relation to indoor and outdoor air temperatures in Ibadan, Nigeria. Building and Environment, 75, 190-205. doi:https://doi.org/10.1016/j.buildenv.2014.02.007

Adunola, A. O. (2017). Ventilation for comfort in passive residential living spaces in a warm-humid urban environment.

International Journal of Civil Engineering, Construction and Estate Management, 5(2), 30-39.

Adunola, O., \& Ajibola, K. (2016). Factors Significant to Thermal Comfort Within Residential Neighborhoods of Ibadan Metropolis and Preferences in Adult Residents' Use of Spaces. Sage, 1 - 19.

Aflaki, A., Mahyuddin, N., Al-Cheikh Mahmoud, Z., \& Baharum, M. R. (2015). A review on natural ventilation applications through building façade components and ventilation openings in tropical climates. Energy and Buildings, 101, 153-162.

doi:https://doi.org/10.1016/j.enbuild.2015.04.033

AGA. (2017). Cleaner Energy. Retrieved from https://www.aga.org/natural-gas/clean-energy/

Agboola, O. P., \& Zango, M. S. (2014). Development of traditional architecture in Nigeria: a case study of Hausa house form. International Journal of African Society Cultures and Traditions, 1(1), 61-74.

Ahmed, R. M. H. B. (2013). The Comparison Between The Thermal Performance of a Contemporary House and Traditional House in the Dense Dhaka City in Bangladesh. Journal of Architecture and Built Environment, 40(1). doi:10.9744/dimensi.40.1.11-18 Ahn, Y. H., Pearce, A. R., Wang, Y., \& Wang, G. (2013). Drivers and barriers of sustainable design and construction: The perception of green building experience. International Journal of Sustainable Building Technology and Urban Development, 4(1), 35-45. doi:10.1080/2093761X.2012.759887

Aigbavboa, C., Ohiomah, I., \& Zwane, T. (2017). Sustainable construction practices:“a lazy view” of construction professionals in the South Africa construction industry. Energy Procedia, 105, 3003-3010.

AIP. (2007). A Hyperlinked History of Climate Change Science. Massachusetts, USA: Havard University Press. Ajibola, K. (1997). Ventilation of Spaces In A Warm, Humid Climate - Case Study of some Housing Types. Renewable Energy, 61 70.

Ajibola, K. (2001). Design for comfort in Nigeria: A bioclimatic approach. Renewable Energy, 23, 57-76.

Akadiri, P. O. (2015). Understanding barriers affecting the selection of sustainable materials in building projects. Journal of Building Engineering, 4, 86-93. doi:https://doi.org/10.1016/j.jobe.2015.08.006

Akagwu, M. (2017). Sustainable Driven Architectural Institutional Framework; the Backbone for an Improved Tropical

Environment in Nigeria Environtropica, 14, 1-15.

Akande, O. K. (2010). Passive design strategies for residential buildings in a hot dry climate in Nigeria. WIT Transactions on Ecology and the Environment, 128, 61-71.

Akande, O. K., Fabiyi, O., \& Mark, I. C. (2015). Sustainable Approach to Developing Energy Efficient Buildings for Resilient Future of the Built Environment in Nigeria. American Journal of Civil Engineering and Architecture, 3(4), 144-152.

Akeel, U., Bell, S., \& Mitchell, J. (2017). Engineering and sustainability education in Nigeria. Paper presented at the 45th SEFI Conference, Azores, Portugal. 


\section{References}

Akinola, A. O., Adeboye, A. B., Oluwatayo, A., Alagbe, O., Babalola, O., \& Afolabi, A. O. (2018). Survey dataset on architect's awareness and adoption of building envelope technologies for energy efficient housing in Lagos State. Data in Brief, 19, $1894-1901$. doi:https://doi.org/10.1016/j.dib.2018.06.093

Akpodiogaga, P., \& Ovuyovwiroye, O. (2010). General Overview of Climate Change Impacts in Nigeria (Vol. 29).

Akuru, U. B., Okoro, O.I., \& Chikuni, E. (2015). Impact of renewable energy deployment on climate change in Nigeria. Journal of Energy in Southern Africa, 26(3), 125-134.

Alao, O., \& Awodele, K. (2018). An Overview of the Nigerian Power Sector, the Challenges of its National Grid and Off-Grid Development as a Proposed Solution. Paper presented at the IEEE PES-IAS PowerAfrica Conference 2018, Cape Town, South Africa.

Alassar, Z. (2017). Louver Windows as a Passive Cooling Strategy. Islamic University of Gaza Publication. Retrieved from https://www.researchgate.net/publication/317040801_Louver_Windows_as_a_Passive_Cooling_Strategy

Alausa, S., Adekoya, B., Aderibigbe, J., \& Nwaokocha, C. (2013). Thermal characteristics of laterite-mud and concrete-block for walls in building construction in Nigeria. International Journal of Engineering, 4(4), 8269.

Alder, M. Z., E. (1996). Gazing into the oracle: The Delphi method and its application to social policy and public health. London, UK: Jessica Kingsley.

Alihodzic, R., Murgul, V., \& Vatin, N. (2014). A relation between function and architectural form in the observers perception. Applied Mechanics and Materials, 680, 494-498.

Aliyu, A. S., Dada, J. O., \& Adam, I. K. (2015). Current status and future prospects of renewable energy in Nigeria. Renewable and Sustainable Energy Reviews, 48, 336-346.

Allu, E. L. (2016). Sustainable Architectural Education: Perceptions from University of Jos Post Graduate Students. Paper presented at the Joint International Conference (JIC) on 21st Century Human Habitat: Issues, Sustainability and Development, Akure, Nigeria.

Allu, L. (2014). Sustainability and architectural education in the University of Jos, Nigeria. Paper presented at the Conference of the International Journal of Arts \& Sciences, University of London.

Allu, L., \& Elimisiemon, C. (2017). The role of the Nigerian architect in the sustainability of the country's built environment: A review. International Journal of Contemporary Applied Sciences 4(5), 94-104.

Allu, L., \& Ochedi, T. (2015). Sustainable Urban Built Environment For Nigeria: A Framework Approach International Journal of Contemporary Applied Sciences, 2(5), 96-107.

Alverson, K. (2012). Climate Change and Sustainable Development in Africa: Seizing the Opportunity. The Green Building eJournal, 6(9), 6-7.

Alwetaishi, M. S. (2016). Impact of Building Function on Thermal Comfort: A Review Paper American Journal of Engineering and Applied Sciences, 9(4), 928-945.

Amasuomo, T. T., \& Amasuomo, J. O. (2016a). Perceived Thermal Discomfort and Stress Behaviours Affecting Students' Learning in Lecture Theatres in the Humid Tropics. Buildings, 6(18), 80-97. doi:10.3390/buildings6020018

Amasuomo, T. T., \& Amasuomo, J. O. (2016c). Improving Durability Of Rural Buildings In Riverine Niger Delta Region: A Case Study On Need To Utilize Appropriate Technology. International Journal of African Society, Cultures and Traditions, 4(1), $17-43$. Amasuomo, T. T., Atanda, J., \& Baird, G. (2017). Development of a Building Performance Assessment and Design Tool for Residential Buildings in Nigeria. . Procedia Engineering, 180, 221-230.

Amasuomo, T. T., \& Baird, G. (2016b). Evolution of buildings in four tropical regions with regards to thermal comfort. Paper presented at the 5oth International Conference of the Architectural Science Association, Adelaide, Australia

Ametepey, O., Aigbavboa, C., \& Ansah, K. (2015). Barriers to successful implementation of sustainable construction in the Ghanaian construction industry. Procedia Manufacturing, 3, 1682-1689.

Anejo, J. A., Abdulhameed, S.A. (2008). An Overview of the National Building Code. Paper presented at the The Nigerian Institute of Building Annual Conference, Oshogbo, Nigeria.

Aniakor, C. C. (1979). Igbo Architecture: A study of forms, functions and typology. (Doctor of Philosophy). Indiana University, Michigan, USA.

Anink, D., Boonstra, C., Mak, J. (1998). Handbook of sustainable building. London, United Kingdom James \& James Ltd. ANS. (2014). Climate Change in Nigeria - Any Impact? African News Service.

ANSI/ASHRAE. (2004). Standard 55-2004: Thermal Environmental Conditions for Human Occupancy. Retrieved from GA, USA: Anyanwu, C. I. (2013). The role of building construction project team members in building projects delivery. Journal of Business and Management, 14(1), 30-34.

ARCON. (2015, 08/09/2016). Registration Of Architects And Architectural Firms December 17, 2015. Annually. 17/12/2015. Retrieved from http://www.arconigeria.org.ng/events/registration-architects-and-architectural-firms-december-17-2015 ARCON. (2016, 07/11/2016). 2016 Architects Colloquium. Annually. 06/06/2015. Retrieved from http://www.arconigeria.org.ng/events/2016-architects-colloquium

ARCON. (2019). Registration Requirements. Retrieved from https://www.arconigeria.org.ng/registration-requirements Arogundade, F. (2015). Generator Explosion Kills Publisher. Retrieved from https://www.pmnewsnigeria.com/2015/02/19/generator-explosion-kills-publisher/

Arthi, V., \& Fenske, J. (2018). Polygamy and child mortality: Historical and modern evidence from Nigeria's Igbo. Review of Economics of the Household, 16(1), 97-141.

ARUP. (2016). Building Energy Efficiency Guideline for Nigeria. Abuja, Nigeria: Federal Ministry of Power, Works and Housing Asekun-Olarinmoye, E. O., Bamidele, J., Odu, O. O., \& Ojofeitimi, E. O. (2014). Public perception of climate change and its impact on health and environment in rural southwestern Nigeria. Research and Reports in Tropical Medicine, 5, 1-10.

ASHRAE. (2016). Ventilation for acceptable indoor air quality. Retrieved from Atlanta, GA:

Atanda, J. O., \& Olukoya, O. A. (2019). Green building standards: Opportunities for Nigeria. Journal of Cleaner Production, 227, 366-377. 


\section{References}

Atkinson, R., \& Flint, J. (2001). Accessing Hidden and Hard-to-Reach Populations: Snowball Research Strategies. Paper presented at the Social Research Update: Sociology at Surrey, Surrey, United Kingdom.

Austin, M. (2001). Pacific Island Architecture. Fabrications: The Journal of the Society of Architectural Historians, Australia and New Zealand.

Awadh, O. (2017). Sustainability and green building rating systems: LEED, BREEAM, GSAS and Estidama critical analysis. Journal of Building Engineering, 11, 25-29.

Awofeso, N. (2011). Generator diesel exhaust: a major hazard to health and the environment in Nigeria. American journal of respiratory and critical care medicine, 183(10), 1437-1437.

Ayarkwa, J., Acheampong, A., Wiafe, F., \& Boateng, E. (2017, 12-14 April 2017). Factors affecting the Implementation of Sustainable Construction in Ghana: The Architect's perspective. Paper presented at the ICIDA 2017 - 6th International Conference on Infrastructure Development in Africa Kumasi, Ghana.

Ayeni, D., \& Adedeji, Y. M. (2015). Strategies for Mitigating Building Collapse in Nigeria: Roles of Architects and Other Stakeholders in the Building Industry Civil and Environmental Research 7(8), 140 - 148.

Ayotamuno, A., \& Owei, O. B. (2015). Housing in Port Harcourt, Nigeria: The modified building approval process. Environmental Management and Sustainable Development, 4(1), 16-28.

Baird, G. (2001). The Architectural Expression of Environmental Control Systems. London, United Kingdom: Spon Press.

Baird, G. (2010). Sustainable building in practice: What the users think. Oxon, United Kingdom Routledge.

Baird, G., Isaacs, N., Kernohan, D., \& Mclndoe, G. (1996). Building Evaluation Techniques. New York: McGraw-Hill.

Baloi, D. (2003). Sustainable Construction: Challenges and oportunities, Greenwood: University of Brighton.

Bamisile, O., Dagbasi, M., Babatunde, A., \& Ayodele, O. (2017). A review of renewable energy potential in Nigeria; Solar power development over the years (Vol. 44).

Bank, W. (2016). Poverty in a rising Africa. Retrieved from International Bank for Reconstruction and Development / The World Bank Washington DC, USA:

Barker, N. V. (1987). Passive and low energy building design for tropical island climates. London, United Kingdom: Commonwealth Secretariat Publications.

Baruch, Y. (1999). Response Rate in Academic Studies - A Comparative Analysis. Human Relations, 52(4), 421-438.

BBC. (2012). The Nigeria Weather. Retrieved from

BBC. (2012). The Nigeria Weather. from British Broadcasting Corporation

BBC. (2015, 24/09/2018). Are we tired of talking about climate change? Retrieved from https://www.bbc.com/news/science-

environment-32131142

BBC. (2018, Jaunary 19, 2018). The city that won't stop growing. Retrieved from http://www.bbc.co.uk/news/resources/idtsh/lagos

Bekleyen, N. D. A. (2011). The influence of climate and privacy on indigenous courtyard houses in Diyarbakır, Turkey. Scientific Research and Essays, 6(4), 908-922. doi:10.5897/SRE10.958

Beng, T. H. (1994). Tropical Architecture and Interiors. Page One Books.

Benneh, G. (1993). Population, environment and sustainable development in Africa. Paper presented at the General Conference and 25th Anniversary Celebration of the AAU, Legon, Ghana.

Beswick, J. (2010). Exploring Eye: West Africa's vernacular architecture. Retrieved from http://www.architecturalreview.com/archive/viewpoints/exploring-eye-west-africas-vernacular-architecture/5217807.fullarticle

Binici, H., Orhan, A., \& Tahir, S. (2005). Investigation of fibre reinforced mud brick as a building material. Construction and Building Materials, 19, $313-318$.

BioclimaticX. (2009). What is Bioclimatic Architecture? Retrieved from http://bioclimaticx.com/bioclimatic-architecture1/

Birx, J. (2006). Architectural Anthropology. Encyclopedia of Anthropology

Blanca, M. J., Alarcón, R., Arnau, J., Bono, R., \& Bendayan, R. (2018). Effect of variance ratio on ANOVA robustness: Might 1.5 be the limit? Behavior Research Methods, 50(3), 937-962. doi:10.3758/s13428-017-0918-2

Blinet, T., Jacqus, G., Guigou-Carter, C., Jean, P., \& Chéné, J.-B. (2013). Sound absorption optimization of thin ceiling panels at low frequencies. Paper presented at the INTER-NOISE and NOISE-CON Congress and Conference Proceedings.

BNRCC. (2008, 06/11/2015). Building Nigeria's Response To Climate Change (BNRCC). 13/05/2000. Retrieved from

https://www.devex.com/organizations/building-nigeria-s-response-to-climate-change-bnrcc-31411

Boadi, K. K., M.; Raheem, K.; \& Hanninen, K. (2005). Urbanisation without development: Environmental and health implications in African cities. Environmental Development and Sustainability 7, 465-500.

Bodach, S. (2014). Climate responsive building design strategies of vernacular architecture in Nepal. Energy and Buildings, 81, 227242.

Boer, B. (1997). An introduction to the climate of the United Arab Emirates. Journal of Arid Environments, 35, 3-16.

Bond, S. (2011). Barriers and drivers to green buildings in Australia and New Zealand. Journal of Property Investment \&amp;

Finance, 29(4/5), 494-509. doi:10.1108/14635781111150367

Booth, C. A., Hammond, F. N., Lamond, J. E., \& Proverbs, D. G. (2012). Introductory Insights to Climate Change Challenges. In C. A. Booth, Hammond, F.N., Lamond, J.E., \& Proverbs, D.G. (Ed.), Solutions to Climate Change Challenges in the Built Environment (pp. 343). West Sussex, United Kingdom: John Wiley \& Sons.

Brand, S. (1995). How Buildings Learn: Penguin Publishing Group, New York, USA.

BRANZ. (2017). Acoustic performance. Retrieved from

https://www.branz.co.nz/cms_show_download.php?id=5c56bbbb25713b856cc6fe1a3d186e89975fbc4d

BREEAM. (2019). Technical Manual: Version: SD5078 - Issue: 3.o. Retrieved from

https://www.breeam.com/NC2018/content/resources/output/10_pdf/a4_pdf/print/nc_uk_a4_print_mono/nc_uk_a4_print_m ono.pdf

Brenda. V., R., V. (1996). Green Architecture: Design for a Sustainable Future. London, United Kingdom: Thames and Hudson. 


\section{References}

Brinkmann, S., \& Kvale, S. (2015). Interviews: Learning the craft of qualitative research interviewing (Vol. 3): Sage Thousand Oaks, CA.

Brisibe, W. G. (2018). Assessing Architects' Knowledge of flood Resilient and Adaptable Buildings in Yenagoa, Nigeria. Journal of Architecture and Construction, 1(2), 16-24.

Brown, R. R., Rogers, B. C., \& Werbeloff, L. (2016). Moving Towards Water Sensitive Cities: A Guidance Manual for Strategists and Policy Makers. Retrieved from https://research.monash.edu/en/publications/moving-towards-water-sensitive-cities-a-guidancemanual-for-strat

Brown, R. R., Rogers, B. C., \& Werbeloff, L. (2016). Moving Towards Water Sensitive Cities: A Guidance Manual for Strategists and Policy Makers. Retrieved from https://research.monash.edu/en/publications/moving-towards-water-sensitive-cities-a-guidancemanual-for-strat

Bryman, A. (2008). Social Research Methods (3 ed.). Oxford, United Kingdom Oxford University Press.

Bryman, A. (2016). Social research methods (5 ed.): Oxford university press.

Buisseret, D. (1980). Historic Architecture of the Caribbean. New Hampshire, USA: Heinemann.

Burberry, P. (1997). Environment and Services. London, UK: Longman Ltd.

Butera, F., Adhikari, R., \& Aste, N. (2015). Sustainable building design for tropical climates. Kenya: United Nations Human Settlements Programme (UN-Habitat)

Byrd, H. (2014). The Coming Blackout Epidemic. Retrieved 11/09/2016, from Motherboard -

http://motherboard.vice.com/en_uk/read/the-coming-blackout-epidemic

C. Huizenga, S. A., L. Zagreus and E. Arens. (2006). Air Quality and Thermal Comfort in Office Buildings: Results of a Large Indoor Environmental Quality Survey. eScholarship, Center for the Built Environment, University of California,

Cachia, M., \& Millward, L. (2011). The telephone medium and semi-structured interviews: a complementary fit. Qualitative Research in Organizations and Management: An International Journal, 6(3), 256-277.

Campbell, J. (2009). Islandness: Vulnerability and Resilience in Oceania. The International Journal of Research into Island Cultures, 3(1).

Campbell-Lendrum, D., \& Corvalan, C. (2007). Climate chnage and developing country cities: Implications for environmental health and equity. Journal of Urban Health: Bulletin of New York Academy of Medicine, 84(1), 109-117.

Caracelli, V. J., \& Greene, C.J. (1993). Data Analysis Strategies for Mixed-Method Evaluation Designs Educational Evaluation and Policy Analy, 15(2), 195-207.

Chambliss, D. F., \& Schutt, R. K. (2009). Making Sense of the Social World: Methods of Investigation. Thousand Oaks, USA: Pine Forge Press.

Chan, A., Darko, A., \& Ameyaw, E. (2017). Strategies for Promoting Green Building Technologies Adoption in the Construction Industry - An International Study. Building: Sustainability, 9(969), 1-18.

Chan, A. P., Darko, A., Ameyaw, E. E., \& Owusu-Manu, D.-G. (2016). Barriers affecting the adoption of green building technologies. Journal of Management in Engineering, 33(3), 04016057.

Chan, A. P. C., Darko, A., \& Ameyaw, E. E. (2017). Strategies for promoting green building technologies adoption in the construction industry-An international study. Sustainability, 9(6), 969.

Chan, A. P. C., Darko, A., Olanipekun, A. O., \& Ameyaw, E. E. (2018). Critical barriers to green building technologies adoption in developing countries: The case of Ghana. Journal of cleaner production, 172, 1067-1079.

Chazan, N. H. (1978). The Africanization of Political Change: Some Aspects of the Dynamics of Political Cultures in Ghana and Nigeria. African Studies Review, 21(2), 15-38. doi:10.2307/523659

Chel, A., \& Tiwari, G. N. (2009). Thermal performance and embodied energy analysis of a passive house - Case study of vault roof mud-house in India. Applied Energy, 86(10), 1956-1969. doi:https://doi.org/10.1016/j.apenergy.2008.12.033

Chen, Q. (2009). Ventilation performance prediction for buildings: A method overview and recent applications. Building and Environment, 44(4), 848-858.

Chinwuba, N. N. (2015). Human Identity: Child Rights and the Legal Framework for Marriage in Nigeria. Marriage \& Family Review, 51(4), 305-336. doi:10.1080/01494929.2014.938286

Christie, H. L. (2010). Understanding New Zealand Homeowners Apparent Reluctance to Adopt Housing-Sustainability Innovations. (Doctor of Philosophy in Building Science). Victoria University of Wellington, Victoria University of Wellington, Wellington, New Zealand.

Chwieduk, D. (2002). Towards sustainable-energy buildings. Applied Energy, 76, 211-217.

Cohen, B. (2006). Urbanization in developing countries: Current trends, future projections, and key challenges for sustainability. Technology in Society, 28, 63-80.

Cohen, D., Crabtree, B. (2006). Qualitative Research Guidelines Project. Retrieved from http://www.qualres.org/HomeCrit3814.html. Retrieved September, 2016 http://www.qualres.org/HomeCrit-3814.html

Cohen, J. (1988). Set correlation and contingency tables. Applied Psychological Measurement, 12(4), 425-434.

Colam, A. M., Norris, E.C., \& Preston, C.C. (1997). Comparing Rating Scales of Different Lengths: Equivalence of Scores From 5Point and 7-Point Scales. Psychological Reports, 80, 355-362.

Comaroff, J., \& Comaroff, J. L. (1993). Modernity and its malcontents: Ritual and power in postcolonial Africa. Chicago: University of Chicago Press.

Conner, J., \& Taylor, J. (2014). Architecture in the South Pacific. Singapore: Editions Didier Millet Pte Ltd.

Courtenay, B. C., \& Weidemann, C. (1985). The effects of a don't know response on Palmore's facts on aging quizzes. The Gerontologist, 25, 177-181.

Cox, E. P. (1980). The Optimal Number of Response Alternatives for a Scale: A Review. Journal of Marketing Research, 17(4), 407422.

Crawleya, D., Handb, J., Kummertc, M., \& Griffith, T.B. (2008). Contrasting the capabilities of building energy performance simulation programs. Building and Environment, 43, 661-673. 
Crawleya, D. B. (2001). EnergyPlus: creating a new-generation building energy simulation program. Energy and Buildings, 33, 319331.

Creswell, J. (2003). Research Design: Qualitative, Quantitative, and Mixed Methods Approaches (2 ed.). California, USA: SAGE Publications.

Creswell, J. W., \& Plano, C. (2011). Designing and Conducting Mixed Methods Research (2 ed.). London, UK: SAGE Publications. Crichton, M. (2004). State of Fear. New York, USA: Avon Books.

Cruz, R. V. (2007). Climate Change 2007: Impacts, Adaptation and Vulnerability. Retrieved from IPCC Fourth Assessment Report: Climate Change 2007:

Cuevas, A., Febrero, M., \& Fraiman, R. (2004). An anova test for functional data. Computational Statistics \& Data Analysis, 47(1), 111-122. doi:https://doi.org/10.1016/j.csda.2003.10.021

Cuevas, A., Febrero, M., \& Fraiman, R. (2004). An anova test for functional data. Computational Statistics \& Data Analysis, 47(1), 111-122. doi:https://doi.org/10.1016/j.csda.2003.10.021

Cunningham, W. P., Cunningham, M.A. \& Saigo, B.W. (2017). Environmental Science: A global concern (14 ed.). New York, USA: McGraw-Hill Education.

D-Maps. (2019). Map Nigeria Federal Republic of Nigeria boundaries, states, names (white). Retrieved from https://dmaps.com/carte.php?num_car=4867\&lang=en

Dahiru, D., Dania, A. A., \& Adejoh, A. (2014). An Investigation into the Prospects of Green Building Practice in Nigeria. Journal of Sustainable Development, 7(6), 158-167.

Dalibi, S., Feng, J., Shuangqin, L., Sadiq, A., Bello, B., \& Danja, I. (2017). Hindrances to Green Building Developments in Nigeria's Built Environment: "The Project Professionals' Perspectives”. IOP Conf. Series: Earth and Environmental Science, 63(012033). Danby, M. (1993). Privacy as a culturally related factor in the built form. In B. F. a. H. Louw (Ed.), Companion to contemporary architectural thought. London: Routledge.

Dantata, M., \& Alibaba, H. (2018). The effects of flooring material on thermal comfort in a comparative manner. Ceramic tile and wood flooring. International Journal of Scientific \& Engineering Research, 9(12), 1470-1486.

Darko, A., \& Chan, A. P. (2017). Review of barriers to green building adoption. Sustainable Development, 25(3), 167-179. Dauda, A. D., Abubakar, A., \& Abubakar, M. (2012). An Evaluation of the Adequacy of the National Building Code for Achieving a Sustainable Built Environment in Nigeria. Research Journal of Environmental and Earth Sciences, 4(10), 857-865.

Davies, M. G. (1987). The passive solar heated school in Wallasey. V. Energy requirements for A passive school building. International Journal of Energy Reserach, 11(1), 1-20.

Dawes, J. (2008). Do data characteristics change according to the number of scale points used? An experiment using 5-point, 7point and 10-point scales. International journal of market research, 50(1), 61-104.

DDA. (2018). Dodge Data \& Analytics: World Green Building Trends 2018 Smart Market Report. Accessed online on May. Retrieved from https://www.buildup.eu/en/practices/publications/world-green-building-trends-2018-smart-market-report de Dear, R., Gail, Brager., \& Donna, Cooper. (1998). Developing an Adaptive Model of Thermal Comfort and Preference. Retrieved from Center for Environmental Design Research, University of California and Macquarie Research Ltd., Macquarie University: de Dear, R., Gail, B. (2001). The adaptive model of thermal comfort and energy conservation in the built environment. International Journal of Biometeorology, 45, 100-108.

de Dear, R. a. G. B. (2002). Thermal comfort in naturally ventilated buildings: revisions to ASHRAE Standard 55. Energy and Buildings., 34(6), 549-561.

De Rosa, M., Bianco, V., Scarpa, F., \& Tagliafico, L. A. (2014). Heating and cooling building energy demand evaluation; a simplified model and a modified degree days approach. Applied energy, 128, 217-229.

de Vaus, D. A. (2002). Surveys in Social Research (5 ed.). New South Wales: Allen \& Unwin.

deDear, R. M., Sanyogita. (2016). Field studies of thermal comfort across multiple climate zones for the subcontinent: India Model for Adaptive Comfort (IMAC). Building and Environment, 98, 55-70.

DeKay, M., \& Brown, G. (2014). Sun, Wind, and Light : Architectural Design Strategies (4 ed.). New Jersey: Wiley.

Denyer, S. (1978). African Traditional Architecture London, UK: Heinemann.

Dillman, D. A., Smyth, J. D., \& Christian, L. M. (2009). Internet, Mail and Mixed-Mode Surveys: The Tailored Design Method (3 ed.). New Jersey, USA: John Wiley \& Sons.

Djokoto, S. D., Dadzie, J., \& Ohemeng-Ababio, E. (2014). Barriers to sustainable construction in the Ghanaian construction industry: consultants perspectives. Journal of Sustainable Development, 7(1), 134.

Dmochowski, R. Z. (1988). Nigerian Traditional Architecture London, UK: Ethnographica

Echefu, N., \& Akpofure, E. (2002). Environmental impact assessment in Nigeria: regulatory background and procedural

framework. Port Harcourt, Nigeria: United Nations Environment Programme (UNEP)

ECN. (2012, 05/11/2016). Energy Commission Nigeria. 10/05/2012. Retrieved from

http://www.energy.gov.ng/index.php?option=com_content\&view=article\&id=85\&Itemid $=85$

ECREEE. (2013, 04/11/2016). UNDP Energy Project: Promoting energy efficiency in the residential and public sector in Nigeria. 05/505/2011. Retrieved from

http://www.ecowrex.org/sites/default/files/documents/projects/nigeria_undp_revised_09102012.pdf

Edomah, N. (2016). On the path to sustainability: Key issues on Nigeria's sustainable energy development. Energy Reports, 2, 2834. doi:https://doi.org/10.1016/j.egyr.2016.01.004

Edwards, D. J. (1983). The first comparative studies of Caribbean architecture. New West Indian Guide/ Nieuwe West-Indische Gids, 57(3-4), 173-200.

Ejiga, O., Obi, P., \& Osasona, C. (2012, 27/06/2012). Sustainability in traditional African architecture: a springboard for sustainable urban cities. Paper presented at the Sustainable Futures: Architecture and Urbanism in the Global South Kampala, Uganda.

El-Shorbagy, A.-M. (2010). Traditional Islamic-Arab House: Vocabulary And Syntax. International Journal of Civil \&

Environmental Engineering 10(04), 15-20. 


\section{References}

Elinwa, U. K., Ogbeba, J. E., \& Agboola, O. P. (2020). Cleaner Energy in Nigeria Residential Housing. Results in Engineering, 100103. doi:https://doi.org/10.1016/j.rineng.2020.100103

Elleh, N. (1997). African Architecture: Evolution and transformation. United States of America: McGraw Hill.

Elleh, N. (2001). Abuja: The single most ambitious urban design project of the 2oth century. Kromsdorf, Germany: VDG, Verlag und Datenbank für Geisteswissenschaften.

Elleh, N. (2016). Architecture and Politics in Nigeria: The Study of a Late Twentieth-Century Enlightenment-Inspired Modernism at Abuja, 1900-2016: Taylor \& Francis.

Elum, Z. A., \& Momodu, A. S. (2017). Climate change mitigation and renewable energy for sustainable development in Nigeria: A discourse approach. Renewable and Sustainable Energy Reviews, 76, 72-80. doi:https://doi.org/10.1016/j.rser.2017.03.040 EnergyPlus. (2016). EnergyPlus.

Enete, I. C. (2010). Potential Impacts Of Climate Change On Solid Waste Management In Nigeria. Retrieved from

https://earthzine.org/2010/10/04/potential-impacts-of-climate-change-on-solid-waste-management-in-nigeria/. from Institute of Electrical and Electronics: Ocenic Engineering Society https://earthzine.org/2010/10/o4/potential-impacts-of-climate-change-onsolid-waste-management-in-nigeria/

Enwerekowe, E. O., \& Mangden, D. D. (2019). Why does Female Underrepresentation Persist in Nigerian Architecture? Civil Engineering and Architecture 7(4), 89-98.

Essenwanger, O. M. (2001). Classification of climates. In World Survey of Climatology 1C, General Climatology. Elsevier Science, 1, 126.

Evans, M. (2012). Tropical design. In L. D (Ed.), New metric handbook: planning and design data (pp. 402 - 511). New York: Routledge, Taylor \& Francis.

Ezema, I., Opoko, P. A., \& Oluwatayo, A. (2016). De-carbonizing the Nigerian housing sector: the role of life cycle CO2 assessment. International Journal of Applied Environmental Sciences, 11(1), 325-349.

Ezema, I. C., Olotuah, A. O., \& O.I., F. (2015). Estimating Embodied Energy in Residential Buildings in a Nigerian Context International Journal of Applied Engineering Research, 10(24), 44140-44149.

Farooq, M. B. (2015). Qualitative telephone interviews: Strategies for success. Paper presented at the 18th Annual Waikato Management School Student Research Conference 2015, Waikato, NZ.

Fathy, H. (1972). The Arab House in the Urban Setting. Essex, United Kingdom: Longman.

Fazio, R. H., \& Towles-Schwen, T. (1999). The MODE model of attitude-behavior processes. Dual-process theories in social psychology, 97-116.

Field, A. (2017). Discovering Statistics Using SPSS. London, United Kingdom: SAGE Publications.

Fink, A. (2015). How to Conduct Surveys: A Step-by-Step Guide. Thousand Oaks, USA: Sage.

Finstad, K. (2010). Response Interpolation and Scale Sensitivity: Evidence Against 5-Point Scales. Journal of Usability Studies, 5(3), 104-110.

Fitch, J., \& Branch, D. (1960). Primitive Architecture and Climate. Scientific American, 203(6), 1-12.

Flavian, H. (2016). Towards teaching and beyond: Strengthening education by understanding students' self-awareness development. Power and Education, 8(1), 88-100. doi:10.1177/1757743815624118

Flynn, A., Tremblay, P.F., Rehm, J., \& Wells, S. (2013). A modified random walk door-to-door recruitment strategy for collecting social and biological data relating to mental health, substance use, addiction, and violence problems in a Canadian community. Int J Alcohol Drug Res, 2(2), 7-16.

Folkers, A. S., \& Van Buiten, B. A. (2019). Modern Architecture in Africa: Practical Encounters with Intricate African Modernity. Amsterdam: Springer.

Forbes. (2015, March 23, 2015). The Little-Known \$15 Billion Empire Of Africa's Richest Man. Forbes.

Fowler, F. J. (2002). Survey Research Methods (3 ed.). Thousand Oaks, USA: Sage Publications.

Foxon, T. J. (2002). Technological and institutional 'lock-in' as a barrier to sustainable innovation. Retrieved from

Foxon, T. J., Hammond, P. G., \& Pearson, P. J. (2008, 24-25 September 2008). Transition pathways for a low carbon energy system in the UK: assessing the compatibility of large-scale and small-scale options. Paper presented at the 7th BIEE Academic Conference, St Johns College, Oxford, Oxford, UK.

Frampton, K. (1985). Modern architecture: Thames and Hudson.

GA, \& UN. (2015). Transforming our world: the 2030 Agenda for Sustainable Development. Division for Sustainable Development Goals: New York, NY, USA.

Galvin, J. F. P. (2016). An Introduction to the Meteorology and Climate of the Tropics (J. F. P. Galvin Ed.). West Sssex, United Kingdom: John Wiley \& Sons.

Garde, F., Adelard, L., Boyer, H., \& Rat, C. (2004). Implementation and experimental survey of passive design specifications used in new low-cost housing under tropical climates. Energy and Buildings, 36, 353 - 366.

GBCSA. (2019). The Green Star Multi Unit Residential v1. Retrieved from https://gbcsa.org.za/certify/green-star-sa/multi-unitresidential-v1/

Gberevbie, D., Joshua, S., Excellence-Oluye, N., \& Oyeyemi, A. (2017). Accountability for Sustainable Development and the Challenges of Leadership in Nigeria, 1999-2015. SAGE Open, 7(4), 2158244017742951. doi:10.1177/2158244017742951

Geels, F. W. (2011). The multi-level perspective on sustainability transitions: Responses to seven criticisms. Environmental Innovation and Societal Transitions, 1(1), 24-40. doi:https://doi.org/10.1016/j.eist.2011.02.002

Georgescu-Roegen, N. (1993). Selection from energy and economic myths' in H.E. Daly \& K.N. Townsend (eds) Valuing the Earth, Economy, Ecology, Ethics, Cambridge, Massachusetts, MIT Press.

Gibson, L. J., \& Miller, M. M. (1990). A Delphi model for planning "preemptive" regional economic diversification. Economic Development Review, 8(2), 34-41.

Giddens, A. (2000). Runaway World: How Globalization is Reshaping Our Lives. New York, USA: Routledge. 
Gifford, R. (2011). The Dragons of Inaction: Psychological Barriers That Limit Climate Change Mitigation and Adaptation. American Psychologist, 66(4), 290-302.

Givoni, B. (1976). Man, Climate and Architecture (2 ed.). United Kingdom: Applied Science Publishers.

Givoni, B. (1992). Climatic Aspects Of Urban Design In Tropical Regions. Atmospheric Envrionment, 26B(3), 397 - 406.

Givoni, B. (1994). Passive and low energy cooling of buildings. New York, USA: Van Nostrand Reinhold.

Givoni, B. (1998). Climate Considerations in Building and Urban Design. New York: Wiley.

Giwa, A., Alabi, A., Yusuf, A., \& Olukan, T. (2017). A comprehensive review on biomass and solar energy for sustainable energy generation in Nigeria. Renewable and Sustainable Energy Reviews, 69, 620-641. doi:https://doi.org/10.1016/j.rser.2016.11.160 Gough, H., Sato, T., Halios, C., Grimmond, C. S. B., Luo, Z., Barlow, J. F., . . Quinn, A. (2018). Effects of variability of local winds on cross ventilation for a simplified building within a full-scale asymmetric array: Overview of the Silsoe field campaign. Journal of Wind Engineering and Industrial Aerodynamics, 175, 408-418. doi:https://doi.org/10.1016/j.jweia.2018.02.010 Gravette, A. (2000). Architectural Heritage of the Caribbean. Oxford, United Kingdom: Signal Books.

Greene, J. (2007). Mixed Methods in Social Inquiry. San Francisco, USA: John Wiley \& Sons.

Greene, J. C., \& Caracelli, V.J. (1997). Advances in mixed-method evaluation: The challenges and benefits of integrating diverse paradigms. San Francisco, USA: Jossey-Bass.

Greene, J. C., Caracelli, V. J., \& Graham, W. F. (1989). Toward a conceptual framework for mixed-method evaluation designs. Educational Evaluation and Pol- icy Analysis, 11, 255-274.

Groat, L., \& Wang, D. (2013). Architectural Research Methods (2 ed.). New Jersey, USA: John Wiley \& Sons, Inc New Jersey, USA. Groves, R. M. (1987). Research on survey data quality. Public Opinion Quarterly, 51, 156-172.

GSMA. (2016). Mobile for Development Utilities Lumos: Pay-as-you-go solar in Nigeria with MTN. Retrieved from Lagos, Nigeria: Guan, X., Zhanbo, X., \& Qing-Shan, J. (2010). Energy-Efficient Buildings Facilitated by Microgrid. IEEE Transactions On Smart Grid, 1(3), 243-252.

Guedes, M. C. (2013). Chapter 16 - Sustainable Architecture in Africa. In A. Sayigh (Ed.), Sustainability, Energy and Architecture (pp. 421-503). Boston: Academic Press.

Guest, G., Bunce, A., \& Johnson, L. (2006). How many interviews are enough? An experiment with data saturation and variability. Field Methods, 18(1).

Guimera, R., \& Sales-Pardo, M. (2006). Form follows function: the architecture of complex networks. Molecular Systems Biology, 2(1).

Haase, M., Amato. A. (2009). An investigation of the potential for natural ventilation and building orientation to achieve thermal comfort in warm and humid climates. Solar Energy, 83, 389-399.

Hacker, J. N., \& Holmes, M. J. (2007). Thermal Comfort: Climate Change and the Environmental Design of Buildings in the United Kingdom. Built Environment, 33(1), 97-114.

Hamilton, L. C. (2006). Statistics with Stata: Updated for Version 9. Belmont, CA: Thomson Higher Education.

Hammond, F. N., Baffour, K., Gyau, A., \& Adiaba, S.Y. (2012). Urbanization and Climate Change. In C. A. Booth, Hammond, F.N., Lamond, J.E., \& Proverbs, D.G. (Ed.), Solutions to Climate Change Challenges. West Sussex, United Kingdom: John Wiley \& Sons. Hansen, J. E., \& Sato, M. (2001). Trends of measured climate forcing agents. Proceedings of the National Academy of Sciences, 98, 14778-14783.

Harford, T. (2008). The Logic of Life: Uncovering the New Economics of Everything. Massachusetts, USA: Little, Brown.

Harris, J., Durdyev, S., Tokbolat, S., Ismail, S., Kandymov, N., \& Mohandes, S. R. (2019). Understanding construction stakeholders' experience and attitudes toward use of the Structurally Insulated Panels (SIPs) in New Zealand. Sustainability, 11(19), 5458.

Hashemi, H. C. A. C. A. (2015). Environmental Impacts and Embodied Energy of Construction Methods and Materials in LowIncome Tropical Housing. Sustainability 7, 7866-7883.

HBS. (2015). Affordable Green Housing For Nigeria. Affordable Green Housing For Nigeria. Retrieved from

https://ng.boell.org/2015/o3/o3/affordable-green-housing-nigeria

HBS. (2015). Living off The Grid In Nigeria. Retrieved from https://ng.boell.org/2015/o9/28/living-grid-nigeria. Retrieved

September 26, 2017, from Heinrich Boll Stiftung https://ng.boell.org/2015/o9/28/living-grid-nigeria

Heilman, V. M. (2016). Factors Hindering the Adoption of Sustainable Design and Construction Practices: The Case of Office Building Development in Dar es Salaam, Tanzania. (Doctor of Philosophy). Städtebau Institut der Universität Stuttgart,

Helena, C. (1998). Bioclimatism in vernacular architecture. Renewable and Sustainable Energy Reviews, 2(1-2), 67-87.

Hendrix, J. (2015). The Dialectics of Form and Function in Architectural Aesthetics. Rivista di estetica(58), 31-45.

Hoffman, D., \& Cloete, C. (2014). Factors Limiting Green Developments in South Africa - Architects' comments. Paper presented at the Association of Schools of Construction in South Africa (ASOCSA), Durban, South Africa.

Hom Rijal., M. H., Fergus Nicol (2015). Adaptive Thermal Comfort in Japanese Houses during the Summer Season: Behavioral Adaptation and the Effect of Humidity. Buildings, 5, 1037-1054.

Hong, T., Chou, S.K., \& Bong, T.Y. (2000). Building simulation: an overview of developments and information sources. Building and Environment, 35, 347-361.

Hoof, V. J., Mazej, M., \& Hassen, J. (2010). Thermal comfort: research and practice. Frontiers in Bioscience, 15(2), $765-788$.

Hosey, L. (2019). Why Equal Representation for Women in Architecture is Better for Everyone. Retrieved from

https://www.archdaily.com/783838/why-equal-representation-of-women-in-architecture-is-better-for-everyone

Howes, M., Wortley, L., Potts, R., Dedekorkut-Howes, A., Serrao-Neumann, S., \& Davidson, J. (2017). Environmental Sustainability: A Case of Policy Implementation Failure? MDPI: Sustainability, 9(165), 1-17.

Huang, X., Ma, X., \& Zhang, Q. (2019). Effect of building interface form on thermal comfort in gymnasiums in hot and humid climates. Frontiers of Architectural Research, 8(1), 32-43. doi:https://doi.org/10.1016/j.foar.2018.11.002

Humpherys, M. (1995). An Adaptive Guideline for UK Office Temperatures. In F. Nichol, Humphreys, M., Sykes, O. \& Roaf, S. (Ed.), Standards for Thermal Comfort: Indoor Air Temperature Standards for the 21st Century. London, United Kingdom: Chapman \& Hall. 


\section{References}

Hyde, R. (2000). Climate responsive design:A study of buildings in moderate and hot humid climates. London, United Kingdom Taylor \& Francis.

Hyde, R., Pedrini, A. (2002). An energy conservation architectural design tool for warm climate (LTV): The tool development and testing. Paper presented at the Tropical Daylight in Buildings, 2002, National University of Singapore, Singapore.

Hyde, R. (2008). Bioclimatic Housing: Innovative Designs for Warm Climates. Oxon, United Kingdom: Taylor \& Francis.

Ibem, E. O., Aduwo, E. B., \& Ayo-Vaughan, E. A. (2017). E-procurement adoption in the Nigerian building industry: Architects' perspective. Pollack Periodica: An International Journal for Engineering and Information Sciences, 12, 167-180. Retrieved from https://link.gale.com/apps/doc/A514177546/AONE?u=vuw\&sid=AONE\&xid=5e319d6e

Ibem, E. O., Akinola, A. O., Erebor, E. M., Tolani, M. O., \& Nwa-uwa, A. E. (2018). Survey data on digitalization of building procurement process by architectural firms in Abuja, Nigeria. Data in Brief, 20, 1062-1067.

doi:https://doi.org/10.1016/j.dib.2018.08.187

ICSU. (2015). The International Council for Science and Climate Change, 6o years

of facilitating climate change research and informing policy. Retrieved from Paris:

Idowu, O. M., Junaid, S. M., \& Humphrey, S. (2018). Effect of Fence Design on Natural Ventilation in Residential Spaces: An Experimental Study. Arid Zone Journal of Engineering, Technology and Environment, 14(3), 469-477.

IEA. (2005). CO2 Emissions From Fuel Combustion. Retrieved from Paris, France:

IEA. (2019). Nigeria Energy Outlook: Analysis from Africa Energy Outlook 2019. Retrieved from

https://www.iea.org/articles/nigeria-energy-outlook

IIED. (2012). Renewable Energy Potential in Nigeria: Low-carbon approaches to tackling Nigeria's energy poverty. London, United Kingdom: International Institute for Environment and Development

Ikemea, J., Ebohon, O.J. (2005). Nigeria's electric power sector reform: What should form the key objectives? Energy Policy, 33, $1213-1221$.

Ikoli, B. D. (2018). Challenges and prospects of architectural practice in Nigeria. Journal of Environmental Sciences and Resources Management 10(2), 122-142.

Immerwahr, D. (2007). The politics of architecture and urbanism in postcolonial Lagos, 1960-1986. Journal of African Cultural Studies, 19(2), 165-186. doi:10.1080/13696810701760450

Independent. (2018, Thursday, 5 July 2018). All-time heat records have been set all over the world this week. The Independent. Inhabitat. (2012). BIOMIMETIC ARCHITECTURE: Green Building in Zimbabwe Modeled After Termite Mounds. Retrieved from http://inhabitat.com/building-modelled-on-termites-eastgate-centre-in-zimbabwe/. Retrieved 15/o8/2016, from Inhabitat http://inhabitat.com/building-modelled-on-termites-eastgate-centre-in-zimbabwe/

Inusa, Y. J., Ajufoh, M.O., \& Lekjep, R.S. (2012). Sustainable Architectural Education: Pedagogical Learning Outcomes Of Sustainable Environmental Design Paper presented at the AARCHES 2012 BGM and Annual Conference, Jos, Nigeria.

IPCC. (2007). Climate Change 2007: Synthesis Report. Contribution of Working Groups I, II and III to the Fourth Assessment Report of the Intergovernmental Panel on Climate Change. Retrieved from Geneva, Switzerland:

Irele, A. (2011). Westernization - Africa - Bibliography. Retrieved from http://science.jrank.org/pages/8152/WesternizationAfrica.html

Irouke, V., \& George, A. (2016). A review of climate's change and architects' perspective towards achieving thermal comfort in buildings in South Eastern Nigeria. International Journal of Advanced Studies in Ecology, Development and Sustainability, 4(1), 113-124.

Irvine, A., Drew, P., \& Sainsbury, R. (2012). Am I not answering your questions properly?' Clarification, adequacy and responsiveness in semi-structured telephone and face-to-face interviews. SAGE: Qualitative Research 13(1), 87-106. Ishwar, C. (1976). Design aids for natural ventilation in buildings. Retrieved from India:

Iwuagwu, B., \& Chioma, M. (2015). Local Building Materials: Affordable Strategy for Housing the Urban Poor in Nigeria (Vol. 118). Izzett, A. (2018). Family Life among the Yoruba, in Lagos, Nigeria. In Social Change in Modern Africa (pp. 305-315): Routledge. Kalnay, K., Cai, M. (2003). Impact of urbanization and land use change on climte. Nature, 423, 528-531.

Karl, R. T., Trenberth, E.K. (2003). Modern Global Climate Change. American Association for the Advancement of Science, 302(5651), 1719-1723. Retrieved from http://www.jstor.org/stable/3835878

Kawuwa, A. S., Sani, A. A., Mustapha, S., \& Ishaku, D. D. (2015). Development of Strategies for Sustainable Energy Efficient Building Codes in Nigeria. International Journal of Scientific and Research 5(4), 1-7.

Keener, V. (2013). NCA Regional Input Reports : Climate Change and Pacific Islands : Indicators and Impacts: Report for the 2012 Pacific Islands Regional Climate Assessment. Hawaii, USA: NCA Regional Input Reports.

Kere, F. (2002). Gando primary school. Retrieved from http://www.kere-architecture.com/projects/primary-school-gando/ Khan, N. (2008). A review on wind driven ventilation techniques. Energy and Buildings, 40, 1586-1604.

Kiamba, L., Rodrigues, L., \& Lau, B. (2014). Climate-responsive Vernacular Swahili Housing Paper presented at the 30th International PLEA Conference, Ahmedabad.

Kimura, K. Y. K. (1982). Passive cooling performance of thatched roofs in traditional Japanese vernacular houses. Paper presented at the The first international PLEA conference

Koboldt, C. (1995). Optimising the Use of Cultural Heritage. Paper presented at the Economic Perspectives of Cultural Heritage, Cannizzaro.

Koenigsberger, H. I., G. (1975). Manual of tropical housing and building: Climatic design Telangana, India: Orient Longman Private Limited.

Kohler, N. (2002). The relevance of BEQUEST: an observers' perspective. Building Research and Information, 30(2), $130-138$. Krosnick, J. A., Narayan, S., \& Smith, W. R. (1996). Satisficing in surveys: Initial evidence. San Francisco, USA: SAGE. Kumar, A., \& Pushplata. (2013). Vernacular practices: As a basis for formulating building regulations for hilly areas. International Journal of Sustainable Built Environment, 2(2), 183-192. doi:https://doi.org/10.1016/j.ijsbe.2014.01.001 


\section{References}

La Roche, P., Liggett, R. (2001). Very Simple Design Tools: A Web Based Assistant for the Design of Climate Responsive Buildings. Architectural Science Review, 44(4), 437-448. doi:10.1080/00038628.2001.9696924

Lancaster, A. G., Dodd, S., \& Williamson, R. P. (2004). Design and analysis of pilot studies: recommendations for good practice. Journal of Evaluation and Clinical Practice, 10(2), 307-312.

LASPPPA. (2019). About planning permit. Retrieved from https://epp.lagosstate.gov.ng/Home/AboutPlanningPermit

Lawal, A., \& Ojo, O. (2011). Assessment of thermal performance of residential buildings in Ibadan land, Nigeria. J. Emerg. Trends Eng. Appl. Sci, 2, 581-586.

Lechner, N. (2015). Heating, Cooling, Lighting: Sustainable design methods for architects New Jersey, USA: John Wiley \& Sons. LEED. (2016). LEED v4 for BUILDING DESIGN AND CONSTRUCTION. In (pp. 1-147). Washington, USA: United State Green Building Council.

LEED. (2019). LEED Certified Building List. Retrieved from http://www.usgbc.org/projects

LEED. (2019). LEED v4 Building Design and Construction. Retrieved from https://www.usgbc.org/resources/leed-v4-buildingdesign-and-construction-current-version

Leung, S.-O. (2011). A comparison of psychometric properties and normality in 4-, 5-, 6-, and 11-point Likert scales. Journal of Social Service Research, 37(4), 412-421.

Lewis, J. R. (1993). Multipoint scales: Mean and median differences and observed significance levels. International Journal of Human-Computer Interaction, 5(4), 383-392.

Linacre, E. (1997). Climates and Weather Explained: Routledge.

Linstone, H., \& Turloff, M. (1975). The Delphi Method: Techniques and applications. London, UK: Addison-Wesley.

Lippsmeier, G. (1980). Building in the Tropics. Munich, Germany: Callwey.

Littlefield, D. (2012). Metric Handbook: Planning and Design Data: Routledge.

Liu, W., Wang, C., \& Mol, A. P. (2013). Rural public acceptance of renewable energy deployment: The case of Shandong in China. Applied energy, 102, 1187-1196.

Lodson, J., Ogbeba, J. E., \& Elinwa, U. K. (2018). A Lesson from vernacular architecture in Nigeria. Journal of Contemporary Urban Affairs, 2(1), 84-95.

Loorbach, D. (2010). Transition Management for Sustainable Development: A Prescriptive, Complexity-Based Governance Framework. Governance, 23(1), 161-183.

Loorbach, D., \& Rotmans, J. (2010). The practice of transition management: Examples and lessons from four distinct cases. Futures, 42(3), 237-246. doi:https://doi.org/10.1016/j.futures.2009.11.009

Lopez, B., \& William, B. (1995). A Primer on Sustainable Building. Colorado, USA: Rocky Mountain Institute.

Lorenzoni, I., Nicholson-Cole, S., \& Whitmarsh, L. (2007). Barriers perceived to engaging with climate change among the UK public and their policy implications. Global Environmental Change, 17, 445-459.

Los, S. (1983). Passive solar systems versus architecture Paper presented at the International PLEA Conference Greece.

Love, P. E. D., Niedzweicki, M., Bullen, P. A., \& Edwards, D. J. (2012). Achieving the Green Building Council of Australia 2019's World Leadership Rating in an Office Building in Perth. Journal of Construction Engineering and Management, 138(5), 652-660. doi:doi:10.1061/(ASCE)CO.1943-7862.0000461

Lucas, R. (2016). Research Methods for Architecture. Laurence King Publishing Ltd London, United Kingdom: Laurence King Publishing Ltd.

Macnaghten, P., \& Jacobs, M. (1997). Public identification with sustainable development: Investigating cultural barriers to participation. Global Environmental Change, 7(1), 5-24

Madden, T. M., \& Klopfer. F. J. (1978). The "cannot decide" option in Thurstone-type attitude scales. Educational and Psychological Measurement, 38, 259-264.

Mahoney, C., Königsberger, O., \& Evans, J. M. (1971). Climate and house design. New York, USA: United Nations

Maina, J., Abba, M., Abba, A., \& Haruna, R. (2016). Housing Transformation Trends in Kundila and Takur Site 2 Estates, Northern Nigeria. 6.

Malama, S. S. A. (1996). Thermal and Economic Implications of Passive Cooling Strategies in Low-Cost Housing in Tropical Upland Climates. Architectural Science Review, 39(2), 185-200.

Malterud, K., Siersma, V. D., \& Guassora, A. D. (2016). Sample Size in Qualitative Interview Studies: Guided by Information Power. Qualitative Health Research, 26(13), 1753-1760.

Mariarty, P., \& Svar, T. I. (1976). Housing Materials and Methods for Tropical Africa. Building Research and Practice, 4(1), 28 - 38. Markus, T. A. M., E.N. (1980). Buildings, Climate and Energy. London, UK,: Pitman Ltd.

Marsh, C. (2005). Sustainable construction. In J. Yang, P. S. Brandon, \& A. C. Sidewall (Eds.), Smart \& Sustainble Built Environment. Oxford, UK: Blackwell Publishing Ltd.

Mason, M. (2010). Sample Size and Saturation in PhD Studies Using Qualitative Interviews. Forum Qualitative Sozialforschung / Forum: Qualitative Social Research, 11(3).

Mawhinney, M. (2002). Sustainable Development: Understanding the Green Debate. Oxford, UK: Blackwell Science

MBIE. (2019). Projects \& consents. Retrieved from https://www.building.govt.nz/projects-and-consents/planning-a-successfulbuild/scope-and-design/choosing-the-right-people-for-your-type-of-building-work/use-licensed-people-for-restricted-buildingwork/restricted-building-work/lbp-licence-classes/

MBIE. (2020). Energy in New Zealand. Retrieved from https://aemo.com.au/-/media/files/pdf/vcr-final-report-appendix--pdfupdated-27-nov-14.pdf

McCarthy, M. (2012). Climate Change: Nature and Emerging Trends. In C. A. Booth, Hammond, F.N., Lamond, J.E., \& Proverbs, D.G. (Ed.), Solutions for Climate Change Challenges in the Built Environment West Sussex, United Kingdom: John Wiley \& Sons, Ltd.

McGranahan, G., Songsore, J., Jacobi, P., Surdjadi, C. \& Klellen, M. (2001). The Citizens at Risk: From Urban Sanitation to Sustainable Cities. London, United Kingdom: Earthscan. 


\section{References}

McKelvie, S. J. (1978). Graphic rating scales: How many categories? British Journal of Psychology, 69, 185-202.

McMichael, A. J., Campbell-Lendrum, D.H., Corvalan, C.F., Ebi, K.L., \& Githeko, A.K. (2003). Climate change. In Climate change and human health: risks and responses. Geneva, Switzerland: Geneva: World Health Organization.

Melodi, A., \& Famakin, S. (2015). A Review of Solar PV-Grid Energy Cost Parity in Akure, South-West Nigeria. International

Journal of Electrical and Computer Engineering (IJECE), 5, 879-886. doi:10.11591/ijece.v5i5.pp879-886

Messick, S. (1993). Validity. Phoenix, USA: Oryx Press.

Mickaityte, A., Zavadskas, E.K., Kaklauskas, A., \& Tupenaite, L. (2008). The concept model of sustainable buildings refurbishment. International Journal of Strategic Property Management, 12(1), 53-68.

Mijinyawa, Y., Adesogan, S. O., \& Ogunkoya, O. G. (2007). A survey of roof failures in Oyo State of Nigeria. Journal of Building Appraisal, 3(1), 52-58. doi:10.1057/palgrave.jba.2950055

Milbrath, L. W. (1995). Psychological, Cultural, and Informational Barriers to Sustainability. Journal of social issues, 51(4), 101-120. Miles, M. B., Huberman, A.M. . (1994). Miles, M.B., \& Huberman, A.M. (1994). Qualitative data analysis: An expanded sourcebook. California, USA: SAGE Publications.

Milfont, T. L. (2010). Global Warming, Climate Change and Human Psychology. New york: Nova Science Publishers INC. Mishra, D., Akman, I., \& Mishra, A. (2014). Theory of reasoned action application for green information technology acceptance. Computers in human behavior, 36, 29-40.

Misni, A. (2013). Modifying the Outdoor Temperature around Single-Family Residences: The influence of landscaping. Procedia Social and Behavioral Sciences 105, 664-673.

MMA. (2019). Zagun House by Murphy Mears Architects. Retrieved from www.murphymears.com

Mohammed, I., Iliyasu, G., \& Habib, A. G. (2017). Emergence and control of epidemic meningococcal meningitis in sub-Saharan Africa. Pathogens and Global Health, 111(1), 1-6. doi:10.1080/20477724.2016.1274068

Molina-Prieto, H. E.-B. L. F. (2015). Adaptation of Vernacular Designs for Contemporary Sustainable Architecture in Middle East and Neotropical region. Environmental Studies and Earth Science, 3(4).

Mooney, D., \& Kroposki, B. (2009). Electricity, resources, and building systems integration at the national renewable energy laboratory. Paper presented at the IEEE Power Energy Society 2009 General Meeting Calgary, Alberta Canada.

Morgan, D. L. (1998). Practical strategies for combining qualitative and quantitative methods: Applications to health research. Qualitative Health Research, 8, 362-376.

Moriarty, P. (1978). Earth wall construction: A Tanzanian case study. Paper presented at the International conference on materials of construction for developing countries, Bangkok, Thailand.

Moriarty, P. (1980). The Case for Traditional Housing in Tropical Africa. Habitat International, 4(3), 285-290.

Morse, J. M. (1991). Approaches to qualitative-quantitative methodological triangulation. Nursing Research, 40, $120-123$.

Mu'Azu, A. I. (2011). Promoting Energy Use Regulations for a Sustainable Built Environment in Nigeria. In O. O. Ogunsote, Arayela, O., Gyoh, L. E., \& Ahmed, Z (Ed.), Architecture and the Nigerian DevelopmentAgenda IV: Sustainable Built Environment (pp. 284293). Abuja, Nigeria: Talos Press.

Nabegu, A. B. (2011). Solid Waste and Its Implications for Climate Change in Nigeria. Journal of Human Ecology, 34(2), 67-73. NASA. (2016). Global temperature. Retrieved from http://climate.nasa.gov/vital-signs/global-temperature/. Retrieved 29/10/2016, from National Aeronautics and Space Administration http://climate.nasa.gov/vital-signs/global-temperature/ Nationsonline. (2015). Political Map of West Africa. Project, Nations Online. Retrieved from http://www.nationsonline.org/oneworld/map/west-africa-map.htm

NBS. (2014). LSMS-Integrated Surveys on Agriculture General Household Survey Panel. Retrieved from http://nigerianstat.gov.ng/elibrary:

NBS. (2019). National Bureau of Statistics E-Library. Retrieved from http://nigerianstat.gov.ng/elibrary NCC. (2018). BNRCC - Building Nigeria's Response To Climate Change. from Nigerian Climate Change

NCDMB. (2019). NCDMB to support Yenagoa New City Project. Retrieved from https://ncdmb.gov.ng/ncdmb-to-support-yenagoanew-city-project/

Nduka, D. O., \& Ogunsanmi, O. E. (2016). Construction professionals' perception on green building awareness and accruable benefits in construction projects in Nigeria. Covenant Journal of Research in the Built Environment, 3(2).

Nematchoua, K. M., \& Orosa, J. A. (2016). Building construction materials effect in tropical wet and cold climates: A case study of office buildings in Cameroon. Case Studies in Thermal Engineering, 7, 55 - 65.

NeweraEnergy. (2013). Wind Energy. Retrieved from http://www.neenigeria.com/html/wind_energy.html NIA. (2016). Nigerian Institute of Architects. Retrieved 08/12/2016, from Nigerian Institute of Architects

NIA. (2017). Energy Efficient Building Design. Retrieved from https://nia.ng/2017/

Nicol, F. (2004). Adaptive thermal comfort standards in the hot-humid tropics. Energy and Buildings, 36, 628-637.

Nielsen, J. (2000). Why You Only Need to Test With 5 Users. Retrieved from http://www.useit.com/alertbox/20000319.html. Nii Addy, M., Adinyira, E., \& Koranteng, C. (2014). Architect's perception on the challenges of building energy efficiency in Ghana. Structural Survey, 32(5), 365-376. doi:10.1108/SS-03-2014-0014

NIMET. (2019). Annual climate review bulletin. Retrieved from https://nimet.gov.ng/quarterly-weather-bulletins NIMET. (2020). State of the Climate in Nigeria. Retrieved from https://www.nimet.gov.ng/seasonal-climate-prediction/ NIQS. (2019). Green Building Council of Nigeria Membership Form and Benefits. Retrieved from http://niqs.org.ng/greenbuilding-council-nigeria-membership-form-and-benefits/

NNPC. (2016). History of the Nigerian Petroleum Industry.

Norland-Tilburg, E. V. (1990). Controlling error in evaluation instruments. Journal of Extension, 28(2), 5-10.

Nwabueze, C., \& Egbra, S. (2016). Newspaper framing of climate change in Nigeria and Ghana. Applied Environmental Education \& Communication, 15(2), 111-124.

Nwofe, P. A. (2014). Need for energy efficient buildings in Nigeria. International Journal of Energy and Environmental Research, 2(3), 1-9. 


\section{References}

Nwokoro, I., \& Onukwube, H. (2011). Sustainable or Green Construction in Lagos, Nigeria: Principles, Attributes and Framework. Journal of Sustainable Development, 4(4), 166-173.

Nworgu, B. G. (1991). Educational Research: Basic Issues and Methodology. Ibadan: Wisdom Publishers Ltd.

NYTimes. (2011). Riches flow into Nigeria, but are lost after arrival. Retrieved from

https://www.nytimes.com/2011/02/o9/world/africa/o9nigeria.html

NZGBC. (2015). Strategic review of the New Zealand green building market 2015. Retrieved from

https://www.nzgbc.org.nz/Attachment?Action=Download\&Attachment_id=338

Odunfa, K., Ojo, T., Odunfa, V., \& Ohunakin, O. (2015). Energy Efficiency in Building: Case of Buildings at the University of Ibadan, Nigeria. Journal of Building Construction and Planning Research, 3, 18-26.

Ogbo, A., Ndubuisi, E.L. \& Ukpere, W. (2013). Risk Management and Challenges of Climate Change in Nigeria. Journal of Human Ecology 41(3), 221-235.

Ogundiran, I. A., \& Adedeji, Y. M. (2012). Urban housing delivery: Expanded polystyrene panels initiative in Abuja, Nigeria. Paper presented at the Procs 4th West Africa Built Environment Research (WABER) Conference.

Ogundiran, I. A., \& Adedeji, Y. M. (2014). Sustainable Construction: Comparative Advantages of Expanded Polystyrene (EPS)

Fascia in Housing Delivery in Nigeria Civil and Environmental Research 6(10), 66 - 75.

Ogunrayewa, M. O., Morakinyo, K.O., \& Adenubi, O. (2012). New Trends in Architectural Curriculum Development - A Panacea for Sustainable Architectural Education in Nigeria. Paper presented at the AARCHES 2012 BGM and Annual Conference, Jos, Nigeria. Ogunsote, O. O. (2010). Optimizing passive cooling systems in residential buildings: A case study of Akure, nigeria. Department of Architecture. Department of Architecture, Faculty of Environmental Sciences University of Jos, Jos, Nigeria. Jos, Nigeria. Ogunsote, O. O. P. O. (2002). Defining climatic zones for architectural design in Nigeria: A systematic delinea- tion. Journal of Environmental Technology, 1, 1 - 14 .

Oisamoje, M. D., \& Oisamoje, E. E. (2013). Exploring the economic and environmental benefits of solar energy generation in developing countires: The Nigerian perspective Journal of Energy Technologies and Policy, 3(6).

Okafor, M. U. (2018). Integrating indoor thermal comfort opportunities from traditional building types into the delivery and management of sustainable built environments. Journal of Construction Project Management and Innovation, 8(1), $1682-1695$. Retrieved from https://journals.co.za/content/journal/10520/EJC-10a4578co6

Oladokun, T. T., Gbadegesin, J. T., \& Ogunba, O. A. (2010). Perceptual Analysis of the Benefits and Implementation Difficulties of Green Building in Lagos Metropolis. Paper presented at the International Conference on Sustainability in Built Environment Nigeria, Colombo, Sri Lanka.

Olamijulo, J. O., Ana, G. R., \& Morakinyo, O. M. (2016). Noise from Portable Electric Power Generators in an Institutional Setting: A Neglected Risk Factor International Journal of Environmental Monitoring and Analysis, 4(4), 115 - 120.

Olanipekun, O. A., Chan, P. C., Xia, B., \& Adedokun, A. O. (2018). Applying the self-determination theory (SDT) to explain the levels of motivation for adopting green building. International Journal of Construction Management, 18(2), $120-131$. Olaniyan, K., McLellan, B., Ogata, S., \& Tezuka, T. (2018). Estimating residential electricity consumption in Nigeria to support energy transitions. Sustainability, 10(5), 1440.

Olgyay, V. (2015). Design with Climate: Bioclimatic approach to architectural regionalism (2015 ed.): Princeton University Press. Oliver, P. (1998). Encyclopedia of Vernacular Architecture of the World. Cambridge, United Kingdom: Cambridge University Press Oloruntoba, D. T., Oluwole, O. O., \& Oguntade, E. O. (2009). Comparative study of corrosion behaviour of galvanized steel and coated $\mathrm{Al} 3103$ roofing sheets in carbonate and chloride environments. Materials \& Design, 30(4), 1371-1376.

doi:https://doi.org/10.1016/j.matdes.2008.06.005

Olufemi, F. (2019). Decriminalisation Of Bigamy In Lagos State And Its Legal Implications. Retrieved from https://www.topeadebayollp.org/insight/decriminalisation-of-bigamy-in-lagos-state-and-its-legal-implications/

Oluwatayo, A., Akinola, A. O., Agomuo, I. U., Mozimo, S. O., Onwuka, C. C., \& Okagbue, H. I. (2018). Survey dataset on factors that influence satisfaction of clients with architectural services in Lagos State, Nigeria. Data in Brief, 20, 118-125

doi:https://doi.org/10.1016/j.dib.2018.07.055

Omidreza, S., Haw, L., Sopian, K., \& Sulaiman, Y. (2012). Review of windcatcher technologies. Renewable and Sustainable Energy Reviews, 16, 1477-1495.

Omonijo, A. G., Adeofun, C. O., Oguntoke, O., \& Matzarakis, A. (2013). Relevance of thermal environment to human health: a case study of Ondo State, Nigeria. Theoretical and Applied Climatology, 113(1), 205-212. doi:10.1007/s00704-012-0777-9

Ong, B. L. (1995). Designing for the Individual: A Radical Reading of ISO 7730. In M. H. F. Nicol, O.Sykes and S. Roaf (Ed.), Standards for Thermal Comfort. Oxon, United Kingdom: Taylor \& Francis.

OnlineNigeria. (2002). Climate - Nigeria. Retrieved from http://www.onlinenigeria.com/links/adv.asp?blurb=69

Opara, C. C., \& Kfuban, B. P. (2014). Impact of Climate Change on Sub-Sahara Africa: Case studies in Cameroon, Nigeria and Uganda. Frankfurt, Germany: Peter Lang GmbH.

Oruwari, Y. (1991). The changing role of women in families and their housing needs: a case study of Port Harcourt, Nigeria. Environment and Urbanization, 3(2), 6-12.

Oseni, M. O. (2012). Households' access to electricity and energy consumption pattern in Nigeria. Renewable and sustainable energy reviews, 16(1), 990-995.

Osuala, E. C. (1991). Introduction to Research Methodology. Onitsha: Sciences FEP.

Otegbulu, A. C. (2011). Economics of Green Design and Environmental Sustainability Journal of Sustainable Development 4(2), 240-248.

Otite, O. (1991). Marriage and family systems in Nigeria. International journal of sociology of the family, 15-54.

OxfordDictionary. (2017). Climate Change. In O. U. Press (Ed.). Oxford, United Kingdom: Oxford University Press.

Oyedepo, O. S. (2012). Energy and sustainable development in Nigeria: the way forward. Energy, Sustainability and Society, 2(15), 56-68.

Oyefusi, N., \& Adeyemo, O. (2019). Critical Review of Factors Inhibiting the Adoption of Green Building Design in Nigeria. 
Pahl, S., Sheppard, S., Boomsma, C., \& Groves, C. (2014). Perceptions of time in relation to climate change. WIREs Climate Change, 5, 375-388.

Papageorgiou, I. (2016). Function follows form architectural form and sound propagation. Paper presented at the The 23rd International Congress on Sound and Vibration, Athens, Greece.

Park, S. Y. (2009). An analysis of the technology acceptance model in understanding university students' behavioral intention to use e-learning. Educational technology \& society, 12(3), 150-162.

Parkinson, H., Alex Parkinson., Richard de Dear. (2015). Introducing the SAMBA indoor environmental quality monitoring system. Paper presented at the 49th International Conference of the Architectural Science Association 2015, Melbourne, Australia Parsons, S. (2011). "Thermal Mass and Thermoregulation: A Study of Thermal Comfort in Temperate Climate Residential Buildings". (Doctor of Philosophy). University of Tasmania, Tasmania, Australia

Patton, M. Q. (1990). Qualitative evaluation and re- search methods (2 ed.). Newbury Park, CA: SAGE Publications. Patton, M. Q. (2014). Qualitative Research and Evaluation Methods (4 ed.). California, USA: SAGE Publications.

Pawlik, K. (1991). The pyschology of global environmental change: Some basic data and an agenda for coopertaive international research. International Journal of Psychology, 26, 547-563.

Pe'rez-Lombard, L. (2008). A review on buildings energy consumption information. Energy and Buildings, 40, $394-398$.

Pearce, J. M., \& Ivana, Z. (2012, February 7, 2018). Barriers to Appropriate Technology Growth in Sustainable Development. Retrieved from http://www.appropedia.org/Barriers_to_Appropriate_Technology_Growth_in_Sustainable_Development Peel, M. C. (2007). Updated world map of the Ko " ppen-Geiger climate classification. Hydrology and Earth System Sciences, 11, 1633-1644.

Preston, C. C., Colam, A.M. (2000). Optimal number of response categories in rating scales:reliability, validity, discriminating power, and respondentpreferences. Acta Psychologica, 104, 1-15.

Priyaa, S., Sundarraja, C., Radhakrishnana, S., \& Vijayalakshmia, L. (2012). Solar passive techniques in the vernacular buildings of coastal regions in Nagapattinam, TamilNadu-India - a qualitative and quantitative analysis. Energy and Buildings, 49, 50-61. Prucnal-Ogunsote, B. (2013). Classification of Nigerian architecture. AARCHES Journal, 1(6), 48 - 56.

Prucnal-Ogunsote, B., Olu, Ogunsote, O., Ola, A., Ude, A., Voitek, A., \& Ogunsote, B. (2018). Towards the establishment of a green building council and the development of a green building rating system for Nigeria. Retrieved from

https://www.researchgate.net/profile/Olu_Ogunsote/publication/267784294_TOWARDS_THE_ESTABLISHMENT_OF_A_GRE EN_BUILDING_COUNCIL_AND_THE_DEVELOPMENT_OF_A_GREEN_BUILDING_RATING_SYSTEM_FOR_NIGERIA/link s/5706b50208aefb22b0934547.pdf

QuartzAfrica. (2016). An unusually intense Lagos heatwave reminds Nigerians they're not ready for climate change. Quartz Africa. Radhakrishna, B. R. (2007). Tips for Developing and Testing Questionnaires/Instruments. Journal of Extension 45(1), 50-55. RIBA. (2019). Convincing clients to go green. Retrieved from https://www.architecture.com/knowledge-and-resources/knowledgelanding-page/convincing-clients-to-go-green

Rikko, L. S., \& Gwatau, D. (2011). The Nigerian architecture: The trend in housing development.

Rittel, J., Webber, M.M. (1973). Dilemmas in a general theory of planning. Political Science, 4, 155-169.

Roaf, S., Crichton, D., \& Nicol, F. (2009). Adapting buildings and cities for climate change: a 21st century survival guide. Oxon, United Kingdom: Routledge.

Roaf, S., Fuentes, M., \& Thomas-Rees, S. (2013). Ecohouse (Vol. 4). Oxon, United Kingdom: Routledge.

Roche, M. (2017). Comparison of costs of electricity generation in Nigeria-Technical Report. Nigerian Economic Summit Group. Roeser, R. W., \& Peck, S. C. (2009). An Education in Awareness: Self, Motivation, and Self-Regulated Learning in Contemplative Perspective. Educational psychologist, 44(2), 119-136. doi:10.1080/00461520902832376

Rolland, S. (2011). Rural electrification with renewable energy: Technologies, quality standards and buisness models. Brussels, Belgium: Alliance for Rural Electrification

Roy, M. (2009). Planning for sustainable urbanization in fast growing cities: Mitigation and adaptation issues addressed in Dhaka, Bangladesh. Habitat International, 33(3), 276-286.

Rubel, M. K. F. (2010). Observed and projected climate shifts 1901-2100 depicted by world maps of the Ko "ppen-Geiger climate classification. Meteorologische Zeitschrift, 19(2), 135-141

Sachs, J. D. (2001). Tropical Underdevelopment. Paper presented at the Economic History Association 6oth Annual Meeting, Los Angeles.

Salant, P., \& Dillman, D.A. (1994). How to Conduct Your Own Survey. New York, USA: John Wiley \& Sons.

Salkind, N. J. (2009). Statistics for People Who (Think They) Hate Statistics (2 ed.). Thousand Oaks, USA: Sage Publications. Sambo, A. S., Garba, B., Zarma, H.I., \& Gaji, M.M. (2012). Electricity Generation and the Present Challenges in the Nigerian Power Sector. Journal of Energy \& Power Engineering, 6(7), 1050-1061.

Sandelowski, M. (2000). Focus on Research Methods: Combining Qualitative and Quantitative Sampling, Data Collection, and Analysis Techniques in Mixed-Method Studies. Research in Nursing \& Health, 23, 246-255.

Satterthwaite, D. (2008). Cities' Contribution to global warming: note allocation of greenhouse gas emissions. Environment and Urbanization, 20(2), 539-550.

Schniedersa, J., Wolfgang, F., \& Ludwig, R. (2015). Passive Houses for different climate zones. Energy and Buildings, $105,71-87$. Schultz, W. P., Nolan, M.J., Cialdini, B.R., Goldstein, J.N., \& Griskevicius, V. (2007). The Constructive, Destructive, and Reconstructive Power of Social Norms. Association for Psychological Science, 18(5), 429-434.

Scudo, G. (1988). Climatic Design in the Arab Courtyard House. Environmental Design: Journal of the Islamic Environmental Design Research Centre, 1(2), 82-91.

SeiDel, D. J. (2008). Widening of the tropical belt in a changing climate. Nature geoscience, 1, 21-24. doi:10.1038/ngeo.2007.38 Serghides, D. K. (2010). The Wisdom of Mediterranean Traditional Architecture Versus Contem- porary Architecture - The Energy Challenge. Construction and Building Technology Journal, 4, 29-38.

Seto, K. C. S., J.M. (2009). Global land use trends and climate impacts. Current Opinion in Environment Sustainability, 1(1), 89-95. 


\section{References}

Shari, Z. (2011). Development of a Sustainability Assessment Framework for Malaysian Office Buildings Using a Mixed-Methods Approach. (Doctor of Philosophy). University of Adelaide, University of Adelaide.

Shittu, A. (2010). Effect of building design for natural ventilation on the comfort of building occupants in south-western Nigeria. (Higher National Diploma (HND) in Building Technology.). Ibadan Polytechnic, Signify. (2019). Mapping the off-grid solar market in Nigeria Retrieved from

https://www.assets.signify.com/is/content/Signify/Assets/signify/global/20201105-mapping-the-off-grid-solar-market-in-nigeria2019.pdf

Silva, O. O. (2014). Community Development in Emerging Cities: A Case for Lagos,Nigeria. (Master of Architecture). University of Massachusetts,

https://scholarworks.umass.edu/cgi/viewcontent.cgi?referer=\&httpsredir=1\&article=1088\&context=masters_theses_2.

Singh, M. K., Mahapatra. S., \& Atreya, S.K. (2009). Bioclimatism and vernacular architecture of north-east India. Building and Environment, 44, 878-888.

Singh, M. K., \& Mahapatra, S., \& Atreya,S.K. (2010). Thermal performance study and evaluation of comfort temperatures in vernacular buildings of North-East India. Building and Environment, 45, 320-329.

Skulmoski, G. J., Hartman, F. T., \& Krahn, J. (2007). The Delphi Method for Graduate Research. Journal of Information

Technology Education, 6, 1-22.

Songsore, J. (2004). Urbanization and Health in Africa: Exploring the Interconnections between Poverty, Inequality and the Burden of Disease. Accra, Ghana: Ghana Universities Press.

SOTT. (2014). State of the Tropics. Retrieved from Queensland, Australia:

Stake, R. (1995). The Art of Case Study Research. Los Angeles, USA: Sage Publications

Statista. (2019, 9/09/2019). Average duration of electricity outages per year in Africa as of 2018, by select country (in hours). 29/05/2019. Retrieved from https://www.statista.com/statistics/617570/average-monthly-electricity-outage-africa-by-selectcountry/

StatisticsSolutions. (2018). Paired Sample T-Test. Retrieved from https://www.statisticssolutions.com/manova-analysis-pairedsample-t-test/

Stern, N., Peters, S., Bakhshi, V., Bowen, A., Cameron, C., Catovsky, S., Crane, D., Cruickshank, S., Dietz, S., Edmonson, N., Garbett, S.L., Hamid L., Hoffman, G. \& Ingram, T. (2006). Stern Review: The Economics of Climate Change. Retrieved from London, United Kingdom:

Sturgis, P., Allum, N. (2004). Science in society: re-evaluating the deficit model of public attitudes. Public Understanding of Science, $13,55-74$

Sturman, N. T. A. (2006). The weather and climate of Australia and New Zealand (2 ed.). Melbourne, Australia: Oxford University Press.

Sun. (2018). Meningitis: Before the heat-wave brings another epidemics. The Sun.

Suri, H. (2007). Expanding possibilities within research syntheses: A methodologically inclusive research synthesis framework. The University of Melbourne.,

Suri, H. (2011). Purposeful Sampling in Qualitative Research Synthesis. Qualitative Research Journal, 11(2), 63-75.

Tashakkori, A., \& Charles, T. (2010). Handbook of Mixed Methods in Social \& Behavioral Research (2 ed.). California, USA: SAGE Publications.

Taylor, W., N,Lu., Jiang, J., Correia, L., Leung, R., \& Wong, P.C. (2009). The temperature sensitivity of the residential load and commercial building load. Paper presented at the IEEE Power Energy Society 2009 General Meeting Calgary, Alberta Canada. Teddlie, C., \& Yu, F. (2007). Mixed Methods Sampling: A typology with examples. Journal of Mixed Methods Research, 1(1), 77-100. Tether, B. (2016). Results of the 2016 Women in Architecture Survey revealed. Retrieved from https://www.architecturalreview.com/rethink/results-of-the-2016-women-in-architecture-survey-revealed/10003314.article

Time. (2017, September 22, 2017). How Architecture Should Adapt to Climate Change. Time Magazine.

Topper, W. W. (2006). Leadership Change In Privately Controlled Businesses: A Delphi Study Of Succession Planning Best Practices (Doctor of Philosophy). Capella University, Capella University.

Torcellini, P., Pless, S., \& Deru, M. (2006). Zero Energy Buildings: A Critical Look at the Definition Paper presented at the National Renewable Energy Laboratory, California, USA.

Trenberth, K. E., \& Fasullo, J.K. (2009). Earth's global energy budget. Bulletin of the American Meteorological Society, 90, 311-323. Trewin, B. (2014). State of the Tropics. Retrieved from Australia:

Trudgill, S. (1990). Barriers to a Better Environment: What Stops Us Solving Environmental Problems. London, United Kingdom: Belhaven Press.

Tunde, A. M., Adeleke, E. A., \& Adeniyi, E. E. (2013). Impact of climate variability on human health in ilorin, nigeria. Environment and Natural Resources Research, 3(1), 127.

Ude, A. D., Umeh, T. O., \& Ukwunna, C. (2017). Town Planning Authority Building Regulations and Compliance Challenges in Nigeria a Case Study Imo State. Journal of Environmental Management and Safety, 8(1), 1 - 10.

Ugbah, P. A., Olaniyan, O., Francis, S. D., \& James, A. (2020). Impact of Climate Change on Growing Season in Nigeria: Seasonal Rainfall Prediction (SRP) as Assessment and Adaptation Tool (1 ed.). Switzerland: Springer International Publishing.

Umar, G. K., Yusuf, D. A., \& Mustapha, A. (2019). Theory and design for the contemporary residential building: a case study of Kano metropolis, north-western part of nigeria. Int. J. Innov. Environ. Stud. Res, 7(1).

UN. (2015). World Population Propspects: The 2015 Revision. from United Nations Department of Public Information

UN (Producer). (2017, 6/02/2018). Sustainable Development Goals in Nigeria Retrieved from

https://sustainabledevelopment.un.org/memberstates/nigeria

UN-Habitat. (2009). Global Report on Human Settlements 2009. Planning Sustainable Cities Directions. Retrieved from London, $\mathrm{UK}$

UNDP. (2008). Promoting Energy Efficiency in the Residential and Public Sector in Nigeria. Retrieved from Abuja, Nigeria: 


\section{References}

UNDP. (2020). Sustainable Development Goals. Retrieved from https://www.undp.org/content/undp/en/home/sustainabledevelopment-goals.html

UNEP. (2006). Africa Environment Outlook 2. Retrieved from Nairobi:

UNEP. (2012). African Ministerial Conference on the Environment. Paper presented at the African Ministerial Conference on the

Environment, Cairo, Egypt.

UNPF. (2007). State of the World's Population 2007: Unleashing the Potential Urban Growth. Retrieved from New York, USA:

Unruh, G. C. (2002). Escaping carbon lock in. Energy Policy, 30(317-325).

USCB. (2018, 26/01/2018). U.S. Census Bureau Current Population. Retrieved from

https://www.census.gov/popclock/print.php?component=counter

Uzendu, P., Ogbonna, I. D., \& Osueke, C. O. . (2013). Study and Evaluation of Solar Energy Variation in Nigeria. International

Journal of Emerging Technology and Advanced Engineering, 3(6), 501-505. doi:9001:2008

Uzoagulu, A. E. (2011). Practical Guide to Writing Research Project Report in Tertiary Institutions. Enugu: Cheston Publishers.

Vaismoradi, M., Turunen, H., \& Bondas, T. (2013). Content analysis and thematic analysis: Implications for conducting a

qualitative descriptive study. Nursing and Health Sciences, 15, 398-405.

Venkatesh, V., \& Bala, H. (2008). Technology acceptance model 3 and a research agenda on interventions. Decision sciences, 39(2), 273-315.

Venkatesh, V., \& Bala, H. (2008). Technology acceptance model 3 and a research agenda on interventions. Decision sciences, 39(2),

273-315.

Ventures. (2016). Heat wave in Nigeria. Ventures Africa.

Walliman, N. (2017). Research Methods: The Basics (2nd ed.). London, UK: Routledge.

Wang, L., \& Hien, N. W. (2007). Applying Natural Ventilation for Thermal Comfort in Residential Buildings in Singapore.

Architectural Science Review, 50(3), 224-233.

Waniko, D. P. (2014). Green Building in Nigeria: Emerging Opportunities for the Quantity Surveying Profession. Nigeria: Academia Retrieved from https://www.academia.edu/12181314/Green_Building_in_Nigeria

Warwick, J. M., Wilcoxen, P.J. (2002). The role of economics in climate change policy. Journal of Economic Perspectives, 16, 107129.

Watson, V. (2009). The planned city sweeps the poor away...Urban planning and 21st century urbanization. Progress in Planning, 72(3), 151-193.

WBCSB. (2009). Energy Efficiency in Buildings: Transforming the market. Retrieved from The World Business Council for Sustainable Development, Geneva:

WBG. (2014). Diesel Power Generation: Inventories and Black Carbon Emissions in Nigeria Washington DC: World Bank Group

WBG. (2019). Climate change knowledge portal. Retrieved from

https://climateknowledgeportal.worldbank.org/country/nigeria/climate-data-historical

WCED. (1987). Our Common Future 'Brudtland Report'. New York, USA: United Nation.

Weatherspark. (2019). Average Weather in Nigeria. Retrieved from https://weatherspark.com/countries/NG

Were, S. W. (2015). Investigation into the adoption of green building concepts in commercial buildings: A case of Nairobi County. (Doctoral dissertation). Jomo Kenyatta University of Agriculture and Technology, Retrieved from

http://ir.jkuat.ac.ke/handle/123456789/1748

Whelton, M. B., G. (2002, 6/08/2002). Wicked problems in project definition. Paper presented at the 10th Annual Conference on International Group for Lean Construction, Porto Alegre, Brazil.

Whiting, L. P. (1991). A Delphi study to determine defining characteristics of interdependence and dysfunctional independence as potential nursing diagnosis. Issues in Mental Health Nursing, 15, 37-47.

WHO. (2015). Climate And Health Country Profile - 2015 Nigeria. Geneva, Switzerland: World Health Organization Retrieved from https://www.who.int/globalchange/resources/PHE-country-profile-Nigeria.pdf?ua=1

Wild, O. (2007). The straight facts on forest, carbon and global warming. Portland, USA: Oregon Wild.

Williams, L. (2008). Nigeria: The bradt travel guide. Chalfont St Peter, UK: Bradt Travel Guides Ltd.

Williamson, T. J., Radford, A., \& Bennetts, H. (2003). Understanding Sustainable Architecture. London, United Kingdom: Taylor \& Francis.

Windapo, A. (2006). The Threat of Building Collapse on Sustainable Development in the Built Environment in Nigeria. Paper presented at the National Conference on Sustainable Development and the Built Environment, Jos, Nigeria.

Winston, N. (2010). Regeneration for sustainable communities? Barriers to implementing sustainable housing in urban areas. Sustainable Development, 18(6), 319-330. doi:10.1002/sd.399

Wittmann, S. (1998). Architects' Perceptions Regarding the Appropriateness of Energy Efficient/Ecologically Sustainable Design Features and Technologies. (Doctor of Philosophy). University of New South Wales, University of New South Wales, Sydney. WMO. (2015). The climate in Africa: 2015. Geneva, Switzerland: World Meteorological Organization

Wojuola, R. N., \& Alant, B. P. (2017). Public perceptions about renewable energy technologies in Nigeria. African Journal of Science, Technology, Innovation and Development, 9(4), 399-409. doi:10.1080/20421338.2017.1340248

Wolfgang, F. (2015). Passive House Planning Package. Darmstadt, Germany: Passive House Institute, Darmstadt.

Wong, N. H., \& Shan, S.K. (2003). Thermal comfort in classrooms in the tropics. Energy and Buildings 35, 337-351.

Woodley, E. (2011). Building Nigeria's Response to Climate Change: Pilot Projects for Community-Based Adaptation in Nigeria. Experiences of Climate Change Adaptation in Africa, 297-315.

WSP. (2014). Local context report: Green Star SA for use in Nigeria (1 ed. Vol. 1). Lagos, Nigeria: WSP Group Africa (Pty) Ltd.

Wu, W. T., Liu, J. F., Li, W. J., \& Hsieh, W. H. (2005). Measurement and correlation of hydraulic resistance of flow through woven metal screens. International Journal of Heat and Mass Transfer, 48(14), 3008-3017.

doi:https://doi.org/10.1016/j.ijheatmasstransfer.2005.01.038 


\section{References}

Yang, J., Brandon, P., \& Sidwell, A. (2008). Introduction - bridging the gaps in smart and sustainable built environments. In J. Yang, Brandon, P. S., Sidwell, A. C. (Ed.), Smart \& Sustainable Built Environments (pp. 368). Oxford, United Kingdom: Blackwell Publishing Ltd.

Yang, K., \& Sun, J. (2016). The Wicked Problem of Climate Change: A New Approach Based on Social Mess and Fragmentation. MDPI: Sustainability 8, 1-14.

Yang, T., \& Clements-Croome, J. (2012). Natural ventilation in built environment. In R. A. Meyers (Ed.), Encyclopedia of Sustainability Science and Technology (pp. 6865-6896). New York, NY: Springer New York.

Yin, R. (2014). Case Study Research: Design and Methods (5 ed.). Los Angeles, USA: Sage Publications.

Yu, C., \& Wong, N.H. (2009). Tropical Urban Heat Islands: Climate Buildings and Greenery (1 ed.). Oxon, United Kingdom:

Routledge.

Zhang, X., \& Wang, Y. (2017). How to reduce household carbon emissions: A review of experience and policy design considerations. Energy Policy, 102, 116-124.

Zhang, Y., Kang, J., \& Jin, H. (2018). A review of green building development in China from the perspective of energy saving. Energies, 11(2), 334.

Zuo, J., \& Zhao, Z.-Y. (2014). Green building research-current status and future agenda: A review. Renewable and sustainable energy reviews, 30, 271-281. 
Appendix A

Appendix A

Architects Survey 
Appendix A

A.1 Ethics approval for stages 1 \& 2 of study: Distribution of questionnaires and interviews with architects in Nigeria

\begin{tabular}{|c|c|c|c|}
\hline \multicolumn{2}{|c|}{ MEMORANDUM } & $\begin{array}{l}\text { Phone } \\
\text { Email }\end{array}$ & $\begin{array}{l}\text { 0-4-463 } 6028 \\
\text { judith.loveridge@vuw.ac.nz }\end{array}$ \\
\hline TO & \multicolumn{3}{|c|}{ Tamaraukuro Amasuomo } \\
\hline FROM & \multicolumn{3}{|c|}{ Dr Judith Loveridge, Convenor, Human Ethics Committee } \\
\hline DATE & \multicolumn{3}{|l|}{1 November 2017} \\
\hline PAGES & \multicolumn{3}{|l|}{1} \\
\hline SUBJECT & \multicolumn{3}{|c|}{$\begin{array}{l}\text { Ethics Approval } \\
\text { Number: } 25400 \\
\text { Title: THE NIGERIAN ARCHITECTS' VIEW ON } \\
\text { ENVIRONMENTAL SUSTAINABLE DESIGN METHODS }\end{array}$} \\
\hline
\end{tabular}

Thank you for your application for ethical approval, which has now been considered by the Human Ethics Committee.

Your application has been approved from the above date and this approval is valid for three years. If your data collection is not completed by this date you should apply to the Human Ethics Committee for an extension to this approval.

Best wishes with the research.

Kind regards,

Judith Loveridge

Convenor, Victoria University of Wellington Human Ethics Committee 


\section{A.2 Questionnaire for architects in Nigeria}

\section{Information for participants}

You are invited to take part in this research. Please read this information before deciding whether or not to take part. If you decide to participate, thank you. If you decide not to participate, thank you for considering this request.

Who am I? My name is Tamaraukuro Tammy Amasuomo and I am a Doctoral student in architecture at the School of Architecture and Design, Victoria University of Wellington This research project is work towards my doctoral thesis.

What is the purpose of this research? The purpose of the study is to find out the architects' view on Environmentally Sustainable Design Methods (ESD) in the design of residential buildings in Nigeria. The results from the survey will provide a comprehensive insight into the development of ESD in Nigeria. This research has been approved by the Victoria University of Wellington Human Ethics Committee application number o000025400

How can you help? You have been invited to participate because of your years of architectural experience and membership with the Architectural Registration Council of Nigeria. If you agree to participate, you will complete an online survey with questions regarding your views on Environmentally Sustainable Design Methods (ESD) and the possible barriers preventing its adoption in Nigeria. It is anticipated that the survey will take no more than 15 minutes to complete. During the research you are free to withdraw at any point before your questionnaire has been completed.

What will happen to the information you give? This research is anonymous. This means that nobody, including the researchers will be aware of your identity. By answering it, you are giving consent for us to use your responses in this research. Your answers will remain completely anonymous and unidentifiable. Once you submit the survey, it will be impossible to retract your answer. Please do not include any personal identifiable information in your responses. The personal information you provide will be destroyed on the 31st of March 2019

What will the project produce? The information from my research will be used in my Doctoral thesis. If you have any questions or problems, who can you contact? If you have any questions, either now or in the future, please feel free to contact either my supervisor or me.

\section{Student:}

Name: Tamaraukuro Tammy Amasuomo | Email: tammy.amasuomo@vuw.ac.nz

\section{Primary Supervisor:}

Name: Prof Regan Potangaroa | Email: regan.potangaroa@vuw.ac.nz

\section{Secondary Supervisor:}

Name: Dr. Emina Perovic | Email: Emina.Petrovic@vuw.ac.nz

\section{Human Ethics Committee information}

If you have any concerns about the ethical conduct of the research, you may contact the Victoria University HEC Convenor: Associate Professor Susan Corbett.

Email: susan.corbett@vuw.ac.nz

\section{Respondents characteristics}

1. Age

$20-40$

$41-60$

60 and above

2. Gender

Male

Female 
Appendix A

\section{Years of architectural experience}

5 - 9 years

10 - 19 years

20 - 30 years

30 years and above

\section{Highest level of educational qualification}

PH.D

M.ARCH, M. SC, M.TECH, MED, B.ARCH

B. SC, B.TECH, BES, BA

HND

OND,HNC

Do architects agree on the need for environmentally sustainable design methods in Nigeria

Please select the option that describes your opinion about the following statements on a scale of 1 to 6 , with 1 being strongly disagree and 6 being strongly agree

\begin{tabular}{|c|c|c|c|c|c|}
\hline $\begin{array}{l}1- \\
\text { trongly } \\
\text { isagree }\end{array}$ & $\begin{array}{c}2- \\
\text { Disagree }\end{array}$ & $\begin{array}{c}3^{-} \\
\text {Somewhat } \\
\text { disagree }\end{array}$ & $\begin{array}{c}4^{-} \\
\text {Somewhat } \\
\text { agree }\end{array}$ & 5 - Agree & $\begin{array}{c}6- \\
\text { Strongly } \\
\text { agree }\end{array}$ \\
\hline
\end{tabular}

1. Form and function has an impact on the indoor thermal conditions of a building

2. Thermally uncomfortable indoor spaces is an architectural problem that needs to be addressed

3. In hot indoor environments, achieving thermal comfort through the use of an electric fan becomes a problem because of the unsatisfactory electricity supply in Nigeria

4. I feel sweaty and uncomfortable most times in a room without an air conditioner or fan

\section{How knowledgeable is the Nigerian architect about environmentally sustainable design methods?}

Please select the option that describes your opinion about the following statements on a scale of 1 to 6 , with 1 being strongly disagree and 6 being strongly agree.

\begin{tabular}{|c|c|c|c|c|c|c|}
\hline & $\begin{array}{l}1- \\
\text { Strongly } \\
\text { disagree }\end{array}$ & $\begin{array}{l}2- \\
\text { Disagree }\end{array}$ & $\begin{array}{l}3^{-} \\
\text {Somewhat } \\
\text { disagree }\end{array}$ & $\begin{array}{l}4^{-} \\
\text {Somewhat } \\
\text { agree }\end{array}$ & $\begin{array}{l}5^{-} \\
\text {Agree }\end{array}$ & $\begin{array}{l}6- \\
\text { Strongly } \\
\text { agree }\end{array}$ \\
\hline $\begin{array}{l}\text { 1. I find that adopting environmentally } \\
\text { sustainable design methods makes it easy to } \\
\text { address other design issues such as: the clients } \\
\text { brief, site allowance/available land etc. }\end{array}$ & & & & & & \\
\hline $\begin{array}{l}\text { 2. As an architectural student, I was always } \\
\text { encouraged to include environmentally } \\
\text { sustainable design methods in my studio/design } \\
\text { courses }\end{array}$ & & & & & & \\
\hline $\begin{array}{l}\text { 3. I always use passive cooling techniques } \\
\text { through reflective and radiative surfaces }\end{array}$ & & & & & & \\
\hline $\begin{array}{l}\text { 4. For most of my designs I specify Photovoltaic } \\
\text { systems or other renewable energy sources }\end{array}$ & & & & & & \\
\hline
\end{tabular}


6. Most architectural designs in Nigeria enhance air movement indoors

7. Most buildings in Nigeria are properly cross-
ventilated
$\begin{gathered}\text { 8. I frequently apply the principles of sun } \\ \text { shading in my design (i.e. shared shade, shadow } \\ \text { umbrella, overhead shades, daylight enhance } \\ \text { shade) }\end{gathered}$
$\begin{gathered}\text { 9. Most architects understand and use building } \\ \text { orientation to minimize heat gain and enhance } \\ \text { air flow into the building }\end{gathered}$
$\begin{gathered}\text { 10. Nigerian architects always provide cross } \\ \text { ventilation in their designs }\end{gathered}$
$\begin{gathered}\text { 11. I design buildings with the intention of } \\ \text { having an air-conditioner and fan }\end{gathered}$

12. I frequently adopt the principles of stack ventilation

13. Most architects design for sun shading/screening

14. I frequently specify earth-air heat exchanger or air-air heat exchanger

15. I frequently design to ensure periodic transformation

\footnotetext{
16. I frequently adopt vent opening with the

strategic arrangement (High or low, a

combination of high \& low, single, two openings on the same wall, two openings with wings, two openings on adjacent walls, two openings on opposite walls)
}

$\begin{gathered}\text { 17. I always ensure my building designs are } \\ \text { interwoven with plants (i.e. landscaping, green } \\ \text { edges, or other forms of planting) } \\ \text { design }\end{gathered}$
$\begin{gathered}\text { 18. If possible, I always include courtyards in my } \\ \text { skylight in my design }\end{gathered}$
19. I frequently provide top light, atrium or
20. I frequently establish stratification zones
21. I frequently provide windcatchers in my
22. I frequently specify auto light/systems
control or task lighting in my design
23. I frequently establish the daylight \& electric
light zones in my design
zones

28. I frequently take advantage of the wind speed and direction in my design 
Appendix A

Do we have the right technology to enhance the adoption of environmentally sustainable design methods?

Please select the option that describes your opinion about the following statements on a scale of 1 to 6 , with 1 being strongly disagree and 6 being strongly agree

\begin{tabular}{|c|c|c|c|c|c|c|}
\hline & $\begin{array}{c}1 \text { - Strongly } \\
\text { disagree }\end{array}$ & $\begin{array}{c}2- \\
\text { Disagree }\end{array}$ & $\begin{array}{c}3^{-} \\
\text {Somewhat } \\
\text { disagree }\end{array}$ & $\begin{array}{l}4^{-} \\
\text {Somewhat } \\
\text { agree }\end{array}$ & 5 - Agree & $\begin{array}{l}6 \text { - Strongly } \\
\text { agree }\end{array}$ \\
\hline $\begin{array}{l}\text { 1. We lack the manpower, skills, } \\
\text { knowledge, and expertise to manufacture } \\
\text { energy efficient and sustainable } \\
\text { appliances/technologies in Nigeria }\end{array}$ & $\bigcirc$ & $\bigcirc$ & $\bigcirc$ & ○ & O & O \\
\hline $\begin{array}{l}\text { 2. Buildings in Nigeria are designed with } \\
\text { the intention that air conditioners and } \\
\text { fans are going to be used in them }\end{array}$ & $\bigcirc$ & ○ & $\bigcirc$ & $\bigcirc$ & $\bigcirc$ & $\bigcirc$ \\
\hline $\begin{array}{l}\text { 3. Poor technological development is a } \\
\text { barrier to environmentally sustainable } \\
\text { design methods (ESD) in Nigeria }\end{array}$ & O & $\bigcirc$ & O & 0 & O & $\bigcirc$ \\
\hline
\end{tabular}

\section{Are economic factors a possible barrier to environmentally sustainable design methods}

Please select the option that describes your opinion about the following statements on a scale of 1 to 6 , with 1 being strongly disagree and 6 being strongly agree

\begin{tabular}{|c|c|c|c|c|c|}
\hline $\begin{array}{c}1- \\
\text { Strongly }\end{array}$ & $\begin{array}{c}2- \\
\text { Disagree }\end{array}$ & $\begin{array}{c}3^{-} \\
\text {Somewhat } \\
\text { disagree }\end{array}$ & $\begin{array}{c}4^{-} \\
\text {Somewhat } \\
\text { agree }\end{array}$ & $\begin{array}{c}5^{-} \\
\text {Agree }\end{array}$ & $\begin{array}{c}6- \\
\text { Strongly } \\
\text { agree }\end{array}$ \\
\hline
\end{tabular}

disagree
$\begin{gathered}\text { 1. I give more importance to } \\ \text { Environmentally Sustainable Design } \\ \text { Methods (ESD) than the budget and cost } \\ \text { of building construction }\end{gathered}$
$\begin{gathered}\text { 2. The government and the private sector } \\ \text { provide sufficient financial incentives and } \\ \text { rewards for saving energy or using } \\ \text { renewable energy sources like solar panels }\end{gathered}$
$\begin{aligned} & \text { 3. Environmentally sustainable design } \\ & \text { methods and renewable energy sources } \\ & \text { like solar panels are expensive }\end{aligned}$

What is the public perception of environmentally sustainable design methods?

Please select the option that describes your opinion about the following statements on a scale of 1 to 6 , with 1 being strongly disagree and 6 being strongly agree

\begin{tabular}{|c|c|c|c|c|}
\hline $\begin{array}{c}1- \\
\text { Strongly } \\
\text { disagree }\end{array}$ & $\begin{array}{c}2- \\
\text { Disagree }\end{array}$ & $\begin{array}{c}3- \\
\text { Somewhat } \\
\text { disagree }\end{array}$ & $\begin{array}{c}4- \\
\text { Somewhat } \\
\text { agree }\end{array}$ & 5 - Agree \\
\hline
\end{tabular}

\begin{tabular}{|c|c|c|c|c|c|c|}
\hline $\begin{array}{l}\text { 1. Architects in Nigeria do not fully adopt } \\
\text { environmentally sustainable design methods (ESD). }\end{array}$ & 0 & 0 & $\bigcirc$ & 0 & $\bigcirc$ & 0 \\
\hline $\begin{array}{l}\text { 2. More importance is given to the clients' brief and } \\
\text { regional/socio-cultural factors than Environmentally } \\
\text { Sustainable Design Methods (ESD) in my design }\end{array}$ & $\bigcirc$ & $\bigcirc$ & 0 & $\bigcirc$ & $\bigcirc$ & $\bigcirc$ \\
\hline $\begin{array}{l}\text { 3. There is a lack of interest in environmentally } \\
\text { sustainable design amongst clients and developers }\end{array}$ & $\bigcirc$ & 0 & 0 & $\bigcirc$ & $\bigcirc$ & 0 \\
\hline $\begin{array}{l}\text { 4. There are limited promotions on sustainable } \\
\text { architecture by the government, media, and } \\
\text { professional bodies }\end{array}$ & $C$ & $\bigcirc$ & $\bigcirc$ & 0 & 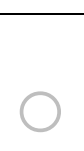 & 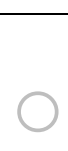 \\
\hline
\end{tabular}


Appendix A

Are there favourable environmentally sustainable design methods policies

Please select the option that describes your opinion about the following statements on a scale of 1 to 6 , with 1 being strongly disagree and 6 being strongly agree

\begin{tabular}{|c|c|c|c|c|c|c|}
\hline & $\begin{array}{l}1- \\
\text { Strongly } \\
\text { disagree }\end{array}$ & $\begin{array}{c}2- \\
\text { Disagree }\end{array}$ & $\begin{array}{l}3^{-} \\
\text {Somewhat } \\
\text { disagree }\end{array}$ & $\begin{array}{l}4^{-} \\
\text {Somewhat } \\
\text { agree }\end{array}$ & 5 - Agree & $\begin{array}{l}6- \\
\text { Strongly } \\
\text { agree }\end{array}$ \\
\hline \multicolumn{7}{|l|}{$\begin{array}{l}\text { 1. I am of the opinion that environmentally } \\
\text { sustainable design has been sufficiently } \\
\text { addressed in Nigeria }\end{array}$} \\
\hline $\begin{array}{l}\text { 2. NIA and ARCON have done so much } \\
\text { towards encouraging the adoption of } \\
\text { environmentally sustainable design (for } \\
\text { example; making ESD a prerequisite for } \\
\text { registration, organizing sustainable design } \\
\text { seminars, etc.) }\end{array}$ & & & & & & \\
\hline $\begin{array}{l}\text { 3. The Nigerian building codes and } \\
\text { regulations sufficiently addresses } \\
\text { environmentally sustainable design }\end{array}$ & & & & & & \\
\hline
\end{tabular}

Please feel free to include here any further comments or suggestions 
Do the architects agree on the need for environmentally sustainable design methods in Nigeria? Please select the option that describes your opinion about the following statements on a scale of 1 to 6 , with 1 being strongly disagree and 6 being strongly

\begin{tabular}{|c|c|c|c|}
\hline \# & Question & Mean & $\begin{array}{c}\text { Std } \\
\text { Deviation }\end{array}$ \\
\hline 1 & $\begin{array}{l}\text { I feel sweaty and uncomfortable most times in a room } \\
\text { without an air conditioner or fan }\end{array}$ & 4.74 & 1.24 \\
\hline 2 & $\begin{array}{c}\text { In hot indoor environments, achieving thermal } \\
\text { comfort through the use of an electric fan becomes a } \\
\text { problem because of the unsatisfactory electricity } \\
\text { supply in Nigeria }\end{array}$ & 5.07 & 1.14 \\
\hline 3 & $\begin{array}{l}\text { Thermally uncomfortable indoor spaces is an } \\
\text { architectural problem that needs to be addressed }\end{array}$ & 5.28 & 1.08 \\
\hline 4 & $\begin{array}{l}\text { Form and function has an impact on the indoor } \\
\text { thermal conditions of a building }\end{array}$ & 5.44 & 0.99 \\
\hline
\end{tabular}

How knowledgeable is the Nigerian architect about environmentally sustainable design methods? Please select the option that describes your opinion about the following statements on a scale of 1 to 6 , with 1 being strongly disagree and 6 being strongly agree

\begin{tabular}{rrcc}
\multicolumn{1}{c}{$\begin{array}{c}\text { Question } \\
\text { Q }\end{array}$} & Mean & $\begin{array}{c}\text { Std } \\
\text { Deviation }\end{array}$ \\
\hline 1 & I frequently take advantage of the wind speed and direction in my design & 2.35 & 0.85 \\
\hline 2 & I frequently adapt solar radiation principles in my design & 1.6 & 0.91 \\
\hline 3 & I frequently apply the principles of daylight availability and obstructions & 1.68 & 0.91 \\
\hline 4 & I frequently provide a load response schedule & 1.26 & 0.56 \\
\hline 5 & I frequently take advantage of buffer/cooling zones & 1.77 & 0.93 \\
\hline 6 & I frequently establish the daylight \& electric light zones in my design & 1.45 & 0.91 \\
\hline 7 & I frequently specify auto light/systems control or task lighting in my design & 1.2 & 0.47 \\
\hline 8 & I frequently provide windcatchers in my design & 1.07 & 0.33 \\
\hline 9 & I frequently establish stratification zones & 1.07 & 0.33 \\
\hline 10 & I frequently provide top light, atrium or skylight in my design & 1.62 & 0.73 \\
\hline 11 & If possible, I always include courtyards in my design & 1.78 & 0.87 \\
\hline 12 & I always ensure my building designs are interwoven with plants (i.e. & & \\
\hline
\end{tabular}

I frequently adopt vent opening with the strategic arrangement (High or low, a combination of high \& low, single, two openings on the same wall, two openings with wings, two openings on adjacent walls, two openings on

\begin{tabular}{|c|c|c|c|}
\hline 13 & opposite walls) & 2.17 & 0.73 \\
\hline 14 & I frequently design to ensure periodic transformation & 1.73 & 1.15 \\
\hline 15 & I frequently specify earth-air heat exchanger or air-air heat exchanger & 1.08 & 0.43 \\
\hline 16 & Most architects design for sun shading/screening & 3.67 & 1.18 \\
\hline 17 & I frequently adopt the principles of stack ventilation & 2.88 & 1.28 \\
\hline 18 & I design buildings with the intention of having an air-conditioner and Fan & 4.1 & 0.99 \\
\hline 19 & Nigerian architects always provide cross ventilation in their designs & 4.49 & 0.81 \\
\hline 20 & $\begin{array}{l}\text { Most architects understand and use building orientation to minimise heat gain } \\
\text { and enhance air flow into the building }\end{array}$ & 3.72 & 1.11 \\
\hline 21 & $\begin{array}{l}\text { I frequently apply the principles of sun shading in my design (i.e. shared } \\
\text { shade, shadow umbrella, overhead shades, daylight enhance shade) }\end{array}$ & 3.85 & 0.96 \\
\hline 22 & Most buildings in Nigeria are properly cross-ventilated & 3.18 & 0.88 \\
\hline 23 & Most architectural designs in Nigeria enhance air movement indoors. & 3.16 & 0.85 \\
\hline 24 & Adobe bricks, clay/mud hybrid composition are commonly used in Nigeria & 2.66 & 0.86 \\
\hline 25 & $\begin{array}{c}\text { For most of my designs I specify Photovoltaic systems or other renewable } \\
\text { energy sources }\end{array}$ & 2.46 & 1.08 \\
\hline 26 & $\begin{array}{l}\text { I always use passive cooling techniques through reflective and radiative } \\
\text { surfaces }\end{array}$ & 3.05 & 1.11 \\
\hline 27 & $\begin{array}{l}\text { As an architectural student, I was always encouraged to include } \\
\text { environmentally sustainable design methods in my studio/design courses }\end{array}$ & 4.31 & 0.97 \\
\hline 28 & $\begin{array}{c}\text { I find that adopting environmentally sustainable design methods makes it easy } \\
\text { to address other design issues such as: the clients brief, site } \\
\text { allowance/available land etc. }\end{array}$ & 3.76 & 1.09 \\
\hline
\end{tabular}


Do we have the right technology to enhance the adoption of ESD? Please select the option that describes your opinion about the following statements on a scale of 1 to 6 , with 1 being strongly disagree and 6 being strongly agree

\begin{tabular}{|c|c|c|c|}
\hline \# & Question & Mean & $\begin{array}{c}\text { Std } \\
\text { Deviation }\end{array}$ \\
\hline 1 & $\begin{array}{c}\text { Poor technological development is a barrier to } \\
\text { environmentally sustainable design methods (ESD) in } \\
\text { Nigeria }\end{array}$ & 4.21 & 1.00 \\
\hline 2 & $\begin{array}{l}\text { Buildings in Nigeria are designed with the intention that } \\
\text { air conditioners and fans are going to be used in them }\end{array}$ & 3.62 & 1.16 \\
\hline 3 & $\begin{array}{c}\text { We lack the manpower, skills, knowledge, and expertise } \\
\text { to manufacture energy efficient and sustainable } \\
\text { appliances/technologies in Nigeria }\end{array}$ & 3.68 & 1.25 \\
\hline
\end{tabular}

Are economic factors a possible barrier to ESD? Please select the option that describes your opinion about the following statements on a scale of 1 to 6 , with 1 being strongly disagree and 6 being strongly agree

\begin{tabular}{cccc} 
Question & Mean & $\begin{array}{c}\text { Std } \\
\text { Deviation }\end{array}$ \\
\hline 1 & $\begin{array}{c}\text { Environmentally sustainable designs methods and renewable } \\
\text { energy sources like solar panels are expensive }\end{array}$ & 3.59 & 1.10 \\
\hline 2 & $\begin{array}{c}\text { The government and the private sector provide sufficient } \\
\text { financial incentives and rewards for saving energy or using } \\
\text { renewable energy sources like solar panels }\end{array}$ & 1.89 & 1.05 \\
\hline
\end{tabular}

3 I give more importance to Environmentally Sustainable Design

3 Methods (ESD) than the budget and cost of building construction

1 - Strongly disagree; 2 - Disagree; 3 - Somewhat disagree; 4 - Somewhat agree; 5 - Agree; 6 - Strongly agree * < 3.5 Disagree, > 3.5 Agree | M - Mean, SD - Standard Deviation

What is the public perception of ESD? Are they interested? Please select the option that describes your opinion about the following statements on a scale of 1 to 6 , with 1 being the lowest and 6 being the highest

\begin{tabular}{|c|c|c|c|}
\hline \# & Question & Mean & $\begin{array}{c}\text { Std } \\
\text { Deviation }\end{array}$ \\
\hline 1 & $\begin{array}{l}\text { There are limited promotions on sustainable architecture by the } \\
\text { government, media, and professional bodies }\end{array}$ & 3.67 & 1.23 \\
\hline 2 & $\begin{array}{c}\text { There is a lack of interest in environmentally sustainable design } \\
\text { amongst clients and developers }\end{array}$ & 3.70 & 1.05 \\
\hline 3 & $\begin{array}{l}\text { More importance is given to the clients' brief and regional/socio- } \\
\text { cultural factors than Environmentally Sustainable Design Methods } \\
\text { (ESD) in my design }\end{array}$ & 3.78 & 1.16 \\
\hline 4 & $\begin{array}{c}\text { Architects in Nigeria do not fully adopt environmentally } \\
\text { sustainable design methods (ESD) }\end{array}$ & 3.65 & 0.88 \\
\hline
\end{tabular}

Are there favourable ESD policies? If no, is that a possible barrier? Please select the option that describes your opinion about the following statements on a scale of 1 to 6 , with 1 being strongly disagree and 6 being strongly agree

\begin{tabular}{|c|c|c|c|}
\hline \# & Question & Mean & $\begin{array}{c}\text { Std } \\
\text { Deviation }\end{array}$ \\
\hline 1 & $\begin{array}{c}\text { The Nigerian building codes and regulations sufficiently addresses } \\
\text { environmentally sustainable design }\end{array}$ & $3 \cdot 77$ & 1.24 \\
\hline 2 & $\begin{array}{l}\text { The Nigerian Institute of Architects (NIA) and the Architectural } \\
\text { Registration Council of Nigeria have done so much towards encouraging } \\
\text { the adoption of environmentally sustainable design (for example; making } \\
\text { ESDs a prerequisite for registration, organizing sustainable design } \\
\text { seminars, etc.) }\end{array}$ & 3.95 & 1.22 \\
\hline 3 & $\begin{array}{c}\text { I am of the opinion that environmentally sustainable design has been } \\
\text { sufficiently addressed in Nigeria }\end{array}$ & 2.54 & 1.39 \\
\hline
\end{tabular}

1 - Strongly disagree; 2 - Disagree; 3 - Somewhat disagree; 4 - Somewhat agree; 5 - Agree; 6 - Strongly agree * < 3.5 Disagree, > 3.5 Agree | M - Mean, SD - Standard Deviation 


\section{Appendix A}

A.4 Cross examination between "I frequently apply the principles of sun shading in my design" and respondents" characteristics

\section{- Gender}

To test the null hypothesis that the dependent variable ("I frequently apply the principles of sun shading in my design" - M $=3.85$, $\mathrm{SD}=0.965$ ) and independent variable (Gender - see Table 4.1) are not statistically different, the one-way ANOVA was performed. The assumption of normality was evaluated and found tenable for all items. The assumption of homogeneity of variance was tested and found tenable using the Levene's Test $F(1,128)=0.001, \mathrm{p}=0.974$. The ANOVA (Table A4.1) was significant, $\mathrm{F}(1,128)=5.237, \mathrm{p}$ $=0.024, \mathrm{n} 2=0.04$. Thus, there is statistical evidence to accept the null hypothesis and the study can conclude that there is no significant relationship between the adoption of sun shading principles and the gender of respondents.

Table A4.1: Analysis of variance between respondents' gender and "I frequently apply the principles of sun shading in my design (i.e. shared shade, shadow umbrella, overhead shades, daylight enhance shade)"

\begin{tabular}{lccccc}
\hline & Sum of Squares & df & Sean & & Square \\
\hline $\begin{array}{l}\text { Between } \\
\text { Groups }\end{array}$ & 4.725 & 1 & 4.725 & 5.237 & .024 \\
\hline Within Groups & 115.498 & 128 & .902 & & \\
\hline Total & 120.223 & 129 & & & \\
\hline
\end{tabular}

\section{- Years of architectural experience}

To test the null hypothesis that the dependent variable ("I frequently apply the principles of sun shading in my design" - M = 3.85, $\mathrm{SD}=0.965$ ) and independent variable (Years of experience - see Table 5.1) are not statistically different, the one-way ANOVA was performed. The assumption of normality was evaluated and found tenable for all items. The assumption of homogeneity of variance was tested and found tenable using the Levene's Test $F(3,124)=1.724, \mathrm{p}=0.166$. The ANOVA (Table A4.2) was significant, $\mathrm{F}(3,124)$ $=0.366, \mathrm{p}=0.009, \mathrm{n}^{2}=0.088$. Thus, there is statistical evidence to accept the null hypothesis and the study can conclude that there is no significant relationship between the adoption of sun shading principles and years of experience.

Table A4.2: Analysis of variance between respondents' years of experience and "I frequently apply the principles of sun shading in my design (i.e. shared shade, shadow umbrella, overhead shades, daylight enhance shade)"

\begin{tabular}{lccccc}
\hline & $\begin{array}{c}\text { Sum of } \\
\text { Squares }\end{array}$ & df & Mean Square & F & Sig. \\
\hline $\begin{array}{l}\text { Between } \\
\text { Groups }\end{array}$ & 10.548 & 3 & 3.516 & 4.003 & .009 \\
\hline Within Groups & 108.921 & 124 & .878 & & \\
\hline Total & 119.469 & 127 & & & \\
& & & & & \\
\hline
\end{tabular}


Appendix A

\section{- Level of educational qualification}

To test the null hypothesis that the dependent variable ("I frequently apply the principles of sun shading in my design" - M = 3.85, $\mathrm{SD}=0.965$ ) and independent variable (Level of educational qualification - see Table 5.1) are not statistically different, the one-way ANOVA was performed. The assumption of normality was evaluated and found tenable for all items. The assumption of homogeneity of variance was tested and found tenable using the Levene's Test $F(3,126)=0.953, \mathrm{p}=0.417$. The ANOVA (Table A4.3) was significant, $\mathrm{F}(3,126)=5.547, \mathrm{p}=0.001, \mathrm{n}^{2}=0.12$. Therefore, there is a statistical evidence to accept the null hypothesis and the study can conclude that there is no significant relationship between the adoption of sun shading principles and level of educational qualification.

Table A4.3: Analysis of variance between level of educational qualification and "I frequently apply the principles of sun shading in my design (i.e. shared shade, shadow umbrella, overhead shades, daylight enhance shade)"

\begin{tabular}{lccccc}
\hline & & \multicolumn{3}{c}{ Mean } \\
& Sum of Squares & df & Square & F & Sig. \\
\hline $\begin{array}{l}\text { Between } \\
\text { Groups }\end{array}$ & 14.025 & 3 & 4.675 & 5.547 & .001 \\
\hline Within Groups & 106.198 & 126 & .843 & & \\
\hline Total & 120.223 & 129 & & & \\
\hline
\end{tabular}

A.5 Cross examination between "Most Nigerian architects always provide cross ventilation in their designs" and respondents' characteristics

\section{- Years of architectural experience}

To test the null hypothesis that the dependent variable ("Most Nigerian architects always provide cross ventilation in their designs" $\mathrm{M}=4.49, \mathrm{SD}=0.809$ ) and independent variable (years of architectural experience - see Table 4.1) are not statistically different, the one-way ANOVA was performed. The assumption of normality was evaluated and found tenable for all items. The assumption of homogeneity of variance was tested and found tenable using the Levene's Test $F(3,124)=1.008, \mathrm{p}=0.392$. The ANOVA (Table A5.1) was significant, $\mathrm{F}(3,124)=4.10, \mathrm{p}=0.008, \mathrm{n}^{2}=0.09$. Therefore, there is significant evidence to reject the null hypothesis and the study can conclude that there is no significant relationship between "Most Nigerian architects always provide cross ventilation in their designs" and years of architectural experience.

Table A5.1: Analysis of variance between respondents' years of architectural experience and "Most Nigerian architects always provide cross ventilation in their designs"

\begin{tabular}{cccccc}
\hline & Sum of Squares & df & Mean Square & F & Sig. \\
\hline Between Groups & 7.576 & 3 & 2.525 & 4.099 & .008 \\
\hline Within Groups & 76.393 & 124 & .616 & & \\
\hline Total & 83.969 & 127 & & & \\
\hline
\end{tabular}


Appendix A

\section{A.6 Interview questions for architects in Nigeria}

\section{Respondents' characteristics}

- Gender

- Years of architectural experience

- Highest level of educational qualification

\section{Agreement: General influences in your approach to design to design of buildings}

- What are the main factors you consider during your design?

\section{Knowledge of Environmentally Sustainable Design Methods}

- What environmentally sustainable design methods are you most knowledgeable of and frequently adopt in your designs?

- How did you know about ESD?

\section{Technology}

- Do you feel we have the right technology to enhance the adoption of ESD in Nigeria? If no, do you consider it a barrier to? preventing the adoption of ESD in Nigerian residential buildings?

\section{Economic}

- Was cost a major determinant in the adoption or rejection of ESD? If no, what was the major determinant?

\section{Social}

- What do you think is the public perception of ESD?

\section{Political}

- Has the government enacted environmentally sustainable policies or played any role in educating the public in general or the building industry in particular on sustainability issues? What about the Nigerian Institute of Architects (NIA) and Architects Registration Council of Nigeria (ARCON)?

\section{Additional Question}

- In your experience, what are the major obstacles to ESD?

A.7 Results from the interview with architects in stage 2 of the survey

\section{Respondents Years of Experience}

\begin{tabular}{lc} 
Code grouped & Category/Count \\
\hline $10-19$ & 8 \\
\hline $20-29$ & 9 \\
\hline $30-39$ & 4 \\
\hline
\end{tabular}

Interview question 1: What are the main factors you consider during your design?

\begin{tabular}{|c|c|c|c|}
\hline Theme & Sub theme & Typical statements & Count \\
\hline \multirow[t]{6}{*}{ Functionality } & Function driven & Form must follow Function; I give more emphasis to the functionality of space. & 16 \\
\hline & $\begin{array}{c}\text { Space } \\
\text { optimization }\end{array}$ & $\begin{array}{c}\text { If you are designing in densely populated areas of Lagos, you might have to go to } \\
\text { maximise space. }\end{array}$ & 8 \\
\hline & $\begin{array}{l}\text { Indoor } \\
\text { circulation }\end{array}$ & Flow within the space. The space must be freely flowing from the living to the kitchen etc. & 7 \\
\hline & $\begin{array}{l}\text { Composition } \\
\text { and order }\end{array}$ & $\begin{array}{l}\text { Composition. Putting together of things so that they become harmonious, i.e. } \\
\text { form, space \& man. }\end{array}$ & 1 \\
\hline & $\begin{array}{l}\text { Structural } \\
\text { stability }\end{array}$ & Structural stability, aesthetics, and it must be economical. & 1 \\
\hline & $\begin{array}{l}\text { Quality of } \\
\text { building } \\
\text { materials }\end{array}$ & Quality of materials & 1 \\
\hline
\end{tabular}


Appendix A

\begin{tabular}{|c|c|c|c|}
\hline \multirow[t]{5}{*}{ Form } & Aesthetics & $\begin{array}{c}\text { Aesthetics of the building. When you design, your building most be bold and } \\
\text { speak out. }\end{array}$ & 9 \\
\hline & Appealing & $\begin{array}{c}\text { For the walls you can either use block walls or glazed walls to achieve a vista \& } \\
\text { wide views. }\end{array}$ & 7 \\
\hline & $\begin{array}{l}\text { Design } \\
\text { expression }\end{array}$ & $\begin{array}{c}\text { I ensure that my design elevates the landscaping of the building and adds to the } \\
\text { general architecture of the neighbourhood. }\end{array}$ & 7 \\
\hline & Form driven & Function follows form. & 3 \\
\hline & & Total & 26 \\
\hline \multirow[t]{4}{*}{ Sustainability } & $\begin{array}{l}\text { Energy } \\
\text { efficiency }\end{array}$ & $\begin{array}{c}\text { As much as possible, I try to reduce the building dependence on mechanical } \\
\text { ventilation. }\end{array}$ & 8 \\
\hline & Recyclability & $\begin{array}{c}\text { Sustainability in terms of efficiency, energy consumption reduction, and cost of } \\
\text { design/recyclability. }\end{array}$ & 2 \\
\hline & $\begin{array}{c}\text { Sustainable } \\
\text { technologies }\end{array}$ & $\begin{array}{c}\text { Energy saving buildings: we encourage our clients to use solar panels, that way } \\
\text { energy is generated. }\end{array}$ & 2 \\
\hline & & Total & 12 \\
\hline \multirow[t]{4}{*}{ Cost } & $\begin{array}{c}\text { Construction } \\
\text { cost }\end{array}$ & I consider the cost. I bring down the construction cost. & 13 \\
\hline & Profit & $\begin{array}{l}\text { I advised the client to build a multipurpose space instead and the client made a } \\
\text { lot of profit. }\end{array}$ & 1 \\
\hline & $\begin{array}{l}\text { Lifecycle and } \\
\text { Maintenance }\end{array}$ & I consider the life cycle and maintenance of the building. & 3 \\
\hline & & Total & 17 \\
\hline \multirow[t]{5}{*}{ Client Brief } & Clients' demand & My design provides solution based on the clients. It differs with the clients. & 17 \\
\hline & Timeframe & Timeframe for the realisation of the client's dream. & 1 \\
\hline & Social influence & $\begin{array}{c}\text { The beautiful things they see influence people: they always want their buildings } \\
\text { to look like what's the norm. }\end{array}$ & 1 \\
\hline & $\begin{array}{c}\text { Occupants } \\
\text { protection from } \\
\text { burglary }\end{array}$ & Defensible spaces, a thinking of how a building can protect itself and occupants. & 1 \\
\hline & & Total & 20 \\
\hline \multirow[t]{4}{*}{ Environment } & Neighbourhood & It depends on the neighbourhood. I consider the environment (neighbourhood) & . \\
\hline & Site analysis & $\begin{array}{l}\begin{array}{l}\text { Site analysis, site features and how they affect the design and geotechnical } \\
\text { issues. }\end{array}\end{array}$ & 4 \\
\hline & $\begin{array}{c}\text { Building } \\
\text { orientation }\end{array}$ & $\begin{array}{c}\text { This can be achieved by positioning the windows in accordance to the sun } \\
\text { orientation. }\end{array}$ & 1 \\
\hline & & Total & 9 \\
\hline \multirow{3}{*}{$\begin{array}{l}\text { Regulations } \\
\text { \& Standards }\end{array}$} & Standards & Standard and best practice. & 1 \\
\hline & $\begin{array}{l}\text { Council } \\
\text { regulations }\end{array}$ & You design not only based on the brief but the town planning restrictions. & 4 \\
\hline & & Total & 5 \\
\hline \multirow[t]{6}{*}{ User Comfort } & $\begin{array}{l}\text { Comfortable } \\
\text { environment }\end{array}$ & Ensuring that humans are at the centre and are comfortable in the space. & 10 \\
\hline & $\begin{array}{c}\text { Natural } \\
\text { ventilation }\end{array}$ & $\begin{array}{c}\text { Natural ventilation. Because of the erratic power supply, even those with } \\
\text { generators can't afford to buy fuel. }\end{array}$ & 7 \\
\hline & $\begin{array}{l}\text { Shading } \\
\text { principles }\end{array}$ & The use of landscape as buffer zones and provide cooling effect. & 1 \\
\hline & $\begin{array}{l}\text { Thermal } \\
\text { comfort }\end{array}$ & We also use floor tiles to reduce heat generation. & 3 \\
\hline & Natural light & $\begin{array}{l}\text { When you are in the tropics the inflow of light into the interior space matters. } \\
\text { The poor power supply in Nigeria warrants optimum access of lighting. }\end{array}$ & 6 \\
\hline & $\begin{array}{c}\text { Cross } \\
\text { ventilation }\end{array}$ & $\begin{array}{c}\text { During my design I consider the weather, i.e. when mechanical systems are not } \\
\text { working how we can utilise cross-ventilation. }\end{array}$ & 1 \\
\hline
\end{tabular}


Appendix A

Interview question 2: What environmentally sustainable design methods are you most knowledgeable of and frequently adopt in your designs?

Theme

Sub theme

Typical statements

Count

Natural Ventilation and

Cross-ventilation

I design to ensure that there is cross-ventilation.

4

Lighting

\begin{tabular}{|c|c|c|c|}
\hline & Natural lighting & I ensure natural lighting by limiting my walls inside. & 11 \\
\hline & $\begin{array}{c}\text { Natural } \\
\text { Ventilation }\end{array}$ & $\begin{array}{l}\text { We also ensure that every space has an opening to the external wall so } \\
\text { you can have light and natural ventilation. }\end{array}$ & 11 \\
\hline & Courtyard & $\begin{array}{l}\text { Yes, in Ibadan, all the rooms had windows at } 2.4 \mathrm{~m} \text { wide and I } \\
\text { used a courtyard and as a result there was no AC in the building. }\end{array}$ & 2 \\
\hline & & Total & 26 \\
\hline $\begin{array}{l}\text { Building Shading and } \\
\text { Building Orientation }\end{array}$ & Orientation & $\begin{array}{l}\text { I also use the building orientation to reduce the temperature and } \\
\text { enhance airflow, enhance thermal comfort. }\end{array}$ & 10 \\
\hline & Building shading & $\begin{array}{l}\text { You can also use roof gardens, external garden/green landscape and } \\
\text { umbrella tress for shading because it helps absorb solar radiation. }\end{array}$ & 5 \\
\hline & Window shading & $\begin{array}{l}\text { I use fins to shade the windows and also landscaping to achieve } \\
\text { adequate shading, but what I use most times is the window hoods. }\end{array}$ & 1 \\
\hline & Roof overhang & Shading the eave. & 1 \\
\hline & Cooling effect & Use of fountains to provide a cooling effect. & 2 \\
\hline & & Total & 19 \\
\hline Thermal Insulation & Building insulation & $\begin{array}{l}\text { I am doing a prototype building design for a church and for the } \\
\text { design we are using rockwool insulation into the roof. }\end{array}$ & 4 \\
\hline & $\begin{array}{c}\text { Reflective \& } \\
\text { radiative surfaces }\end{array}$ & $\begin{array}{c}\text { The colour was light to reflect the sun rays as opposed to dark } \\
\text { colours. }\end{array}$ & 3 \\
\hline & & Total & 7 \\
\hline $\begin{array}{l}\text { Energy generation and } \\
\text { recycling }\end{array}$ & Recycling & $\begin{array}{l}\text { Yes, for two of my projects in Enugu, because of the water } \\
\text { problem we tried to harvest water. }\end{array}$ & 2 \\
\hline & $\begin{array}{l}\text { Renewable energy } \\
\text { (i.e. solar panels) }\end{array}$ & The use of solar panels prevents the use of generators. & 9 \\
\hline & Energy saving & $\begin{array}{l}\text { The use of energy saving bulbs, blenders and other energy saving } \\
\text { appliances. }\end{array}$ & 3 \\
\hline
\end{tabular}

Interview question 3: How did you know about ESD?

Theme

International

Architectural

Education

Nigerian Architectural
Education

Seminars/Publications
Sub theme

Master's or Bachelor's degree or equivalent Overseas
When I was at the university in SOVIET Union, we were taught to 2 design not just for the context, but for the environment.

While I was at the university in Lagos, I was encouraged to adopt ESD by a couple of my lecturers who are currently my mentors. degree or equivalent in Nigeria

Subscription to publications

Reading books

\section{Total}

I subscribe to a lot of international organisations and I read a lot of articles.
Typical statements

\section{Total}

Count 2 2 7

7
including different books. 
Appendix A

Interview question 4: Do you feel we have the right technology to enhance the adoption of ESD in Nigeria?

If no, do you consider it a barrier preventing the adoption of ESD in Nigerian residential buildings?

Theme

Yes, technology is a
barrier
Sub theme

Poor

Infrastructural development

No manufacturing industries
Typical statements

The level of developing building materials depends on available technology. In my project, I wanted a soil test, but it was so expensive and inefficient due to the lack of technology. Finally, I stabilised my soil by using a chemical I got from Canada.
Count

4
There is no technology, Nigerians are not doing anything to improve their technology, and everything is imported.

\begin{tabular}{ccc}
\hline & Total & 13 \\
\hline $\begin{array}{c}\text { No, technology is } \\
\text { Lot barrier }\end{array}$ & $\begin{array}{c}\text { Social political } \\
\text { issues }\end{array}$ & $\begin{array}{c}\text { If students are being taught at the university to adopt these methods, } \\
\text { within the next decade these methods would be adopted. }\end{array}$ \\
\hline & $\begin{array}{c}\text { It is more of a socio-cultural problem and not technology. } \\
\text { No, because one can always source for technology, but when the } \\
\text { challenge is not there, you won't be encouraged. Things would only } \\
\text { change when we have a government that is willing to do things the right } \\
\text { way. }\end{array}$ \\
Total
\end{tabular}

Interview question 5: Was cost a major determinant in the adoption or rejection of ESD?

If no, what was the major determinant?

Theme Sub theme Typical statements

Count

\begin{tabular}{|c|c|c|c|}
\hline \multirow[t]{4}{*}{$\begin{array}{l}\text { Yes, cost is } \\
\text { a barrier }\end{array}$} & Affordability & $\begin{array}{l}\text { When you speak to people about solar panels, they say it is too expensive and the } \\
\text { maintenance is very high. When the batteries go bad, you have to change it and we } \\
\text { lack the professionals and expertise to maintain it. }\end{array}$ & 7 \\
\hline & Initial cost & $\begin{array}{l}\text { Ifeel it all boils down to finance, most clients just want to get a place so whenever you } \\
\text { bring these things they are not interested. }\end{array}$ & 3 \\
\hline & $\begin{array}{l}\text { Maintenance } \\
\text { cost }\end{array}$ & $\begin{array}{l}\text { In one of our projects, we had } 20 \text { solar panels at } N 200, \text { ooo for one and after three } \\
\text { years you are required to replace the batteries which are in turn a high cost of } \\
\text { maintenance. }\end{array}$ & 3 \\
\hline & & Total & 13 \\
\hline \multirow[t]{3}{*}{$\begin{array}{l}\text { No, cost is } \\
\text { not a } \\
\text { barrier }\end{array}$} & $\begin{array}{l}\text { Lack of } \\
\text { awareness }\end{array}$ & $\begin{array}{l}\text { Cost is not a problem, but the perception of cost is the problem. If you look at the overall } \\
\text { operational cost, you realize that it is cheaper. }\end{array}$ & 4 \\
\hline & No interest & $\begin{array}{l}\text { I think cost is a problem. Although most clients are more interested in aesthetics. They } \\
\text { value more current trends that would make the building fine. }\end{array}$ & 2 \\
\hline & $\begin{array}{l}\text { No } \\
\text { government } \\
\text { encouragement }\end{array}$ & $\begin{array}{l}\text { Currently, there are no regulations yet, so people are not taking it seriously. } \\
\text { The government is not supporting ESD. }\end{array}$ & 2 \\
\hline
\end{tabular}


Appendix A

Interview question 6: What do you think is the public perception of ESD?

\begin{tabular}{|c|c|c|c|}
\hline Theme & Sub theme & Typical statements & Count \\
\hline \multirow[t]{4}{*}{ Knowledge } & Lack of & There is a lack of demand due to a lack of awareness. & 6 \\
\hline & & People are not really aware, on a scale on 1-10, I would rate the level of awareness as & \\
\hline & $\begin{array}{c}\text { Lack of } \\
\text { information }\end{array}$ & $\begin{array}{l}\text { If they are well informed, they will. The issue of ESD is for wellbeing, so if people are } \\
\text { informed, they will welcome it. They will have questions for the architect. }\end{array}$ & 3 \\
\hline & & Total & 9 \\
\hline \multirow[t]{4}{*}{ Demand } & No interest & The market for ESD is not matured due to a lack of demand. & 3 \\
\hline & & Clients don't request for ESD, only a very few requests for it. & \\
\hline & $\begin{array}{l}\text { No community } \\
\text { encouragement } \\
\text { or acceptability }\end{array}$ & It is not really accepted. I would rate it at $35 \%$ acceptability. & 2 \\
\hline & & Total & 5 \\
\hline \multirow[t]{2}{*}{$\begin{array}{l}\text { Social } \\
\text { norms }\end{array}$} & Status symbol & $\begin{array}{c}\text { Nigerians like certain things, they are not interested in ESD. They are only interested } \\
\text { in what's trending. }\end{array}$ & 4 \\
\hline & Status-quo & $\begin{array}{c}\text { Ijust think it's the status-quo, e.g. you have people doing the wrong thing and you } \\
\text { know it's wrong but lack the willpower. }\end{array}$ & 3 \\
\hline
\end{tabular}

Interview question 7: Has the government enacted environmentally sustainable policies or played any role in educating the public in general or the building industry in particular on sustainability issues? What about the Nigerian Institute of Architects (NIA) and Architects Registration Council of Nigeria (ARCON)?

The Government?

\begin{tabular}{cclc}
$\begin{array}{c}\text { Theme } \\
\begin{array}{c}\text { No, NBC \& BCA } \\
\text { have not } \\
\text { encouraged ESD }\end{array}\end{array}$ & $\begin{array}{c}\text { Sub theme } \\
\text { knowledgeable }\end{array}$ & $\begin{array}{l}\text { The NBC and approval authorities are not professionals, so they are clueless and } \\
\text { not informed. }\end{array}$ & $\begin{array}{c}\text { Count } \\
6\end{array}$ \\
\hline & $\begin{array}{c}\text { No } \\
\text { enforcement }\end{array}$ & $\begin{array}{l}\text { We tried to sanitise the BCA but due to lack of a bill, it was squashed. } \\
\text { The government might talk about it, but the implementation is a problem. }\end{array}$ \\
\hline & Self-interest & $\begin{array}{l}\text { The BCA does not care, it's all about the money. They don't care about } \\
\text { specification, materials or the design. They are all interested in the money. }\end{array}$ \\
\hline $\begin{array}{c}\text { Yes, NBC \& BCA } \\
\text { have encouraged } \\
\text { ESD }\end{array}$ & Building code & $\begin{array}{l}\text { The NBC spells out most of these methods, but the BCA are not strictly adhering to } \\
\text { these codes. }\end{array}$ & \multicolumn{1}{c}{ Total } \\
\hline
\end{tabular}

What about the Nigerian Institute of Architects (NIA) and Architects Registration Council of Nigeria (ARCON)?

\begin{tabular}{|c|c|c|c|}
\hline Theme & Sub theme & Typical statements & Count \\
\hline \multirow{4}{*}{$\begin{array}{l}\text { No, NIA \& ARCON } \\
\text { have not } \\
\text { encouraged ESD }\end{array}$} & Self-interest & $\begin{array}{l}\text { The only thing they have done is review professional fees. They haven't } \\
\text { done anything to improve the architects. }\end{array}$ & 3 \\
\hline & $\begin{array}{l}\text { Disagreement } \\
\text { between ARCON \& } \\
\text { NIA }\end{array}$ & $\begin{array}{l}\text { Yes, NIA and ARCON have been involved, well, I mean they have been } \\
\text { involved in a battle hence their poor performance. }\end{array}$ & 3 \\
\hline & No action & $\begin{array}{l}\text { All they do is talk, and I don't like talking because it is cheap. They have } \\
\text { programmes, but it's just talking. }\end{array}$ & 6 \\
\hline & & Total & 12 \\
\hline $\begin{array}{l}\text { Yes, NIA \& ARCON } \\
\text { have encouraged } \\
\text { ESD }\end{array}$ & Organising seminars & $\begin{array}{l}\text { Yes, NIA and ARCON have organised seminars to educate architects on } \\
\text { ESD, so I believe the next generation would adopt it. }\end{array}$ & 9 \\
\hline
\end{tabular}


Appendix A

Interview question 8: In your experience, what are the major obstacles to ESD?

Theme Sub theme Typical statements

Count

Government Building code The building code addresses sustainability in theory but not in practise.

Government The state governments need to have the political will to encourage ESD.

policies

Deliberate policies by the government.

\begin{tabular}{clll}
\hline $\begin{array}{c}\text { ARCON \& } \\
\text { NIA }\end{array}$ & Policies & Total \\
\hline & Self-interest & $\begin{array}{l}\text { Ifind ignorance and lack of professionalism and self-interest within the } \\
\text { professional bodies. }\end{array}$ \\
\hline Knowledge & $\begin{array}{c}\text { Architectural } \\
\text { education }\end{array}$ & Update of the curriculum in the institutions. \\
& ...by emphasising it in our schools of architecture. \\
\hline
\end{tabular}

awareness and

advocacy More awareness on ESD is required.

Proper research will need to be promoted on how best our built environments can take advantage of the numerous benefits of the ESD.

Total

\begin{tabular}{cc} 
& \\
\hline Cost & Maintenance \\
& cost
\end{tabular}

For example, the solar panels: the problem now is the lifespan of the batteries, the whole maintenance and affordability issues.

Affordability $\quad$ Sustainable energy such as solar panels are still for the wealthy.

\begin{tabular}{|c|c|c|}
\hline & Affordability & Sustainable energy such as solar panels are still for the wealthy. \\
\hline & & Total \\
\hline $\begin{array}{l}\text { Social } \\
\text { factors }\end{array}$ & Lack of demand & The market for ESD is not matured due to a lack of demand. \\
\hline & $\begin{array}{c}\text { Public } \\
\text { perception }\end{array}$ & $\begin{array}{l}\text { ESD is really complicated, and when you want to use louvres for example, peo } \\
\text { question its modernity. So, I try to make the louvres look modern by using } \\
\text { wooden and aluminium slats to give it the modern effect. }\end{array}$ \\
\hline & & $\begin{array}{l}\text { Because of the wide eaves, the client request for burglary proofs at the eave to } \\
\text { prevent burglars into the building. }\end{array}$ \\
\hline
\end{tabular}


Appendix B

Appendix B

Building owners survey 
Appendix B

B.1 Ethics approval for Stage 3 of Study: Distribution of questionnaires to building owners and physical survey of their buildings

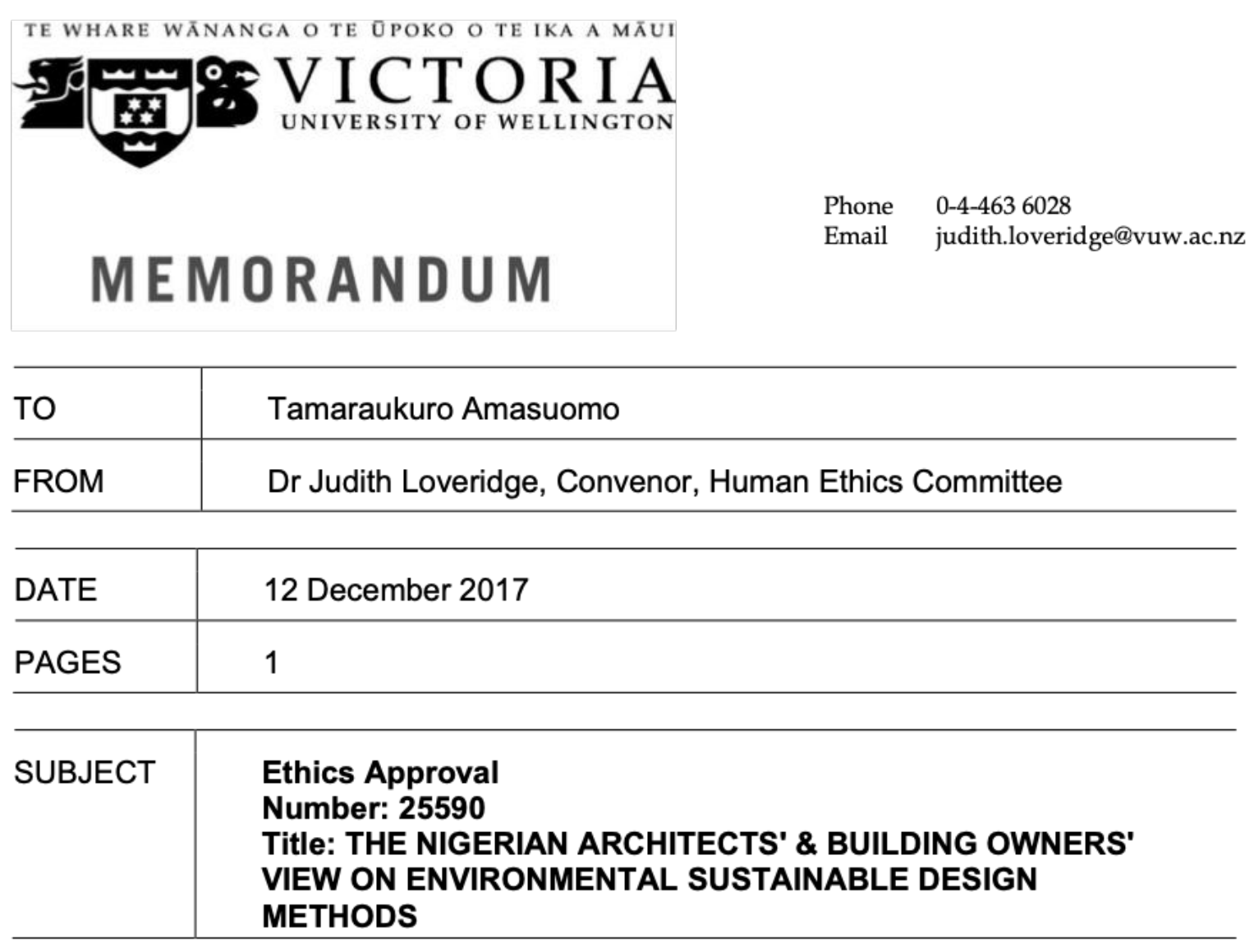

Thank you for your application for ethical approval, which has now been considered by the Human Ethics Committee.

Your application has been approved from the above date and this approval is valid for three years. If your data collection is not completed by this date you should apply to the Human Ethics Committee for an extension to this approval.

Best wishes with the research.

Kind regards,

Judith Loveridge

Convenor, Victoria University of Wellington Human Ethics Committee 


\section{B.2 Questionnaire for building owners in Nigeria}

\section{Information for participants}

You are invited to take part in this research. Please read this information before deciding whether or not to take part. If you decide to participate, thank you. If you decide not to participate, thank you for considering this request.

Who am I? My name is Tamaraukuro Tammy Amasuomo and I am a Doctoral student in architecture at the School of Architecture and Design, Victoria University of Wellington This research project is work towards my doctoral thesis.

What is the purpose of this research? The purpose of the study is to find out the Nigerian building owners' view on Environmentally Sustainable Design Methods (ESDs) in the design of residential buildings in Nigeria. The results from the survey will provide a comprehensive insight into the development of ESDs in Nigeria. This research has been approved by the Victoria University of Wellington Human Ethics Committee application number 0000025590

How can you help? You have been invited to participate because you own a building and have been involved in the design and construction of the building. If you agree to participate, you will complete an online survey with questions regarding your views on Environmentally Sustainable Design Methods (ESDs) and the possible barriers preventing its adoption in Nigeria. It is anticipated that the survey will take no more than 15 minutes to complete. During the process, you are free to withdraw at any point before your questionnaire has been completed. After the completion of the questionnaire, with your permission, I will be conducting a physical survey of your building. It is anticipated that the physical survey of your building will take no more than 45 minutes to complete. The physical survey will be included photos and physical measurements of your building. During the physical survey of your building you are free to request at any time that I stop the process and destroy any photos and measurements taking.

What will happen to the information you give? This research is confidential. This means that the researcher named below will be aware of your identity, but the research data will be combined, and your identity will not be revealed in any reports, presentations, or public documentation. Only the researcher will read the notes or transcript of the interview. The interview transcripts, summaries, and any recordings will be kept securely and destroyed on 31/03/2019.

What will the project produce? The information from my research will be used in my Doctoral thesis. The overall findings may be submitted for publication in a scientific journal or presented at scientific conferences.

If you have any questions or problems, who can you contact? If you have any questions, either now or in the future, please feel free to contact either my supervisor or me.

\section{Student:}

Name: Tamaraukuro Tammy Amasuomo

Email: tammy.amasuomo@vuw.ac.nz

\section{Primary Supervisor:}

Name: Prof Regan Potangaroa

Email: regan.potangaroa@vuw.ac.nz

\section{Secondary Supervisor:}

Name: Dr. Emina Perovic Email: Emina.Petrovic@vuw.ac.nz

\section{Human Ethics Committee information}

If you have any concerns about the ethical conduct of the research, you may contact the Victoria University HEC Convenor: Associate Professor Susan Corbett.

Email: susan.corbett@vuw.ac.nz

\section{PARTICIPANT CONSENT FORM}

I have read the Information Sheet and the project has been explained to me. My questions have been answered to my satisfaction. I understand that I can ask further questions at any time. 


\section{Appendix B}

I understand that:

- I can withdraw at any point before the questionnaire has been completed.

- During the physical survey of the building, I can request at any time that the process is stopped, and all photos and measurements destroyed immediately.

- The identifiable information I have provided will be destroyed on 31/03/2019. Furthermore, I will have an opportunity to request a copy of the final report or make any further enquires simply by sending an email to the researcher Tamaraukuro Tammy Amasuomo on tammy.amasuomo@vuw.ac.nz.

- I understand that I have the right to withdraw simply by sending an email to the researcher on or before the 31/02/2018 and request that every information I have provided be deleted.

- Any information I provide will be kept confidential to the researcher.

- I understand that the results will be used for a PhD dissertation.

- My personal information such as my house address and name, will not be used in reports, nor will any information that would identify me.

Please indicate (by ticking the boxes below) which of the following apply:

I agree to take part in this research

I do not agree to take part in this research

Please indicate (by ticking the boxes below) which of the following apply:

I would like a summary of the survey

I would like to receive a copy of the final report and have added my email address below

I consent to photos and physical measurements of my building

Number of bedrooms

One

Two

Three

Four

Five

Others

Housing type

Semi-Detached Bungalow

Single-Family Bungalow

Multi- Storey Building (Block of flats)

Single-Storey Duplex

Two-Storey Duplex

Others 


\section{Appendix B}

How many persons live in this house (including adults and children)
One
Two
Three
Four
Five
Others

B.3 Descriptive statistics from stage 2 survey: Distribution of questionnaires to building owners

\section{What the building owner considers most important during the design and construction of a building}

On a scale of 1-6, with 1 being not important and 6 being extremely important, please rate the most important factors you considered during the design and construction of your house

\begin{tabular}{|c|c|c|c|c|c|c|}
\hline & $\begin{array}{l}\text { 1. Not } \\
\text { important }\end{array}$ & 2 & 3 & 4 & 5 & $\begin{array}{c}6 . \\
\text { Extremely } \\
\text { important } \\
(6)\end{array}$ \\
\hline $\begin{array}{l}\text { 1. Security (i.e. burglary proof, security doors, perimeter } \\
\text { fencing, etc.) }\end{array}$ & $\bigcirc$ & $\bigcirc$ & $\bigcirc$ & $\bigcirc$ & $\bigcirc$ & $\bigcirc$ \\
\hline $\begin{array}{l}\text { 2. Comfort (i.e. indoor air movement, natural lighting, ease } \\
\text { of circulation within the space, etc.) }\end{array}$ & $\bigcirc$ & $\bigcirc$ & $\bigcirc$ & $\bigcirc$ & $\bigcirc$ & $\bigcirc$ \\
\hline 3. Building materials (i.e. interior and exterior finishes) & $\bigcirc$ & $\bigcirc$ & $\bigcirc$ & $\bigcirc$ & $\bigcirc$ & $\bigcirc$ \\
\hline 4. Finance/cost of the building construction & $\bigcirc$ & $\bigcirc$ & $\bigcirc$ & $\bigcirc$ & $\bigcirc$ & $\bigcirc$ \\
\hline 5. Location of the house/neighbourhood & O & $\bigcirc$ & $\bigcirc$ & $\bigcirc$ & $\bigcirc$ & $\bigcirc$ \\
\hline 6. Energy conservation/sustainable design & $\bigcirc$ & $\bigcirc$ & $\bigcirc$ & $\bigcirc$ & $\bigcirc$ & ○ \\
\hline 7. Size of bedrooms, kitchen, living room, and toilet & $\bigcirc$ & $\bigcirc$ & $\bigcirc$ & $\bigcirc$ & $\bigcirc$ & ○ \\
\hline 8. Aesthetics & O & O & ○ & O & O & 0 \\
\hline
\end{tabular}

9. Number of bedrooms 
Appendix B

\section{The building owners' level of satisfaction with the building}

On a scale of 1-6, with 1 being extremely dissatisfied and 6 being extremely satisfied, how satisfied or dissatisfied are you with your house in terms of the following

\begin{tabular}{|c|c|c|c|c|c|c|}
\hline & $\begin{array}{l}\text { 1. Extremely } \\
\text { dissatisfied }\end{array}$ & 2 & 3 & 4 & 5 & $\begin{array}{c}6 . \\
\text { Extremely } \\
\text { satisfied }\end{array}$ \\
\hline $\begin{array}{l}\text { 1. Electricity supply from the national grid for powering the } \mathrm{AC} \text { or fan } \\
\text { when its exceptionally hot }\end{array}$ & O & $\bigcirc$ & $\bigcirc$ & $\bigcirc$ & $\bigcirc$ & $\bigcirc$ \\
\hline 2. Number of bedrooms & O & $\bigcirc$ & $\bigcirc$ & $\bigcirc$ & $\bigcirc$ & $\bigcirc$ \\
\hline 3. Exterior landscaping e.g. planting of trees, paving, etc. & O & O & $\bigcirc$ & $\bigcirc$ & $\bigcirc$ & $\bigcirc$ \\
\hline $\begin{array}{l}\text { 4. Protection against noise in the building e.g. from generators, } \\
\text { vehicular traffic etc. }\end{array}$ & O & $\bigcirc$ & O & $\bigcirc$ & $\bigcirc$ & $\bigcirc$ \\
\hline 5. Thermal comfort in the house when there is no $\mathrm{AC}$ or fan & $\bigcirc$ & $\bigcirc$ & $\bigcirc$ & $\bigcirc$ & $\bigcirc$ & O \\
\hline 6. Quality of natural light in the bedrooms, kitchen, toilet \& living area & O & O & O & $\bigcirc$ & $\bigcirc$ & O \\
\hline $\begin{array}{l}\text { 7. Quality of natural ventilation in the bedrooms, kitchen, toilet \& } \\
\text { living area }\end{array}$ & O & $\bigcirc$ & $\bigcirc$ & $\bigcirc$ & $\bigcirc$ & $\bigcirc$ \\
\hline 8. Size of the bedrooms, kitchen, toilet \& living area & . & O & O & 0 & 0 & 0 \\
\hline
\end{tabular}

What is the building owner's level of ESD awareness and the public interest in ESD?

On a scale of 1-6, with 1 being extremely low extent and 6 being extremely high extent, please rate the following statements

\begin{tabular}{|c|c|c|c|c|c|c|}
\hline & \begin{tabular}{|c}
1. \\
Extremely \\
low \\
extent
\end{tabular} & 2 & 3 & 4 & 5 & $\begin{array}{c}6 . \\
\text { Extremely } \\
\text { high extent }\end{array}$ \\
\hline $\begin{array}{l}\text { 1. Government and the private sector provision of financial incentives } \\
\text { and rewards for saving energy or using energy efficient appliances like } \\
\text { solar panels }\end{array}$ & $\bigcirc$ & $\bigcirc$ & $\bigcirc$ & $\bigcirc$ & $\bigcirc$ & $\bigcirc$ \\
\hline $\begin{array}{l}\text { 2. Demand and supply in Nigeria for environmentally sustainable } \\
\text { appliances/technologies such as: solar panels, energy efficient lighting, } \\
\text { energy efficient building materials etc }\end{array}$ & $\bigcirc$ & $\bigcirc$ & $\bigcirc$ & $\bigcirc$ & $\bigcirc$ & $\bigcirc$ \\
\hline $\begin{array}{l}\text { 3. Available information on ESD, i.e. promotion of sustainability by the } \\
\text { government, media, professional bodies, etc. }\end{array}$ & $\bigcirc$ & $\bigcirc$ & $\bigcirc$ & $\mathrm{O}$ & $\bigcirc$ & O \\
\hline 4. The general public interest and enlightenment on ESD & $\bigcirc$ & $\bigcirc$ & O & $\bigcirc$ & $\bigcirc$ & $\mathrm{O}$ \\
\hline 5. ESD adoption in any of your residential projects & $\bigcirc$ & $\bigcirc$ & $\bigcirc$ & $\bigcirc$ & $\bigcirc$ & $\bigcirc$ \\
\hline $\begin{array}{l}\text { 6. Your level of awareness on environmentally sustainable design } \\
\text { methods (ESD) }\end{array}$ & O & O & $\bigcirc$ & $\bigcirc$ & $\mathrm{O}$ & 0 \\
\hline \multicolumn{7}{|c|}{$\begin{array}{l}\text { During the building design consultation with your architect, did he or she inform you of any environmentally sustainable design } \\
\text { methods? }\end{array}$} \\
\hline \multicolumn{7}{|l|}{ Yes } \\
\hline \multicolumn{7}{|l|}{ No } \\
\hline Others & & & & & & \\
\hline
\end{tabular}

Most comfortable space in the house and why?

Please feel free to add any additional comments or suggestions 
Appendix B

What the building owner considers most important during the design and construction of a building. On a scale of 1-6, with 1 being not important and 6 being extremely important, please rate the most important factors you considered during the design and construction of your house

\begin{tabular}{|c|c|c|c|}
\hline$\#$ & Question & Mean & $\begin{array}{c}\text { Std } \\
\text { Deviation }\end{array}$ \\
\hline 1 & Number of bedrooms & 4.15 & 1.16 \\
\hline 2 & Aesthetics & 4.06 & 1.32 \\
\hline 3 & Size of bedrooms, kitchen, living room, and toilet & 4.45 & 0.96 \\
\hline 4 & Energy conservation/sustainable design & 3.15 & 1.33 \\
\hline 5 & Location of the house/neighbourhood & 4.39 & 1.11 \\
\hline 6 & Finance/cost of the building construction & 4.96 & 0.96 \\
\hline 7 & Building materials (i.e. interior and exterior finishes) & 4.57 & 1.02 \\
\hline 8 & $\begin{array}{l}\text { Comfort (i.e. indoor air movement, natural lighting, } \\
\text { ease of } \\
\text { circulation within the space, etc.) }\end{array}$ & 4.26 & 1.07 \\
\hline 9 & $\begin{array}{l}\text { Security (i.e. burglary proof, security doors, perimeter } \\
\text { fencing, etc.) }\end{array}$ & 4.66 & 1 \\
\hline
\end{tabular}

The building owners' level of satisfaction with the building. On a scale of 1-6, with 1 being extremely dissatisfied and 6 being extremely satisfied, how satisfied or dissatisfied are you with your house in terms of the following

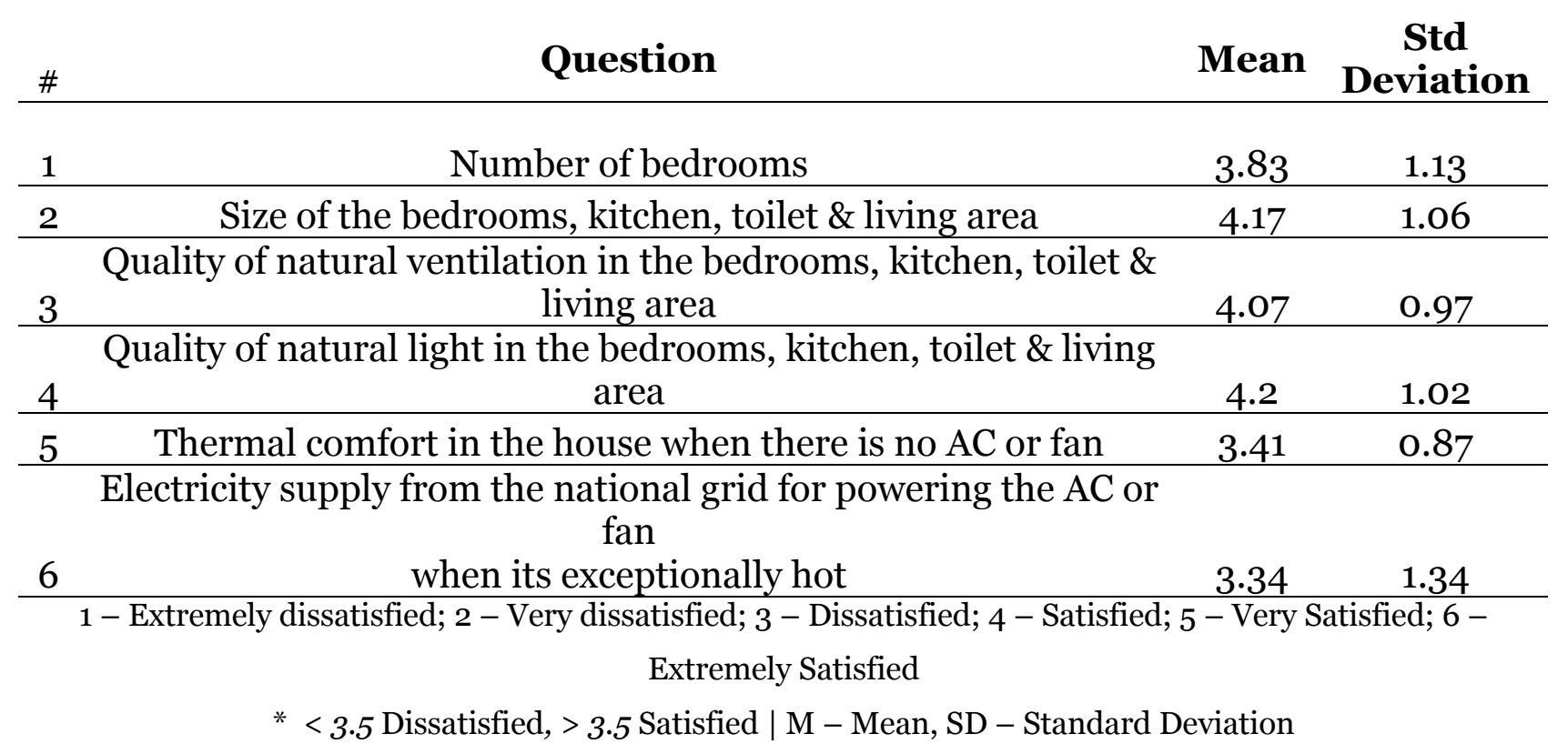

What is the building owner's level of ESD awareness and the public interest in ESD? On a scale of 1-6, with 1 being extremely low extent and 6 being extremely high extent, please rate the following statements

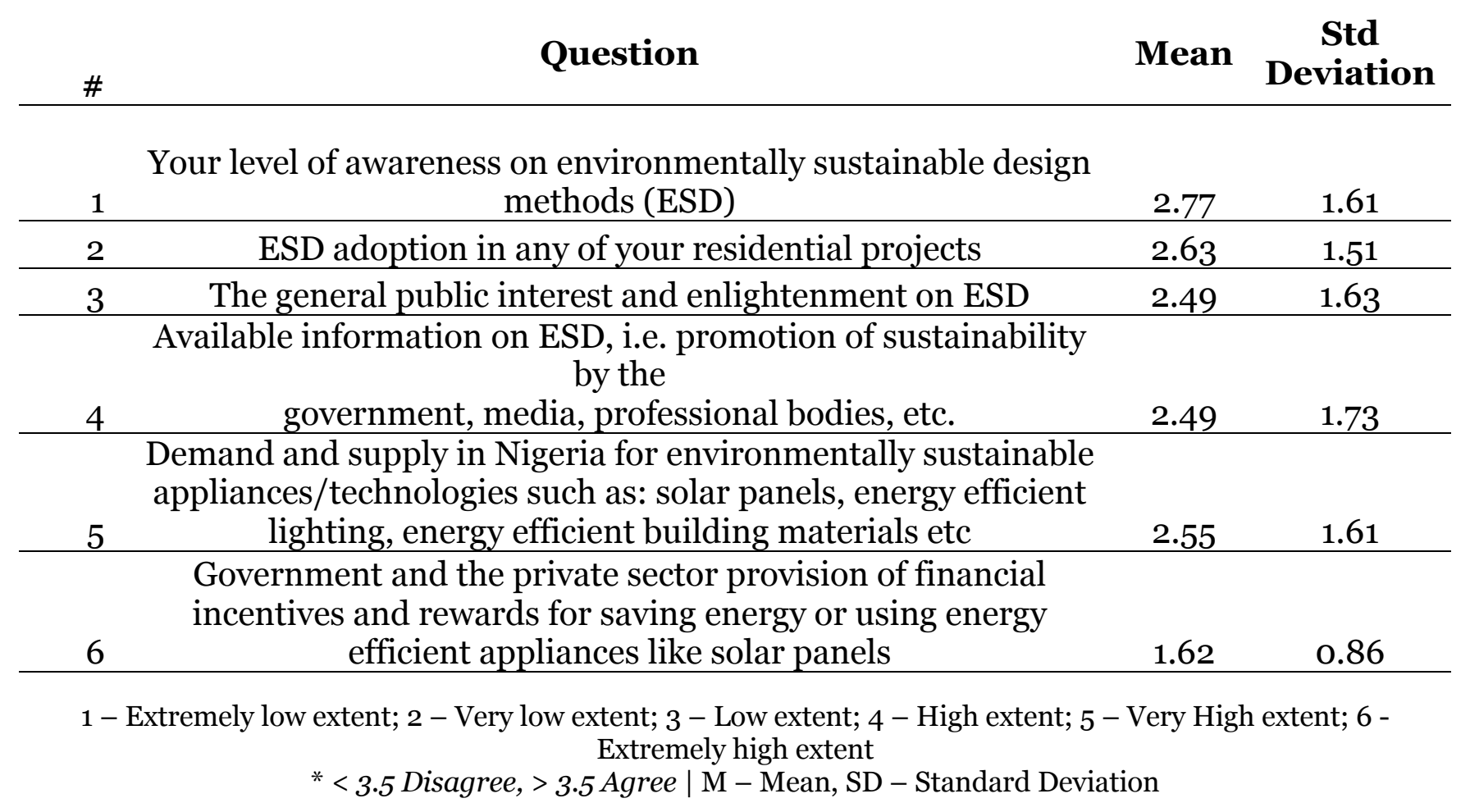




\begin{tabular}{|c|c|c|}
\hline \multicolumn{3}{|c|}{ Checklist for Visual Physical Examination of Buildings } \\
\hline \multirow[t]{2}{*}{$\begin{array}{l}\text { CROSS VENTILATION/NATURAL } \\
\text { LIGHTING }\end{array}$} & & \\
\hline & YES & NO \\
\hline Living/sitting room & 138 & 4 \\
\hline Kitchen & 12 & 130 \\
\hline Bedroom 1 & 113 & 29 \\
\hline Bedroom 2 & 113 & 29 \\
\hline Bedroom 3 & 110 & 32 \\
\hline Bedroom 4 & 71 & 25 \\
\hline Bedroom 5 & 27 & 17 \\
\hline Bathroom & 2 & 77 \\
\hline \multicolumn{3}{|l|}{$\begin{array}{l}\text { VENTILATION/NATURAL } \\
\text { LIGHTING/OUTDOOR SPACE }\end{array}$} \\
\hline & YES & $\mathrm{NO}$ \\
\hline Permeable open/loose plan & o & 142 \\
\hline Glazed casement windows & 83 & 59 \\
\hline Glazed louvre windows & 5 & 137 \\
\hline Wooden louvre windows & 10 & 132 \\
\hline Sliding windows & 98 & 44 \\
\hline Skylight & 0 & 142 \\
\hline $\begin{array}{l}\text { Vent opening/window above exterior/interior } \\
\text { doors }\end{array}$ & 10 & 132 \\
\hline Vent opening/window above exterior windows & 7 & 135 \\
\hline $\begin{array}{l}\text { Low height interior partition walls or roll-back } \\
\text { walls }\end{array}$ & 1 & 141 \\
\hline Windcatcher/wind towers & O & 142 \\
\hline Courtyard & 2 & 140 \\
\hline Large Porch/Balcony & 56 & 86 \\
\hline Window screen/nets & 143 & o \\
\hline \multicolumn{3}{|l|}{ THERMAL COMFORT } \\
\hline & YES & NO \\
\hline Cooling and shading effect using vegetation & 28 & 114 \\
\hline Concrete hood or baffles & 41 & 101 \\
\hline Large roof overhang & 92 & 50 \\
\hline Overhead shade screens & 6 & 135 \\
\hline Window opening with wings & o & 142 \\
\hline Shared shade & 18 & 124 \\
\hline Shadow umbrella & 4 & 138 \\
\hline Daylight enhance shade & 6 & 136 \\
\hline \multicolumn{3}{|l|}{ COOLING /INTERNAL NOISE LEVELS } \\
\hline & YES & NO \\
\hline Earth-air heat exchanger & o & 142 \\
\hline Air-air heat exchanger & 0 & 142 \\
\hline Vented foundation & 0 & 142 \\
\hline Roof insulation & 0 & 142 \\
\hline Vented roof & 24 & 118 \\
\hline Vented ceiling & 17 & 125 \\
\hline Floor insulation & $\mathrm{O}$ & 142 \\
\hline Ceramic flooring & 140 & 2 \\
\hline Terrazzo flooring & 15 & 127 \\
\hline Carpet flooring & 6 & 136 \\
\hline Vinyl flooring & 1 & 141 \\
\hline Wooden flooring & 4 & 138 \\
\hline Concrete block walls & 140 & 2 \\
\hline Adobe brick walls & 8 & 134 \\
\hline Curtain walls & 2 & 140 \\
\hline
\end{tabular}


Appendix B

\begin{tabular}{l|c|c}
\hline Clay/mud walls & O & 142 \\
\hline Timber walls & O & 142 \\
\hline Wall insulation & 0 & 142 \\
\hline ENERGY & & \\
\hline & YES & NO \\
\hline Auto light/systems control & 15 & 127 \\
\hline Energy efficient bulbs & 60 & 82 \\
\hline Solar panels & 29 & 113 \\
\hline Wind turbine & 0 & 142 \\
\hline $\begin{array}{l}\text { Thermal energy (i.e. Biomass, underground } \\
\text { spring, etc.) }\end{array}$ & 0 & 142 \\
\hline National grid & 0 & 142 \\
\hline Generator & 0 & 142 \\
\hline
\end{tabular}


Appendix B

B.5 Ethics approval for Pilot Study

\begin{tabular}{|c|c|c|c|}
\hline \multicolumn{2}{|c|}{ MEMORANDUM } & $\begin{array}{l}\text { Phone } \\
\text { Email }\end{array}$ & $\begin{array}{l}0-4-4636028 \\
\text { judith.loveridge@vuw.ac.nz }\end{array}$ \\
\hline TO & \multicolumn{3}{|c|}{ Tamaraukuro Amasuomo } \\
\hline FROM & \multicolumn{3}{|c|}{ Dr Judith Loveridge, Convenor, Human Ethics Committee } \\
\hline DATE & \multicolumn{3}{|l|}{2 July 2017} \\
\hline PAGES & \multicolumn{3}{|l|}{1} \\
\hline SUBJECT & \multicolumn{3}{|c|}{$\begin{array}{l}\text { Ethics Approval } \\
\text { Number: } 24837 \\
\text { Title: ARCHITECTS PERCEPTION OF THE IMPLEMENTATION } \\
\text { OF ENVIRONMENTALLY SUSTAINABLE DESIGN (ESDs) IN } \\
\text { NIGERIA: Pilot study }\end{array}$} \\
\hline
\end{tabular}

Thank you for your application for ethical approval, which has now been considered by the Human Ethics Committee.

Your application has been approved from the above date and this approval is valid until the end date of the research which is 28 July 2017.

Best wishes with the research.

Kind regards,

Judith Loveridge

Convenor, Victoria University of Wellington Human Ethics Committee 